FACULDADE DE ZOOTECNIA E ENGENHARIA DE ALIMENTOS

IGOR AUGUSTO ANDRETA PAIOLA

Perfil metabólico de vacas receptoras e de bezerros da raça Nelore produzidos por fertilização in vitro (FIV) 
Perfil metabólico de vacas receptoras e de bezerros da raça Nelore produzidos por fertilização in vitro (FIV)

Versão Corrigida

Dissertação apresentada à Faculdade de Zootecnia e Engenharia de Alimentos da Universidade de São Paulo, como parte dos requisitos para a obtenção do título de Mestre em Ciências.

Área de concentração: Biociência Animal

Orientador: Prof. Dr. Eduardo Harry Birgel Junior 
Ficha catalográfica elaborada pelo

Serviço de Biblioteca e Informação, FZEA/USP, com os dados fornecidos pelo(a) autor(a)

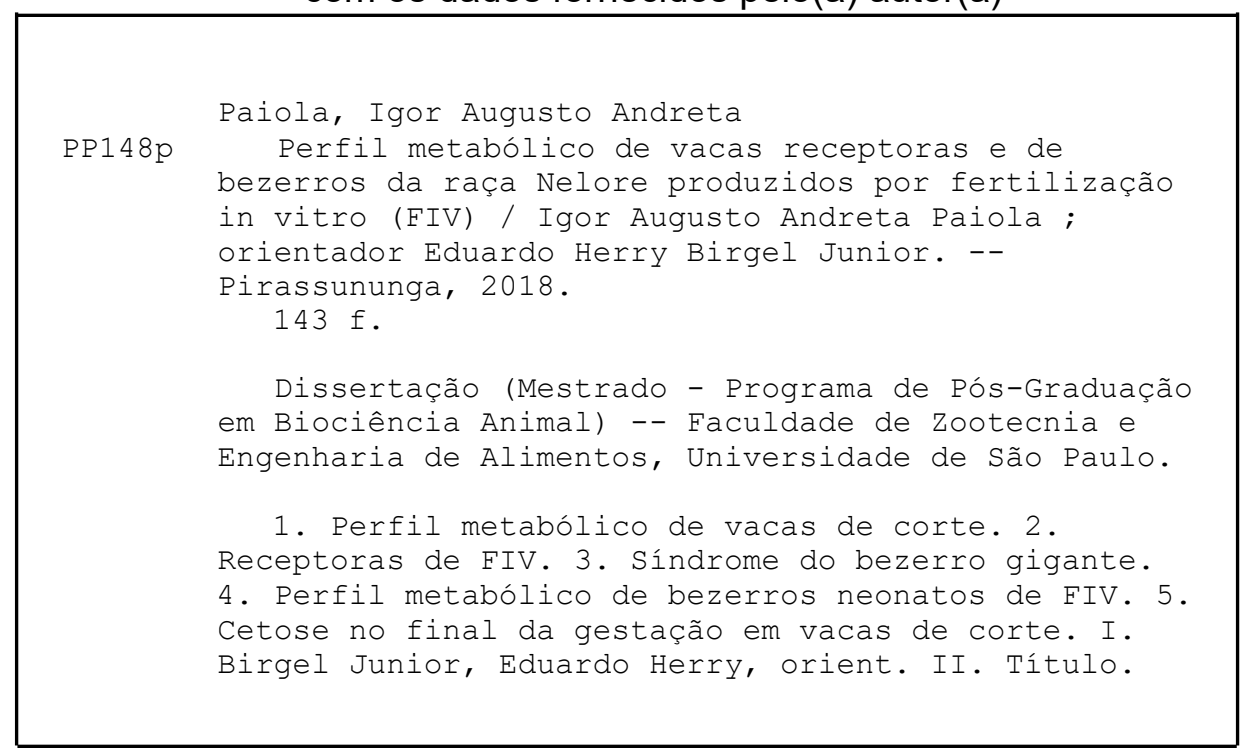

Permitida a cópia total ou parcial deste documento, desde que citada a fonte - o autor 
IGOR AUGUSTO ANRETA PAIOLA

\section{Perfil metabólico de vacas receptoras e de bezerros da raça Nelore produzidos por fertilização in vitro (FIV)}

Dissertação apresentada à Faculdade de Zootecnia e Engenharia de Alimentos da Universidade de São Paulo, como parte dos requisitos para a obtenção do título de Mestre em Ciências.

Área de concentração: Biociência Animal

Data de aprovação: $\underline{17 / \underline{09} / \underline{2018}}$

Banca Examinadora:

Prof. Dr. Luciano Andrade Silva - Presidente da Banca Examinadora Faculdade de Zootecnia e Engenharia de Alimentos - USP

Prof. Dr. Flávio Vieira Meirelles

Faculdade de Zootecnia e Engenharia de Alimentos - USP

Prof. Dr. Fabio Celidonio Pogliani

Faculdade de Medicina Veterinária e Zootecnia - USP

Prof. Dr. Bruno Fornitano Cholfe

Centro Universitário de Rio Preto - UNIRP 


\section{DEDICATÓRIA}

A Deus,

por estar sempre ao meu lado nos

momentos mais difíceis.

"Pelos caminhos retos ele me leva, por amor do seu nome." Salmo 22:3

À minha esposa Maria Carolina e a minha filha Giovanna pelo amor e compreensão que me deram forças para trilhar este caminho até o fim. 


\section{AGRADECIMENTOS}

Aos meus pais e irmãos que, com muito carinho e apoio, me deram forças para que eu chegasse até esta etapa de minha vida.

Ao meu orientador Prof. Doutor Eduardo Herry Birgel Junior pela oportunidade, pela confiança e pela sabedoria que sempre me transmitiu em nossas conversas ao longo da pós-graduação.

Ao professor Halim Atique Netto por ter me dado a primeira oportunidade docente, e por ter me ajudado a viabilizar esta pós-graduação.

A amiga Daniela Becker Birgel, pela ajuda imprescindível que tornou possível a realização deste trabalho

A amiga Melina Marie Yasuoka pelo apoio e amizade ao longo desta caminhada.

Aos amigos Guilherme Fabretti Gonçalves Santos, Bruno Fornitano Cholfe, Suellen Miguez Gonzalez e João Morelli Junior, sem a ajuda de vocês seria impossível vencer esta etapa.

A todos os funcionários do Hospital Veterinário e do Campus FZEA/USP que me ajudaram direta e indiretamente deste trabalho.

A todos os funcionários e residentes do Hospital Veterinário "Dr. Halim Atique" UNIRP que ajudaram direta e indiretamente deste trabalho.

Ao senhor Luiz Antonio da Silva por abrir as portas de sua propriedade e permitir a realização deste trabalho 


\section{RESUMO}

PAIOLA, I. A. A. Perfil metabólico de vacas receptoras e de bezerros da raça Nelore produzidos por fertilização in vitro (FIV). 2018. 62f. Dissertação (Mestrado) - Faculdade de Zootecnia e Engenharia de Alimentos, Universidade de São Paulo, Pirassununga, 2018

A biotecnologia de fertilização in vitro (FIV) de embriões aplicadas a reprodução em bovinos permitiu grandes avanços genéticos para a pecuária mundial, particularmente no Brasil. A massificação do uso comercial da FIV no Brasil se deve, em parte, ao predomínio da raça Nelore na pecuária de corte nacional, devido às características da fisiologia reprodutiva. Entretanto as condições sub-ótimas no ambiente embrionário in vitro, geram distúrbios no desenvolvimento do embrião, da placenta e do feto, resultando em morte embrionária, abortamentos e falhas na adaptação neonatal a vida extrauterina. Distúrbios cardio-respiratórios com hipóxia, hipercapnia e acidose, hipoglicemia e hipotermia associados a macrossomia são frequentemente diagnosticados nesses neonatos. Para caracterizar as diferenças do metabolismo energético de bezerros da raça Nelore produzidos por fertilização in vitro daqueles produzidos por inseminação artificial (IA); as possíveis repercussões da hipóxia sobre o metabolismo energético no final da gestação; da macrossomia sobre o metabolismo energético materno no final da gestação; documentar o controle glicêmico dos fetos e das vacas durante o último mês de gestação; a determinação da existência ou não de resistência à insulina nos bezerros recémnascidos de FIV, o presente projeto compreendeu: No primeiro experimento, avaliar o último mês de gestação de 8 vacas receptoras de embriões de FIV da raça Nelore e 12 vacas Nelores com gestações por IA submetidas a cesariana sendo colhido amostras de sangue venoso em 5 momentos (270, 280 dias de gestação, antes da indução do parto, 12 horas após a indução do parto e 24 horas após a indução, antes da cesariana), para determinação dos teores séricos de ureia, creatinina, proteína, albumina, y-glutamil transferase, colesterol, triglicérides, BHB, NEFA, teores plasmáticos de glicose e lactato. Nos respectivos bezerros obtidos por cesariana foram avaliados e colhidos sangue venoso em 11 momentos $(0,3,6$, $12,24,48,72$ horas após o nascimento, $5,7,15$ e 30 dias após o nascimento) para determinação dos teores séricos de ureia, creatinina, proteína, albumina, y-glutamil transferase, colesterol, triglicérides, BHB, NEFA e, teores plasmáticos de glicose e lactato, frutosamina ao nascimento e insulina sérica nos momentos $(0,12,24$ horas e 7 dias após o nascimento) . No segundo experimento foram avaliadas 17 e 16 vacas receptoras de embriões de FIV da raça Nelore com bezerros de peso padrão e de peso elevado, respectivamente e 16 vacas Nelores com gestações por IA com parto natural e colhido amostras de sangue venoso em 2 momentos (288 dias de gestação e após o parto), sendo realizado as determinações supracitadas das vacas do experimento 1. Nos respectivos bezerros nascidos naturalmente foram avaliados e colhidos sangue venoso em 2 momentos (até 6 horas de vida e entre 24 a 36 horas de vida) para realização das determinações dos teores séricos de ureia, creatinina, proteína, albumina, $\mathrm{y}$-glutamil transferase, colesterol, triglicérides, BHB, NEFA, insulina e teores plasmáticos de glicose e lactato.

Palavras-chave: Bovino. Síndrome do bezerro gigante. Síndrome do bezerro anormal. Cetose. Hipóxia. Hiperglicemia. Hipoglicemia. Desequilíbrio ácido-base. 


\begin{abstract}
PAIOLA, I. A. A. Metabolic profile of recipient cows and Nelore calves produced by in vitro fertilization (IVF). 2018 62f. M.Sc. Dissertation - Faculdade de Zootecnia e Engenharia de Alimentos, Universidade de São Paulo, Pirassununga, 2018
\end{abstract}

The objective of this study was to evaluate the effects of giant calf syndrome (macrossomia) on the metabolic profile and glycemic control of IVF recipients or AI pregnant cows and their calves. This investigation includes four experiments in which venous blood was collected from all animals to determine serum levels of urea, creatinine, protein, albumin, GGT, cholesterol, triglycerides, $\beta-H B O$, NEFA, glucose and lactate. In the first experiment Nelore embryo recipient cows were used for IVF $(n=8)$ and Al pregnant Nelore cows submitted to cesarean section $(n=12)$. Five moments were evaluated: 270, 280 gestation days, before labor induction, 12 and 24 hours after induction. In the second experiment the cesarean section obtained calves were evaluated in 11 moments: $0,3,6,12,24,48,72$ hours and 5, 7, 15 and 30 days after birth. Besides the birth measured fruitosamine and serum insulin at the moments: 0, 12, 24 hours and 7 days after birth. In the third experiment, Nelore IVF embryo recipient cows were evaluated for standard weight calves $(n=17)$, high weight $(n=16)$ and natural calving Al gestation Nelore cows $(n=16)$ as control group. The evaluated moments were 288 gestation days and up to 6 hours after the natural calving. Two moments were determined: 288 gestation days and after calving. In the fourth experiment, newborn Nelore calves $(n=76)$ were used, divided in three groups: Nelore calves by term AI $(n=27)$, Nelore calves by term IVF with standard breed weight $(n=32)$ and Nelore calves by term with macrosomia $(n=17$, weight> $45 \mathrm{~kg}$ ). The evaluated moments were up to 6 hours and between 24 and 36 hours of life. In addition to the fruitosamine measured at the first moment. For statistical analysis in experiments 1 and 2, Tukey's test was used for time and Student for treatment effect, in experiments 3 and 4, Tukey's test was used for treatment effect and Paired t-test for time effect, using the statistical program Sigma Stat 3.5. IVF calves with macrosomia were 33\% (16/48). Regarding the urea of the IVF recipient or Al pregnant cows, there was statistical difference between the treatments within each time (cesarean section). Regarding kidney function, there was a statistical difference between urea and creatinine in the first and fourth experiment, respectively. In the evaluation of energy metabolism there was a difference in cholesterol, triglycerides and plasma glucose among the animals of the first and second experiments. Also, in the penultimate there was statistical relevance of the non-esterified fatty acid. In the comparison between the third experiment animals there was difference for cholesterol and triglycerides. In the fourth experiment, there was a difference in cholesterol and plasma lactate $(P<0.05)$. Therefore, it is suggested that the renal and metabolic profile are similar between IVF recipient and AI pregnant cows, as well as among their calves. In addition, it is recommended to monitor IVF calves during the first week of life due to hypoglycaemia and hyperinsulinemia.

Keywords: Bovine. Calf. Macrossomia. IVP. Biochemical profile. 


\section{LISTA DE FIGURAS}

Gráfico 01 - Médias com erros padrão para peso ao nascimento de bezerros oriundos de FIV e por IA obtidos por parto natural - Pirassununga - 2018 .

Gráfico 02 - Médias com erros padrão para ureia sérica de vacas gestantes por FIV e por IA no final da gestação até a indução e a realização da cesariana -

Pirassununga - 2018

Gráfico 03 - Médias com erros padrão para creatinina sérica de vacas gestantes por FIV e por IA no final da gestação até a indução e a realização da cesariana Pirassununga - 2018

Gráfico 04 - Médias com erros padrão para ureia sérica de bezerros oriundos de FIV e por IA nos primeiros 30 dias de vida obtidos por cesariana com indução do parto -

Pirassununga - 2018 .52

Gráfico 05 - Médias com erros padrão para creatinina sérica de bezerros oriundos de FIV e por IA nos primeiros 30 dias de vida obtidos por cesariana com indução do parto - Pirassununga - 2018

Gráfico 06 - Médias com erros padrão para ureia sérica de vacas receptoras de FIV de bezerros com peso elevado após o nascimento, receptoras de FIV com bezerros de peso padrão após o nascimento e vacas gestantes por IA, no final da gestação e até $6 \mathrm{~h}$ após o parto natural a termo - Pirassununga - 2018 .56

Gráfico 07 - Médias com erros padrão para creatinina sérica de vacas receptoras de FIV de bezerros com peso elevado após o nascimento, receptoras de FIV com bezerros de peso padrão após o nascimento e vacas gestantes por IA, no final da gestação e até $6 \mathrm{~h}$ após o parto natural a termo - Pirassununga - 2018

Gráfico 08 - Médias com erros padrão para ureia sérica de bezerros oriundos de FIV e por IA nas primeiras 36 horas devida obtidos por parto natural - Pirassununga 2018

Gráfico 09 - Médias com erros padrão para creatinina plasmática de bezerros oriundos de FIV e por IA nas primeiras 36 horas devida obtidos por parto natural Pirassununga - 2018

Gráfico 10 - Médias com erros padrão para GGT sérico de vacas gestantes por FIV e por IA no final da gestação até a indução e a realização da cesariana -

Pirassununga - 2018

Gráfico 11 - Médias com erros padrão para GGT sérico de bezerros oriundos de FIV e por IA nos primeiros 30 dias de vida obtidos por cesariana com indução do parto Pirassununga - 2018

Gráfico 12 - Médias com erros padrão para GGT sérico de vacas receptoras de FIV de bezerros com peso elevado após o nascimento, receptoras de FIV com bezerros de peso padrão após o nascimento e vacas gestantes por IA, no final da gestação e até 6 h após o parto natural a termo - Pirassununga - 2018

Gráfico 13 - Medianas com erros padrão para GGT sérico de bezerros oriundos de FIV e por IA nas primeiras 36 horas devida obtidos por parto natural - Pirassununga $-2018$ 
Gráfico 14 - Médias com erros padrão para proteína sérica de vacas gestantes por FIV e por IA no final da gestação até a indução e a realização da cesariana -

Pirassununga - 2018

Gráfico 15 - Médias com erros padrão para albumina sérica de vacas gestantes por FIV e por IA no final da gestação até a indução e a realização da cesariana -

Pirassununga - 2018

Gráfico 16 - Médias com erros padrão para proteína sérica de bezerros oriundos de FIV e por IA nos primeiros 30 dias de vida obtidos por cesariana com indução do parto - Pirassununga - 2018

Gráfico 17 - Médias com erros padrão para albumina sérica de bezerros oriundos de FIV e por IA nos primeiros 30 dias de vida obtidos por cesariana com indução do parto - Pirassununga - 2018

Gráfico 18 - Médias com erros padrão para proteína sérica de vacas receptoras de FIV de bezerros com peso elevado após o nascimento, receptoras de FIV com bezerros de peso padrão após o nascimento e vacas gestantes por IA, no final da gestação e até $6 \mathrm{~h}$ após o parto natural a termo - Pirassununga - 2018

Gráfico 19 - Médias com erros padrão para albumina sérica de vacas receptoras de FIV de bezerros com peso elevado após o nascimento, receptoras de FIV com bezerros de peso padrão após o nascimento e vacas gestantes por IA, no final da gestação e até $6 \mathrm{~h}$ após o parto natural a termo - Pirassununga - 2018

Gráfico 20 - Médias com erros padrão para proteína sérica de bezerros oriundos de FIV e por IA nas primeiras 36 horas devida obtidos por parto natural - Pirassununga $-2018$

Gráfico 21 - Médias com erros padrão para albumina sérica de bezerros oriundos de FIV e por IA nas primeiras 36 horas devida obtidos por parto natural - Pirassununga $-2018$

Gráfico 22 - Médias com erros padrão para colesterol sérico de vacas gestantes por FIV e por IA no final da gestação até a indução e a realização da cesariana Pirassununga - 2018

Gráfico 23 - Médias com erros padrão para Triglicérides sérico de vacas gestantes por FIV e por IA no final da gestação até a indução e a realização da cesariana Pirassununga - 2018

Gráfico 24 - Médias com erros padrão para glicose plasmática de vacas gestantes por FIV e por IA no final da gestação até a indução e a realização da cesariana Pirassununga - 2018

Gráfico 25 - Médias com erros padrão para lactato plasmático de vacas gestantes por FIV e por IA no final da gestação até a indução e a realização da cesariana Pirassununga - 2018

Gráfico 26 - Médias com erros padrão para $\beta$-hidroxibutirato sérico de vacas gestantes por FIV e por IA no final da gestação até a indução e a realização da cesariana - Pirassununga - 2018

Gráfico 27 - Médias com erros padrão para NEFA sérico de vacas gestantes por FIV e por IA no final da gestação até a indução e a realização da cesariana - 
Gráfico 28 - Médias com erros padrão para colesterol sérico de bezerros oriundos de FIV e por IA nos primeiros 30 dias de vida obtidos por cesariana com indução do parto - Pirassununga - 2018

Gráfico 29 - Médias com erros padrão para Triglicérides plasmático de bezerros oriundos de FIV e por IA nos primeiros 30 dias de vida obtidos por cesariana com indução do parto - Pirassununga - 2018

Gráfico 30 - Médias com erros padrão para glicose plasmática de bezerros oriundos de FIV e por IA nos primeiros 30 dias de vida obtidos por cesariana com indução do parto - Pirassununga - 2018

Gráfico 31 - Médias com erros padrão para lactato plasmático de bezerros oriundos de FIV e por IA nos primeiros 30 dias de vida obtidos por cesariana com indução do parto - Pirassununga - 2018 101

Gráfico 32 - Médias com erros padrão para $\beta$-hidroxibutirato sérico de bezerros oriundos de FIV e por IA nos primeiros 30 dias de vida obtidos por cesariana com indução do parto - Pirassununga - 2018.

Gráfico 33 - Médias com erros padrão para NEFA sérico de bezerros oriundos de FIV e por IA nos primeiros 30 dias de vida obtidos por cesariana com indução do parto - Pirassununga - 2018

Gráfico 34 - Médias com erros padrão para insulina sérica de bezerros oriundos de FIV e por IA nos primeiros 30 dias de vida obtidos por cesariana com indução do parto - Pirassununga - 2018

Gráfico 35 - Médias com erros padrão para frutosamina plasmática de bezerros oriundos de FIV e por IA nos primeiros 30 dias de vida obtidos por cesariana com indução do parto - Pirassununga - 2018

Gráfico 36 - Médias com erros padrão para colesterol sérico de vacas receptoras de FIV de bezerros com peso elevado após o nascimento, receptoras de FIV com bezerros de peso padrão após o nascimento e vacas gestantes por IA, no final da gestação e até $6 \mathrm{~h}$ após o parto natural a termo - Pirassununga - 2018

Gráfico 37 - Médias com erros padrão para triglicérides sérico de vacas receptoras de FIV de bezerros com peso elevado após o nascimento, receptoras de FIV com bezerros de peso padrão após o nascimento e vacas gestantes por IA, no final da gestação e até $6 \mathrm{~h}$ após o parto natural a termo - Pirassununga - 2018

Gráfico 38 - Médias com erros padrão para glicose plasmática de vacas receptoras de FIV de bezerros com peso elevado após o nascimento, receptoras de FIV com bezerros de peso padrão após o nascimento e vacas gestantes por IA, no final da gestação e até $6 \mathrm{~h}$ após o parto natural a termo - Pirassununga - 2018

Gráfico 39 - Médias com erros padrão para Lactato plasmático de vacas receptoras de FIV de bezerros com peso elevado após o nascimento, receptoras de FIV com bezerros de peso padrão após o nascimento e vacas gestantes por IA, no final da gestação e até $6 \mathrm{~h}$ após o parto natural a termo - Pirassununga - 2018

Gráfico 40 - Médias com erros padrão para $\beta$-hidroxibutirato sérico de vacas receptoras de FIV de bezerros com peso elevado após o nascimento, receptoras de FIV com bezerros de peso padrão após o nascimento e vacas gestantes por IA, no final da gestação e até $6 \mathrm{~h}$ após o parto natural a termo - Pirassununga $-2018 \ldots .117$ 
Gráfico 41 - Médias com erros padrão para NEFA plasmático de vacas receptoras de FIV de bezerros com peso elevado após o nascimento, receptoras de FIV com bezerros de peso padrão após o nascimento e vacas gestantes por IA, no final da gestação e até $6 \mathrm{~h}$ após o parto natural a termo - Pirassununga - 2018

Gráfico 42 - Médias com erros padrão para Colesterol plasmático de bezerros oriundos de FIV e por IA nas primeiras 36 horas devida obtidos por parto natural Pirassununga - 2018

Gráfico 43 - Médias com erros padrão para triglicérides sérico de bezerros oriundos de FIV e por IA nas primeiras Entre $24 \mathrm{~h}$ e $36 \mathrm{~h}$ de vida obtidos por parto natural -

Pirassununga - 2018

Gráfico 44 - Médias com erros padrão para glicose plasmática de bezerros oriundos de FIV e por IA nas primeiras 36 horas devida obtidos por parto natural -

Pirassununga - 2018

Gráfico 45 - Médias com erros padrão para Lactato plasmático de bezerros oriundos de FIV e por IA nas primeiras 36 horas devida obtidos por parto natural -

Pirassununga - 2018

Gráfico 46 - Médias com erros padrão para $\beta$-hidroxibutirato sérico de bezerros oriundos de FIV e por IA nas primeiras 36 horas devida obtidos por parto natural -

Pirassununga - 2018

Gráfico 47 - Médias com erros padrão para NEFA plasmático de bezerros oriundos de FIV e por IA nas primeiras 36 horas devida obtidos por parto natural -

Pirassununga - 2018

Gráfico 48 - Médias com erros padrão para frutosamina sérica ao nascimento de bezerros oriundos de FIV e por IA obtidos por parto natural - Pirassununga - 2018 


\section{LISTA DE TABELAS}

Tabela 01 - Médias, erros padrão, medidas mínimas e máximas para peso $(\mathrm{Kg})$ ao nascimento de bezerros oriundos de FIV e por IA nas primeiras 36 horas de vida obtidos por parto natura

Tabela 02 - Médias, erros padrão, medidas mínimas e máximas para ureia sérica $(\mathrm{mg} / \mathrm{dL})$ de vacas gestantes por FIV e por IA no final da gestação, período de indução e antes de serem submetidas a cesariana

Tabela 03 - Médias, erros padrão, medidas mínimas e máximas para creatinina sérica $(\mathrm{mg} / \mathrm{dL})$ de vacas gestantes por FIV e por IA no final da gestação, período de indução e antes de serem submetidas a cesariana

Tabela 04 - Médias, erros padrão, medidas mínimas e máximas para ureia sérica ( $\mathrm{mg} / \mathrm{dL}$ ) de bezerros oriundos de FIV e por IA nos primeiros 30 dias de vida obtidos por cesariana com indução do parto

Tabela 05 - Médias, erros padrão, medidas mínimas e máximas para creatinina sérica $(\mathrm{mg} / \mathrm{dL}$ ) de bezerros oriundos de FIV e por IA nos primeiros 30 dias de vida obtidos por cesariana com indução do parto.

Tabela 06 - Médias, erros padrão, medidas mínimas e máximas para ureia sérica $(\mathrm{mg} / \mathrm{dL})$ de vacas gestantes por FIV e por IA no final da gestação e até $6 \mathrm{~h}$ após o parto natural

Tabela 07 - Médias, erros padrão, medidas mínimas e máximas para creatinina sérica $(\mathrm{mg} / \mathrm{dL})$ de vacas gestantes por FIV e por IA no final da gestação e até $6 \mathrm{~h}$ após o parto natural

Tabela 08 - Médias, erros padrão, medidas mínimas e máximas para ureia sérica ( $\mathrm{mg} / \mathrm{dL}$ ) de bezerros oriundos de FIV e por IA nas primeiras 36 horas devida obtidos por parto natural

Tabela 09 - Médias, erros padrão, medidas mínimas e máximas para creatinina plasmática $(\mathrm{mg} / \mathrm{dL})$ de bezerros oriundos de FIV e por IA nas primeiras 36 horas devida obtidos por parto natural

Tabela 10 - Médias, erros padrão, medidas mínimas e máximas para GGT sérico (U/L) de vacas gestantes por FIV e por IA no final da gestação, período de indução e antes de serem submetidas a cesariana.....

Tabela 11 - Medianas, erros padrão, medidas mínimas e máximas para GGT sérico $(\mathrm{U} / \mathrm{L})$ de bezerros oriundos de FIV e por IA nos primeiros 30 dias de vida obtidos por cesariana com indução do parto

Tabela 12 - Médias, erros padrão, medidas mínimas e máximas para GGT sérico $(\mathrm{U} / \mathrm{L})$ de vacas gestantes por FIV e por IA no final da gestação e até $6 \mathrm{~h}$ após o parto natural

Tabela 13 - Medianas, erros padrão, medidas mínimas e máximas para GGT sérico $(\mathrm{U} / \mathrm{L})$ de bezerros oriundos de FIV e por IA nas primeiras 36 horas devida obtidos por parto natural 
Tabela 14 - Médias, erros padrão, medidas mínimas e máximas para proteína sérica ( $\mathrm{g} / \mathrm{dL})$ de vacas gestantes por FIV e por IA no final da gestação, período de indução e antes de serem submetidas a cesariana

Tabela 15 - Médias, erros padrão, medidas mínimas e máximas para albumina sérica $(\mathrm{g} / \mathrm{dL})$ de vacas gestantes por FIV e por IA no final da gestação, período de indução e antes de serem submetidas a cesariana

Tabela 16 - Médias, erros padrão, medidas mínimas e máximas para proteína sérica ( $\mathrm{g} / \mathrm{dL})$ de bezerros oriundos de FIV e por IA nos primeiros 30 dias de vida obtidos por cesariana com indução do parto

Tabela 17 - Médias, erros padrão, medidas mínimas e máximas para albumina sérica $(\mathrm{g} / \mathrm{dL})$ de bezerros oriundos de FIV e por IA nos primeiros 30 dias de vida obtidos por cesariana com indução do parto.

Tabela 18 - Médias, erros padrão, medidas mínimas e máximas para proteína sérica (g/dL) de vacas gestantes por FIV e por IA no final da gestação e até 6h após o parto natural

Tabela 19 - Médias, erros padrão, medidas mínimas e máximas para albumina sérica $(\mathrm{g} / \mathrm{dL})$ de vacas gestantes por FIV e por IA no final da gestação e até $6 \mathrm{~h}$ após o parto natural

Tabela 20 - Médias, erros padrão, medidas mínimas e máximas para proteína sérica ( $\mathrm{g} / \mathrm{dL}$ ) de bezerros oriundos de FIV e por IA nas primeiras 36 horas devida obtidos por parto natural

Tabela 21 - Médias, erros padrão, medidas mínimas e máximas para albumina sérica $(\mathrm{g} / \mathrm{dL})$ de bezerros oriundos de FIV e por IA nas primeiras 36 horas devida obtidos por parto natural

Tabela 22 - Médias, erros padrão, medidas mínimas e máximas para colesterol sérico $(\mathrm{mg} / \mathrm{dL})$ de vacas gestantes por FIV e por IA no final da gestação, período de indução e antes de serem submetidas a cesariana

Tabela 23 - Médias, erros padrão, medidas mínimas e máximas para triglicérides sérico ( $\mathrm{mg} / \mathrm{dL}$ ) de vacas gestantes por FIV e por IA no final da gestação, período de indução e antes de serem submetidas a cesariana

Tabela 24 - Médias, erros padrão, medidas mínimas e máximas para glicose plasmática ( $\mathrm{mg} / \mathrm{dL})$ de vacas gestantes por FIV e por IA no final da gestação, período de indução e antes de serem submetidas a cesariana

Tabela 25 - Médias, erros padrão, medidas mínimas e máximas para lactato plasmático $(\mathrm{mg} / \mathrm{dL})$ de vacas gestantes por FIV e por IA no final da gestação, período de indução e antes de serem submetidas a cesariana

Tabela 26 - Médias, erros padrão, medidas mínimas e máximas para $\beta$ hidroxibutirato sérico ( $\mathrm{mg} / \mathrm{dL}$ ) de vacas gestantes por FIV e por IA no final da gestação, período de indução e antes de serem submetidas a cesariana.....

Tabela 27 - Médias, erros padrão, medidas mínimas e máximas para NEFA sérico ( $\mathrm{mmol} / \mathrm{L})$ de vacas gestantes por FIV e por IA no final da gestação, período de indução e antes de serem submetidas a cesariana 
Tabela 28 - Médias, erros padrão, medidas mínimas e máximas para colesterol sérico $(\mathrm{mg} / \mathrm{dL})$ de bezerros oriundos de FIV e por IA nos primeiros 30 dias de vida obtidos por cesariana com indução do parto.

Tabela 29 - Médias, erros padrão, medidas mínimas e máximas para Triglicérides plasmático $(\mathrm{mg} / \mathrm{dL})$ de bezerros oriundos de FIV e por IA nos primeiros 30 dias de vida obtidos por cesariana com indução do parto

Tabela 30 - Médias, erros padrão, medidas mínimas e máximas para glicose plasmática $(\mathrm{mg} / \mathrm{dL})$ de bezerros oriundos de FIV e por IA nos primeiros 30 dias de vida obtidos por cesariana com indução do parto

Tabela 31 - Médias, erros padrão, medidas mínimas e máximas para lactato plasmático ( $\mathrm{mg} / \mathrm{dL})$ de bezerros oriundos de FIV e por IA nos primeiros 30 dias de vida obtidos por cesariana com indução do parto

Tabela 32 - Médias, erros padrão, medidas mínimas e máximas para $\beta$ hidroxibutirato sérico ( $\mathrm{mg} / \mathrm{dL}$ ) de bezerros oriundos de FIV e por IA nos primeiros 30 dias de vida obtidos por cesariana com indução do parto.

Tabela 33 - Médias, erros padrão, medidas mínimas e máximas para NEFA sérico ( $\mathrm{mmol} / \mathrm{L})$ de bezerros oriundos de FIV e por IA nos primeiros 30 dias de vida obtidos por cesariana com indução do parto

Tabela 34 - Médias, erros padrão, medidas mínimas e máximas para insulina sérica ( $\mathrm{ng} / \mathrm{mL}$ ) de bezerros oriundos de FIV e por IA nos primeiros 30 dias de vida obtidos por cesariana com indução do parto

Tabela 35 - Médias, erros padrão, medidas mínimas e máximas para frutosamina plasmática $(\mu \mathrm{mol} / \mathrm{L})$ de bezerros oriundos de FIV e por IA nos primeiros 30 dias de vida obtidos por cesariana com indução do parto

Tabela 36 - Médias, erros padrão, medidas mínimas e máximas para colesterol sérico $(\mathrm{mg} / \mathrm{dL})$ de vacas gestantes por FIV e por IA no final da gestação e até $6 \mathrm{~h}$ após o parto natural

Tabela 37 - Médias, erros padrão, medidas mínimas e máximas para triglicérides sérico $(\mathrm{mg} / \mathrm{dL})$ de vacas gestantes por FIV e por IA no final da gestação e até $6 \mathrm{~h}$ após o parto natural

Tabela 38 - Médias, erros padrão, medidas mínimas e máximas para glicose plasmática $(\mathrm{mg} / \mathrm{dL})$ de vacas gestantes por FIV e por IA no final da gestação e até $6 \mathrm{~h}$ após o parto natural

Tabela 39 - Médias, erros padrão, medidas mínimas e máximas para lactato plasmático ( $\mathrm{mg} / \mathrm{dL})$ de vacas gestantes por FIV e por IA no final da gestação e até 6h após o parto natural

Tabela 40 - Médias, erros padrão, medidas mínimas e máximas para $\beta$ hidroxibutirato sérico $(\mathrm{mg} / \mathrm{dL})$ de vacas gestantes por FIV e por IA no final da gestação e até $6 \mathrm{~h}$ após o parto natural.

Tabela 41 - Médias, erros padrão, medidas mínimas e máximas para NEFA plasmático $(\mathrm{mmol} / \mathrm{L})$ de vacas gestantes por FIV e por IA no final da gestação e até $6 \mathrm{~h}$ após o parto natural 
Tabela 42 - Médias, erros padrão, medidas mínimas e máximas para Colesterol plasmático ( $\mathrm{mg} / \mathrm{dL})$ de bezerros oriundos de FIV e por IA nas primeiras 36 horas devida obtidos por parto natural

Tabela 43 - Médias, erros padrão, medidas mínimas e máximas para triglicérides sérico $(\mathrm{mg} / \mathrm{dL})$ de bezerros oriundos de FIV e por IA nas primeiras 36 horas devida obtidos por parto natural

Tabela 44 - Médias, erros padrão, medidas mínimas e máximas para glicose plasmática ( $\mathrm{mg} / \mathrm{dL}$ ) de bezerros oriundos de FIV e por IA nas primeiras 36 horas devida obtidos por parto natural

Tabela 45 - Médias, erros padrão, medidas mínimas e máximas para Lactato plasmático $(\mathrm{mg} / \mathrm{dL})$ de bezerros oriundos de FIV e por IA nas primeiras 36 horas devida obtidos por parto natural

Tabela 46 - Médias, erros padrão, medidas mínimas e máximas para $\beta$ hidroxibutirato sérico ( $\mathrm{mg} / \mathrm{dL}$ ) de bezerros oriundos de FIV e por IA nas primeiras 36 horas devida obtidos por parto natural

Tabela 47 - Médias, erros padrão, medidas mínimas e máximas para NEFA plasmático $(\mathrm{mmol} / \mathrm{L})$ de bezerros oriundos de FIV e por IA nas primeiras 36 horas devida obtidos por parto natural

Tabela 48 - Médias, erros padrão, medidas mínimas e máximas para frutosamina $(\mu \mathrm{mol} / \mathrm{L})$ ao nascimento $(\mathrm{Kg})$ de bezerros oriundos de FIV e por IA nas primeiras 36 horas devida obtidos por parto natura. 


\section{SUMÁRIO}

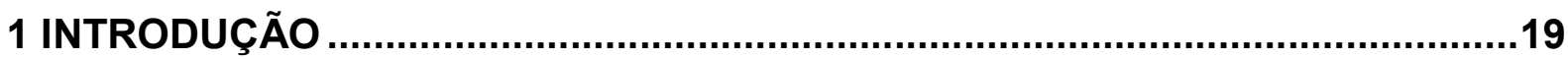

2 JUSTIFICATIVA E OBJETIVOS ...............................................................21

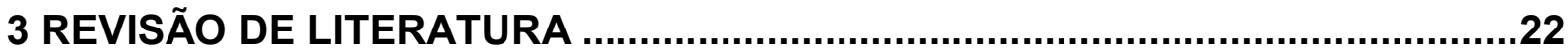

3.1 USO COMERCIAL DA FIV NA REPRODUÇÃO EM BOVINOS: AVANÇOS E

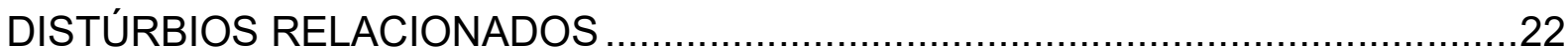

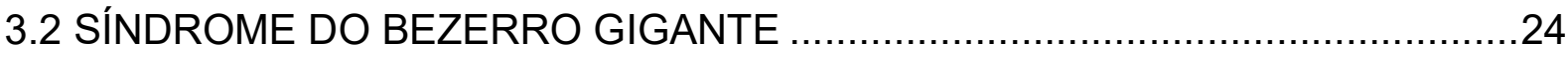

3.2.1 Alterações morfológicas e funcionais da placenta..................................26

3.3 METABOLISMO ENERGÉTICO GESTACIONAL ...................................28

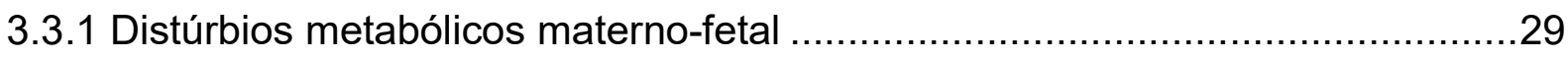

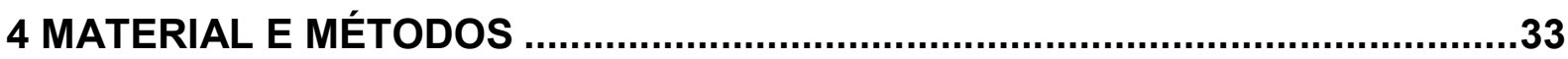

4.1 PROCEDIMENTO EXPERIMENTAL 1: Avaliação da influência do período final da gestação e da indução do parto no perfil metabólico de vacas receptoras de embriões de FIV.

4.2 PROCEDIMENTO EXPERIMENTAL 2: Avaliação das modificações no perfil nos primeiros 30 dias de vida de bezerros da raça Nelore obtidos por FIV e nascidos por meio de cesariana .34

4.3 PROCEDIMENTO EXPERIMENTAL 3: Avaliação da influência da síndrome do bezerro gigante (macrossomia) no perfil metabólico de receptoras de gestações de FIV com parto natural a termo

4.4 PROCEDIMENTO EXPERIMENTAL 4: Avaliação da influência da síndrome do bezerro gigante (macrossomia) no perfil metabólico de bezerros da raça Nelores oriundos de FIV nascidos por parto natural a termo.........................................36

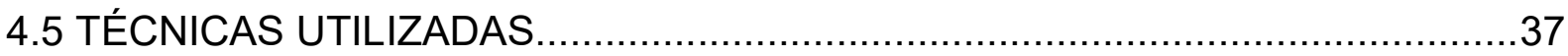

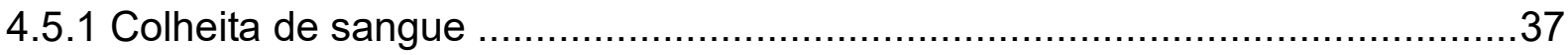


4.5.2 Determinação sérica de colesterol

4.5.3 Determinação sérica de triglicérides .39

4.5.4 Determinação sérica de ß-hidroxibutirato (BHB) 39

4.5.5 Determinação sérica de ácidos graxos livres não esterificados (NEFA) 39

4.5.6 Determinação sérica da ureia. .40

4.5.7 Determinação sérica da creatinina 40

4.5.8 Determinação sérica da proteína 41

4.5.9 Determinação sérica da albumina

4.5.10 Determinação sérica da Y-glutamil transferase

4.5.11 Determinação sérica plasmáticos de glicose

4.5.12 Determinação plasmática de lactato

4.5.13 Determinação plasmática da frutosamina

4.5.14 Determinação plasmática da insulina

4.6 ANÁLISE ESTATÍSTICA DO PROCEDIMENTO EXPERIMENTAL 1

4.7 ANÁLISE ESTATÍSTICA DO PROCEDIMENTO EXPERIMENTAL 2

4.8 ANÁLISE ESTATÍSTICA DO PROCEDIMENTO EXPERIMENTAL 3 44

4.9 ANÁLISE ESTATÍSTICA DO PROCEDIMENTO EXPERIMENTAL 4 .44

5 RESULTADOS E DISCUSSÃO .45

5.1 PESO AO NASCIMENTO 45

5.2 FUNÇÃO RENAL .47

5.2.1 Procedimento experimental 1 .47

5.2.2 Procedimento experimental 2 .50 
5.2.3 Procedimento experimental 3

5.2.4 Procedimento experimental 4 .58

5.3 FUNÇÃO HEPÁTICA .61

5.3.1 Procedimento experimental 1 61

5.3.2 Procedimento experimental 2 .63

5.3.3 Procedimento experimental 3 .65

5.3.4 Procedimento experimental 4 67

5.4 PROTEINOGRAMA 69

5.4.1 Procedimento experimental 1 69

5.4.2 Procedimento experimental 2 .73

5.4.3 Procedimento experimental 3 .77

5.4.4 Procedimento experimental 4 .80

5.5 FUNÇÃO DO METABOLISMO ENERGÉTICO .83

5.5.1 Procedimento experimental 1 .83

5.5.2 Procedimento experimental 2 .93

5.5.3 Procedimento experimental 3 109

5.5.4 Procedimento experimental 4 119

6 CONCLUSÃO 131 REFERÊNCIAS 


\section{INTRODUÇÃO}

As biotecnologias aplicadas a reprodução de bovinos, como a fertilização "in vitro" (FIV) permitiram a seleção de animais genotipicamente superiores e com maior eficiência produtiva, colocando o Brasil em destaque entre os países produtores de carne bovina e como o maior produtor mundial de embriões in vitro, sendo o responsável por $80 \%$ da produção de embriões in vitro (PIV), já em 2007 (MARTINS, 2010).

Problemas como a macrossomia, também denominada de síndrome do bezerro gigante ou síndrome do bezerro anormal (FARIN; PIEDRAHITA; FARIN, 2006), são considerados como multifatorial (MCEVOY et al., 2006) e já foram relatados, em bezerros produzidos por fertilização in vitro (HASLER, 1996; KRUIP; den DAAS, 1997; PRESTES, 2005) e em bezerros produzidos por clonagem (BATCHELDER et al., 2007; CHAVATTE-PALMER et al., 2004; MEIRELLES et al. 2010). Verificou-se que $34,3 \%$ (86/251) dos bezerros da raça holandesa produzidos por FIV apresentavam macrossomia (KRUIP; den DAAS, 1997). Os bezerros produzidos por FIV são em média $7 \mathrm{Kg}$ mais pesados que bezerros oriundos de inseminação artificial (HASLER, 1996), apresentam maior perímetro e peso cardíaco, além de maior comprimento dos ossos longos (FARIN; FARIN, 1995).

Associado a síndrome do bezerro anormal, observou-se, em $23 \%$ dos bezerros clonados, hipoglicemia e/ou distúrbios de termoregulação nas primeiras 24 horas de vida (BIRGEL JUNIOR et al., 2011a; BIRGEL JUNIOR et al., 2011b; MEIRELLES et al., 2010). Distúrbios de termorregulação nas primeiras 24 horas de vida, também, foram descritos em bezerros prematuros obtidos de IA e bezerros prematuros de FIV (SANGILD et al., 2000). Na Medicina, descreve-se a ocorrência de macrossomia em bebês gerados por mulheres com diabetes gestacional não controlada. Apesar da mortalidade perinatal dos neonatos associados a diabetes gestacional tenha diminuído (DICKINSON; PALMER, 1990), as incidências de morbidade perinatal, cesarianas e macrossomia fetal humana permanecem aumentadas (DICKINSON; PALMER, 1990; HALES; BARKER, 2013).

Por outro lado, é sabido, que gestações complicadas, nas quais os bebês estavam em situação de hipóxia crônica apresentam aumento plasmático de lactato 
e que a hipóxia prolongada em neonatos humanos acarreta mudanças nos níveis circulantes de glicose e cortisol sérico, reduz o metabolismo da termorregulação e causa danos ao sistema nervoso central e simpático dos recém-nascidos (BELLOWS; LAMMOGLIA, 2000). Da mesma forma, aventa-se a possibilidade que os distúrbios do metabolismo de carboidratos observados em bezerros clonados poderiam estar relacionados ao consumo das reservas de glicogênio hepático decorrente da hipóxia durante a vida intrauterina e perinatal (BIRGEL JUNIOR et al., 2011a).

A cetose, condição que corresponde ao distúrbio do metabolismo energético em ruminantes, é caracterizado pelo conjunto da elevação anormal de corpos cetônicos séricos e na urina, e diminuição de $\mathrm{pH}$ sanguíneo e urinário, decorrente de situações em que há aumento da metabolização dos ácidos graxos do tecido adiposo diante de hipoglicemia (FLEMING, 2009; FRANDSON; WILKE; FAILS, 2011). Relata-se na literatura a ocorrência de cetose na fase final da gestação em vacas de corte (BAILEY, 2015; CORREA; SCHILD; MENDEZ, 1990), como resultado do aumento da demanda energética no final da gestação, associado a redução da capacidade de ingestão de matéria seca nas últimas semanas antes do parto, acarretando em maior mobilização de gordura corpórea, (JUCHEM et al., 2000).

Baseado nos estudos que avaliaram as alterações no perfil fisiológico de bezerros oriundos de sistemas de produção in vitro durante o final da gestação, nos momentos perinatal e neonatal. Os neonatos podem ter tamanho normal ou serem maiores do que a média da raça, podendo ter alterações clínicas, de parâmetros hematológicos e bioquímicos (KRUIP; Den DAAS, 1997; MILES et al., 2004; SINCLAIR; BROADBENT; DOLMAN, 1995).

O delineamento experimental proposto terá a finalidade de conhecer melhor o perfil metabólico das vacas no final da gestação e dos bezerros originados de FIV, obtidos por cesariana e parto natural, com o intuito de propor protocolos de cuidados ao neonato, que aumente a sobrevivência de animais advindos de gestações de risco ou de animais nascidos prematuramente. 


\section{JUSTIFICATIVA E OBJETIVOS}

A existência de poucas informações na literatura brasileira referente ao metabolismo lipídico de bezerros da raça Nelore produzidos por fertilização in vitro. Principalmente, pela ausência, na literatura nacional, de pesquisas relacionadas à caracterização do perfil metabólico, bem como a avaliação das alterações do metabolismo energético de bezerros prematuros foram os motivos que nos fizeram propor o presente projeto de pesquisa com o objetivo de compreender o que ocorre com bezerros obtidos por FIV nascidos por cesariana após indução e parto natural.

Portanto, em continuidade as pesquisas relacionadas aos distúrbios na adaptação neonatal de bezerros, o delineamento experimental proposto terá a finalidade de:

- Caracterizar as diferenças do perfil metabólico de bezerros da raça Nelore produzidos por FIV e daqueles obtidos por IA,

- Estudar as possíveis repercussões da macrossomia sobre o metabolismo energético materno no final da gestação por FIV

- Documentar o grau de controle glicêmico dos fetos durante o último mês de gestação por FIV e IA por meio da determinação da frutosamina.

- Determinar a existência ou não de resistência à insulina bezerros recémnascidos por FIV 


\section{REVISÃO DE LITERATURA}

\subsection{USO COMERCIAL DA FIV NA REPRODUÇÃO EM BOVINOS: AVANÇOS E DISTÚRBIOS RELACIONADOS}

O desenvolvimento de técnicas para produção de embriões bovinos in vitro constituiu importante passo para a expansão do uso das biotecnologias à campo em condições comerciais (FARIN; ALEXANDER; FARIN, 2010). Nos últimos anos a FIV tornou-se comercialmente mais acessível e consolidou-se como uma importante ferramenta, que permite aumentar a taxa de ganho genético, em um curto espaço de tempo. Já em $2005,48,6 \%$ do total de embriões produzidos na América do Sul correspondiam a FIV (THIBIER, 2006). Em 2006, o mercado mundial de transferência de embriões originados por PIV realizou 196.663 transferências em receptoras, destes, mais de $90 \%$ correspondiam a raças de corte. No ano seguinte, o Brasil consolidou-se como maior produtor de embriões in vitro, respondendo por quase $80 \%$ dessas transferências no âmbito mundial (MARTINS, 2010). Já no relatório de 2015 da IETS, a América do Sul correspondeu por 62\% das 599.307 transferências de embriões in vitro, sendo que o Brasil foi responsável por $96 \%$ (PERRY, 2015).

Desde o início da aplicação das biotecnologias in vitro no Brasil, as raças zebuínas correspondiam por mais de 90\% dos embriões produzidos, o que representou ser o ponto chave para o sucesso de sua aplicação comercial (VIANA et al., 2012), uma vez que a viabilidade econômica dos sistemas de transferência de embriões FIV tornou-se efetiva graças as já conhecidas características fisiológicas da dinâmica folicular das fêmeas Bos indicus (FIGUEIREDO et al., 1997; VIANA et al., 2000; WATANABE et al., 1999). Dentre as raças zebuínas, a Nelore ganha destaque por ser a raça predominante na pecuária de corte nacional com representatividade de cerca de $80 \%$ do rebanho (ROSA; MENEZES, 2016) e 69\% dos embriões in vitro transferidos do total geral de embriões de raças zebuínas no período entre 2006 e 2015 (ASSOCIAÇÃO BRASILEIRA DOS CRIADORES DE ZEBU - ABCZ, 2016). 
Diante do desenvolvimento de novas técnicas como a FIV com uso de sêmen sexado e a vitrificação para preservação de embriões, aumenta os horizontes de aplicação da FIV comercial, confirmando a tendência de crescimento de mercado, como verificado entre 2014 e 2015 pelo aumento de mais de 30\% de embriões produzidos (SARTORI et al., 2016).

Apesar da consolidação FIV no mercado de transferência de embriões na bovinocultura comercial, sua expansão segue depende do sucesso na obtenção dos objetivos pretendidos: alta taxa de prenhez, gestações sem complicações e bezerros nascidos saudáveis e com vitalidade. Entretanto, sabe-se que, bezerros originados dos sistemas in vitro são descritos como menos viáveis do que os bezerros originados de técnicas in vivo, IA e monta natural (HORTA, 1999; SANGILD et al., 2000). Desde a década de 1990, já era conhecido que as biotecnologias de produção de embriões in vitro estavam associadas ao aumento de anormalidades no desenvolvimento embrionário, fetal e placentário (FARIN; FARIN 1995; HASLER et al., 1995; YOUNG; SINCLAIR; WILMUT, 1998).

Os fatores perturbadores e os mecanismos foram creditados à condições desfavoráveis no ambiente dos embriões nos momentos iniciais dos processos de maturação, fertilização e cultivo in vitro, até o estágio de blastocisto, assim como no período após a transferência, nas fases de pré-implantação e pós-implantação. Os possíveis agentes causadores ligados aos meios, estão associados aos fatores de crescimento, radicais livres, amônia, co-cultivo com as células da granulosa ou a alta concentração de soro no meio de cultivo in vitro, já os fatores ligados às receptoras, são relacionados ao nível de progesterona e a nutrição. Contudo, sem conseguir identificar como os fatores, associados ou isoladamente, causam os distúrbios de desenvolvimento e se existe um período crítico para sua ocorrência (BEHBOODI et al., 1995; BERTOLINI; ANDERSON, 2002; FARIN; FARIN; MUNGAL, 1997; FARIN; FARIN, 1995; JACOBSEN et al., 2000a; NUMABE et al., 2000; YOUNG et al., 1998).

Hoje sabe-se que os complexos meios de cultivo in vitro são constituídos por importantes componentes que modulam a atividade metabólica do embrião, entretanto, as condições sub-ótimas do cultivo in vitro, resultam em desequilíbrios nutricionais. Estes desequilíbrios são apontados como os possíveis responsáveis pelo estresse metabólico que origina as várias diferenças entre embriões derivados in vivo e in vitro (KHURANA; NIELMAN, 2000; KRUIP; BEVERS; KEMP, 2000; VAN 
WAGTENDONK-DE LEEUW et al., 2000). Resultando em consequências negativas para o desenvolvimento fetal e para a sobrevivência perinatal e neonatal (VAN WAGTENDONK-DE LEEUW et al., 2000).

Estas alterações acarretam em uma variada gama de distúrbios como o aumento de perdas embrionárias precoces (FARIN; FARIN, 1995; HASLER et al., 1995; TAVERNE et al., 2002), abortos (HASLER et al., 1995; KRUIP; den DAAS, 1997; TAVERNE et al., 2002), alterações placentárias (FARIN; FARIN, 1995; HASLER et al., 1995; HASLER, 1996; MILES et al., 2004), gestações prolongadas (RÉRAT et al., 2005; SINCLAIR; BROADBENT; DOLMAN, 1995), aumentos dos índices de natimortalidade, perimortalidade (BEHBOODI et al., 1995; KRUIP; Den DAAS, 1997; PRESTES et al., 2009; STACCHEZZINI; FABARO; CREMONESI, 1997), do peso ao nascimento (BEHBOODI et al., 1995; HASLER, 1996; KRUIP; Den DAAS, 1997; MILES et al., 2004; VAN WAGTENDONK-DE LEEUW et al., 2000) com megalias fenotípicas (CROSIER et al., 2002; FARIN; ALEXANDER; FARIN, 2010; FARIN; FARIN, 1995), má formações congênitas (VAN WAGTENDONK-DE LEEUW et al., 1998) e índices de distocias com necessidades de auxilio ao parto e até a necessidade de realização de cesarianas (BEHBOODI et al., 1995; KRUIP; Den DAAS, 1997; PRESTES, 2005; SINCLAIR; BROADBENT; DOLMAN, 1995; STACCHEZZINI; FABARO; CREMONESI, 1997).

\subsection{SÍNDROME DO BEZERRO GIGANTE}

Primeiramente a condição foi denominada como síndrome do bezerro gigante, mas, como se trata de um conjunto de anormalidades, que podem surgir por diferentes mecanismos, aliados à imprevisibilidade da ocorrência do evidente aumento do peso e tamanho do bezerro e da placenta, foi proposta nova denominação como síndrome do bezerro anormal (FARIN; PIEDRAHITA; FARIN, 2006).

Esta síndrome parece acometer todos os embriões de PIV, em graus variados (YOUNG et al., 1998), além de estar presente em diversas raças (CAMARGO et al., 2010; KRUIP; Den DAAS, 1997; NUMABE et al., 2000; STACCHEZZINI; FABARO; CREMONESI, 1997; WILSON et al., 1995) e apresentar incidência mundial de cerca de $20 \%$ além do normal (KRUIP; Den DAAS, 1997). 
O aumento em cerca de $7 \%$ do peso no momento do nascimento está relacionado somente a distúrbios no desenvolvimento uterino do feto, uma vez que a variação do tamanho e peso corporal, diminui com o tempo de vida sem apresentar diferenças estatísticas com bezerros oriundos de IA e monta natural (WILSON et al., 1995).

Apesar de haver uma relação positiva em bezerros oriundos de produção de embriões in vitro sobre o peso ao nascimento, a dificuldade ao parto com o prolongamento da gestação (SINCLAIR; BROADBENT; DOLMAN, 1995), o aumento do peso ao nascimento não poderia ser explicado, inteiramente, pelo prolongamento da gestação (VAN WAGTENDONK-DE LEEUW et al., 1998; VAN WAGTENDONKDE LEEUW et al., 2000). Uma vez que, já houve a confirmação de nascimentos de bezerros originados por produção de embriões in vitro com peso elevado, sem que houvesse prolongamento da gestação (BERTOLINI; ANDRESON, 2002; NUMABE et al., 2000). Contudo, não há uma explicação definitiva para o aumento do peso ao nascimento e prolongamento da gestação (NUMABE et al., 2000).

As circunstâncias anormais, durante o período in vitro, devido às condições sub-ótimas dos meios de cultivo, geram alterações no desenvolvimento embrionário, que podem interferir na sobrevivência fetal durante o início da gestação, principalmente, ao utilizar células da granulosa ou alta concentração de soro nos meios in vitro (BLOCK et al., 2011; FARIN; CROSIER; FARIN, 2001; HERAS et al., 2016; JACOBSEN et al., 2000a). Contudo, as anormalidades observadas em recém-nascidos obtidos por FIV, sugerem que a gênese dos distúrbios ocorra durante a vida fetal, ocasionando dificuldades para a adaptação à vida extrauterina no bezerro. Estes fatos geram problemas para o uso comercial dos sistemas de PIV, pelo aumento da dificuldade de parto e a baixa vitalidade dos bezerros ao nascimento (FARIN; CROSIER; FARIN, 2001; MCEVOY et al., 2006). O que torna fundamental a identificação das causas da baixa viabilidade perinatal para permitir a massificação do uso das biotecnologias da reprodução in vitro na bovinocultura comercial (BERTOLINI; ANDERSON, 2002; SANGILD et al., 2000). 
3.2.1 Alterações morfológicas e funcionais da placenta

O desenvolvimento adequado da placenta dos mamíferos é de suma importância para determinar a disponibilidade de nutrientes, a regulação das trocas gasosas e a remoção de resíduos para o feto ao longo da gestação (MILES et al., 2004). O aumento da incidência de hidropsias dos envoltórios fetais em gestações de FIV pode estar associado a anormalidades de formação placentária (HASLER et al., 1995; MILES et al., 2004). Uma vez que as placentas de embriões originados de FIV possuem menor número de placentônios (FARIN; FARIN, 1995; MIGLINO et al., 2007; MILES et al., 2004), menor superfície caruncular e, paralelamente, as placentas mais pesadas são positivamente associadas com bezerros mais pesados (FARIN et al., 2000; MIGLINO et al., 2007; MILES et al., 2004).

Ao avaliar morfologicamente e realizar mensurações nos fetos derivados in vitro e in vivo aos 222 dias de gestação, Farin e Farin (1995), verificaram que bezerros originados por FIV eram significativamente maiores e questionaram se o aumento do peso era uma consequência do prolongamento gestacional. Embora não tenha esclarecido a origem causal da elevação do peso Farin e Farin (1995), sugeriram maiores investigações sobre o assunto.

Segundo Bertolini et al. (2002a), as gestações oriundas de FIV apresentam padrão de desenvolvimento embrionário e fetal pós-implantação com diferenças no metabolismo e desenvolvimento intrauterino. No dia 37 de gestação os placentônios são menores e mais finos, do dia 51 até o dia 63 o seu tamanho assemelha-se aos de gestações sem manipulações in vitro e a partir do dia 93 os placentônios começam a ficar maiores. Juntamente com este padrão placentário há a constatação do retardo de crescimento fetal entre os dias 37 e 58 de gestação. Ao final do primeiro trimestre, entre os dias 65 e 72, Bertolini et al. (2002a) observaram uma mudança no padrão de crescimento fetal, que passou de retardo no crescimento inicial, para uma maior taxa de crescimento dos fetos FIV.

Foi constatado, também, que os placentônios que envolviam o feto na região média da placenta de gestações de FIV eram mais longos e finos no terço médio e no final do $1^{\circ}$ trimestre, os placentônios e os cotilédones possuíam um tamanho aumentado e com maior área de superfície bruta, 21\% menos cotilédones, mas com maior área de superfície cotiledonária (BERTOLINI; ANDERSON, 2002) além de 
carúnculas com maior volume de vasos sanguíneos, possivelmente, como mecanismo compensatório, devido à diminuição da área de contato feto-materna. (MILES et al., 2004).

A constatação de que as placentas de gestações originadas de FIV possuem menor número de placentônios e menor superfície caruncular sugere que a disponibilidade de nutrientes ou trocas gasosas pode ser limitada no final da gestação para os fetos, o que pode explicar a morbidade e mortalidade perinatal e neonatal, entretanto, não explica o aumento do peso corporal dos fetos (FARIN et al., 2000; FARIN; FARIN, 1995; MILES et al., 2004). Contudo, não se deve considerar, apenas, que as alterações morfológicas podem afetar o desenvolvimento placentário, como também, há de se considerar os transtornos funcionais de síntese e secreção de hormônios e troca de nutrientes e resíduos (BERTOLINI et al. 2002a; BERTOLINI; ANDERSON, 2002).

Considera-se que o placentônio seja o principal local de transporte de moléculas pequenas de fácil difusão, como oxigênio, dióxido de carbono e também aminoácidos e glicose (HILL et al., 2000). Posteriormente foi confirmado que há diferenças bioquímicas e metabólicas entre fetos derivados de FIV e IA, com significativa diminuição da disponibilidade de glicose e oxigênio para sua metabolização, assim como aumento de lactato no final da gestação com repercussões na maturação fetal e adaptação à vida extrauterina (SANGILD et al., 2000).

O período perinatal é caracterizado por dramáticas modificações fisiológicas e metabólicas, decorrentes da troca gasosa respiratória e estão associados a alterações, tanto nas tensões dos gases arteriais, como na função cardiovascular, situações onde ocorre asfixia, o fluxo sanguíneo cerebral diminui, como consequência, o aporte de oxigênio (GARDINER, 1980). O parto prolongado, em conjunto com distocias, pode resultar em distúrbios ácido-base no bezerro recémnascido (JACOBSEN et al., 2000b), encefalopatias, insuficiência renal isquêmica e diversos graus de disfunções gastrointestinais (VAALA; LESTER, 2009).

Em estudo sobre características pós-natal em bezerros clonados realizado por Garry et al. (1996), revelou, pela avaliação clínica e mensuração do metabolismo energético no pós-parto imediato, alterações como fraqueza, hipotermia, hipoxemia, hipoglicemia e acidose metabólica na maioria dos bezerros. Juntos sugerem a 
existência de distúrbios no metabolismo energético no período gestacional. Entretanto, esses distúrbios do metabolismo energético não estavam relacionados a hormônios como o do crescimento, IGF-1, cortisol e glucagon, uma vez que não houve diferenças entre os grupos experimentais.

Em bezerros de gestações FIV observou-se comportamento semelhante para as avaliações clínicas (JACOBSEN et al., 1999; OLIVEIRA, 2011; SCHMIDT et al., 1996). No dia 7 do desenvolvimento embrionário em gestações FIV, a expressão de IGF-1 do embrião, também não apresentou diferença. Entretanto, o IGF-2 parece ter importante papel para a ocorrência das manifestações, uma vez que apresentou um padrão de expressão gênica dez vezes menor no mesmo período, assim como as expressões gênicas de GLUT-1 e GLUT-3 também estarem diminuídas (BERTOLINI et al., 2002b).

\subsection{METABOLISMO ENERGÉTICO GESTACIONAL}

A glicose é a principal fonte de energia celular, responsável pela produção de ATP, tanto em condições aeróbicas como anaeróbicas. Considerada uma molécula polar, portanto não é capaz de atravessar a membrana celular, sendo transportadas através de difusão facilitada, a favor de seu gradiente de concentração, por proteínas transportadoras (GLUTs) presente na membrana plasmática de todas as células (MACHADO, 1998). Atualmente 13 isoformas de proteínas transportadoras de glicose já foram_sequenciadas (GLUT 1 ao GLUT 13). A GLUT 4 é a proteína que mais caracteriza alteração tecidual da expressão observada nos músculos e no tecido adiposo (JAMES, 1995; MUECKLER, 1994). Já a GLUT 1 é importante para a absorção de glicose para utilização da placenta, enquanto a GLUT 3 pode estar ligado à transferência da glicose para o feto (EHRHARDT; BELL, 1997).

Em continuidade para aumentar os conhecimentos sobre o metabolismo energético gestacional, outra pesquisa não encontrou diferenças entre os grupos estudados (gestações de embriões produzidos in vitro e controle) e períodos gestacionais (90 e 180 dias), com relação à transcrição dos transportadores de glicose GLUT 1, 3 e 5 em placentônios. A expressão gênica de GLUT 1 e 3 foi semelhante e independente de grupo ou período de gestação. Com relação ao GLUT 5 no alantoide fetal, observou-se uma expressão de 10 a 100 vezes maior se 
comparada com GLUT 1 e 3. Os autores correlacionaram a maior expressão do GLUT 5 com aumento da quantidade de líquido alantoideano, assim como aumento das concentrações de glicose e frutose no líquido alantoideano (BERTOLINI et al., 2004). A GLUT-1 é importante na captação de glicose para a utilização da placenta e a GLUT-3 para a transferência de glicose para o feto. A menor expressão dos genes transportadores de glicose GLUT-1 e GLUT-3 podem afetar a captação de glicose e o metabolismo e desenvolvimento embrionário (BERTOLINI et al., 2002b).

\subsubsection{Distúrbios metabólicos materno-fetal}

O fato de vários laboratórios utilizarem diferentes meios de cultivo dificulta a identificação dos genes que influenciam de forma crítica o desenvolvimento embrionário (FARIN; FARIN; PIEDRAHITA, 2004), do mesmo modo, a ligação fisiológica entre uma expressão gênica individual e as alterações fenotípicas da síndrome do bezerro anormal ainda não está clara, até porque as manifestações são variáveis, podendo ou não ter diferenças de peso ao nascimento como a associação de problemas perinatais (BERTOLINI; ANDERSON, 2002). Neste contexto, as anormalidades metabólicas crônicas durante a gestação podem explicar a variação do peso ao nascimento e os problemas perinatais que refletem na dificuldade transitória de adaptação a vida extrauterina (BERTOLINI et al., 2002b; GARRY et al., 1996), similar a diabetes gestacional humana não controlada (GARRY et al., 1996).

As perdas perinatais e neonatais decorrentes do sofrimento fetal em condições de hipóxia intrauterina são característicos dos distúrbios de adaptação a vida extrauterina em bezerros de FIV (KRUIP; Den DAAS, 1997) e bezerros clonados (BIRGEL JUNIOR et al., 2011b), como dito anteriormente, parecem decorrer por déficits sobre o controle do metabolismo energético (BERTOLINI et al., 2002b; GARRY et al., 1996).

Semelhante ao que ocorre em distocias, prejudicam os mecanismos de adaptações cardiopulmonares para o ambiente extrauterino, os processos que seriam promovidos em decorrência da ruptura do cordão umbilical, com diminuição da tensão de oxigênio, e o aumento das concentrações de dióxido de carbono são precocemente iniciados no ambiente intrauterino. Nestas condições, o feto desenvolve hipercapnia ou acidose metabólica, acarretando em depressão do sistema nervoso central e inibição os reflexos de expansão pulmonar (NAGY, 2009). 
Os neonatos que conseguem sobreviver a estes distúrbios de adaptação a vida extra-uterina são menos propensos a ingerir colostro no momento adequado, posteriormente, são mais susceptíveis a óbito por hipotermia e por infecções devido à hipogamaglobulinemia (HOUSE, 2009).

Os mecanismos de compensação fetal incluem a diminuição do consumo de oxigênio e a realização da glicólise anaeróbica (VAALA; LESTER, 2009). Como resultado ocorre o aumento do quociente de lactato, evidenciado em fetos originados por FIV, entre os dias 246 e 253 de gestação, através de cateterização cirúrgica intrauterina (SANGILD et al., 2000).

Uma forma não invasiva para avaliar os distúrbios do metabolismo de glicose fetal durante o terço final de gestação seria a mensuração da frutosamina, imediatamente após o nascimento. A frutosamina corresponde as proteínas glicadas totais associadas às proteínas séricas (FEITOSA; ANDRADE; 2014; ROOK, 2000; SUMITA; ANDRIOLO, 2006). A avaliação dos níveis médios de glicemia em períodos mais curtos, dependendo da vida útil das proteínas, pode ser obtida pela dosagem de frutosamina, a qual é capaz de informar acerca do controle glicêmico, das últimas quatro a seis semanas em humanos (SUMITA; ANDRIOLO, 2006) e das 3 a 4 semanas em pequenos ruminantes (ROOK, 2000).

Em humanos encontra-se aumentada em portadores de diabetes mellitus e é proporcional a concentração da glicemia, sua determinação sérica é utilizada para monitoração da glicemia ao longo das gestações em mulheres diabéticas (FEITOSA; ANDRADE; 2014), sendo útil na avaliação da eficácia de mudança terapêutica (SUMITA; ANDRIOLO, 2006)

Os ácidos graxos voláteis (ácido acético, ácido propiônico e ácido butírico) absorvidos a partir dos compartimentos gástricos anteriores são a principal fonte de energia para os ruminantes adultos. Responsáveis também pelas menores variações normais nos níveis sanguíneos de glicose em adultos comparados com outros herbívoros (bovinos, 45 a $80 \mathrm{mg} / \mathrm{dL}$; equinos 60 a $110 \mathrm{mg} / \mathrm{dL}$ ), a normoglicemia é obtida por gliconeogênese contínua no fígado na presença de glucagon (FRANDSON; WILKE; FAILS, 2011).

Em situações de balanço energético negativo (BEN), o desequilíbrio energético com déficits de glicose sérico e hepático, com aumento de estímulo para síntese de glucagon, inibição da insulina, decréscimo de glicogênio e aumento da 
mobilização lipídica, desencadeia, nos ruminantes, o estado metabólico de cetose, mais especificamente a cetose tipo 1, clássica primária ou cetose espontânea, caracterizada por elevação anormal das concentrações dos corpos cetônicos, acetona (Ac), ácido Acetoacético (AcAc) e $\beta$-hidroxibutirato $(\mathrm{BHB})$ no organismo. Há redução do $\mathrm{pH}$ sanguíneo e urinário, presença de corpos cetônicos na urina, além das elevações sérica de ácidos graxos (FAA, sigla em inglês) e ácido graxo não esterificado (NEFA, sigla em inglês) (FLEMING, 2009; FRANDSON; WILKE; FAILS, 2011; OETZEL, 2003). Efeito semelhante ao que ocorre na diabetes melitus tipo 1, embora por razões diferentes onde os déficits primários de síntese pancreática de insulina resultam em predomínio do glucagon, mobilizando ácidos graxos e consequentemente a síntese de cetonas (FRANDSON; WILKE; FAILS, 2011; OETZEL, 2003).

A cetose tipo 2, também pode ser comparada à diabetes melitus tipo 2 (OETZEL, 2003), sendo caracterizada por altos níveis de insulina sérica e hiperglicemia transitória, secundário aos infiltrados gordurosos no fígado, em vacas com alto escore de condição corporal $(E C C)$ a resistência transitória a insulina está presente no início da formação da cetose (FLEMING, 2009; OETZEL, 2003).

A ocorrência de cetose durante a gestação, também conhecida como toxemia da prenhes em vacas de corte, ocorre nos últimos dois meses de gestação em vacas de todas as idades, uma vez que, com o máximo crescimento uterino o ambiente abdominal fica limitado, restringindo o consumo de alimentos. Esta condição é mais comum em vacas com alto escore de condição corporal, associado a gestações gemelares e em situações de baixa qualidade de alimentos fornecidos ou limitações de ingestão (BAILEY, 2015). Considerado um excelente marcador da ocorrência de cetose, utiliza-se a determinação do BHB sérico, sendo o teste considerado positivo para valores acima de $14,4 \mathrm{mg} / \mathrm{dL}$, embora valores acima de $11,2 \mathrm{mg} / \mathrm{dL}$ também são considerados para definir a condição de cetose (FRANDSON; WILKE; FAILS, 2011; OETZEL, 2003)

$\mathrm{Na}$ gestação em humanos, o metabolismo dos carboidratos sofre grande impacto para suprir as demandas metabólicas energéticas para o organismo materno e fetal. O crescente requerimento nutricional fetal no final do segundo e no terceiro trimestres são prontamente fornecidos graças a resistência à insulina, que aumenta ao longo do terceiro trimestre. A ingestão materna de nutrientes induz 
elevações persistentes da glicose sérica, nesta condição, na diabetes gestacional, os níveis de glicose séricos ficam anormalmente aumentados. (DICKINSON; PALMER; 1990).

Além das alterações hormonais e de glicemia, a diabetes gestacional também está associada a alterações morfológicas e fisiológicas na placenta que interferem no metabolismo fetal. As placentas de gestações de mulheres com diabetes possuem menor número de receptores para insulina, entretanto com maior afinidade e maior área de superfície periférica, capilar e do volume das vilosidades. Isto sugere mecanismos compensatórios da placenta diante dos distúrbios metabólicos que permitem sustentar o crescimento fetal (DICKINSON; PALMER; 1990).

Os distúrbios metabólicos ocasionados pela diabetes gestacional promovem alterações no metabolismo fisiológico fetal no terço final da gestação, a hiperglicemia materna resulta em hiperinsulinemia e hiperglicemia fetal, como consequência, ocorre a macrossomia. Isto posto, há clara associação do metabolismo materno da glicose com o crescimento e maturação fetal, o conjunto de manifestações da fetopatia diabética também inclui prematuridade, síndrome da asfixia neonatal (DICKINSON; PALMER; 1990).

A hipótese de Garry et al. (1996) sobre a possibilidade de que no útero das vacas receptoras de embriões FIV exista diferenças no fornecimento e utilização de energia que resultam nas diferenças do crescimento gestacional, além de predispor dificuldades na regulação do equilíbrio energético durante a transição para a vida extrauterina, pudesse ser comparável com o que ocorre em bebês humanos de mães com diabetes gestacional não regulado, não pôde ser confirmada em pesquisa realizada por Reinders et al. (1998), talvez, por não ter ocorrido diferenças fenotípicas entre os grupos de bezerros FIV e IA estudados. 


\section{MATERIAL E MÉTODOS}

Para avaliação do perfil metabólico de receptoras de gestações de FIV e de bezerros obtidos por FIV foram conduzidas quatro avaliações experimentais, a seguir apresentadas.

4.1 PROCEDIMENTO EXPERIMENTAL 1: Avaliação da influência do período final da gestação e da indução do parto no perfil metabólico de vacas receptoras de embriões de FIV

Para avaliação do perfil metabólico de vacas e receptoras em período final de gestação, foram utilizadas 12 vacas gestantes de bezerros da raça Nelore por IA e 8 vacas receptoras de embriões de FIV da raça Nelore. Conforme apresentado no quadro 1 , os animais foram avaliados nos 20 dias finais de gestação, sendo as avaliações realizadas nos seguintes momentos: 270 dias de gestação, 280 dias de gestação, imediatamente após a indução do parto, que será realizado entre 285 e 288 dias de gestação com o uso de $25 \mathrm{mg}$ de dexametasona por via intramuscular, 12 horas após a indução do parto e antes da cesariana, 24 horas após a indução do parto (imediatamente antes da cesariana).

Quadro 1 - Constituição dos grupos experimentais para determinação do perfil metabólico das vacas gestantes de bezerros da raça Nelore submetidas à cesariana

\begin{tabular}{|ccc|}
\hline Momento das Colheitas & $\begin{array}{c}\text { Vacas com } \\
\text { gestações por IA }\end{array}$ & $\begin{array}{c}\text { Receptoras de } \\
\text { gestações por FIV }\end{array}$ \\
\hline 270 dias de gestação & 8 & 12 \\
$\mathbf{2 8 0}$ dias de gestação & 8 & 12 \\
$\begin{array}{c}\text { Imediatamente antes da indução } \\
\text { do parto }\end{array}$ & 8 & 12 \\
$\mathbf{1 2}$ horas após a indução do parto & 8 & 12 \\
$\begin{array}{c}\mathbf{2 4} \text { horas após a indução do parto } \\
\text { (imediatamente antes da } \\
\text { cesariana) }\end{array}$ & 8 & 12 \\
\hline
\end{tabular}

Fonte: Própria autoria. 
Nos cinco momentos discriminados foram realizadas a colheita de sangue para as seguintes determinações nas vacas com gestações por IA e receptoras de embriões de FIV da raça Nelore: teores séricos de BHB, NEFA, triglicérides, colesterol, ureia, creatinina, proteína, albumina, y-glutamil transferase (GGT), teores plasmáticos de lactato e glicose.

4.2 PROCEDIMENTO EXPERIMENTAL 2: Avaliação das modificações no perfil nos primeiros 30 dias de vida de bezerros da raça Nelore obtidos por FIV e nascidos por meio de cesariana

Para avaliação das modificações no perfil metabólico nos primeiros 30 dias de vida de bezerros da raça Nelore obtidos por FIV e nascidos por meio de cesariana eletiva foram utilizados 20 bezerros da raça Nelore, divididos em 2 grupos experimentais: bezerros Nelore por IA nascidos por cesariana eletiva e bezerros Nelore por FIV nascidos por cesariana eletiva. As cesarianas foram realizadas 24 horas após a indução do parto. A indução do parto foi realizada entre 285 e 288 dias de gestação com o uso de $25 \mathrm{mg}$ de dexametasona por via intramuscular. Foram realizadas as colheitas de sangue em 11 momentos, conforme discriminado a seguir: 0, 3, 6, 12, 24, 48, 72, 120, 168 horas de vida, 15 e 30 dias de vida; (Quadro 2).

Nos 11 momentos discriminados para o sangue venoso foram realizadas as seguintes determinações: teores séricos de BHB, NEFA, triglicérides, colesterol, insulina, ureia, creatinina, proteína, albumina, y-glutamil transferase (GGT), teores plasmáticos de glicose e lactato. Com a intenção de avaliar o grau de controle glicêmico de fetos durante o último mês de gestação foi realizada somente no momento do nascimento a determinação de frutosamina sérica.

Nos procedimentos experimentais 1 e 2 os animais foram mantidos no Biotério de Pesquisa em Doenças de Ruminantes da Faculdade de Zootecnia e Engenharia de Alimentos da Universidade de São Paulo (FZEA/USP) e no biotério do Hospital Veterinário "Dr. Halim Atique" (UNIRP) de São José do Rio Preto. 
Quadro 2 - Constituição dos grupos experimentais para determinação do perfil metabólico dos bezerros da raça Nelore nascidos por cesariana após indução do pato

\begin{tabular}{|c|c|c|}
\hline Momento das Colheitas & Bezerros IA & Bezerros FIV \\
\hline 0 horas & 12 & 8 \\
\hline 3 horas & 12 & 8 \\
\hline 6 horas & 12 & 8 \\
\hline 12 horas & 12 & 8 \\
\hline 24 horas & 12 & 8 \\
\hline 48 horas ( $2^{\circ}$ dia de vida) & 12 & 8 \\
\hline 72 horas ( $3^{\circ}$ dia de vida) & 12 & 8 \\
\hline 120 horas ( $5^{\circ}$ dia de vida) & 12 & 8 \\
\hline 168 horas ( $7^{\circ}$ dia de vida) & 12 & 8 \\
\hline 360 horas ( $15^{\circ}$ dia de vida) & 12 & 8 \\
\hline 720 horas ( $30^{\circ}$ dia de vida) & 12 & 8 \\
\hline
\end{tabular}

Fonte: Própria autoria.

4.3 PROCEDIMENTO EXPERIMENTAL 3: Avaliação da influência da síndrome do bezerro gigante (macrossomia) no perfil metabólico de receptoras de gestações de FIV com parto natural a termo

Neste projeto foi considerado síndrome do bezerro gigante (macrossomia) todo bezerro com peso ao nascimento acima de $45 \mathrm{Kg}$, de acordo com pesquisa realizada por Meirelles et al (2010) onde avaliou o peso ao nascimento de 9047 bezerros da raça Nelore oriundos de gestação por IA. Os bezerros apresentaram, ao nascimento, peso médio de $38 \mathrm{Kg}$ e distribuição normal entre 20 e $45 \mathrm{Kg}$.

Para a avaliação das diferenças do perfil metabólico de vacas receptoras de embrião por FIV da raça Nelore de vacas gestantes por IA da raça Nelore, foi acompanhado a última semana de gestação de 17 vacas receptoras com embriões de bezerros da raça Nelore produzidos por FIV com peso elevado (síndrome do bezerro gigante) ao nascimento, 32 vacas receptoras de embrião de FIV da raça 
Nelore com bezerros de peso ao nascimento dentro do padrão para a raça e 16 vacas, da raça Nelore, gestantes de bezerros da raça Nelore por IA. As respectivas vacas foram realizadas as colheitas de sangue realizadas nos seguintes momentos: 288 dias de gestação e até 6 horas após o parto natural a termo (Quadro 3).

Nos 2 momentos discriminados foram realizadas as seguintes determinações nas vacas de gestação de Nelores por IA e receptoras de embriões de Nelores de FIV: determinação dos teores séricos de BHB, NEFA, triglicérides, colesterol, ureia, creatinina, proteína, albumina, y-glutamil transferase (GGT), teores plasmáticos de glicose e lactato.

Quadro 3 - Constituição dos grupos experimentais para determinação do perfil metabólico das vacas com parto natural

\begin{tabular}{|cccc|}
\hline $\begin{array}{c}\text { Momento das } \\
\text { Colheitas }\end{array}$ & $\begin{array}{c}\text { Vacas IA } \\
\text { (Grupo Controle) }\end{array}$ & $\begin{array}{c}\text { Receptoras de } \\
\text { FIV com Bezerros } \\
\text { de peso padrão }\end{array}$ & $\begin{array}{c}\text { Receptoras de FIV } \\
\text { com Bezerros de } \\
\text { peso elevado }\end{array}$ \\
\hline $\begin{array}{c}\mathbf{2 8 8} \text { dias de } \\
\text { gestação }\end{array}$ & 16 & 32 & 17 \\
$\begin{array}{c}\text { Até 6 horas } \\
\text { após o parto }\end{array}$ & 16 & 32 & 17 \\
\hline
\end{tabular}

Fonte: Própria autoria.

4.4 PROCEDIMENTO EXPERIMENTAL 4: Avaliação da influência da síndrome do bezerro gigante (macrossomia) no perfil metabólico de bezerros da raça Nelores oriundos de FIV nascidos por parto natural a termo

Para a avaliação das diferenças do perfil metabólico de bezerros da raça Nelore produzidos por FIV com peso dentro do padrão para a raça e com síndrome do bezerro gigante (macrossomia) foram utilizados 76 bezerros recém-nascidos da raça Nelore, divididos em 3 grupos experimentais: 27 bezerros Nelore por IA a termo, 32 bezerros Nelore por FIV a termo com peso ao nascimento dentro do padrão para a raça e 17 bezerros Nelore a termo com síndrome do bezerro gigante (peso ao nascimento acima de $45 \mathrm{Kg}$ ). As colheitas de sangue foram realizadas em dois momentos conforme a seguir discriminado: até 6 horas de vida e entre 24 e 36 horas de vida (Quadro 4). 
Nesses dois momentos discriminados foram realizadas as seguintes determinações: teores séricos de BHB, NEFA, triglicérides, colesterol, ureia, creatinina, proteína, albumina, $Y$-glutamil transferase (GGT), insulina, teores plasmáticos de glicose, lactato. Com a intenção de avaliar o grau de controle glicêmico de fetos durante o último mês de gestação foi realizada somente no momento até 6 horas de vida a determinação de frutosamina sérica

Nos procedimentos experimentais 3 e 4 os animais foram mantidos nas dependências da Fazenda Mundial - São José do Rio Preto.

Quadro 4 - Constituição dos grupos experimentais para determinação do perfil metabólico dos bezerros da raça Nelore nascidos naturalmente a termo

\begin{tabular}{|cccc|}
\hline $\begin{array}{c}\text { Momento das } \\
\text { Colheitas }\end{array}$ & $\begin{array}{c}\text { Bezerros IA a } \\
\text { (controle) }\end{array}$ & $\begin{array}{c}\text { Bezerros FIV } \\
\text { peso padrão }\end{array}$ & $\begin{array}{c}\text { Bezerros FIV } \\
\text { peso elevado }\end{array}$ \\
\hline $\begin{array}{l}\text { Até } \mathbf{6} \text { horas de vida } \\
\begin{array}{c}\text { Entre } 24 \text { e } 36 \text { horas } \\
\left(2^{\circ} \text { dia de vida }\right)\end{array}\end{array}$ & 27 & 32 & 17 \\
\hline
\end{tabular}

Fonte: Própria autoria.

\subsection{TÉCNICAS UTILIZADAS}

Para melhor entendimento, os procedimentos, as técnias e as determinações bioquímicas realizados durante os procedimentos experimentais nas vacas e nos bezerros, juntamente com a análise estatística foram dispostos separadamente.

\subsubsection{Colheita de sangue}

As amostras de sangue venoso foram colhidas através da punção da veia jugular externa, utilizando-se o Sistema Vacutainer ${ }^{\circledR}$. Sendo $3,0 \mathrm{~mL}$ de sangue em tubo de 4,0mL com EDTA para a realização de hemograma. As amostras para avaliação sérica de colesterol, triglicérides, ácidos graxos não esterificados (NEFA), $\beta$-hidroxibutirato ( $\beta$-HBO), ureia, creatinina, proteína, albumina e $\mathrm{Y}$-glutamil transferase (GGT) foram colhidas em tubos de vidro siliconados de $9 \mathrm{ml}$ sem anti- 
coagulantes, e mantidas em temperatura ambiente para facilitar a retração do coágulo.

No laboratório as amostras foram centrifugadas com força real de centrifugação igual a 2500rpm, durante 15 minutos, para a ocorrência da sinérese do coágulo, sendo, a seguir, o soro sanguíneo separado por aspiração em quatro alíquotas cada, sendo o material acondicionado em tubos plásticos providos de tampas tipo Eppendorf de $2 \mathrm{~mL}$ por momento de cada animal. As alíquotas de soro foram conservadas em freezer a menos $20^{\circ} \mathrm{C}$ até a realização das provas.

As amostras para a determinação dos teores plasmáticos de glicose, insulina, lactato e frutosamina foram colhidas em tubos de vidro siliconados de $4 \mathrm{~mL}$ contendo fluoreto de sódio e mantidas refrigeradas durante o transporte. No laboratório, as amostras foram centrifugadas com força real de centrifugação igual a 2500rpm, durante 15 minutos, para a sedimentação dos elementos figurados do sangue. O plasma sanguíneo foi separado por aspiração em duas alíquotas, sendo o material acondicionado em tubos plásticos providos de tampas tipo Eppendorf com capacidade para $2 \mathrm{~mL}$ por momento de cada animal. As alíquotas de plasma foram conservadas em freezer a menos $20^{\circ} \mathrm{C}$ até a realização das provas.

\subsubsection{Determinação sérica de colesterol}

A determinação dos teores séricos de colesterol foi quantificada por metodologia enzimática colorimétrica, em Analisador Bioquímico Automático, Randox, modelo Rx daytona, United Kingdom - RANDOX Laboratories Ltda, com respectivo kit comercial, de referência $\mathrm{CH} 3810$.

Por esse método, o colesterol sofre a ação da colesterol-esterase e posteriormente da colesterol-oxidase, originando um produto intermediário e água oxigenada. A água oxigenada formada reage com a 4-amino antipirina e fenol, na presença de peroxidase, dando origem a um complexo colorido, cuja intensidade de cor é diretamente proporcional à concentração de colesterol presente na amostra, em $500 \mathrm{~nm}$ (ALLAIN et al., 1974). Os resultados foram expressos em mmol/L. 


\subsubsection{Determinação sérica de triglicérides}

A determinação dos teores séricos de triglicérides foi quantificada por metodologia enzimática colorimétrica, em Analisador Bioquímico Automático, Randox, modelo Rx daytona, United Kingdom - RANDOX Laboratories Ltda, , com respectivo kit comercial, de referência TR3823.

Por este método, os triglicérides são hidrolisados pela lipase presente no reagente, liberando glicerol, que é catalisado pela glicerol-quinase e glicerol fosfato oxidase, havendo geração de peróxido de hidrogênio. O peróxido de hidrogênio sofre a ação da peroxidase concomitantemente à produção de um complexo colorido, a quinolaimina, devido a um sistema reagente existente composto de clorofenol e antipirina. A coloração desenvolvida é proporcional à concentração de triglicérides da amostra, em $500 \mathrm{~nm}$ (FOSSATI; PRENCIPE, 1982). Os resultados foram expressos em $\mathrm{mmol} / \mathrm{L}$.

\subsubsection{Determinação sérica de ß-hidroxibutirato (BHB)}

A determinação dos teores séricos de BHB foi quantificada por metodologia enzimática colorimétrica, em Analisador Bioquímico Automático, Randox, modelo Rx daytona, United Kingdom - RANDOX Laboratories Ltda, utilizando-se kit comercial da Ranbut, (D-3-Hydroxibutyrate), de referência RB1007, Randox, Laboratories Ltd, Reino Unido.

O princípio da prova está baseado na reação desencadeada pela ßhidroxibutirato desidrogenase presente no reagente e que catalisa o $\mathrm{BHB}$ formando o acetoacetato. Concomitantemente, o NAD presente é reduzido a NADH, sendo a absorbância do NADH em 340 nm diretamente proporcional à concentração de BHB presente na amostra (WILLIAMSON; MELLANBY; KREBS, 1962). Os resultados foram expressos em $\mathrm{mmol} / \mathrm{L}$.

\subsubsection{Determinação sérica de ácidos graxos livres não esterificados (NEFA)}

A determinação dos teores séricos de NEFA foi quantificada por metodologia enzimática colorimétrica, em Analisador Bioquímico Automático, Randox, modelo Rx 
Daytona, United Kingdom - RANDOX Laboratories Ltda, com respectivo kit comercial, de referência FA115.

O princípio da prova está baseado na ação da acil CoA sintetase, na presença de ATP e cofatores, sobre os ácidos graxos livres não esterificados (NEFA) dando origem a acil CoA, AMP e Ppi. Essa Acil-CoA é então oxidada, produzindo peróxido de hidrogênio, que foi auxiliar na reação de condensação de uma hidroxianilina com a aminoantipirina, ambos presentes no reagente, havendo a formação de um complexo de coloração púrpura, cuja intensidade de coloração em $550 \mathrm{~nm}$ é diretamente proporcional à quantidade de NEFA presente na amostra (método desenvolvido pelo fabricante do kit, ainda não publicado, sendo a reação de coloração baseada em Elphick (1968). Os resultados foram expressos em $\mu \mathrm{mol} / \mathrm{L}$.

\subsubsection{Determinação sérica da ureia}

A determinação dos teores séricos de ureia foi realizada, por meio de método

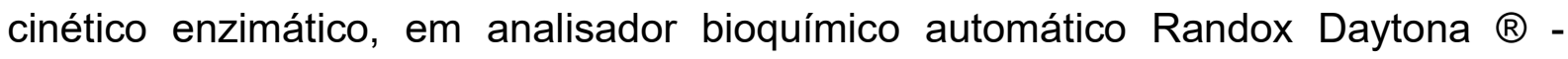
Randox Laboratories, Reino Unido, com respectivo kit comercial, de referência UR3825.

O princípio do método baseia-se na hidrólise da ureia pela urease, produzindo gás carbônico e íons amônio. Estes são captados pela enzima glutamato desidrogenase, a qual, em presença de outros substratos como o NADH2 e $\alpha$ cetoglutarato, produz NAD e glutamato. A diminuição da concentração de NADH2 pode ser medida por espectrofotometria, utilizando comprimento de onda igual a 340 nm, uma vez que é proporcional à concentração de uréia na amostra. Os resultados obtidos foram expressos em $\mathrm{mg} / \mathrm{dL}$.

\subsubsection{Determinação sérica da creatinina}

A determinação dos teores séricos de creatinina foi realizada por método colorimétrico, em Analisador Bioquímico Automático da marca Randox Daytona® Randox Laboratories, Reino Unido, com respectivo kit comercial, de referência CR3814. 
O princípio do método baseia-se na reação da creatinina, em solução alcalina, com o picrato, a qual origina um complexo colorido, cuja intensidade é determinada, em comprimento de onda igual a $340 \mathrm{~nm}$, e diretamente proporcional a atividade de creatinina existente na amostra, sendo os resultados obtidos, expressos em mg/dL.

\subsubsection{Determinação sérica da proteína}

A determinação dos teores séricos de proteína total foi feita de acordo com a técnica preconizada por Gornall et al. (1949) modificada por Strufaldi (1987), em Analisador Bioquímico Automático da marca Randox Daytona ${ }^{\circledR}$ - Randox Laboratories, Reino Unido, com respectivo kit comercial, de referência TP4001.

O princípio da técnica baseia-se na reação entre os tripeptídeos, polipeptídeos e proteínas, existentes no soro sanguíneo, com íons de cobre, presentes no reativo de biureto, formando, em meio alcalino, um complexo de coloração violeta, cuja intensidade é diretamente proporcional à concentração proteica presente na amostra, com resultado expresso em $\mathrm{g} / \mathrm{dL}$.

\subsubsection{Determinação sérica da albumina}

A determinação dos teores séricos de albumina foi feita de acordo com a técnica preconizada por Doumas, Biggs e Watson (1971), em Analisador Bioquímico Automático da marca Randox Daytona ${ }^{\circledR}$ - Randox Laboratories, Reino Unido, com respectivo kit comercial, de referência $A B 3800$.

O princípio da técnica baseia-se na reação entre a albumina, presente na amostra, e o verde de bromocresol, os quais, em meio ácido, originam um complexo, cuja intensidade de coloração é diretamente proporcional à concentração de albumina presente na amostra, com resultado expresso em $\mathrm{g} / \mathrm{dL}$.

\subsubsection{Determinação sérica da y-glutamil transferase}

A atividade enzimática sérica de GGT foi determinada em Analisador Bioquímico Automático da marca Randox Daytona ${ }^{\circledR}$ - Randox Laboratories, Reino Unido, com respectivo kit comercial, de referência GT3817. 
Pela técnica, a enzima gama-glutamiltransferase cataliza a transferência do resíduo gama-glutamil da L-gama-glutamil-3-carboxi-4-nitrobenzoato para glicilglicina, sendo o composto 3-carboxi-4-nitroanilina, formado na reação, diretamente proporcional à atividade enzimática, existente na amostra. Na realização desta prova, quantificou-se o aumento da densidade óptica em $405 \mathrm{~nm}$, sendo o resultado expresso em $\mathrm{U} / \mathrm{I}$.

\subsubsection{Determinação sérica plasmáticos de glicose}

Para a determinação dos teores plasmáticos de glicose foi utilizado o método descrito por Barham e Trinder (1972), em Analisador Bioquímico Automático, Randox, modelo Rx daytona, United Kingdom - RANDOX Laboratories Ltd, com respectivo kit comercial, de referência GL3815.

O princípio do método está baseado na oxidação da glicose em ácido glicurônico e peróxido de hidrogênio pela enzima glicose-oxidase; na presença de peroxidase o peróxido de hidrogênio formado na reação anterior, reage com a 4aminofenazona e com o 2,4-diclofenol, produzindo antipirilcloroquinonimina que desenvolve coloração rósea, cuja intensidade mantém relação direta com a quantidade de glicose presente na amostra. Os resultados foram expressos em $\mathrm{mmol} / \mathrm{L}$.

\subsubsection{Determinação plasmática de lactato}

A determinação dos teores plasmáticos de lactato foi realizada em Analisador Bioquímico Automático da marca Randox Daytona ${ }^{\circledR}$ - Randox Laboratories, Reino Unido, com respectivo kit comercial, de referência LC3980.

O teor sérico de lactato foi obtido por determinação enzimática, correlacionando a ação catalítica da enzima Lactato Oxidase, diretamente proporcional à quantidade de lactato na amostra. A leitura, por espectrofotometria, utilizou comprimento de onda igual a $340 \mathrm{~nm}$, sendo os resultados obtidos, expressos em mg/dL. 
4.5.13 Determinação plasmática da frutosamina

A nova metodologia para a determinação da frutosamina tem como princípio a ligação da glicose aos grupamentos das proteínas formando uma base de Schiff (aldimina), que após um rearranjo molecular transforma-se em uma cetoamina estável denominada genericamente frutosamina. $\mathrm{Em} \mathrm{pH}$ alcalino, a frutosamina é convertida à forma enólica, que reduz o nitroazul de tetrazólio (NBT) a uma cor azul púrpura. Nesta prova, outros agentes redutores podem estar presentes na amostra causando interferência no ensaio. No novo reagente enzimático colorimétrico para a determinação de frutosamina foi incorporada a uricase, um agente clarificador à base de detergente com o objetivo de minimizar os interferentes presentes na amostra. A mensuração da diferença de absorbância em espectrofotômetro, após incubação por 10 a 15 minutos é proporcional a concentração de frutosamina na amostra (WATANABE et al., 2004). Os resultados foram expressos em $\mu \mathrm{mol} / \mathrm{L}$

\subsubsection{Determinação plasmática da insulina}

A insulina plasmática das amostras de soro foram avaliadas pelo método radioimunoensaio. (RIA) - kit Coat A count da Diagnostic Products Corporation (DPC) de fase sólida, utilizando técnica desenvolvida por Yalow e Berson (1960). Os resultados foram expressos em $\mathrm{ng} / \mathrm{mL}$.

\subsection{ANÁLISE ESTATÍSTICA DO PROCEDIMENTO EXPERIMENTAL 1}

Foi realizada Análise de Medidas Repetidas no Tempo (One Way Repeated Measures) para comparação dos animais ao longo do tempo de avalição $(P<0,05)$, dentro de cada tratamento, separadamente. Quando significativa, foi realizado o Teste de Tukey $(P<0,05)$ para comparação das médias. Para comparação dos tratamentos, dentro de cada tempo, foi realizado o Teste $t$ (de Student) $(P<0,05)$. $O$ programa estatístico usado foi o Sigma Stat 3.5 


\subsection{ANÁLISE ESTATÍSTICA DO PROCEDIMENTO EXPERIMENTAL 2}

Foi realizada Análise de Medidas Repetidas no Tempo (One Way Repeated Measures) para comparação dos animais ao longo do tempo de avalição $(P<0,05)$, dentro de cada tratamento, separadamente. Quando significativa, foi realizado o Teste de Tukey $(\mathrm{P}<0,05)$ para comparação das médias. Para comparação dos tratamentos, dentro de cada tempo, foi realizado o Teste $t$ (de Student) $(P<0,05)$. Devido a grande variação nos valores dentro de cada tempo da GGT, foi realizada Análise não-paramétrica de Friedman (Repeated Measures) para comparação dos animais ao longo do tempo de avalição $(P<0,05)$, dentro de cada tratamento, separadamente. Quando significativa, foi realizado o Teste de Tukey $(P<0,05)$ para comparação das médias. Para comparação dos tratamentos, dentro de cada tempo, foi realizado o Teste de Mann-Whitney $(P<0,05)$. O programa estatístico usado foi o Sigma Stat 3.5

\subsection{ANÁLISE ESTATÍSTICA DO PROCEDIMENTO EXPERIMENTAL 3}

Foi realizado o Test $\mathrm{t}$ pareado para comparação dos animais nos dois períodos de avalição $(P<0,05)$, dentro de cada tratamento, separadamente. Para comparação dos tratamentos, dentro de cada tempo, foi realizado Análise de Variância e quando significativa foi realizado o Teste de Tukey para comparação das médias $(P<0,05)$. O programa estatístico usado foi o Sigma Stat 3.5

\subsection{ANÁLISE ESTATÍSTICA DO PROCEDIMENTO EXPERIMENTAL 4}

Foi realizado o Test $\mathrm{t}$ pareado para comparação dos animais nos dois períodos de avalição $(P<0,05)$, dentro de cada tratamento, separadamente. Para comparação dos tratamentos, dentro de cada tempo, foi realizado Análise de Variância e quando significativa foi realizado o Teste de Tukey para comparação das médias $(P<0,05)$. Para comparação dos tratamentos para o parâmetro peso ao nascer e frutosamina foi realizado Análise de Variância e quando significativa foi realizado o Teste de Tukey para comparação das médias $(P<0,05)$. O programa estatístico usado foi o Sigma Stat 3.5. 


\section{RESULTADOS E DISCUSSÃO}

A utilização do perfil bioquímico sanguíneo nos animais tornou-se de extrema importância para o auxílio no diagnóstico das doenças e na tomada de decisão sobre as abordagens preventivas e terapêuticas na pecuária (BAILEY, 2015). Do mesmo modo, a análise do perfil metabólico permite a avaliação de variações no desempenho produtivo e mudanças nas condições fisiológicas. A avaliação do balanço energético é realizada com base nos parâmetros que indicam o grau de deposição e de mobilização das reservas de energia na forma de gordura, relacionado ao metabolismo lipídico (FERNANDES et al., 2012).

Os resultados apresentados no presente estudo foram documentados $\mathrm{e}$ ilustrados através de tabelas e gráficos com a finalidade de facilitar a visualização e interpretação dos resultados obtidos sobre o perfil bioquímico e metabólico de bezerros da raça Nelore, oriundos de FIV e suas receptoras, comparados aos bezerros da raça Nelore oriundos de IA e suas progenitoras, referentes aos procedimentos experimentais $1,2,3$ e 4 .

Para a melhor interpretação durante a discussão, os resultados do perfil bioquímico foram divididos por tópicos em relação a cada função. As tabelas serão apresentadas conforme os números de animais avaliados, as médias, erros padrão, mínimos e máximos, já os gráficos demonstrarão as médias e erros padrão.

Exceto para GGT dos bezerros do procedimento experimental 2 e 4, Devido à grande variação nos valores, foi apresentado os números de animais avaliados, as medianas, erros padrão, mínimos e máximos.

\subsection{PESO AO NASCIMENTO}

Houve diferença estatística significativa entre os tratamentos, para o peso ao nascimento $(P<0,05)$, como mostrados na tabela 1 e no gráfico 1 . A média do peso após o nascimento dos bezerros FIV com peso elevado (síndrome do bezerro gigante) foi de $50 \mathrm{Kg}$, já os bezerros FIV com peso dentro do padrão para a raça foi de $40 \mathrm{Kg}$ e para os bezerros IA (controle) a média foi de $37 \mathrm{Kg}$. Para o grupo controle, o valor do peso após o nascimento, foi semelhante ao relatado por 
Meirelles et al. (2010), para bezerros da raça Nelore oriundos de gestação por IA nascidos naturalmente. A ocorrência de bezerros oriundos de FIV com peso acima do normal foi de $33 \%$ (16/48), porcentagem semelhante a encontrada por Kruip e Den Daas (1997) em bezerros de diversas raças.

Tabela 01 - Médias, erros padrão, medidas mínimas e máximas para peso $(\mathrm{Kg})$ ao nascimento de bezerros oriundos de FIV e por IA nas primeiras 36 horas de vida obtidos por parto natura

\begin{tabular}{|c|c|c|c|c|}
\hline & & & té $6 \mathrm{~h}$ de vida & \\
\hline & $\mathrm{n}$ & Média & Erro Padrão & Min e Max \\
\hline $\begin{array}{l}\text { Bezerros } \\
\text { FIV peso } \\
\text { elevado }\end{array}$ & 16 & $50,01 a$ & 1,10 & $\begin{array}{l}45,40 \\
59,00\end{array}$ \\
\hline $\begin{array}{l}\text { Bezerros } \\
\text { FIV peso } \\
\text { padrão }\end{array}$ & 32 & $39,57 \mathrm{~b}$ & 0,79 & $\begin{array}{l}26,90 \\
45,00\end{array}$ \\
\hline $\begin{array}{l}\text { Bezerros IA } \\
\text { (controle) }\end{array}$ & 16 & $36,97 \mathrm{~b}$ & 1,15 & $\begin{array}{l}30,50 \\
46,30\end{array}$ \\
\hline
\end{tabular}

Médias seguidas por letra minúscula diferente na coluna diferiram estatisticamente entre si pelo Teste de Tukey $(P<0,05)$.

Fonte: Própria autoria.

Gráfico 01 - Médias com erros padrão para peso ao nascimento de bezerros oriundos de FIV e por IA obtidos por parto natural - Pirassununga - 2018

$\square$ Bezerros FIV peso elevado aBezerros FIV peso padrão $\quad$ aBezerros IA (controle)

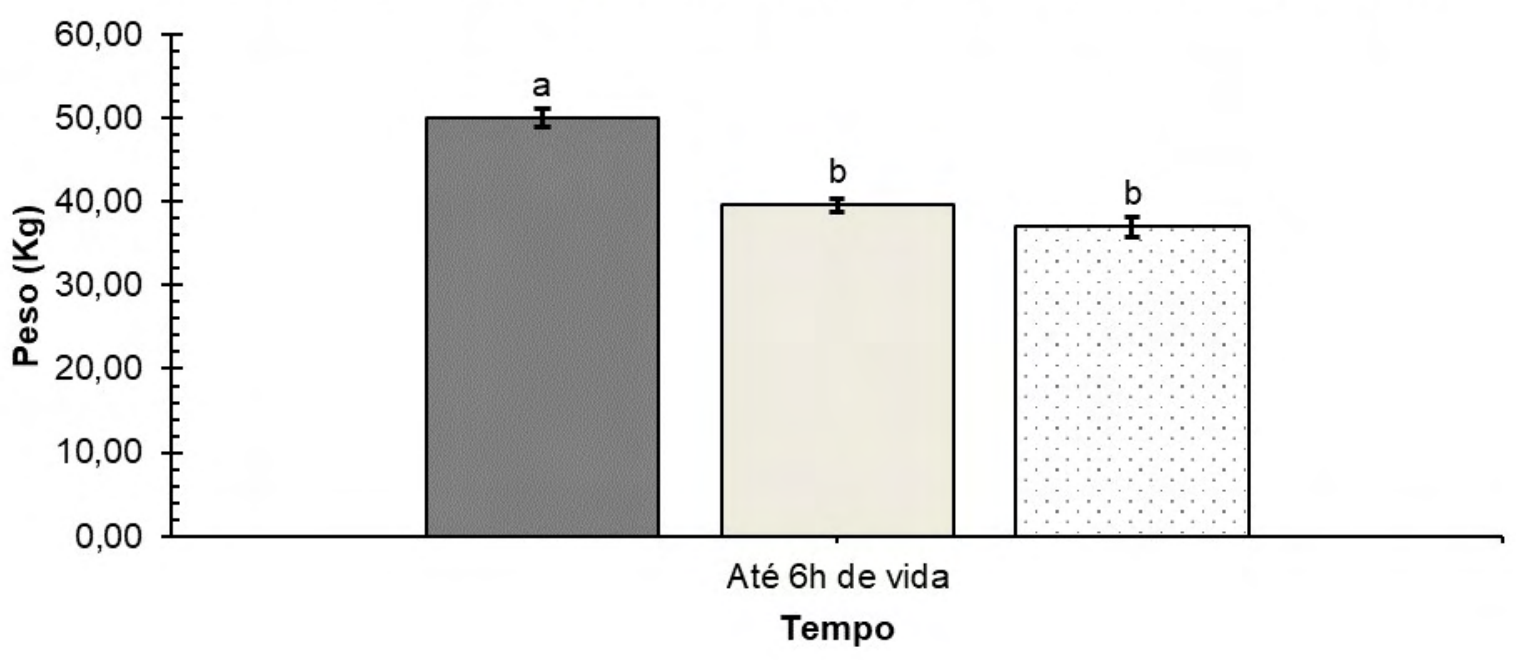

Colunas com diferentes letras diferiram estatisticamente entre si pelo Teste de Tukey $(P<0,05)$

Fonte: Própria autoria 


\subsection{FUNÇÃO RENAL}

Para facilitar o entendimento durante a apresentação dos resultados e discussão as determinações bioquímicas de uéria e creatinina para avaliação da função renal das vacas e dos bezerros foram divididas para cada procedimento experimental.

\subsubsection{Procedimento experimental 1}

Na tabela 2 e no gráfico 2 estão apresentados os resultados da ureia sérica de vacas receptoras de embriões por FIV da raça Nelore e vacas gestantes de bezerros da raça Nelore por IA (grupo controle). Houve diferença estatística significativa entre os tratamentos, separadamente no momento cesariana $(P<0,05)$, houve entre os períodos de avaliação para as vacas IA $(P>0,05)$.

Os valores médios de ambos os grupos estavam próximos dos valores de referência para bovinos adultos $(20-30 \mathrm{mg} / \mathrm{dL}$ ) relatados por Kaneko, Harvey e Bruss (2008) e dos observados por Oliveira (2015). Contudo, em amostras colhidas imediatamente antes da cesariana, foi possível observar que os teores séricos de ureia eram maiores no grupo controle, constatou-se também que neste grupo, diferente das receptoras de embriões por FIV, houve variação ascendente nas médias com o decorrer dos momentos avaliados, sendo que a maior diferença foi entre 270 dias de gestação (15,4 mg/dL) e cesariana (40,5 mg/dL).

A ureia é sintetizada nos hepatócitos a partir da amônia (THRALL et al., 2015) e seus teores séricos podem variar de acordo com o nível de proteína na dieta (CORRÊA; GONZÁLEZ; SILVA, 2010) e por outros fatores do metabolismo da ureia quanto à síntese hepática e excreção renal e intestinal (THRALL et al., 2015). Contudo, nos bovinos, em situações de mudança de manejo, ambiente e de lotes resulta na diminuição na ingestão de alimentos. O déficit alimentar acarreta no aumento do catabolismo de aminoácidos, com consequente aumento dos teores séricos da ureia (CORRÊA; GONZÁLEZ; SILVA, 2010). 
Tabela 02 - Médias, erros padrão, medidas mínimas e máximas para ureia sérica $(\mathrm{mg} / \mathrm{dL})$ de vacas gestantes por FIV e por IA no final da gestação, período de indução e antes de serem submetidas a cesariana

\begin{tabular}{|c|c|c|c|c|c|c|c|c|}
\hline \multirow[b]{2}{*}{ Tempo } & \multicolumn{4}{|c|}{ Receptoras FIV } & \multicolumn{4}{|c|}{ Vacas IA } \\
\hline & $\mathrm{n}$ & Média & $\begin{array}{c}\text { Erro } \\
\text { Padrão }\end{array}$ & $\begin{array}{l}\text { Min e } \\
\text { Max }\end{array}$ & $\mathrm{n}$ & Média & $\begin{array}{c}\text { Erro } \\
\text { Padrão }\end{array}$ & $\begin{array}{l}\text { Min e } \\
\text { Max }\end{array}$ \\
\hline 270 & 8 & $19,2 \mathrm{aA}$ & 3,3 & $\begin{array}{c}8,8 \\
34,6\end{array}$ & 8 & 15,4 bA & 4,0 & $\begin{array}{c}8,8 \\
43,0\end{array}$ \\
\hline 280 & 8 & $24,2 \mathrm{aA}$ & 2,9 & $\begin{array}{l}13,1 \\
40,1\end{array}$ & 8 & $29,0 \mathrm{abA}$ & 5,2 & $\begin{array}{c}8,8 \\
46,4\end{array}$ \\
\hline $\begin{array}{c}\text { antes } \\
\text { indução }\end{array}$ & 8 & $26,3 \mathrm{aA}$ & 2,7 & $\begin{array}{l}12,2 \\
34,2\end{array}$ & 8 & $33,9 \mathrm{aA}$ & 3,3 & $\begin{array}{l}20,2 \\
45,6\end{array}$ \\
\hline $\begin{array}{c}12 \mathrm{~h} \\
\text { indução }\end{array}$ & 8 & $26,5 \mathrm{aA}$ & 2,9 & $\begin{array}{l}10,9 \\
41,0\end{array}$ & 6 & $39,1 \mathrm{aA}$ & 4,5 & $\begin{array}{l}22,6 \\
49,0\end{array}$ \\
\hline cesariana & 8 & $28,3 \mathrm{aB}$ & 3,1 & $\begin{array}{l}17,9 \\
43,6 \\
\end{array}$ & 11 & $40,5 \mathrm{aA}$ & 3,4 & $\begin{array}{l}20,1 \\
59,4 \\
\end{array}$ \\
\hline
\end{tabular}

Médias seguidas por letras minúsculas diferentes na coluna diferiram estatisticamente entre si pelo Teste de Tukey $(P<0,05)$. Médias seguidas por letras maiúsculas diferentes na linha diferiram estatisticamente entre si pelo Teste $t$ (Student) $(P<0,05)$

Fonte: Própria autoria.

Gráfico 02 - Médias com erros padrão para ureia sérica de vacas gestantes por FIV e por IA no final da gestação até a indução e a realização da cesariana Pirassununga -2018

- Receptoras FIV $\quad$ Vacas IA

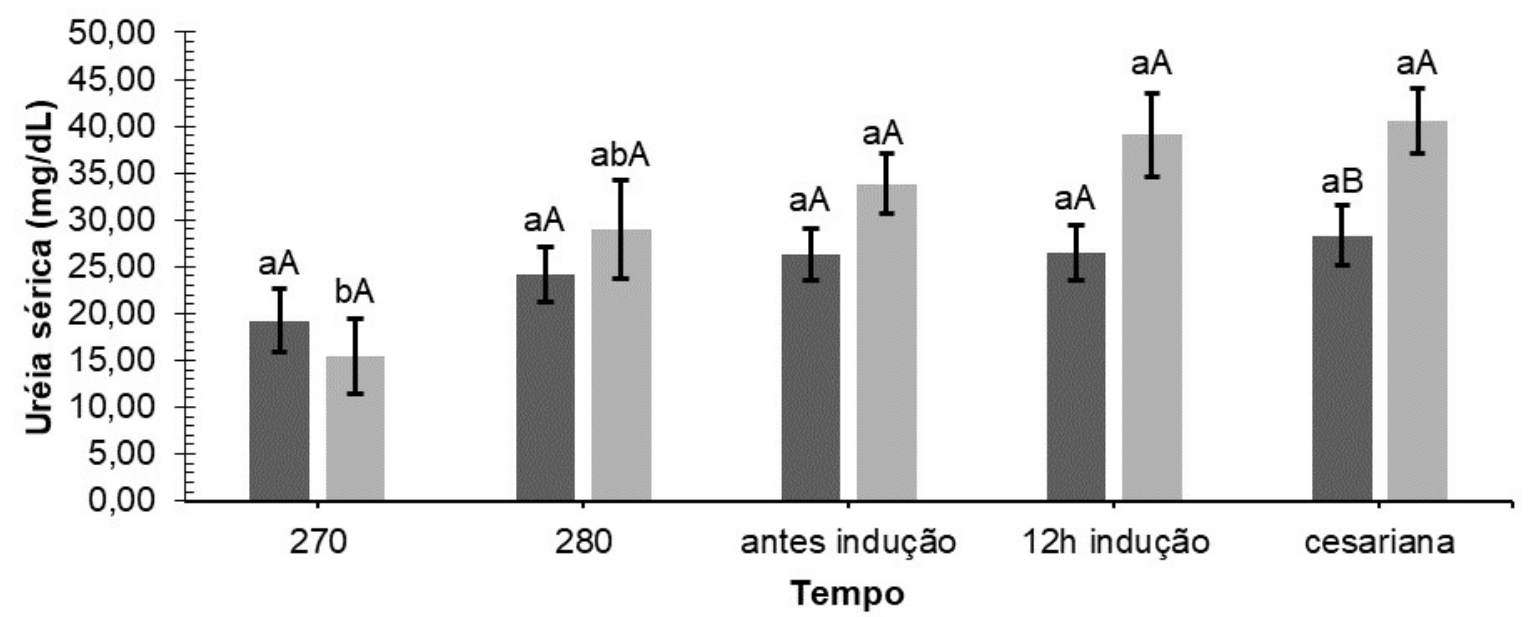

Colunas de mesma cor seguidas com letras minúsculas diferentes, diferiram estatisticamente entre si pelo Teste de Tukey $(P<0,05)$. Colunas de cor diferente dentro de cada tempo seguidas por letras maiúsculas diferentes, diferiram estatisticamente entre si pelo Teste $t$ (Student) $(P<0,05)$

Fonte: Própria autoria.

A adoção de técnicas de manejo, como a mudança das vacas no final da gestação para piquetes maternidade dois dias antes do início do período experimental, adotado no presente trabalho, obrigou a formação de novas 
hierarquias de grupo, contribuindo para a diminuição do consumo de alimento. Panorama similar em vacas leiteiras diante dos manejos de mudanças de lotes relatados por Grant e Albright (2001). Sugere-se que as vacas do grupo controle, por serem da raça Nelore, tiveram maior dificuldade para se adaptar as mudanças de manejo durante o período final do experimento.

Na tabela 3 e no gráfico 3 estão apresentados os resultados da creatinina sérica das vacas receptoras de embriões por FIV da raça Nelore e vacas gestantes de bezerros da raça Nelore por IA (grupo controle). Não houve diferença estatística significativa entre os tratamentos dentro de cada tempo separadamente $(P>0,05)$, nem entre os períodos de avaliação dentro de cada tratamento $(P>0,05)$. As médias de ambos os grupos estavam próximos dos valores de referência para bovinos adultos (1,0 - 2,0 mg/dL) relatados por Kaneko, Harvey e Bruss (2008) em todos o momento avaliados.

A creatinina é o produto da decomposição fosfatocreatina e da creatina muscular, é um importante marcador para função renal junto com a ureia (THRALL et al., 2015). Os valores séricos permaneceram constantes no tempo, em ambos os grupos, indicando que a variação encontrada na análise da ureia não tem relação com a taxa de filtração glomerular (TFG).

Tabela 03 - Médias, erros padrão, medidas mínimas e máximas para creatinina sérica $(\mathrm{mg} / \mathrm{dL})$ de vacas gestantes por FIV e por IA no final da gestação, período de indução e antes de serem submetidas a cesariana

\begin{tabular}{|c|c|c|c|c|c|c|c|c|}
\hline \multirow[b]{2}{*}{ Tratamento } & \multicolumn{4}{|c|}{ Receptoras FIV } & \multicolumn{4}{|c|}{ Vacas IA } \\
\hline & $\mathrm{n}$ & Média & $\begin{array}{c}\text { Erro } \\
\text { Padrão }\end{array}$ & $\begin{array}{l}\text { Min e } \\
\text { Max }\end{array}$ & $\mathrm{n}$ & Média & $\begin{array}{c}\text { Erro } \\
\text { Padrão }\end{array}$ & $\begin{array}{l}\text { Min e } \\
\text { Max }\end{array}$ \\
\hline \multirow{2}{*}{270} & \multirow{2}{*}{8} & \multirow{2}{*}{$2,07 \mathrm{aA}$} & \multirow{2}{*}{0,1} & 1,6 & \multirow{2}{*}{8} & \multirow{2}{*}{2,13 aA } & \multirow{2}{*}{0,1} & 1,8 \\
\hline & & & & 2,4 & & & & 2,4 \\
\hline \multirow{2}{*}{280} & \multirow{2}{*}{8} & \multirow{2}{*}{$2,11 \mathrm{aA}$} & \multirow{2}{*}{0,1} & 1,8 & \multirow{2}{*}{8} & \multirow{2}{*}{$2,09 \mathrm{aA}$} & \multirow{2}{*}{0,1} & 1,6 \\
\hline & & & & 2,5 & & & & 2,6 \\
\hline \multirow{2}{*}{$\begin{array}{c}\text { antes } \\
\text { indução }\end{array}$} & \multirow{2}{*}{8} & \multirow{2}{*}{$1,99 \mathrm{aA}$} & \multirow{2}{*}{0,2} & 1,4 & \multirow{2}{*}{8} & \multirow{2}{*}{$2,04 a A$} & \multirow{2}{*}{0,2} & 1,4 \\
\hline & & & & 2,8 & & & & 3,1 \\
\hline \multirow{2}{*}{$\begin{array}{c}12 \mathrm{~h} \\
\text { indução }\end{array}$} & \multirow{2}{*}{8} & \multirow{2}{*}{$2,02 \mathrm{aA}$} & \multirow{2}{*}{0,1} & 1,7 & \multirow{2}{*}{7} & \multirow{2}{*}{2,15 aA } & \multirow{2}{*}{0,1} & 1,9 \\
\hline & & & & 2,6 & & & & 2,4 \\
\hline \multirow{2}{*}{ cesariana } & \multirow{2}{*}{8} & \multirow{2}{*}{$1,72 \mathrm{aA}$} & \multirow{2}{*}{0,2} & 0,9 & \multirow{2}{*}{11} & \multirow{2}{*}{$1,79 \mathrm{aA}$} & \multirow{2}{*}{0,1} & 1,4 \\
\hline & & & & 2,5 & & & & 2,5 \\
\hline
\end{tabular}

Médias seguidas por letras minúsculas diferentes na coluna diferiram estatisticamente entre si pelo Teste de Tukey $(P<0,05)$. Médias seguidas por letras maiúsculas diferentes na linha diferiram estatisticamente entre si pelo Teste $t$ (Student) $(P<0,05)$

Fonte: Própria autoria 
Gráfico 03 - Médias com erros padrão para creatinina sérica de vacas gestantes por FIV e por IA no final da gestação até a indução e a realização da cesariana Pirassununga - 2018

\section{- Receptoras FIV $\quad$ Vacas IA}

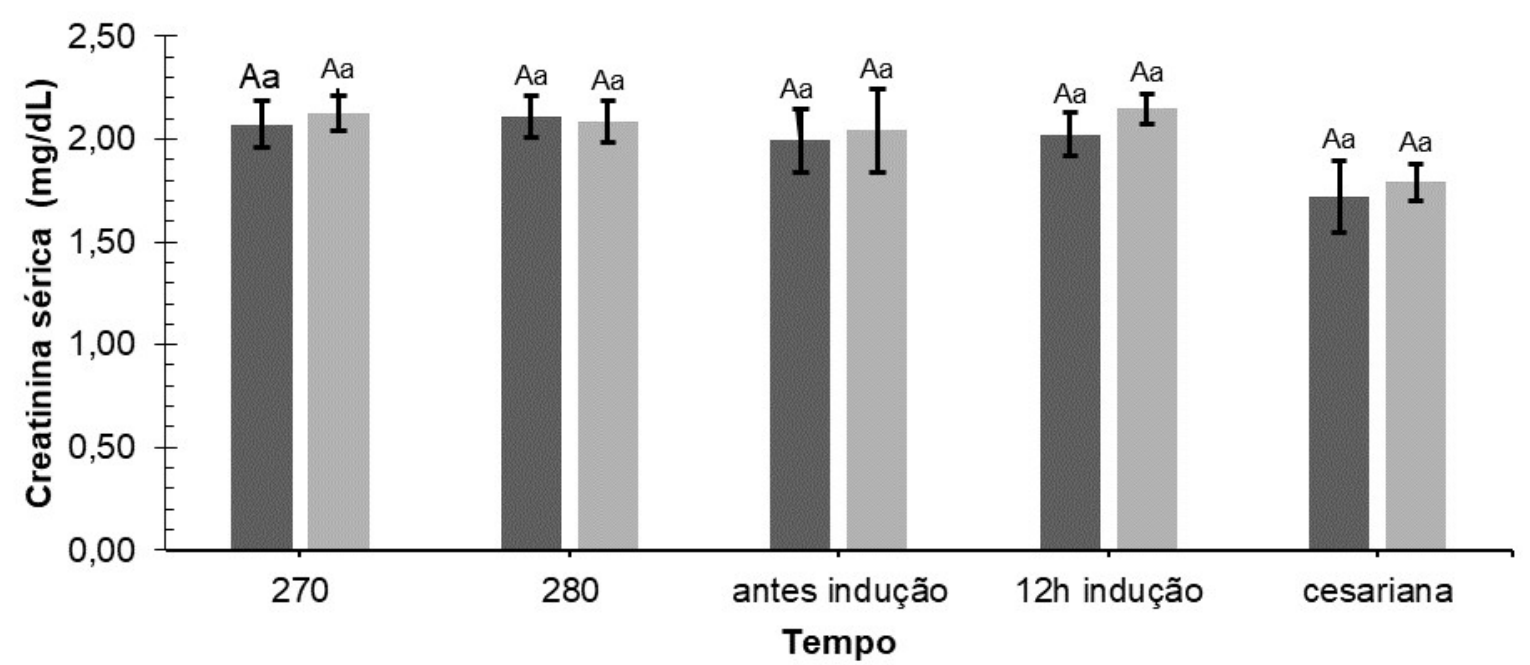

Colunas de mesma cor seguidas com letras minúsculas diferentes, diferiram estatisticamente entre si pelo Teste de Tukey $(P<0,05)$. Colunas de cor diferente dentro de cada tempo seguidas por letras maiúsculas diferentes, diferiram estatisticamente entre si pelo Teste $t$ (Student) $(P<0,05)$

Fonte: Própria autoria

\subsubsection{Procedimento experimental 2}

Na tabela 4 e no gráfico 4 estão representados os resultados da ureia sérica dos bezerros oriundos de FIV e por IA (grupo controle). Não houve diferença estatística significativa entre os tratamentos dentro de cada tempo separadamente $(P>0,05)$, e houve entre os períodos de avaliação dentro de cada tratamento $(P<0,05)$.

Assim como ocorreu com as vacas do procedimento experimental 1, as médias de ambos os grupos estavam próximos dos valores de referência para bovinos adultos (20 - $30 \mathrm{mg} / \mathrm{dL}$ ) relatados por Kaneko, Harvey e Bruss (2008), também foi semelhante ao observado por Benesi et al. (2005) e por Marchese (2014), exceto nos tempos 15 e 30 dias de vida para os bezerros oriundos de FIV, cujos valores estavam abaixo dos valores de referenciados acima. Contudo, ao considerar o valor de referência para bezerros lactentes da raça Nelore $(14,39$ $\mathrm{mg} / \mathrm{dL}$ ), citados por Fagliari et al. (1998), as médias de ambos os grupos se 
encontravam elevadas, exceto para os bezerros oriundos de FIV nos tempos 15 e 30 dias de vida, cujos valores foram semelhantes.

Tabela 04 - Médias, erros padrão, medidas mínimas e máximas para ureia sérica ( $\mathrm{mg} / \mathrm{dL}$ ) de bezerros oriundos de FIV e por IA nos primeiros 30 dias de vida obtidos por cesariana com indução do parto

\begin{tabular}{|c|c|c|c|c|c|c|c|c|}
\hline \multirow[b]{2}{*}{ Tempo } & \multicolumn{4}{|c|}{ Bezerros FIV } & \multicolumn{4}{|c|}{ Bezerros IA } \\
\hline & $\mathrm{n}$ & Média & $\begin{array}{c}\text { Erro } \\
\text { Padrão } \\
\end{array}$ & $\begin{array}{c}\text { Min e } \\
\text { Max }\end{array}$ & $\mathrm{n}$ & Média & $\begin{array}{c}\text { Erro } \\
\text { Padrão } \\
\end{array}$ & $\begin{array}{c}\text { Min e } \\
\text { Max }\end{array}$ \\
\hline $\mathrm{Oh}$ & 7 & $30,97 \mathrm{abA}$ & 3,86 & $\begin{array}{l}14,42 \\
47,78\end{array}$ & 12 & 28,76 aA & 3,30 & $\begin{array}{l}13,35 \\
52,18\end{array}$ \\
\hline $3 h$ & 8 & $28,51 \mathrm{abA}$ & 3,00 & $\begin{array}{l}14,91 \\
44,13\end{array}$ & 12 & $27,72 \mathrm{abA}$ & 3,11 & $\begin{array}{l}15,50 \\
51,92\end{array}$ \\
\hline $6 h$ & 8 & $27,54 \mathrm{abcA}$ & 3,25 & $\begin{array}{c}9,01 \\
39,62\end{array}$ & 12 & $27,14 \mathrm{abA}$ & 2,15 & $\begin{array}{l}19,04 \\
42,08\end{array}$ \\
\hline $12 \mathrm{~h}$ & 8 & $27,08 \mathrm{abcA}$ & 2,60 & $\begin{array}{l}21,16 \\
43,69\end{array}$ & 12 & $27,16 \mathrm{abA}$ & 1,75 & $\begin{array}{l}18,39 \\
37,33\end{array}$ \\
\hline $24 \mathrm{~h}$ & 8 & $24,41 \mathrm{abcA}$ & 2,80 & $\begin{array}{l}17,76 \\
42,25\end{array}$ & 12 & $25,93 \mathrm{abA}$ & 1,61 & $\begin{array}{l}18,62 \\
37,61\end{array}$ \\
\hline $48 \mathrm{~h}$ & 8 & $30,84 a b A$ & 3,58 & $\begin{array}{l}16,72 \\
49,36\end{array}$ & 12 & $22,84 \mathrm{abA}$ & 2,43 & $\begin{array}{l}10,00 \\
38,45\end{array}$ \\
\hline 3 dias & 8 & $34,34 \mathrm{aA}$ & 4,54 & $\begin{array}{l}18,68 \\
58,48\end{array}$ & 12 & $27,09 \mathrm{abA}$ & 3,21 & $\begin{array}{l}11,40 \\
48,42\end{array}$ \\
\hline 5 dias & 8 & $23,39 \mathrm{abcA}$ & 4,08 & $\begin{array}{c}8,76 \\
41,92\end{array}$ & 11 & 17,44 bA & 1,86 & $\begin{array}{c}8,76 \\
26,87\end{array}$ \\
\hline 7 dias & 8 & 18,85 bcA & 1,45 & $\begin{array}{l}13,44 \\
26,50\end{array}$ & 12 & $23,44 a b A$ & 3,21 & $\begin{array}{l}10,18 \\
50,43\end{array}$ \\
\hline 15 dias & 8 & $15,06 \mathrm{cB}$ & 1,06 & $\begin{array}{c}9,20 \\
18,82\end{array}$ & 12 & $23,94 \mathrm{abA}$ & 2,14 & $\begin{array}{l}14,74 \\
36,34\end{array}$ \\
\hline 30 dias & 8 & $14,99 \mathrm{cB}$ & 1,74 & $\begin{array}{c}9,71 \\
22,84\end{array}$ & 12 & $26,62 \mathrm{abA}$ & 2,35 & $\begin{array}{l}10,20 \\
37,87\end{array}$ \\
\hline
\end{tabular}

Médias seguidas pela mesma letra minúscula na coluna não diferiram estatisticamente entre si pelo Teste de Tukey $(P>0,05)$. Médias seguidas pela mesma letra maiúscula na linha não diferiram estatisticamente entre si pelo Teste $t$ (Student) $(P<0,05)$.

Fonte: Própria autoria.

Em bezerros neonatos, os teores séricos podem diminuir com o passar do tempo. Esta influência do fator etário ocorre, uma vez que após o nascimento, a 
partir da ruptura do cordão umbilical o fluxo sanguíneo renal aumenta e o rim tornase, progressivamente, ativo para a função excretora, o que antes era realizada pela placenta (BENESI et al., 2005). Embora Feitosa et al. (2009), em sua pesquisa, não tenha demonstrado esta variação em bezerros.

Além das causas já citadas de variação nos valores séricos da ureia em bezerros pelo efeito etário, o consumo e a degradação de proteína colostral torna-se um importante fator de oscilação na sua concentração sérica (SOUZA et al., 2014). Este fator poderia explicar as maiores concentrações de ureia em ambos os grupos, uma vez que logo após o nascimento por cesariana, foi adotado a colostragem com o uso de banco de colostro.

Gráfico 04 - Médias com erros padrão para ureia sérica de bezerros oriundos de FIV e por IA nos primeiros 30 dias de vida obtidos por cesariana com indução do parto Pirassununga - 2018

.....Bezerros FIV $\longrightarrow \Delta=$ Bezerros IA

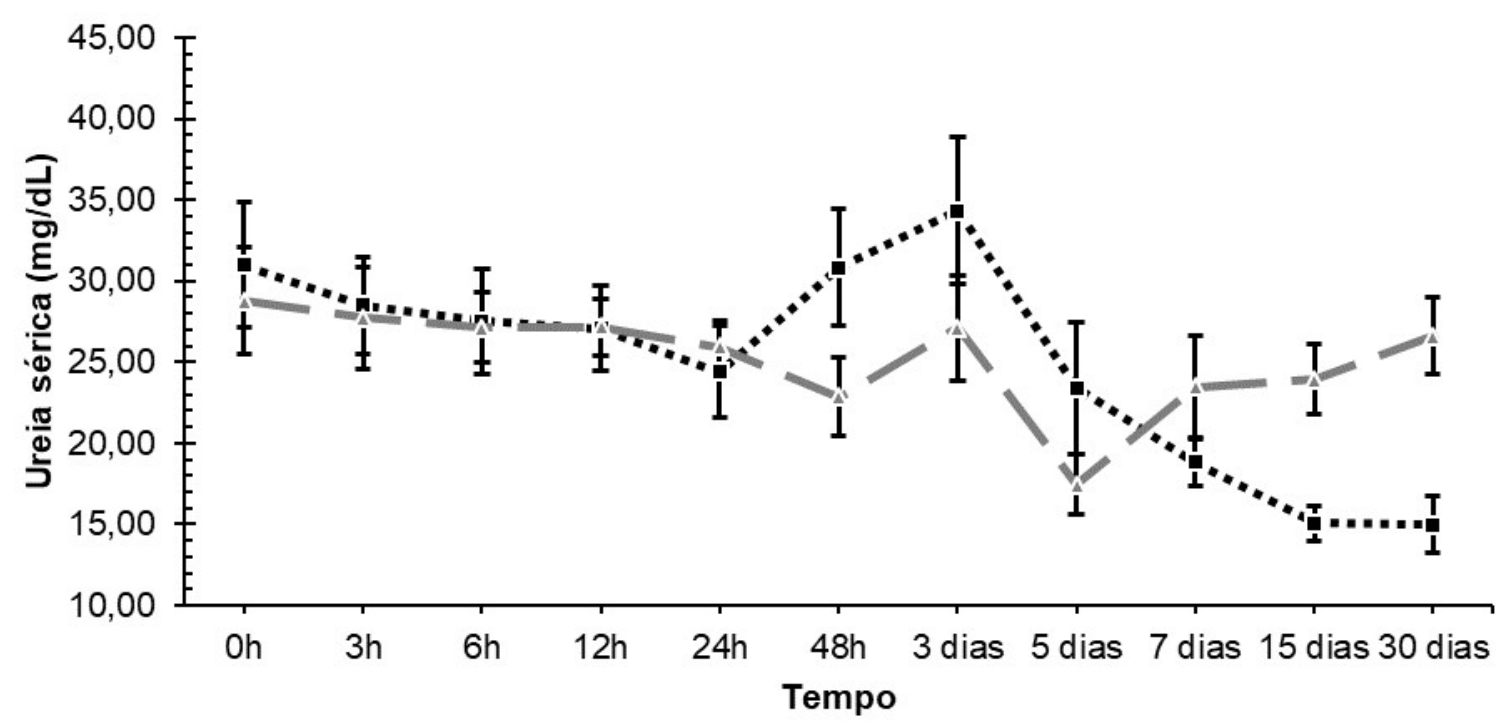

Fonte: Própria autoria.

Na tabela 5 e no gráfico 5 estão representados os resultados da creatinina sérica dos bezerros oriundos de FIV e por IA (grupo controle). Não houve diferença estatística significativa entre os tratamentos dentro de cada tempo separadamente $(P>0,05)$, houve entre os períodos de avaliação dentro de cada tratamento $(P<0,05)$. Os valores da concentração sérica de creatinina de ambos os grupos apresentaram acentuada diminuição das médias nas primeiras 24 horas de vida, comportamento semelhante ao observado por Benesi et al. (2005) e por Marchese (2014). Os teores 
de ambos os grupos estavam acima dos valores de referência nas primeiras horas e na sequência dos momentos avaliados, aproximaram-se da faixa de referência para bovinos adultos $(1,0-2,0 \mathrm{mg} / \mathrm{dL})$ relatados por Kaneko, Harvey e Bruss (2008).

Tabela 05 - Médias, erros padrão, medidas mínimas e máximas para creatinina sérica $(\mathrm{mg} / \mathrm{dL})$ de bezerros oriundos de FIV e por IA nos primeiros 30 dias de vida obtidos por cesariana com indução do parto

\begin{tabular}{|c|c|c|c|c|c|c|c|c|}
\hline \multirow[b]{2}{*}{ Tempo } & \multicolumn{4}{|c|}{ Bezerros FIV } & \multicolumn{4}{|c|}{ Bezerros IA } \\
\hline & $\mathrm{n}$ & Média & $\begin{array}{c}\text { Erro } \\
\text { Padrão }\end{array}$ & $\begin{array}{l}\text { Mine } \\
\text { Max }\end{array}$ & $\mathrm{n}$ & Média & $\begin{array}{c}\text { Erro } \\
\text { Padrão }\end{array}$ & $\begin{array}{l}\text { Mine } \\
\text { Max }\end{array}$ \\
\hline \multirow{2}{*}{$\mathrm{Oh}$} & \multirow{2}{*}{7} & \multirow{2}{*}{$2,79 a A$} & \multirow{2}{*}{0,38} & 1,54 & \multirow{2}{*}{12} & \multirow{2}{*}{$3,24 \mathrm{aA}$} & \multirow{2}{*}{0,30} & 1,63 \\
\hline & & & & 4,43 & & & & 5,05 \\
\hline \multirow{2}{*}{$3 \mathrm{~h}$} & \multirow{2}{*}{8} & \multirow{2}{*}{$2,41 \mathrm{abA}$} & \multirow{2}{*}{0,28} & 1,54 & \multirow{2}{*}{12} & \multirow{2}{*}{$2,94 \mathrm{abA}$} & \multirow{2}{*}{0,28} & 1,80 \\
\hline & & & & 3,77 & & & & 4,66 \\
\hline \multirow{2}{*}{$6 \mathrm{~h}$} & \multirow{2}{*}{8} & \multirow{2}{*}{$2,10 \mathrm{abA}$} & \multirow{2}{*}{0,19} & 1,39 & \multirow{2}{*}{12} & \multirow{2}{*}{$2,65 \mathrm{bcA}$} & \multirow{2}{*}{0,28} & 1,32 \\
\hline & & & & 2,81 & & & & 4,57 \\
\hline \multirow{2}{*}{$12 \mathrm{~h}$} & \multirow{2}{*}{8} & \multirow{2}{*}{$1,83 \mathrm{bcA}$} & \multirow{2}{*}{0,12} & 1,17 & \multirow{2}{*}{12} & \multirow{2}{*}{$2,19 \mathrm{cA}$} & \multirow{2}{*}{0,19} & 1,15 \\
\hline & & & & 2,28 & & & & 3,35 \\
\hline \multirow{2}{*}{$24 \mathrm{~h}$} & \multirow{2}{*}{8} & & & 0,92 & & & & 0,93 \\
\hline & & 1,28 cdA & 0,08 & 1,50 & 12 & $1,50 \mathrm{dA}$ & 0,10 & 2,21 \\
\hline $10 \mathrm{~h}$ & 0 & $100 \mathrm{dr}$ & 000 & 0,68 & 12 & $140 \mathrm{dn}$ & (0) & 0,88 \\
\hline $48 n$ & 8 & 1,06 aA & 0,08 & 1,33 & 12 & $1,13 \mathrm{dA}$ & 0,06 & 1,67 \\
\hline 2 ding & 8 & & 007 & 0,69 & 12 & $111 \mathrm{dn}$ & 007 & 0,86 \\
\hline 3 dias & 8 & $0,99 \mathrm{dA}$ & 0,07 & 1,28 & 12 & $1,14 \mathrm{dA}$ & 0,01 & 1,51 \\
\hline & & & & 0,66 & & & & 0,83 \\
\hline 5 dias & 8 & $1,05 \mathrm{dA}$ & 0,08 & 1,30 & 111 & $1,14 \mathrm{dA}$ & 0,0 r & 1,50 \\
\hline 7 dias & 8 & $113 d A$ & 009 & 0,84 & 12 & $115 \mathrm{dA}$ & 005 & 0,89 \\
\hline 1 alas & 8 & $1,13 \mathrm{dA}$ & & 1,60 & & $1,15 \mathrm{dA}$ & & 1,54 \\
\hline 15 dias & 8 & $109 \mathrm{dA}$ & 0.12 & 0,52 & 12 & $110 \mathrm{dA}$ & 006 & 0,74 \\
\hline & & & 0,12 & 1,61 & 12 & $1,10 \mathrm{UA}$ & & 1,54 \\
\hline P0 ding & 0 & 110 ad & 000 & 0,91 & 12 & $110 \mathrm{dn}$ & (207 & 0,77 \\
\hline 30 dias & 8 & 1,19 COA & 0,08 & 1,48 & 12 & $1,18 \mathrm{dA}$ & 0,07 & 1,56 \\
\hline
\end{tabular}

Médias seguidas por letras minúsculas diferentes na mesma coluna diferiram estatisticamente entre si pelo Teste de Tukey $(P<0,05)$. Médias seguidas por letras maiúsculas diferentes na mesma linha diferiram estatisticamente entre si pelo Teste t (Student) $(P<0,05)$

Fonte: Própria autoria. 
O decréscimo dos valores séricos da creatinina em neonatos, assim como o da ureia, ocorre devido ao aumento do fluxo sanguíneo renal imediatamente após o rompimento do cordão umbilical, passando a exercer a função excretória antes realizada pela placenta, assim como a eficiência da função renal, evoluir com a idade (DOORNENBAL; TONG; MURRAY, 1988). No presente trabalho, os valores da creatinina e da ureia apresentaram comportamento semelhante aos relatados por Egli e Blum (1998) e por Benesi et al. (2005) respectivamente.

Gráfico 05 - Médias com erros padrão para creatinina sérica de bezerros oriundos de FIV e por IA nos primeiros 30 dias de vida obtidos por cesariana com indução do parto - Pirassununga - 2018
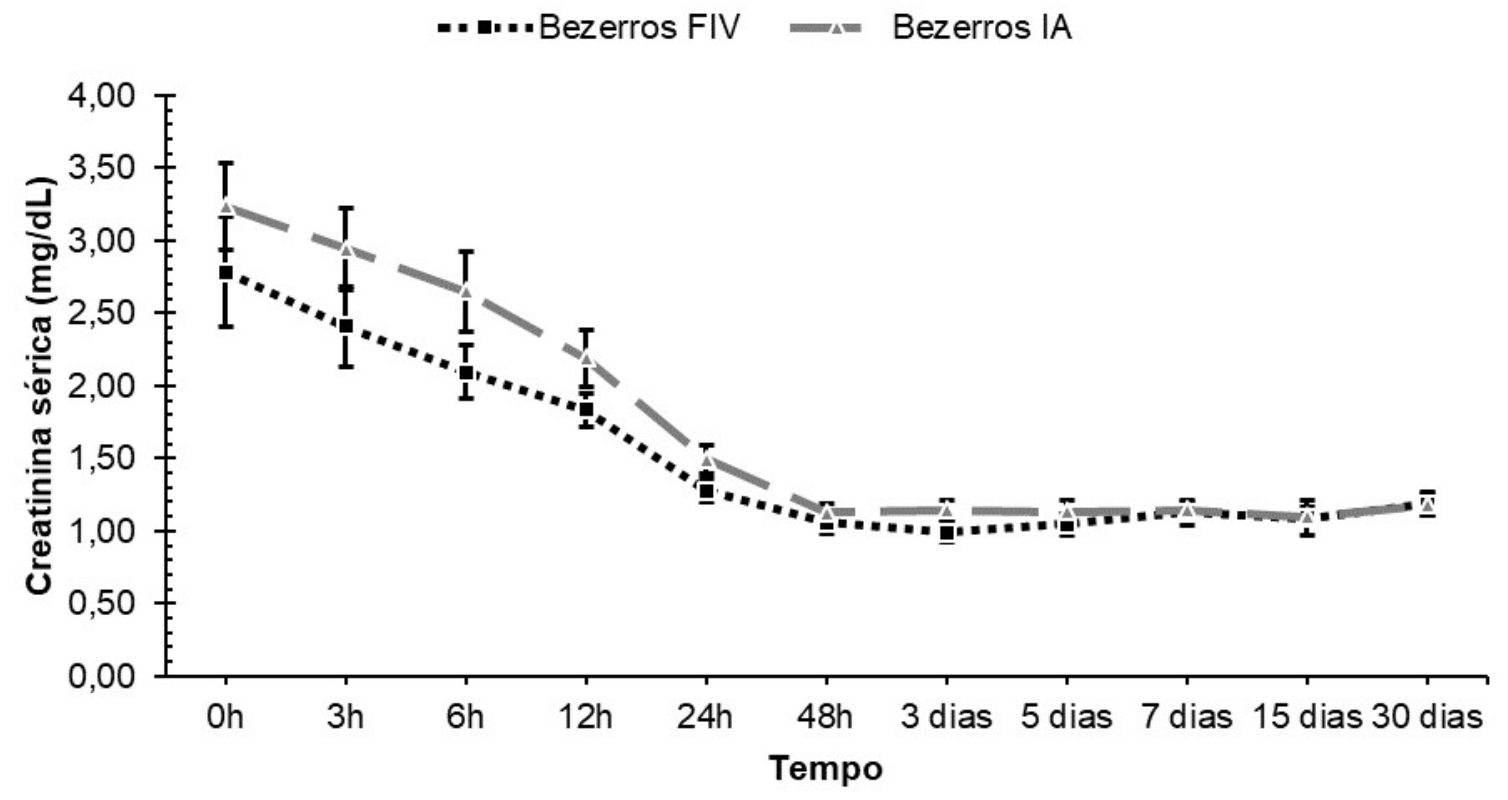

Fonte: Própria autoria.

\subsubsection{Procedimento experimental 3}

Na tabela 6 e no gráfico 6 estão apresentados os resultados da ureia sérica de vacas receptoras de embriões por FIV da raça Nelore com bezerros apresentando peso elevado ao nascimento (síndrome do bezerro gigante), vacas receptoras de embriões por FIV da raça Nelore com bezerros apresentando peso dentro do padrão da raça ao nascimento e vacas gestantes de bezerros da raça Nelore por IA (grupo controle). Não houve diferença estatística significativa entre os tratamentos dentro de cada tempo separadamente $(P>0,05)$, nem entre os períodos de avaliação dentro de cada tratamento $(P>0,05)$. As médias de ambos os grupos 
estavam próximos dos valores de referência para bovinos adultos (20 - $30 \mathrm{mg} / \mathrm{dL}$ ) relatados por Kaneko, Harvey e Bruss (2008) e superiores aos observados por Oliveira (2015).

O fato de as vacas dos dois grupos não terem apresentado variação dos teores entre os tempos avaliados e não terem apresentado diferença entre os tratamentos, pode ser explicado por não haver expectativa da existência de fatores que pudessem causar lesão renal. Assim como pelo menor número de manejos ao qual as vacas foram expostas, comparadas ao procedimento experimental 1.

Neste procedimento experimental as vacas já estavam divididas em lotes devido manejo da propriedade, também não foram observadas alterações no fornecimento e ingestão da dieta que pudessem levar ao catabolismo dos aminoácidos e consequente elevação da ureia sérica. Contudo, a expectativa de déficit nutricional nas vacas de FIV com bezerros apresentando síndrome do bezerro gigante, que pudesse aumentar a concentração sérica da ureia não se confirmou.

Tabela 06 - Médias, erros padrão, medidas mínimas e máximas para ureia sérica (mg/dL) de vacas gestantes por FIV e por IA no final da gestação e até $6 \mathrm{~h}$ após o parto natural

\begin{tabular}{|c|c|c|c|c|c|c|c|c|}
\hline \multirow[b]{2}{*}{ Tratamento } & \multicolumn{4}{|c|}{288 dias } & \multicolumn{4}{|c|}{ Até 6h após o parto } \\
\hline & $\mathrm{n}$ & Média & $\begin{array}{c}\text { Erro } \\
\text { Padrão }\end{array}$ & $\begin{array}{l}\operatorname{Min} e \\
\operatorname{Max} \\
\end{array}$ & $\mathrm{n}$ & Média & $\begin{array}{c}\text { Erro } \\
\text { Padrão } \\
\end{array}$ & $\begin{array}{l}\text { Min e } \\
\text { Max }\end{array}$ \\
\hline Receptoras & & & & 8,8 & & & & 19,9 \\
\hline $\begin{array}{l}\text { FIV bez } \\
\text { peso } \\
\text { elevado }\end{array}$ & 17 & 32,7 aA & 3,2 & 46,0 & 17 & 34,5 aA & 2,1 & 46,1 \\
\hline Receptoras & & & & 8,8 & & & & 8,8 \\
\hline $\begin{array}{l}\text { FIV bez } \\
\text { peso } \\
\text { padrão }\end{array}$ & 30 & $30,9 \mathrm{aA}$ & 2,1 & 50,3 & 32 & $35,8 \mathrm{aA}$ & 2,5 & 79,1 \\
\hline \multirow{2}{*}{$\begin{array}{l}\text { Vacas IA } \\
\text { (controle) }\end{array}$} & \multirow{2}{*}{15} & \multirow{2}{*}{31,3 aA } & \multirow{2}{*}{3,3} & 11,6 & \multirow{2}{*}{16} & \multirow{2}{*}{$27,9 \mathrm{aA}$} & \multirow{2}{*}{2,2} & 13,4 \\
\hline & & & & 52,9 & & & & 47,2 \\
\hline
\end{tabular}

Médias seguidas por letras minúsculas diferentes na mesma coluna diferiram estatisticamente entre si pelo Teste de Tukey $(P<0,05)$. Médias seguidas por letras maiúsculas diferentes na mesma linha diferiram estatisticamente entre si pelo Teste t pareado $(P<0,05)$

Fonte: Própria autoria. 
Gráfico 06 - Médias com erros padrão para ureia sérica de vacas receptoras de FIV de bezerros com peso elevado após o nascimento, receptoras de FIV com bezerros de peso padrão após o nascimento e vacas gestantes por IA, no final da gestação e até $6 \mathrm{~h}$ após o parto natural a termo - Pirassununga - 2018
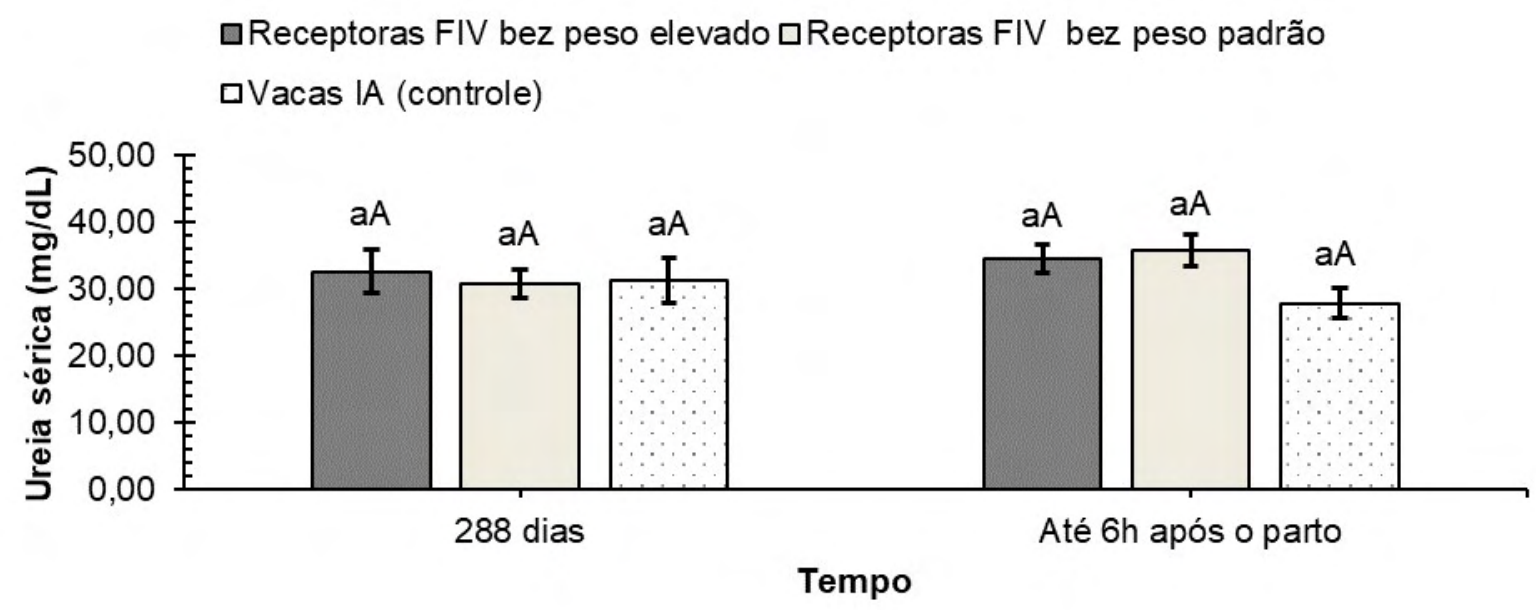

Colunas de cores diferentes seguidas com letras minúsculas diferentes, no mesmo tempo, diferiram estatisticamente entre si pelo Teste de Tukey $(P<0,05)$. Colunas de mesma cor seguidas por letras maiúsculas diferentes, diferiram estatisticamente entre si pelo Teste t pareado $(P<0,05)$

Fonte: Própria autoria.

Na tabela 7 e no gráfico 7 estão apresentados os resultados da creatinina sérica de vacas receptoras de embriões por FIV da raça Nelore com bezerros apresentando peso elevado ao nascimento, vacas receptoras de embriões por FIV da raça Nelore com bezerros apresentando peso dentro do padrão da raça ao nascimento e vacas gestantes de bezerros da raça Nelore por IA. No momento 288 dias de gestação houve diferença estatística significativa entre os tratamentos $(P<0,05)$, e nas vacas do grupo controle, entre os momentos avaliados $(P<0,05)$.

As médias de ambos os grupos e momentos estavam próximos dos valores de referência para bovinos adultos $(1,0-2,0 \mathrm{mg} / \mathrm{dL})$ relatados por Kaneko, Harvey e Bruss (2008). Mesmo dentro da faixa de referência, as vacas receptoras dos bezerros com peso elevado ao nascimento apresentaram valores menores que as vacas do grupo controle. Também foi observado que, aos 288 dias de gestação, a média dos valores das vacas do grupo controle foi maior que no momento até 6 horas após o parto. As variações observadas nos valores das receptoras de FIV e das vacas controle sugere-se maior relação com fatores de manejo e alimentação, principalmente pela ingestão de proteína, como observado por Oliveira (2015). 
Tabela 07 - Médias, erros padrão, medidas mínimas e máximas para creatinina sérica $(\mathrm{mg} / \mathrm{dL})$ de vacas gestantes por FIV e por IA no final da gestação e até $6 \mathrm{~h}$ após o parto natural

\begin{tabular}{|c|c|c|c|c|c|c|c|c|}
\hline \multirow[b]{2}{*}{ Tratamento } & \multicolumn{4}{|c|}{288 dias } & \multicolumn{4}{|c|}{ Até $6 \mathrm{~h}$ após o parto } \\
\hline & $\mathrm{n}$ & Média & $\begin{array}{c}\text { Erro } \\
\text { Padrão }\end{array}$ & $\begin{array}{l}\text { Min e } \\
\text { Max }\end{array}$ & $\mathrm{n}$ & Média & $\begin{array}{c}\text { Erro } \\
\text { Padrão }\end{array}$ & $\begin{array}{c}\text { Min } \\
e \\
\text { Max }\end{array}$ \\
\hline Receptoras & & & & 0,6 & & & & 0,3 \\
\hline $\begin{array}{l}\text { FIV bez } \\
\text { peso } \\
\text { elevado }\end{array}$ & 17 & $1,54 \mathrm{bA}$ & 0,1 & 2,0 & 17 & $1,55 \mathrm{aA}$ & 0,1 & 2,2 \\
\hline Receptoras & & & & 1,2 & & & & 1,1 \\
\hline $\begin{array}{l}\text { FIV bez } \\
\text { peso } \\
\text { padrão }\end{array}$ & 30 & $1,73 \mathrm{abA}$ & 0,1 & 3,9 & 32 & $1,66 \mathrm{aA}$ & 0,1 & 2,5 \\
\hline $\begin{array}{l}\text { Vacas IA } \\
\text { (controle) }\end{array}$ & 15 & $1,91 \mathrm{aA}$ & 0,1 & $\begin{array}{l}1,3 \\
2,5\end{array}$ & 16 & $1,76 \mathrm{aB}$ & 0,1 & $\begin{array}{l}1,3 \\
2,5\end{array}$ \\
\hline
\end{tabular}

Médias seguidas por letras minúsculas diferentes na mesma coluna diferiram estatisticamente entre si pelo Teste de Tukey $(P<0,05)$. Médias seguidas por letras maiúsculas diferentes na mesma linha diferiram estatisticamente entre si pelo Teste t pareado $(P<0,05)$

Fonte: Própria autoria.

Gráfico 07 - Médias com erros padrão para creatinina sérica de vacas receptoras de FIV de bezerros com peso elevado após o nascimento, receptoras de FIV com bezerros de peso padrão após o nascimento e vacas gestantes por IA, no final da gestação e até $6 \mathrm{~h}$ após o parto natural a termo - Pirassununga - 2018

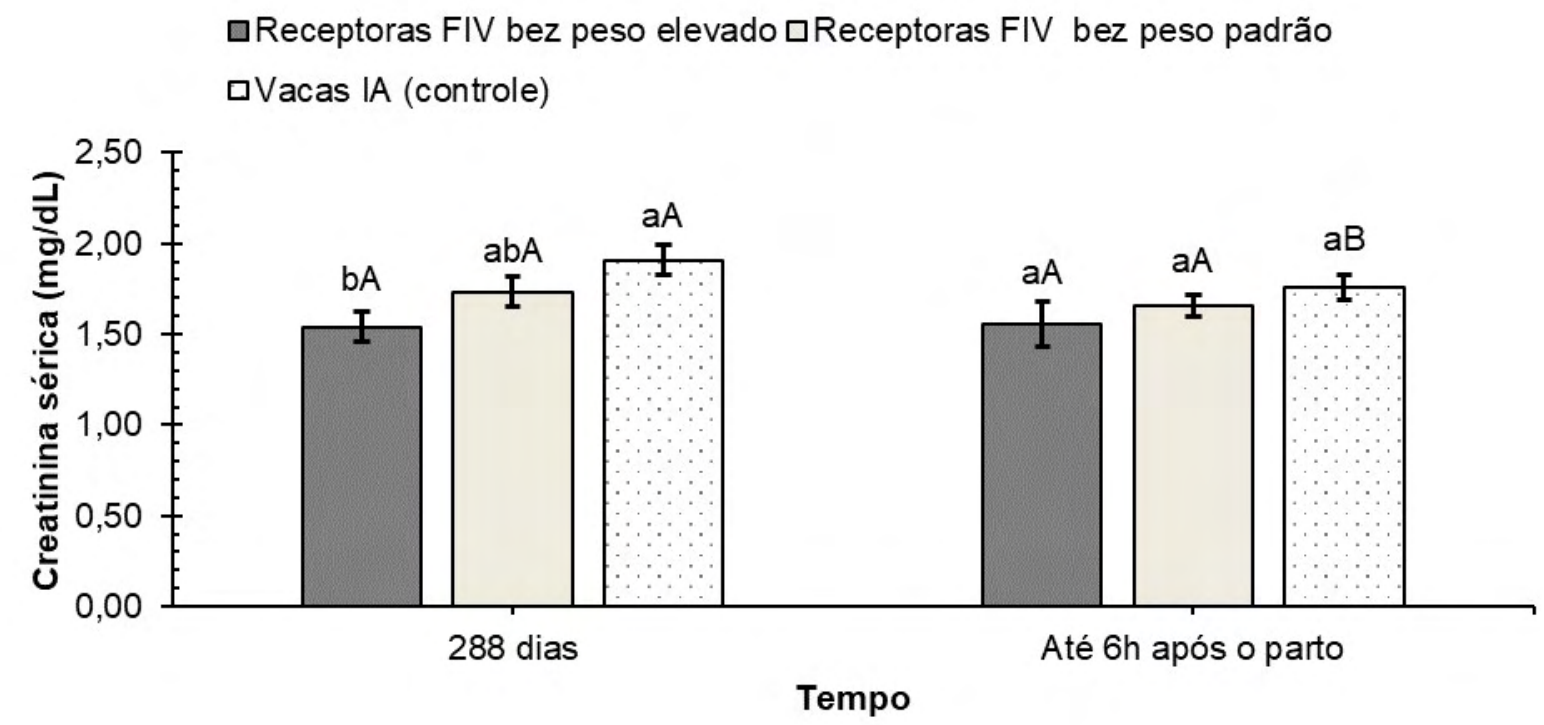

Colunas de cores diferentes seguidas com letras minúsculas diferentes, no mesmo tempo, diferiram estatisticamente entre si pelo Teste de Tukey $(P<0,05)$. Colunas de mesma cor seguidas por letras maiúsculas diferentes, diferiram estatisticamente entre si pelo Teste t pareado $(P<0,05)$

Fonte: Própria autoria. 


\subsubsection{Procedimento experimental 4}

Na tabela 8 e no gráfico 8 estão representados os resultados da ureia sérica dos bezerros oriundos de FIV com peso ao nascimento elevado (síndrome do bezerro gigante), bezerros oriundos de FIV com peso ao nascimento dentro do padrão da raça e por IA (grupo controle). Não houve diferença estatística significativa entre os tratamentos dentro de cada tempo separadamente $(P>0,05)$, nem entre os períodos de avaliação dentro de cada tratamento $(P>0,05)$.

As médias de ambos os grupos estavam próximos dos valores de referência para bovinos adultos $(20-30 \mathrm{mg} / \mathrm{dL})$ relatados por Kaneko, Harvey e Bruss (2008) e semelhantes aos valores encontrados por Gasparelli (2007). Contudo, ao considerar os valores de referência para bezerros lactentes da raça nelore $(14,39 \mathrm{mg} / \mathrm{dL})$, citados por Fagliari et al. (1998), as médias de ambos os grupos estavam elevados nos dois momentos avaliados. Não foi observado efeito da síndrome do bezerro gigante na concentração sérica da ureia, uma vez que os teores dos bezerros com peso elevado após o nascimento apresentaram comportamento semelhante aos outros grupos.

Tabela 08 - Médias, erros padrão, medidas mínimas e máximas para ureia sérica (mg/dL) de bezerros oriundos de FIV e por IA nas primeiras 36 horas devida obtidos por parto natural

\begin{tabular}{|c|c|c|c|c|c|c|c|c|}
\hline \multirow[b]{2}{*}{ Tratamento } & \multicolumn{4}{|c|}{ Até $6 \mathrm{~h}$ de vida } & \multicolumn{4}{|c|}{ Entre $24 \mathrm{~h}$ e $36 \mathrm{~h}$ de vida } \\
\hline & $\mathrm{n}$ & Média & $\begin{array}{c}\text { Erro } \\
\text { Padrão }\end{array}$ & $\begin{array}{l}\text { Min e } \\
\text { Max }\end{array}$ & $\mathrm{n}$ & Média & $\begin{array}{c}\text { Erro } \\
\text { Padrão }\end{array}$ & $\begin{array}{l}\text { Min e } \\
\text { Max }\end{array}$ \\
\hline Bezerros & & & & 9,15 & & & & 9,75 \\
\hline $\begin{array}{l}\text { FIV peso } \\
\text { elevado }\end{array}$ & 16 & $24,91 \mathrm{aA}$ & 2,35 & 41,97 & 17 & 30,66 aA & 3,43 & 64,49 \\
\hline Bezerros & & & & 8,76 & & & & 8,76 \\
\hline $\begin{array}{l}\text { FIV peso } \\
\text { padrão }\end{array}$ & 31 & 25,55 aA & 2,03 & 64,99 & 31 & 25,93 aA & 2,08 & 46,99 \\
\hline Bezerros IA & 27 & 20,76 aA & 1.63 & 8,76 & 27 & $21.32 \mathrm{aA}$ & 245 & 8,76 \\
\hline (controle) & & & & 41,28 & & & & 65,46 \\
\hline
\end{tabular}

Médias seguidas por letras minúsculas diferentes na mesma coluna diferiram estatisticamente entre si pelo Teste de Tukey $(P<0,05)$. Médias seguidas por letras maiúsculas diferentes na mesma linha diferiram estatisticamente entre si pelo Teste t pareado $(P<0,05)$

Fonte: Própria autoria. 
Gráfico 08 - Médias com erros padrão para ureia sérica de bezerros oriundos de FIV e por IA nas primeiras 36 horas devida obtidos por parto natural - Pirassununga 2018

$\square$ Bezerros FIV peso elevado $\quad$ Bezerros FIV peso padrão $\quad$ Bezerros IA (controle)

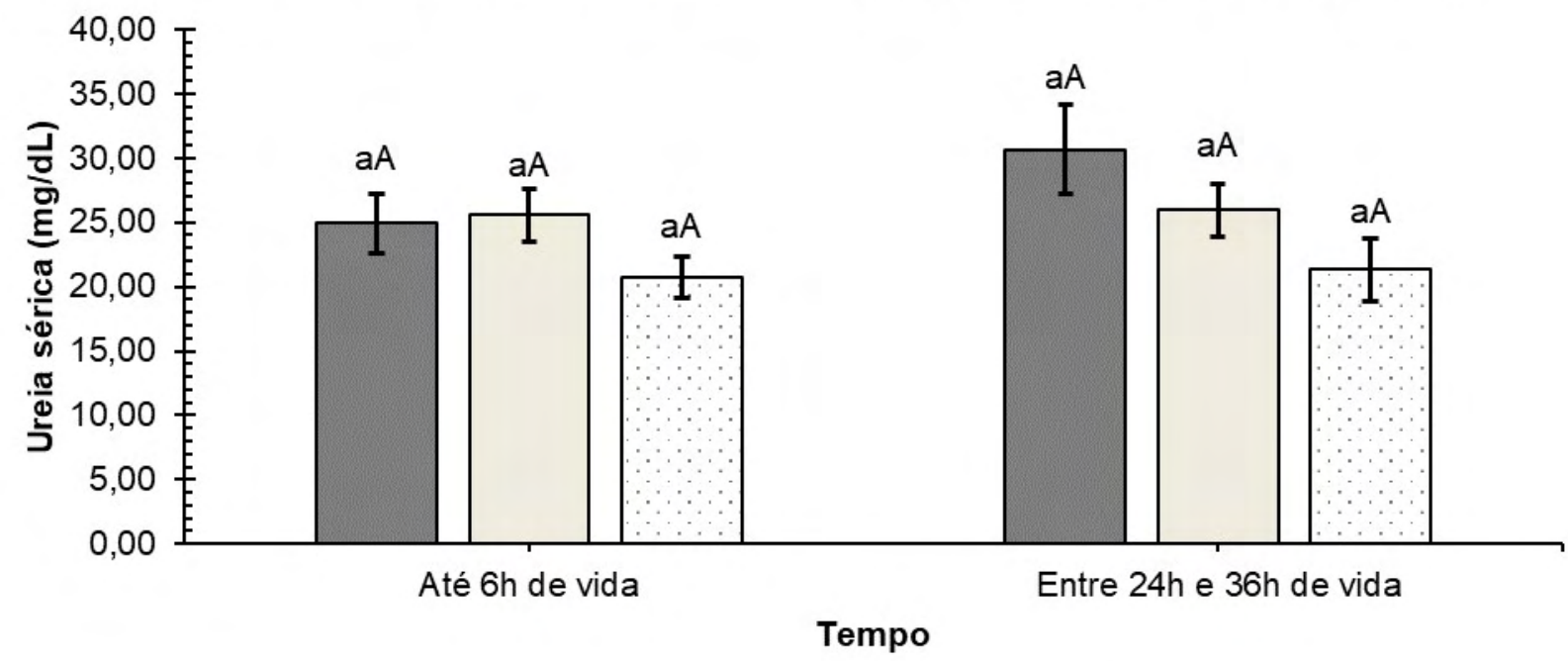

Colunas de cores diferentes seguidas com letras minúsculas diferentes, no mesmo tempo, diferiram estatisticamente entre si pelo Teste de Tukey $(P<0,05)$. Colunas de mesma cor seguidas por letras maiúsculas diferentes, diferiram estatisticamente entre si pelo Teste t pareado $(P<0,05)$

Fonte: Própria autoria.

Na tabela 9 e no gráfico 9 estão representados os resultados da creatinina sérica dos bezerros oriundos de FIV com peso ao nascimento elevado (síndrome do bezerro gigante), bezerros oriundos de FIV com peso ao nascimento dentro do padrão da raça e por IA (grupo controle). Não houve diferença estatística significativa entre os tratamentos dentro de cada tempo separadamente $(P>0,05)$, houve entre os períodos de avaliação dentro de cada tratamento $(P<0,05)$.

Os valores da concentração sérica de creatinina de ambos os grupos apresentaram diminuição entre o primeiro e segundo momento avaliados, este comportamento foi semelhante ao observado por Gasparelli (2007). Apenas nos bezerros com peso elevado ao nascimento, no momento até 6 horas de vida, a média estava acima dos valores de referência, entretanto, na sequência também ficou próximo a referência para bovinos adultos $(1,0-2,0 \mathrm{mg} / \mathrm{dL})$ relatados por Kaneko, Harvey e Bruss (2008). 
Tabela 09 - Médias, erros padrão, medidas mínimas e máximas para creatinina plasmática $(\mathrm{mg} / \mathrm{dL})$ de bezerros oriundos de FIV e por IA nas primeiras 36 horas devida obtidos por parto natural

\begin{tabular}{|c|c|c|c|c|c|c|c|c|}
\hline \multirow[b]{2}{*}{ Tratamento } & \multicolumn{4}{|c|}{ Até $6 \mathrm{~h}$ de vida } & \multicolumn{4}{|c|}{ Entre $24 \mathrm{~h}$ e $36 \mathrm{~h}$ de vida } \\
\hline & $\mathrm{n}$ & Média & $\begin{array}{c}\text { Erro } \\
\text { Padrão }\end{array}$ & $\begin{array}{l}\text { Min e } \\
\text { Max }\end{array}$ & $\mathrm{n}$ & Média & $\begin{array}{c}\text { Erro } \\
\text { Padrão }\end{array}$ & $\begin{array}{l}\text { Min e } \\
\text { Max }\end{array}$ \\
\hline Bezerros & & & & 0,53 & & & & 0,88 \\
\hline $\begin{array}{l}\text { FIV peso } \\
\text { elevado }\end{array}$ & 16 & $2,38 \mathrm{aA}$ & 0,70 & 12,66 & 17 & $1,56 \mathrm{aB}$ & 0,37 & 7,41 \\
\hline Bezerros & & & & 0,61 & & & & 0,33 \\
\hline $\begin{array}{l}\text { FIV peso } \\
\text { padrão }\end{array}$ & 31 & $1,82 \mathrm{aA}$ & 0,09 & 2,84 & 31 & $1,25 \mathrm{aB}$ & 0,07 & 2,31 \\
\hline $\begin{array}{l}\text { Bezerros IA } \\
\text { (controle) }\end{array}$ & 27 & 1,79 aA & 0,09 & $\begin{array}{l}0,70 \\
2,61\end{array}$ & 27 & $1,33 \mathrm{aB}$ & 0,05 & $\begin{array}{l}0,89 \\
1,89 \\
\end{array}$ \\
\hline
\end{tabular}

Médias seguidas por letras minúsculas diferentes na mesma coluna diferiram estatisticamente entre si pelo Teste de Tukey $(P<0,05)$. Médias seguidas por letras maiúsculas diferentes na mesma linha diferiram estatisticamente entre si pelo Teste t pareado $(P<0,05)$

Fonte: Própria autoria.

Gráfico 09 - Médias com erros padrão para creatinina plasmática de bezerros oriundos de FIV e por IA nas primeiras 36 horas devida obtidos por parto natural Pirassununga -2018

口Bezerros FIV peso elevado aBezerros FIV peso padrão aBezerros IA (controle)

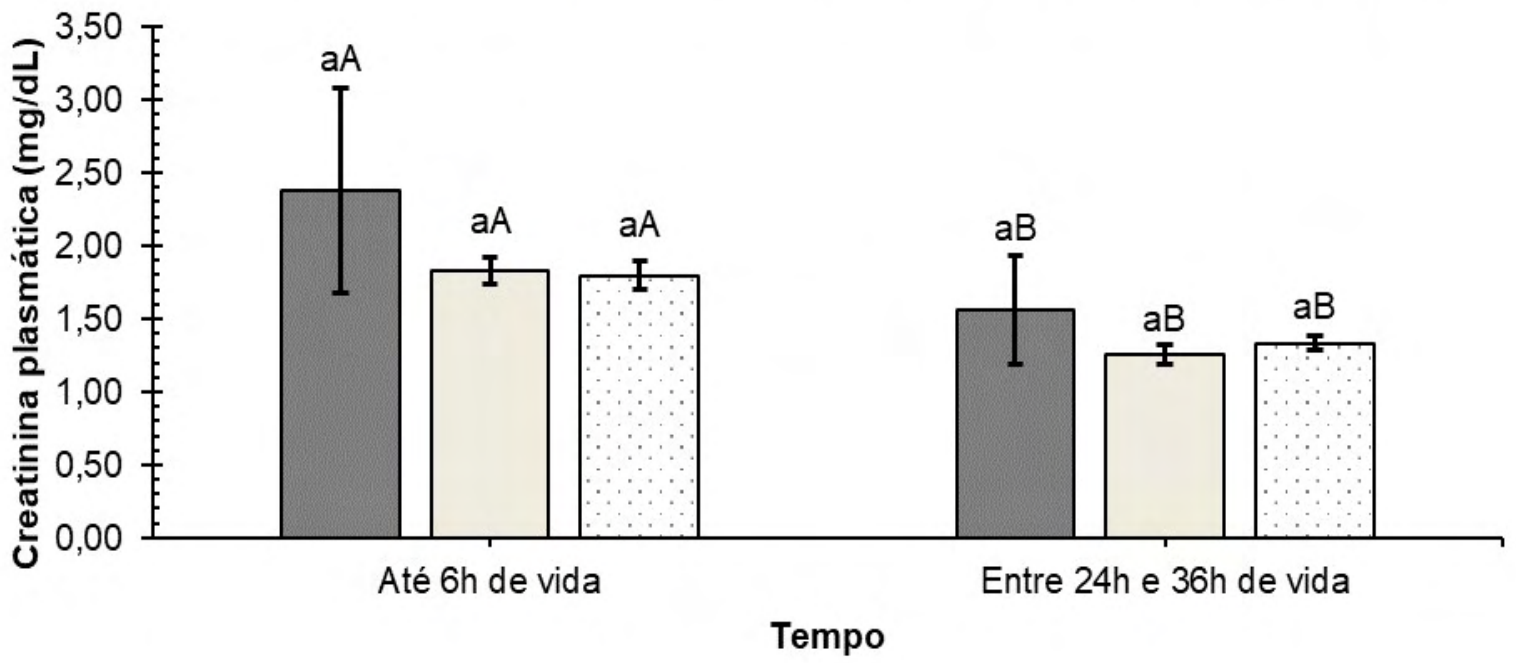

Colunas de cores diferentes seguidas com letras minúsculas diferentes, no mesmo tempo, diferiram estatisticamente entre si pelo Teste de Tukey $(P<0,05)$. Colunas de mesma cor seguidas por letras maiúsculas diferentes, diferiram estatisticamente entre si pelo Teste t pareado $(P<0,05)$

Fonte: Própria autoria 
Credita-se que a diminuição nos valores da creatinina entre o primeiro e segundo momento avaliados, tenha relação com as modificações fisiológicas observados por Doornenbal, Tong e Murray,1998. A análise dos resultados da ureia e da creatinina, reforçam as observações de Gasparelli (2007) que não detectaram alterações na função renal de bezerros produzidos por FIV. Pontua-se que bezerros com a síndrome do bezerro gigante não apresentam déficit na função renal.

\subsection{FUNÇÃO HEPÁTICA}

Para facilitar o entendimento durante a apresentação dos resultados e discussão as determinações bioquímicas da y-glutamil transferase para avaliação da função hepática das vacas e dos bezerros foi dividida para cada procedimento experimental.

\subsubsection{Procedimento experimental 1}

Na tabela 10 e no gráfico 10 estão apresentados os resultados da Y-glutamil transferase sérico de vacas receptoras de embriões por FIV da raça Nelore e vacas gestantes de bezerros da raça Nelore por IA (grupo controle). Houve diferença estatística significativa entre os tratamentos no momento cesariana $(P<0,05)$, e houve entre os períodos de avaliação para o grupo receptoras FIV $(P<0,05)$.

As médias de ambos os grupos estavam próximos dos valores de referência para bovinos adultos (6,1 - 17,4 U/L) relatados por Kaneko, Harvey e Bruss (2008), entretanto foram superiores aos observados por Oliveira (2015) e inferiores aos constatados para novilhas gestantes por Abud et al. (2016). Observou-se que no grupo das receptoras de FIV o teor sérico de GGT apresentou comportamento ascendente, verificando-se diferença estatística entre os momentos 270 dias de gestação e antes da cesariana, já no grupo controle manteve-se sem diferença entre os tempos avaliados. Ao comparar os grupos, as médias das receptoras FIV foram superiores aos do grupo controle, somente no momento imediatamente antes da cesariana. 
A existência de cetose no final da gestação em vacas de corte (BAILEY, 2015; CORREA; SCHILD; MENDEZ, 1990) devido a instalação do BEN, pode acarretar na mobilização da gordura corpórea (JUCHEM et al., 2000). Em condição de BEN moderado pode levar a formação do fígado gorduroso, neste instante a GGT pode apresentar elevações séricas, como indicativo de lesão hepática (PEEK et al., 2003).

Nos ruminantes, a síntese de glicose depende de um bom funcionamento hepático (GONZÁLEZ et al., 2000). Como a GGT é sintetizada nos hepatócitos e é considerada uma enzima de indução, seu aumento sérico frequentemente está relacionado a lesão hepática, sendo apontado como bom indicador para a função deste órgão (THRALL et al., 2015). No presente estudo não demonstrou valores sugestivos de lesão no sistema hepatobiliar no final da gestação, assim como não apresentou, influência da gestação por FIV sobre a função hepática no final da gestação.

Tabela 10 - Médias, erros padrão, medidas mínimas e máximas para GGT sérico (U/L) de vacas gestantes por FIV e por IA no final da gestação, período de indução e antes de serem submetidas a cesariana

\begin{tabular}{|c|c|c|c|c|c|c|c|c|}
\hline \multirow[b]{2}{*}{ Tempo } & \multicolumn{4}{|c|}{ Receptoras FIV } & \multicolumn{4}{|c|}{ Vacas IA } \\
\hline & $\mathrm{n}$ & Média & $\begin{array}{c}\text { Erro } \\
\text { Padrão }\end{array}$ & $\begin{array}{l}\text { Min e } \\
\text { Max }\end{array}$ & $\mathrm{n}$ & Média & $\begin{array}{c}\text { Erro } \\
\text { Padrão }\end{array}$ & $\begin{array}{l}\text { Min e } \\
\text { Max }\end{array}$ \\
\hline 270 & 8 & $6,4 \mathrm{bA}$ & 1,4 & $\begin{array}{c}1,0 \\
12,0\end{array}$ & 8 & 10,4 aA & 2,4 & $\begin{array}{c}1,0 \\
21,0\end{array}$ \\
\hline 280 & 8 & $7,6 \mathrm{abA}$ & 1,9 & $\begin{array}{c}1,0 \\
15,0\end{array}$ & 8 & 11,6 aA & 1,8 & $\begin{array}{c}1,0 \\
16,0\end{array}$ \\
\hline $\begin{array}{c}\text { antes } \\
\text { indução }\end{array}$ & 8 & $8,0 \mathrm{abA}$ & 2,0 & $\begin{array}{c}1,0 \\
16,0\end{array}$ & 8 & 11,5 aA & 3,1 & $\begin{array}{c}1,0 \\
23,0\end{array}$ \\
\hline $\begin{array}{c}12 \mathrm{~h} \\
\text { indução }\end{array}$ & 8 & $10,8 \mathrm{abA}$ & 2,1 & $\begin{array}{c}1,0 \\
17,0\end{array}$ & 6 & $10,8 \mathrm{aA}$ & 2,4 & $\begin{array}{c}1,0 \\
27,0\end{array}$ \\
\hline cesariana & 8 & 14,4 aA & 2,1 & $\begin{array}{c}7,0 \\
25,0\end{array}$ & 11 & $6,8 \mathrm{aB}$ & 2,4 & $\begin{array}{c}1,0 \\
24,0\end{array}$ \\
\hline
\end{tabular}

Médias seguidas por letras minúsculas diferentes na mesma coluna diferiram estatisticamente entre si pelo Teste de Tukey $(\mathrm{P}<0,05)$. Médias seguidas por letras maiúsculas diferentes na mesma linha diferiram estatisticamente entre si pelo Teste $t$ (Student) $(P<0,05)$

Fonte: Própria autoria. 
Gráfico 10 - Médias com erros padrão para GGT sérico de vacas gestantes por FIV e por IA no final da gestação até a indução e a realização da cesariana Pirassununga - 2018

- Receptoras FIV $\quad$ Vacas IA

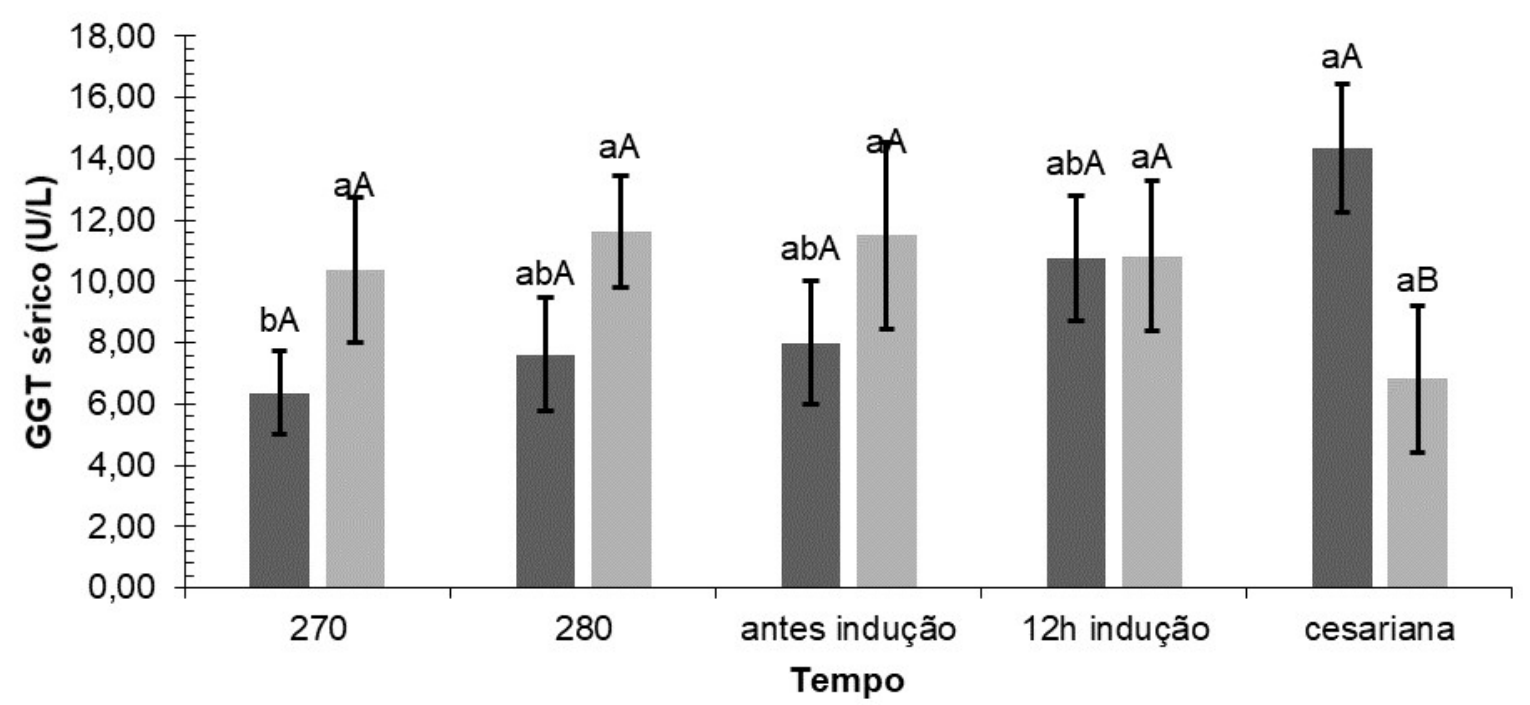

Colunas de mesma cor seguidas com letras minúsculas diferentes, diferiram estatisticamente entre si pelo Teste de Tukey $(P<0,05)$. Colunas de cor diferente dentro de cada tempo seguidas por letras maiúsculas diferentes, diferiram estatisticamente entre si pelo Teste $t$ (Student) $(P<0,05)$

Fonte: Própria autoria

\subsubsection{Procedimento experimental 2}

Na tabela 11 e no gráfico 11 estão representados os resultados da Y-glutamil transferase sérico dos bezerros oriundos de FIV e por IA (grupo controle). Não houve diferença estatística significativa entre os tratamentos dentro de cada tempo separadamente $(P>0,05)$, houve entre os períodos de avaliação dentro de cada tratamento $(P<0,05)$.

Em bezerros neonatos a avaliação sérica da GGT trata-se de um método de indireto para determinar a eficácia da transferência de imunidade passiva. No colostro de fêmeas bovinas além de grante quantidade de imunoglulinas, apresenta alta concentração de GGT, havendo moderada correlação entre a absorção de imunoglobulinas e GGT pelo bezerro. Possui tempo de meia vida curto e pico sérico nas primeiras $24 \mathrm{~h}$ de vida (RADOSTITS et al. 2002).

O comportamento dos valores medianos da GGT foi semelhante entre os grupos, havendo diferença estatística pelo efeito etário. Evidenciou-se que entre 6 horas e 3 dias de vida as concentrações séricas de GGT variaram entre 858,5 e 
$836,5 \mathrm{U} / \mathrm{L}$, com pico às $12 \mathrm{~h}(2218,5 \mathrm{U} / \mathrm{L})$ e mantendo-se até as $24 \mathrm{~h}$ para os bezerros de FIV e entre 102,0 e $324,0 \mathrm{U} / \mathrm{L}$, com pico às $24 \mathrm{~h}(1262,0 \mathrm{U} / \mathrm{L})$ para os animais do grupo controle. As variações do presente trabalho foram semelhantes ao relatado por Marchese (2014) no seu grupo controle e por Gasparelli (2007) em bezerros de FIV eutócitos.

Tabela 11 - Medianas, erros padrão, medidas mínimas e máximas para GGT sérico (U/L) de bezerros oriundos de FIV e por IA nos primeiros 30 dias de vida obtidos por cesariana com indução do parto

\begin{tabular}{|c|c|c|c|c|c|c|c|c|}
\hline \multirow[b]{2}{*}{ Tempo } & \multicolumn{4}{|c|}{ Bezerros FIV } & \multicolumn{4}{|c|}{ Bezerros IA } \\
\hline & $\mathrm{n}$ & Mediana & $\begin{array}{c}\text { Erro } \\
\text { Padrão }\end{array}$ & $\begin{array}{c}\text { Min e } \\
\text { Max }\end{array}$ & $\mathrm{n}$ & Mediana & $\begin{array}{c}\text { Erro } \\
\text { Padrão }\end{array}$ & $\begin{array}{l}\text { Min e } \\
\text { Max }\end{array}$ \\
\hline $\mathrm{Oh}$ & 7 & $2,0 \mathrm{dA}$ & 2,3 & $\begin{array}{l}1,0 \\
9,0\end{array}$ & 12 & $10,0 \mathrm{eA}$ & 1,8 & $\begin{array}{c}8,0 \\
12,5\end{array}$ \\
\hline $3 \mathrm{~h}$ & 8 & $17,0 \mathrm{~cd} A$ & 45,2 & $\begin{array}{c}8,5 \\
56,5\end{array}$ & 12 & $17,0 \mathrm{deA}$ & 57,7 & $\begin{array}{l}12,0 \\
81,5\end{array}$ \\
\hline $6 \mathrm{~h}$ & 8 & $858,5 \mathrm{abcA}$ & 569,8 & $\begin{array}{c}125,0 \\
2293,0\end{array}$ & 12 & 102,0 abcdA & 264,8 & $\begin{array}{c}35,0 \\
541,5\end{array}$ \\
\hline $12 \mathrm{~h}$ & 8 & 2218,5 aA & 979,1 & $\begin{array}{c}698,5 \\
6278,0\end{array}$ & 12 & $570,5 \mathrm{abA}$ & 497,1 & $\begin{array}{c}422,5 \\
2568,0\end{array}$ \\
\hline $24 \mathrm{~h}$ & 8 & 2218,5 aA & 979,0 & $\begin{array}{c}694,0 \\
6312,0\end{array}$ & 12 & 1262,0 aA & 388,2 & $\begin{array}{c}666,0 \\
1898,0\end{array}$ \\
\hline $48 h$ & 8 & $1416,5 \mathrm{abA}$ & 672,0 & $\begin{array}{c}313,0 \\
3523,0\end{array}$ & 12 & $557,0 \mathrm{abA}$ & 118,0 & $\begin{array}{l}257,0 \\
804,0\end{array}$ \\
\hline 3 dias & 8 & 836,5 abcA & 378,0 & $\begin{array}{c}199,0 \\
1956,5\end{array}$ & 12 & $324,0 \mathrm{abcA}$ & 73,1 & $\begin{array}{l}168,5 \\
586,5\end{array}$ \\
\hline 5 dias & 8 & 508,0 abcdA & 197,6 & $\begin{array}{c}106,0 \\
1036,0\end{array}$ & 11 & 150,0 abcdA & 50,8 & $\begin{array}{c}84,8 \\
325,8\end{array}$ \\
\hline 7 dias & 8 & 381,5 abcdA & 123,2 & $\begin{array}{c}73,0 \\
630,0\end{array}$ & 12 & 123,0 bcdeA & 38,9 & $\begin{array}{c}77,0 \\
282,0\end{array}$ \\
\hline 15 dias & 8 & 145,5 bcdA & 63,4 & $\begin{array}{c}26,5 \\
327,5\end{array}$ & 12 & $71,0 \mathrm{cdeA}$ & 17,8 & $\begin{array}{c}75,5 \\
143,0\end{array}$ \\
\hline 30 dias & 8 & $38,0 \mathrm{~cd} A$ & 17,7 & $\begin{array}{c}15,0 \\
115,0 \\
\end{array}$ & 12 & $42,5 \mathrm{cde} A$ & 5,5 & $\begin{array}{l}30,0 \\
59,5 \\
\end{array}$ \\
\hline
\end{tabular}

Medianas seguidas por letras minúsculas diferentes na mesma coluna diferiram estatisticamente entre si pelo Teste de Tukey $(P<0,05)$. Médias seguidas por letras maiúsculas diferentes na mesma linha diferiram estatisticamente entre si pelo Teste $t$ (Student) $(P<0,05)$

Fonte: Própria autoria. 
Gráfico 11 - Médias com erros padrão para GGT sérico de bezerros oriundos de FIV e por IA nos primeiros 30 dias de vida obtidos por cesariana com indução do parto Pirassununga - 2018

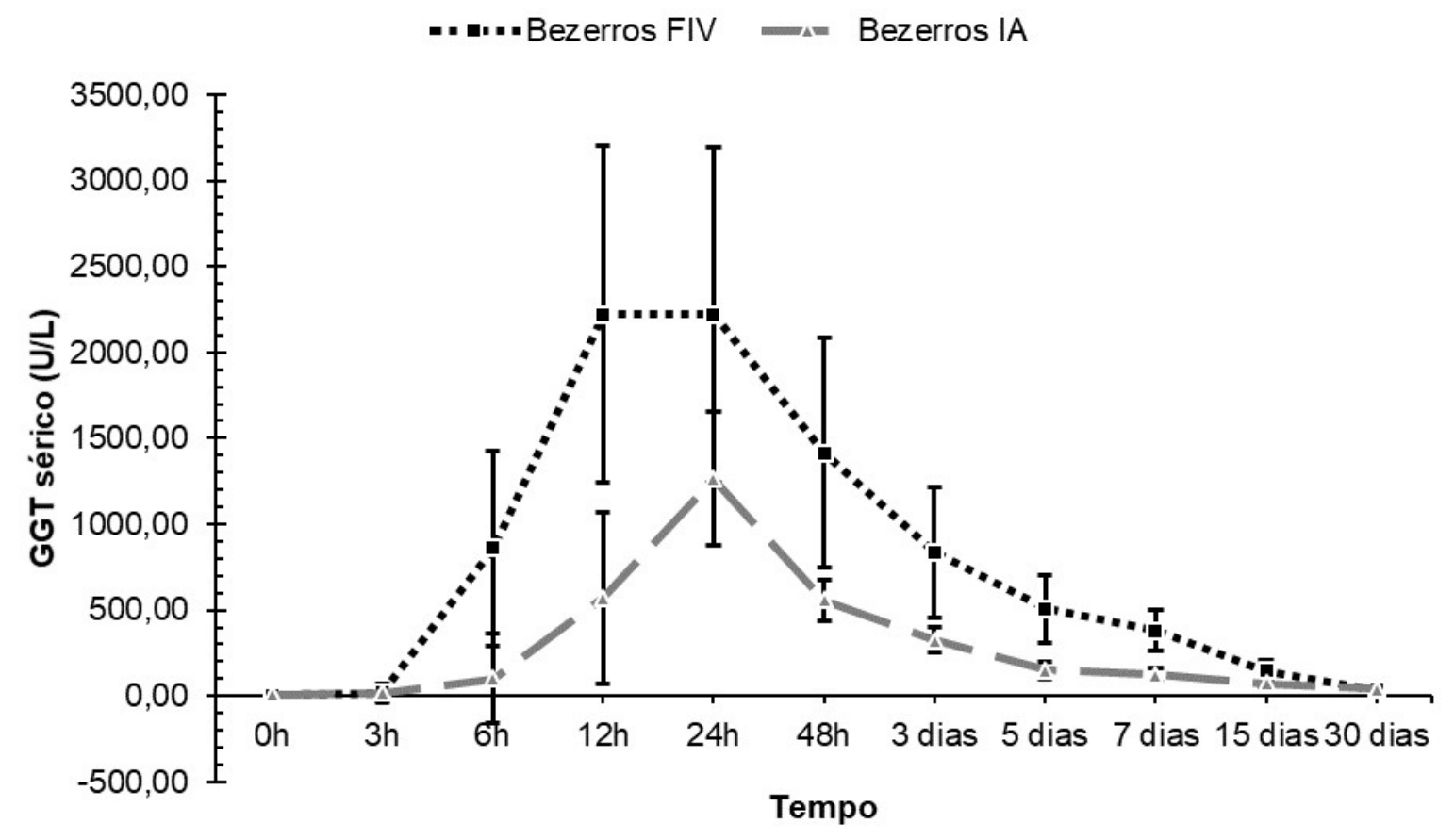

Fonte: Própria autoria.

Neste estudo ficou demonstrada a influência do colostro na atividade da enzima GGT como também relatados por Feitosa et al. (2009), os quais encontraram maior atividade sérica desta enzima entre 6 e 12 horas de vida, e sua diminuição a partir do $16^{\circ}$ dia e alcança níveis semelhantes a bovinos adultos após 5 semanas. $O$ fato de não haver diferença estatística entre os grupos avaliados neste trabalho mostra que os bezerros produzidos por FIV apresentam a mesma capacidade de absorção de imunoglobulinas colostrais de bezerros produzidos por IA ao nascer na condição de parto induzido e nascimento por cesariana.

\subsubsection{Procedimento experimental 3}

Na tabela 12 e no gráfico 12 estão apresentados os resultados da Y-glutamil transferase sérico de vacas receptoras de embriões por FIV da raça Nelore com bezerros apresentando peso elevado ao nascimento, vacas receptoras de embriões por FIV da raça Nelore com bezerros apresentando peso dentro do padrão da raça 
ao nascimento e vacas gestantes de bezerros da raça Nelore por IA (grupo controle). Não houve diferença estatística significativa entre os tratamentos dentro de cada tempo separadamente $(P>0,05)$, houve entre os períodos de avaliação dentro de cada tratamento $(P<0,05)$ nos dois grupos de bezerros de FIV.

As médias de ambos os grupos estavam próximos dos valores de referência para bovinos adultos (6,1 - 17,4 U/L) relatados por Kaneko, Harvey e Bruss (2008) e superiores aos encontrados por Oliveira (2015). Os grupos das receptoras de FIV apresentaram, aos 288 dias, teores inferiores aos de até 6 horas após o parto, não observado no grupo das vacas controle.

Mesmo, os grupos de vacas receptoras de FIV, apresentando diferença entre os tempos, os valores permaneceram próximos da faixa de referência. Este resultado indica que, assim como no procedimento experimental 1 , não houve valores sugestivos de lesão no sistema hepatobiliar no final da gestação, ou efeito da FIV ou da síndrome do bezerro gigante na função hepática no final da gestação.

Tabela 12 - Médias, erros padrão, medidas mínimas e máximas para GGT sérico $(\mathrm{U} / \mathrm{L})$ de vacas gestantes por FIV e por IA no final da gestação e até 6h após o parto natural

\begin{tabular}{|c|c|c|c|c|c|c|c|c|}
\hline \multirow[b]{2}{*}{ Tratamento } & \multicolumn{4}{|c|}{288 dias } & \multicolumn{4}{|c|}{ Até 6h após o parto } \\
\hline & $\mathrm{n}$ & Média & $\begin{array}{c}\text { Erro } \\
\text { Padrão }\end{array}$ & $\begin{array}{l}\text { Min e } \\
\text { Max }\end{array}$ & $\mathrm{n}$ & Média & $\begin{array}{c}\text { Erro } \\
\text { Padrão }\end{array}$ & $\begin{array}{l}\text { Min e } \\
\text { Max }\end{array}$ \\
\hline Receptoras & & & & 3,0 & & & & 7,0 \\
\hline $\begin{array}{l}\text { FIV bez } \\
\text { peso } \\
\text { elevado }\end{array}$ & 17 & $11,4 \mathrm{aB}$ & 1,0 & 19,0 & 17 & $18,7 \mathrm{aA}$ & 2,4 & 47,0 \\
\hline Receptoras & & & & 1,0 & & & & 1,0 \\
\hline $\begin{array}{l}\text { FIV bez } \\
\text { peso } \\
\text { padrão }\end{array}$ & 30 & $13,2 \mathrm{aB}$ & 1,3 & 30,0 & 32 & $17,8 \mathrm{aA}$ & 1,7 & 42,0 \\
\hline Vacas IA & 15 & $155 \mathrm{aA}$ & 22 & 1,0 & 16 & $174 \mathrm{aA}$ & 26 & 1,0 \\
\hline (controle) & & 10,0 a & & 33,0 & 10 & $11,4 \mathrm{~d} A$ & 2,0 & 39,0 \\
\hline
\end{tabular}

Médias seguidas por letras minúsculas diferentes na mesma coluna diferiram estatisticamente entre si pelo Teste de Tukey $(P<0,05)$. Médias seguidas pela mesma letra maiúscula na linha não diferiram estatisticamente entre si pelo Teste t pareado $(P>0,05)$

Fonte: Própria autoria. 
Gráfico 12 - Médias com erros padrão para GGT sérico de vacas receptoras de FIV de bezerros com peso elevado após o nascimento, receptoras de FIV com bezerros de peso padrão após o nascimento e vacas gestantes por IA, no final da gestação e até $6 \mathrm{~h}$ após o parto natural a termo - Pirassununga - 2018

口Receptoras FIV bez peso elevado $\square$ Receptoras FIV bez peso padrão 口Vacas IA (controle)

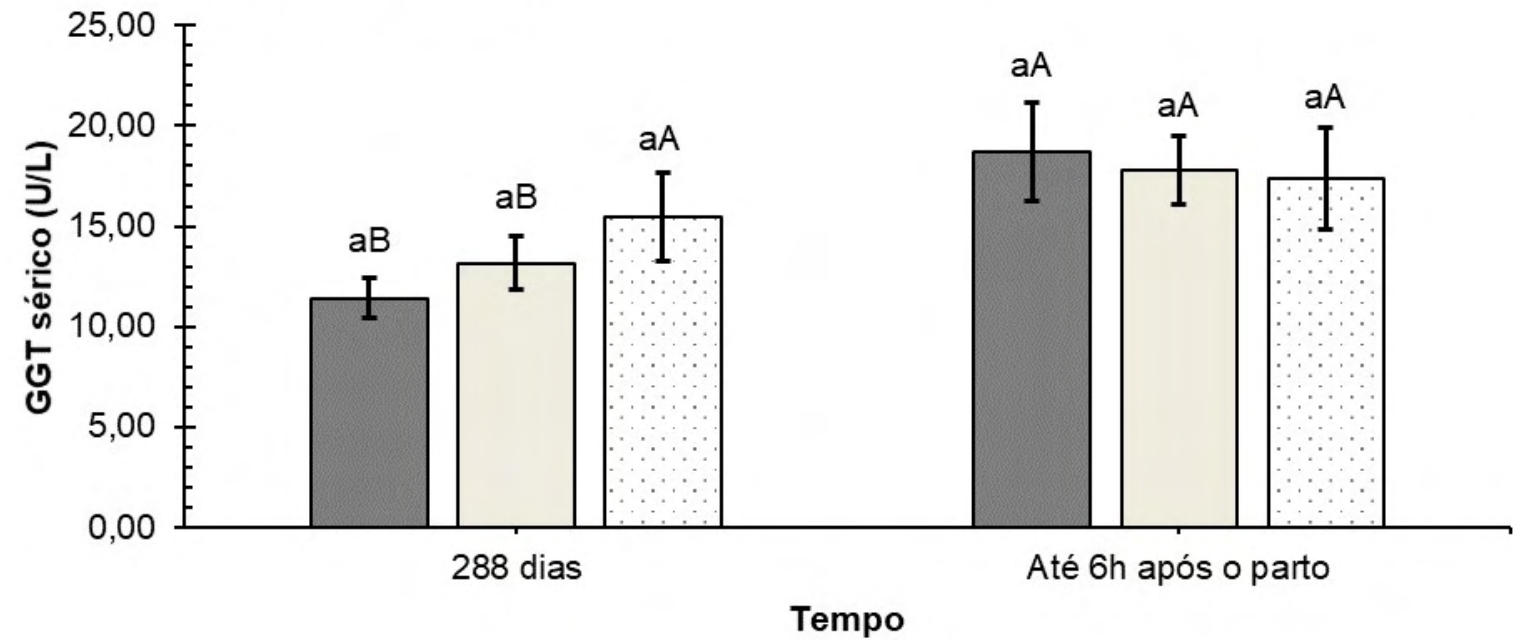

Colunas de cores diferentes seguidas com letras minúsculas diferentes, no mesmo tempo, diferiram estatisticamente entre si pelo Teste de Tukey $(P<0,05)$. Colunas de mesma cor seguidas por letras maiúsculas diferentes, diferiram estatisticamente entre si pelo Teste t pareado $(P<0,05)$

Fonte: Própria autoria.

\subsubsection{Procedimento experimental 4}

Na tabela 13 e no gráfico 13 estão representados os resultados da Y-glutamil transferase sérico dos bezerros oriundos de FIV com peso ao nascimento elevado, bezerros oriundos de FIV com peso ao nascimento dentro do padrão da raça e por IA (grupo controle). Houve diferença estatística significativa entre os bezerros de FIV com peso elevado ao nascimento e o grupo controle, no momento ente 6 a 12 horas após o parto $(P<0,05)$, não houve entre os períodos de avaliação dentro de cada tratamento $(P>0,05)$.

As médias observadas no presente trabalho foram semelhantes aos relatados por Gasparelli (2007). Os menores valores séricos de GGT verificados nos bezerros com peso elevado ao nascimento, no momento até 6 horas de vida, pode ser atribuído a menor capacidade absortiva das imunoglobulinas pelo fornecimento de colostro, uma vez que mesmo quando não apresentavam condições de mamada 
espontânea, era realizado a colostragem por mamadeiras ou sondas oroesofágica quando não apresentavam reflexo de sucção.

Em seu trabalho, Fagliari et al. (1996) determinou correlação positiva entre a absorção de imunoglobulinas e a elevação da GGT entre o nascimento e 24 a 30 horas de vida. Em outro estudo, Feitosa et al. (2001) verificou alta transferência de imunidade passiva e probabilidade sobrevivência dos bezerros (82\%) quando os teores séricos de GGT encontravam-se acima de 840 U/L com 24 horas de vida. Estes valores foram confirmados nos bezerros de FIV com peso elevado ao nascimento, ainda no primeiro momento avaliado, embora os menores valores da GGT nestes bezerros terem sido menores comparados aos outros grupos, foi suficiente para conferir transferência de imunidade passiva, não apresentando assim influência da síndrome do bezerro gigante sobre a capacidade absortiva de imunoglobulinas.

Tabela 13 - Medianas, erros padrão, medidas mínimas e máximas para GGT sérico (U/L) de bezerros oriundos de FIV e por IA nas primeiras 36 horas devida obtidos por parto natural

\begin{tabular}{|c|c|c|c|c|c|c|c|c|}
\hline \multirow[b]{2}{*}{ Tratamento } & \multicolumn{4}{|c|}{$\begin{array}{c}\text { Entre } 6 \text { e } 12 \text { horas } \\
\text { de vida }\end{array}$} & \multicolumn{4}{|c|}{ Entre $24 \mathrm{~h}$ e $36 \mathrm{~h}$ de vida } \\
\hline & $\mathrm{n}$ & Mediana & $\begin{array}{c}\text { Erro } \\
\text { Padrão }\end{array}$ & $\begin{array}{l}\text { Min e } \\
\text { Max } \\
\end{array}$ & $\mathrm{n}$ & Mediana & $\begin{array}{c}\text { Erro } \\
\text { Padrão }\end{array}$ & $\begin{array}{l}\text { Min e } \\
\text { Max }\end{array}$ \\
\hline $\begin{array}{l}\text { Bezerros } \\
\text { FIV peso } \\
\text { elevado }\end{array}$ & 16 & $856,5 \mathrm{bA}$ & 324,42 & $\begin{array}{c}42,0 \\
2364,0\end{array}$ & 17 & 1636,0 aA & 263,52 & $\begin{array}{c}999,2 \\
2484,0\end{array}$ \\
\hline $\begin{array}{l}\text { Bezerros } \\
\text { FIV peso } \\
\text { padrão }\end{array}$ & 31 & $1695,0 \mathrm{abA}$ & 250,08 & $\begin{array}{c}233,5 \\
3111,0\end{array}$ & 31 & 1250,0 aA & 185,35 & $\begin{array}{r}566,0 \\
2061,8\end{array}$ \\
\hline $\begin{array}{l}\text { Bezerros IA } \\
\text { (controle) }\end{array}$ & 27 & 2998,0 aA & 484,44 & $\begin{array}{c}714,0 \\
4330,5\end{array}$ & 27 & 1820,0 aA & 300,07 & $\begin{array}{r}690,0 \\
2547,8\end{array}$ \\
\hline
\end{tabular}

Medianas seguidas por letras minúsculas diferentes na mesma coluna diferiram estatisticamente entre si pelo Teste de Tukey $(P<0,05)$. Médias seguidas por letras maiúsculas diferentes na mesma linha diferiram estatisticamente entre si pelo Teste t pareado $(P<0,05)$

Fonte: Própria autoria. 
Gráfico 13 - Medianas com erros padrão para GGT sérico de bezerros oriundos de FIV e por IA nas primeiras 36 horas devida obtidos por parto natural - Pirassununga $-2018$

$\square$ Bezerros FIV peso elevado $\quad$ Bezerros FIV peso padrão $\quad$ Bezerros IA (controle)

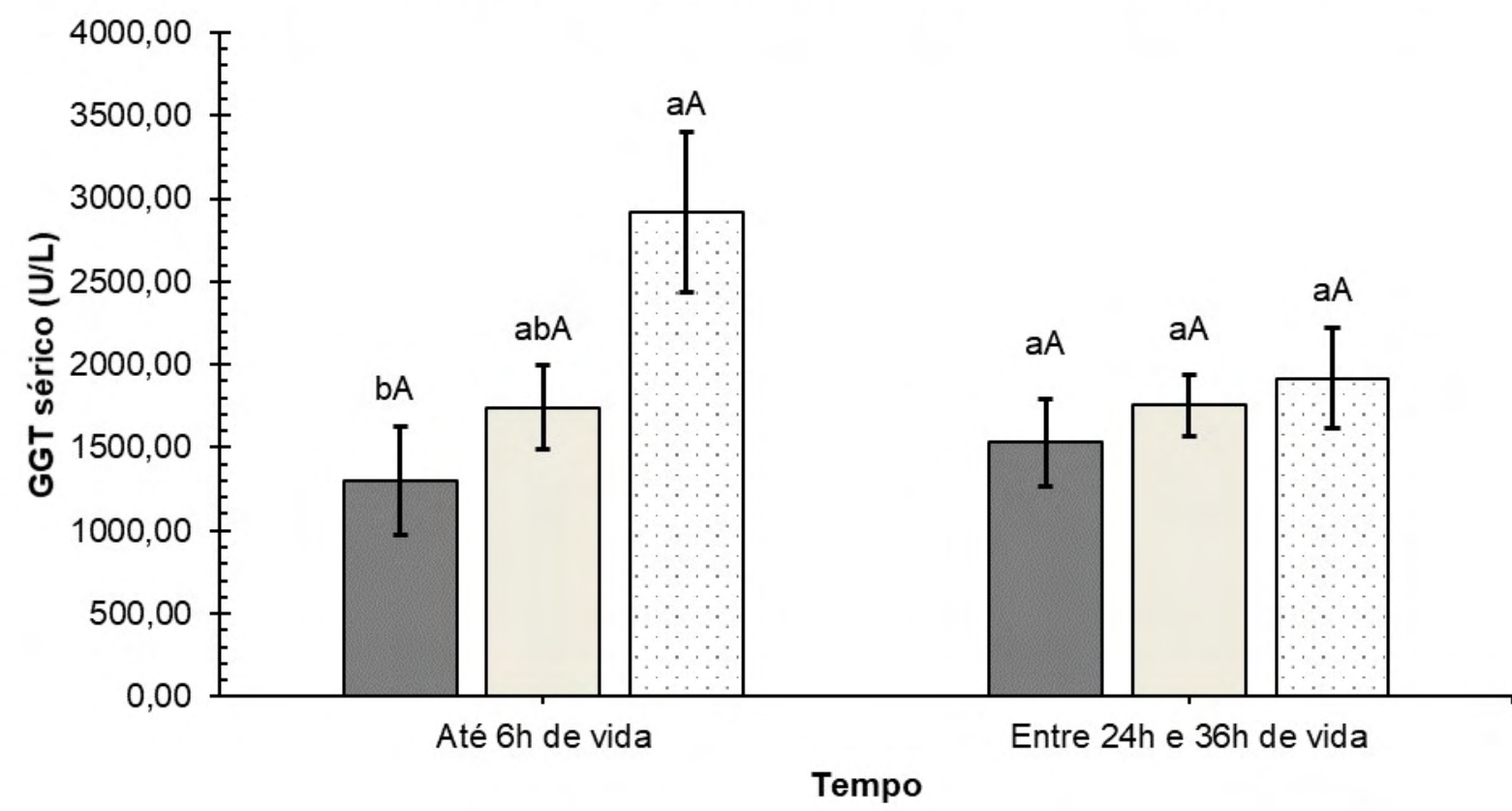

Colunas de cores diferentes seguidas com letras minúsculas diferentes, no mesmo tempo, diferiram estatisticamente entre si pelo Teste de Tukey $(P<0,05)$. Colunas de mesma cor seguidas por letras maiúsculas diferentes, diferiram estatisticamente entre si pelo Teste t pareado $(P<0,05)$

Fonte: Própria autoria.

\subsection{PROTEINOGRAMA}

Para facilitar o entendimento durante a apresentação dos resultados e discussão as determinações bioquímicas de prodeína e albumina para avaliação do proteinograma das vacas e dos bezerros foram divididas para cada procedimento experimental.

\subsubsection{Procedimento experimental 1}

Nas tabelas 14 e 15 e nos gráficos 14 e 15 estão apresentados, respectivamente, os resultados da proteína e albumina sérica de vacas receptoras de embriões por FIV da raça Nelore e vacas gestantes de bezerros da raça Nelore por IA (grupo controle). Houve diferença estatística significativa entre os tratamentos 
dentro de cada tempo (antes da indução e cesariana) separadamente para proteína $(P<0,05)$, não houve entre os períodos de avaliação dentro de cada tratamento $(P>0,05)$. Houve diferença estatística significativa entre os tratamentos dentro de cada tempo separadamente para albumina $(P<0,05)$, não houve entre os períodos de avaliação dentro de cada tratamento $(P>0,05)$.

Neste trabalho, observou-se que no grupo das receptoras de FIV, nos momentos antes da indução e antes da cesariana, os teores plasmáticos de proteína foram estatisticamente menores que no grupo controle. Contudo, as médias de proteína de ambos os grupos estavam próximos dos valores de referência para bovinos adultos $(6,7-7,5 \mathrm{~g} / \mathrm{dL})$ relatados por Kaneko, Harvey e Bruss (2008) e inferiores aos observados para novilhas gestantes por Abud et al. (2016), e em vacas Nelore por Oliveira (2015). As proteínas séricas são compostas, principalmente por albumina (aproximadamente 50\%) e globulinas, sem o fibrinogênio e a fibrina por terem sido consumidas durante o processo de coagulação (THRALL et al., 2015).

Tabela 14 - Médias, erros padrão, medidas mínimas e máximas para proteína sérica (g/dL) de vacas gestantes por FIV e por IA no final da gestação, período de indução e antes de serem submetidas a cesariana

\begin{tabular}{|c|c|c|c|c|c|c|c|c|}
\hline \multirow[b]{2}{*}{ Tempo } & \multicolumn{4}{|c|}{ Receptoras FIV } & \multicolumn{4}{|c|}{ Vacas IA } \\
\hline & $\mathrm{n}$ & Média & $\begin{array}{c}\text { Erro } \\
\text { Padrão }\end{array}$ & $\begin{array}{l}\text { Min e } \\
\text { Max }\end{array}$ & $\mathrm{n}$ & Média & $\begin{array}{c}\text { Erro } \\
\text { Padrão }\end{array}$ & $\begin{array}{l}\text { Min e } \\
\text { Max }\end{array}$ \\
\hline \multirow{2}{*}{270} & \multirow{2}{*}{8} & \multirow{2}{*}{6,5 aA } & \multirow{2}{*}{0,3} & 4,9 & \multirow{2}{*}{8} & \multirow{2}{*}{6,7 aA } & \multirow{2}{*}{0,1} & 6,5 \\
\hline & & & & 7,2 & & & & 7,0 \\
\hline \multirow{2}{*}{280} & \multirow{2}{*}{8} & \multirow{2}{*}{6,4 aA } & \multirow{2}{*}{0,2} & 5,4 & \multirow{2}{*}{8} & \multirow{2}{*}{6,7 aA } & \multirow{2}{*}{0,1} & 6,3 \\
\hline & & & & 7,1 & & & & 7,0 \\
\hline \multirow{2}{*}{$\begin{array}{c}\text { antes } \\
\text { indução }\end{array}$} & \multirow{2}{*}{8} & \multirow{2}{*}{$6,4 \mathrm{aB}$} & \multirow{2}{*}{0,2} & 5,8 & \multirow{2}{*}{8} & \multirow{2}{*}{6,9 aA } & \multirow{2}{*}{0,1} & 6,4 \\
\hline & & & & 7,0 & & & & 7,6 \\
\hline \multirow{2}{*}{$\begin{array}{c}12 \mathrm{~h} \\
\text { indução }\end{array}$} & \multirow{2}{*}{8} & \multirow{2}{*}{$6,4 \mathrm{aA}$} & \multirow{2}{*}{0,2} & 5,7 & \multirow{2}{*}{7} & \multirow{2}{*}{6,7 aA } & \multirow{2}{*}{0,0} & 6,5 \\
\hline & & & & 7,1 & & & & 6,8 \\
\hline \multirow{2}{*}{ cesariana } & \multirow{2}{*}{8} & \multirow{2}{*}{$6,5 \mathrm{aB}$} & \multirow{2}{*}{0,3} & 5,5 & \multirow{2}{*}{11} & \multirow{2}{*}{7,0 aA } & \multirow{2}{*}{0,1} & 6,4 \\
\hline & & & & 7,6 & & & & 7,8 \\
\hline
\end{tabular}

Médias seguidas por letras minúsculas diferentes na mesma coluna diferiram estatisticamente entre si pelo Teste de Tukey $(P<0,05)$. Médias seguidas por letras maiúsculas diferentes na mesma linha diferiram estatisticamente entre si pelo Teste $t$ (Student) $(P<0,05)$

Fonte: Própria autoria. 
Gráfico 14 - Médias com erros padrão para proteína sérica de vacas gestantes por FIV e por IA no final da gestação até a indução e a realização da cesariana Pirassununga - 2018

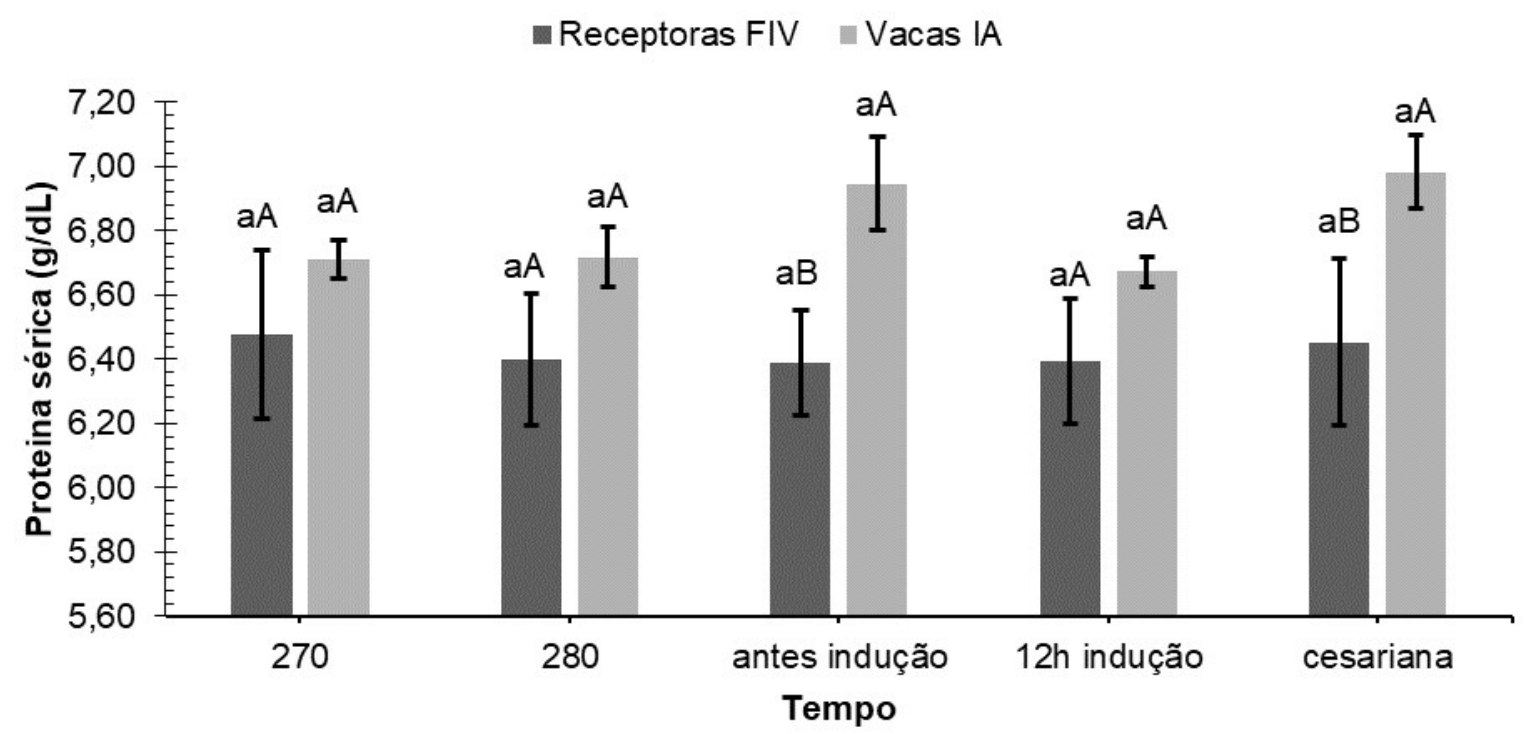

Colunas de mesma cor seguidas com letras minúsculas diferentes, diferiram estatisticamente entre si pelo Teste de Tukey $(P<0,05)$. Colunas de cor diferente dentro de cada tempo seguidas por letras maiúsculas diferentes, diferiram estatisticamente entre si pelo Teste $t$ (Student) $(P<0,05)$

Fonte: Própria autoria.

Já para albumina, as médias do grupo controle foram superiores aos das vacas receptoras de FIV que estavam próximos dos valores de referência para bovinos adultos (3,0 - 3,5 g/dL) relatados por Kaneko, Harvey e Bruss (2008), assim como aos observados por Abud et al. (2016) para novilhas gestantes Nelore e por Oliveira (2015) em vacas Nelore. A albumina é sintetizada no fígado e assim como a ureia, pode apresentar variações de acordo com o consumo proteico na dieta, contudo seus valores séricos, essencialmente, revelam a capacidade da síntese hepática (GONZÁLEZ et al., 2000).

Como visto na avaliação da GGT os animais deste experimento não apresentavam indícios de lesão hepática, também estavam submetidas ao mesmo manejo alimentar. Apesar dos valores de proteína (nos momentos antes da indução e imediatamente antes da cesariana) e de albumina (em todos os momentos) terem sido superiores nas vacas controle, os teores encontravam-se próximos dos valores de referência. Não indicando efeito da gestação por FIV sobre as concentrações séricas de proteína e albumina. 
Tabela 15 - Médias, erros padrão, medidas mínimas e máximas para albumina sérica $(\mathrm{g} / \mathrm{dL})$ de vacas gestantes por FIV e por IA no final da gestação, período de indução e antes de serem submetidas a cesariana

\begin{tabular}{|c|c|c|c|c|c|c|c|c|}
\hline \multirow[b]{2}{*}{ Tempo } & \multicolumn{4}{|c|}{ Receptoras FIV } & \multicolumn{4}{|c|}{ Vacas IA } \\
\hline & $\mathrm{n}$ & Média & $\begin{array}{c}\text { Erro } \\
\text { Padrão }\end{array}$ & $\begin{array}{l}\text { Min e } \\
\operatorname{Max}\end{array}$ & $n$ & Média & $\begin{array}{c}\text { Erro } \\
\text { Padrão }\end{array}$ & $\begin{array}{l}\text { Min e } \\
\text { Max }\end{array}$ \\
\hline \multirow{2}{*}{270} & \multirow{2}{*}{8} & \multirow{2}{*}{$3,3 \mathrm{aB}$} & \multirow{2}{*}{0,2} & 2,5 & \multirow{2}{*}{8} & \multirow{2}{*}{3,8 aA } & \multirow{2}{*}{0,1} & 3,4 \\
\hline & & & & 3,8 & & & & 4,1 \\
\hline \multirow{2}{*}{280} & \multirow{2}{*}{8} & \multirow{2}{*}{$3,3 \mathrm{aB}$} & \multirow{2}{*}{0,1} & 2,9 & \multirow{2}{*}{8} & \multirow{2}{*}{3,8 aA } & \multirow{2}{*}{0,1} & 3,3 \\
\hline & & & & 3,7 & & & & 4,1 \\
\hline \multirow{2}{*}{$\begin{array}{c}\text { antes } \\
\text { indução }\end{array}$} & \multirow{2}{*}{8} & \multirow{2}{*}{$3,3 \mathrm{aB}$} & \multirow{2}{*}{0,1} & 2,4 & \multirow{2}{*}{8} & \multirow{2}{*}{$3,8 \mathrm{aA}$} & \multirow{2}{*}{0,1} & 3,4 \\
\hline & & & & 3,7 & & & & 4,2 \\
\hline \multirow{2}{*}{$\begin{array}{c}12 \mathrm{~h} \\
\text { indução }\end{array}$} & \multirow{2}{*}{8} & \multirow{2}{*}{$3,3 \mathrm{aB}$} & \multirow{2}{*}{0,1} & 2,4 & \multirow{2}{*}{7} & \multirow{2}{*}{$4,0 \mathrm{aA}$} & \multirow{2}{*}{0,1} & 3,8 \\
\hline & & & & 3,7 & & & & 4,4 \\
\hline \multirow{2}{*}{ cesariana } & \multirow{2}{*}{8} & \multirow{2}{*}{$3,4 \mathrm{aB}$} & \multirow{2}{*}{0,1} & 2,9 & \multirow{2}{*}{11} & \multirow{2}{*}{$3,9 \mathrm{aA}$} & \multirow{2}{*}{0,1} & 3,4 \\
\hline & & & & 3,8 & & & & 4,3 \\
\hline
\end{tabular}

Médias seguidas por letras minúsculas diferentes na mesma coluna diferiram estatisticamente entre si pelo Teste de Tukey $(P<0,05)$. Médias seguidas por letras maiúsculas diferentes na mesma linha diferiram estatisticamente entre si pelo Teste $t$ (Student) $(P<0,05)$

Fonte: Própria autoria.

Gráfico 15 - Médias com erros padrão para albumina sérica de vacas gestantes por FIV e por IA no final da gestação até a indução e a realização da cesariana Pirassununga -2018

- Receptoras FIV $=$ Vacas IA

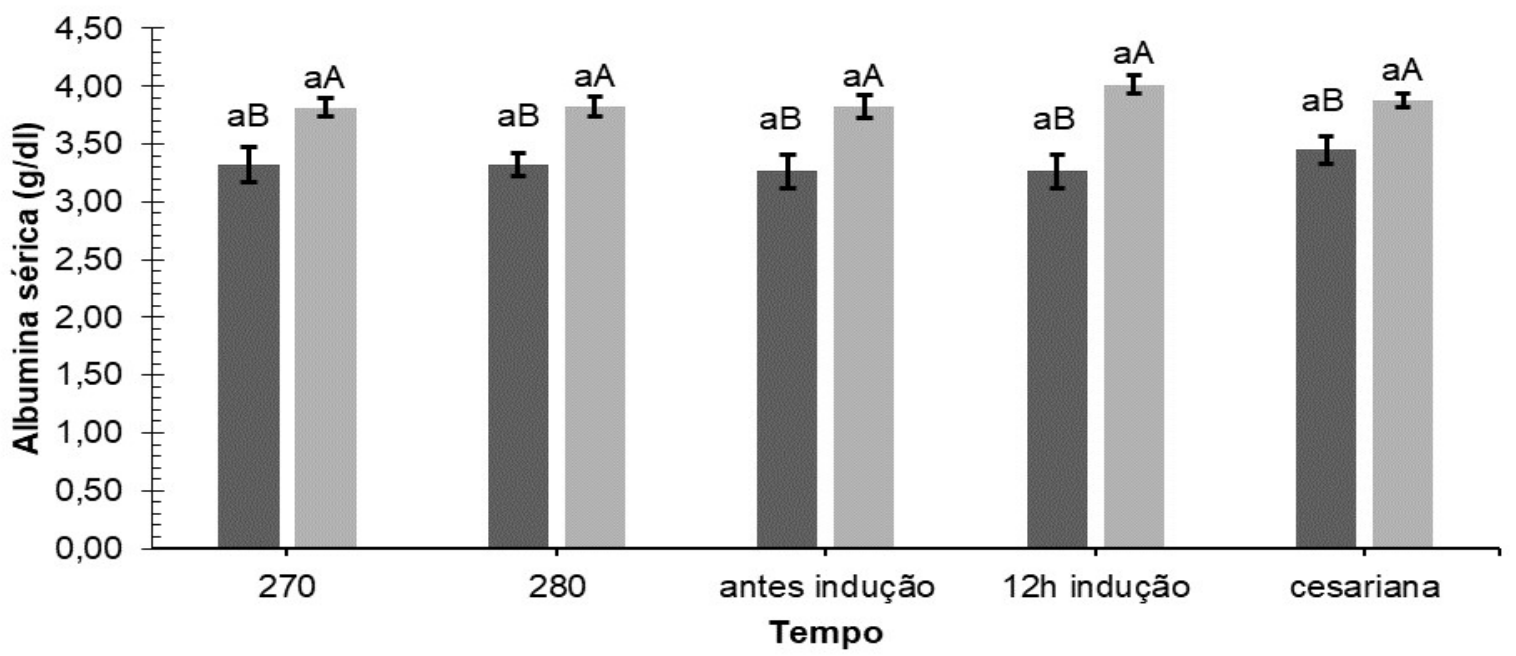

Colunas de mesma cor seguidas com letras minúsculas diferentes, diferiram estatisticamente entre si pelo Teste de Tukey $(P<0,05)$. Colunas de cor diferente dentro de cada tempo seguidas por letras maiúsculas diferentes, diferiram estatisticamente entre si pelo Teste $t$ (Student) $(P<0,05)$

Fonte: Própria autoria. 


\subsubsection{Procedimento experimental 2}

Nas tabelas 16 e 17 e nos gráficos 16 e 17 estão apresentados, respectivamente, os resultados da proteína e albumina sérica dos bezerros oriundos de FIV e por IA (grupo controle). Não houve diferença estatística significativa entre os tratamentos dentro de cada tempo separadamente $(P>0,05)$, houve entre os períodos de avaliação $(P<0,05)$ tanto para proteína como para albumina.

Para a proteína, constatou-se variação de acordo com o tempo dentro de cada grupo, decorrentes do fator etário. Ao nascimento a média foi de $4,54 \mathrm{~g} / \mathrm{dL}$ para os bezerros de FIV e de 4,15 g/dL para os bezerros do grupo controle, sendo as maiores diferenças às 48 horas de vida para o bezerro de FIV $(5,58 \mathrm{~g} / \mathrm{dL})$ e às 24 horas para os bezerros do grupo controle, comportamento semelhante ao observado por Marchese (2014), mas com valores inferiores no presente trabalho.

O aumento dos valores de proteína após a mamada do colostro já está descrito em várias raças (BORGES et al., 2001; LEITE et al., 2017). Foi possível observar neste estudo, significativo aumento dos teores séricos de proteína nas primeiras 24 horas de vida em ambos os grupos, decorrente da absorção intestinal de imunoglobulinas presentes no colostro, assim como relatado por Feitosa et al. (2001) e por Fagliari et al. (2006).

Teores séricos de proteína maiores do que 6,0 g/dL com 24 horas de vida, em animais que não estejam desidratados, considera-se transferência de imunidade passiva bem-sucedida e que valores inferiores a partir de 4,5 g/dL torna-se fatal para os neonatos (FEITOSA et al., 2001). Apesar da colostragem ter sido realizada, mesmo quando foi necessário a utilização de mamadeira e de banco de colostro, ambos os grupos apresentaram valores intermediários (5, 49 e 5,88 g/dL) o que indicaria falha parcial de transferência de imunidade passiva, contrastante aos resultados da GGT.

Para os teores de albumina foi possível observar que, ao nascimento, estavam próximos dos valores de referência para bovinos adultos $(3,0-3,5 \mathrm{~g} / \mathrm{dL})$ relatados por Kaneko, Harvey e Bruss (2008), nos momentos seguintes os teores diminuíram com maior diferença as 24 horas de vida, na sequência voltaram a se elevar até que aos 30 dias de vida ascenderam aos valores de referência supracitado. A análise dos resultados da albumina do presente estudo demonstrou 
comportamento e valores semelhantes ao relatado por Marchese (2014) com diminuição dos teores nas primeiras 24 horas e recuperação até os 30 dias de vida. Estes resultados realçam não haver influência da FIV na concentração sérica de proteína e albumina em bezerros neonatos.

Tabela 16 - Médias, erros padrão, medidas mínimas e máximas para proteína sérica $(\mathrm{g} / \mathrm{dL})$ de bezerros oriundos de FIV e por IA nos primeiros 30 dias de vida obtidos por cesariana com indução do parto

\begin{tabular}{|c|c|c|c|c|c|c|c|c|}
\hline \multirow[b]{2}{*}{ Tempo } & \multicolumn{4}{|c|}{ Bezerros FIV } & \multicolumn{4}{|c|}{ Bezerros IA } \\
\hline & $\mathrm{n}$ & Média & $\begin{array}{c}\text { Erro } \\
\text { Padrão }\end{array}$ & $\begin{array}{l}\text { Min e } \\
\text { Max }\end{array}$ & $n$ & Média & $\begin{array}{c}\text { Erro } \\
\text { Padrão }\end{array}$ & $\begin{array}{c}\text { Min e } \\
\text { Max }\end{array}$ \\
\hline Oh & 7 & 4,45 bA & 0,56 & $\begin{array}{l}3,49 \\
7,74\end{array}$ & 12 & $4,15 \mathrm{cA}$ & 0,07 & $\begin{array}{l}3,59 \\
4,52\end{array}$ \\
\hline $3 h$ & 8 & 4,43 bA & 0,52 & $\begin{array}{l}3,42 \\
7,97\end{array}$ & 12 & $3,84 \mathrm{cA}$ & 0,28 & $\begin{array}{l}0,81 \\
4,28\end{array}$ \\
\hline $6 \mathrm{~h}$ & 8 & $4,80 \mathrm{abA}$ & 0,44 & $\begin{array}{l}3,54 \\
7,72\end{array}$ & 12 & $4,35 \mathrm{cA}$ & 0,18 & $\begin{array}{l}3,71 \\
6,12\end{array}$ \\
\hline $12 \mathrm{~h}$ & 8 & $5,30 \mathrm{abA}$ & 0,31 & $\begin{array}{l}4,15 \\
6,65\end{array}$ & 12 & 5,07 bA & 0,29 & $\begin{array}{l}4,02 \\
7,99\end{array}$ \\
\hline $24 h$ & 8 & $5,49 a b A$ & 0,29 & $\begin{array}{l}4,45 \\
6,97\end{array}$ & 12 & $5,88 \mathrm{aA}$ & 0,29 & $\begin{array}{l}4,17 \\
8,23\end{array}$ \\
\hline $48 \mathrm{~h}$ & 8 & $5,58 \mathrm{aA}$ & 0,28 & $\begin{array}{l}4,52 \\
6,70\end{array}$ & 12 & $5,74 a b A$ & 0,27 & $\begin{array}{l}4,45 \\
8,11\end{array}$ \\
\hline 3 dias & 8 & $5,45 a b A$ & 0,28 & $\begin{array}{l}4,35 \\
6,32\end{array}$ & 12 & $5,66 \mathrm{abA}$ & 0,25 & $\begin{array}{l}4,69 \\
7,88\end{array}$ \\
\hline 5 dias & 8 & $5,14 a b A$ & 0,26 & $\begin{array}{l}4,11 \\
6,08\end{array}$ & 11 & $5,64 \mathrm{abA}$ & 0,25 & $\begin{array}{l}4,33 \\
7,48\end{array}$ \\
\hline 7 dias & 8 & $5,29 a b A$ & 0,31 & $\begin{array}{l}4,14 \\
7,05\end{array}$ & 12 & $5,60 \mathrm{abA}$ & 0,25 & $\begin{array}{l}4,54 \\
7,76\end{array}$ \\
\hline 15 dias & 8 & $5,39 \mathrm{abA}$ & 0,30 & $\begin{array}{l}4,61 \\
7,29\end{array}$ & 12 & $5,34 \mathrm{abA}$ & 0,18 & $\begin{array}{l}4,32 \\
6,87\end{array}$ \\
\hline 30 dias & 8 & $5,18 a b A$ & 0,28 & $\begin{array}{l}4,34 \\
6,99\end{array}$ & 12 & $5,45 a b A$ & 0,14 & $\begin{array}{c}4,8 \\
6,62\end{array}$ \\
\hline
\end{tabular}

Médias seguidas por letras minúsculas diferentes na mesma coluna diferiram estatisticamente entre si pelo Teste de Tukey $(P<0,05)$. Médias seguidas por letras maiúsculas diferentes na mesma linha diferiram estatisticamente entre si pelo Teste $t$ (Student) $(P<0,05)$

Fonte: Própria autoria. 
Tabela 17 - Médias, erros padrão, medidas mínimas e máximas para albumina sérica $(\mathrm{g} / \mathrm{dL})$ de bezerros oriundos de FIV e por IA nos primeiros 30 dias de vida obtidos por cesariana com indução do parto

\begin{tabular}{|c|c|c|c|c|c|c|c|c|}
\hline \multirow[b]{2}{*}{ Tempo } & \multicolumn{4}{|c|}{ Bezerros FIV } & \multicolumn{4}{|c|}{ Bezerros IA } \\
\hline & $\mathrm{n}$ & Média & $\begin{array}{l}\text { Erro } \\
\text { Padrão }\end{array}$ & $\begin{array}{l}\operatorname{Min} e \\
\operatorname{Max}\end{array}$ & $\mathrm{n}$ & Média & $\begin{array}{l}\text { Erro } \\
\text { Padrão }\end{array}$ & $\begin{array}{l}\text { Mine } \\
\text { Max }\end{array}$ \\
\hline $\mathrm{Oh}$ & 7 & $3,01 \mathrm{abA}$ & 0,12 & $\begin{array}{l}2,50 \\
3,40\end{array}$ & 12 & $2,94 \mathrm{bA}$ & 0,05 & $\begin{array}{l}2,60 \\
3,20\end{array}$ \\
\hline $3 \mathrm{~h}$ & 8 & $2,96 \mathrm{abcd} A$ & 0,09 & $\begin{array}{l}2,50 \\
3,30\end{array}$ & 12 & $2,93 \mathrm{bcA}$ & 0,04 & $\begin{array}{l}2,70 \\
3,10\end{array}$ \\
\hline $6 \mathrm{~h}$ & 8 & 2,88 abcdeA & 0,08 & $\begin{array}{l}2,60 \\
3,20\end{array}$ & 12 & $2,88 \mathrm{bcdA}$ & 0,04 & $\begin{array}{l}2,60 \\
3,10\end{array}$ \\
\hline $12 \mathrm{~h}$ & 8 & 2,59 efA & 0,08 & $\begin{array}{l}2,20 \\
3,00\end{array}$ & 12 & $2,78 \operatorname{cdef} A$ & 0,06 & $\begin{array}{l}2,50 \\
3,10\end{array}$ \\
\hline $24 \mathrm{~h}$ & 8 & $2,49 \mathrm{fA}$ & 0,07 & $\begin{array}{l}2,10 \\
2,80\end{array}$ & 12 & $2,65 \mathrm{fA}$ & 0,05 & $\begin{array}{l}2,40 \\
2,90\end{array}$ \\
\hline $48 \mathrm{~h}$ & 8 & 2,64 defA & 0,07 & $\begin{array}{l}2,40 \\
2,90\end{array}$ & 12 & 2,70 efA & 0,04 & $\begin{array}{l}2,40 \\
2,90\end{array}$ \\
\hline 3 dias & 8 & 2,70 cdefA & 0,07 & $\begin{array}{l}2,40 \\
3,00\end{array}$ & 12 & $2,74 \operatorname{def} A$ & 0,05 & $\begin{array}{l}2,50 \\
3,00\end{array}$ \\
\hline 5 dias & 8 & 2,70 bcdefA & 0,08 & $\begin{array}{l}2,40 \\
3,00\end{array}$ & 11 & 2,80 bcdef $A$ & 0,05 & $\begin{array}{l}2,60 \\
3,10\end{array}$ \\
\hline 7 dias & 8 & 2,81 bcdefA & 0,13 & $\begin{array}{l}2,20 \\
3,40\end{array}$ & 12 & $2,83 \mathrm{bcde} A$ & 0,04 & $\begin{array}{l}2,50 \\
3,00\end{array}$ \\
\hline 15 dias & 8 & $3,01 \mathrm{abcA}$ & 0,10 & $\begin{array}{l}2,70 \\
3,50\end{array}$ & 12 & $2,93 \mathrm{bcA}$ & 0,03 & $\begin{array}{l}2,80 \\
3,10\end{array}$ \\
\hline 30 dias & 8 & $3,18 \mathrm{aA}$ & 0,09 & $\begin{array}{l}2,90 \\
3,50\end{array}$ & 12 & $3,16 \mathrm{aA}$ & 0,05 & $\begin{array}{l}2,90 \\
3,50\end{array}$ \\
\hline
\end{tabular}

Médias seguidas por letras minúsculas diferentes na mesma coluna diferiram estatisticamente entre si pelo Teste de Tukey $(P<0,05)$. Médias seguidas por letras maiúsculas diferentes na mesma linha diferiram estatisticamente entre si pelo Teste $t$ (Student) $(P<0,05)$

Fonte: Própria autoria. 
Gráfico 16 - Médias com erros padrão para proteína sérica de bezerros oriundos de FIV e por IA nos primeiros 30 dias de vida obtidos por cesariana com indução do parto - Pirassununga - 2018
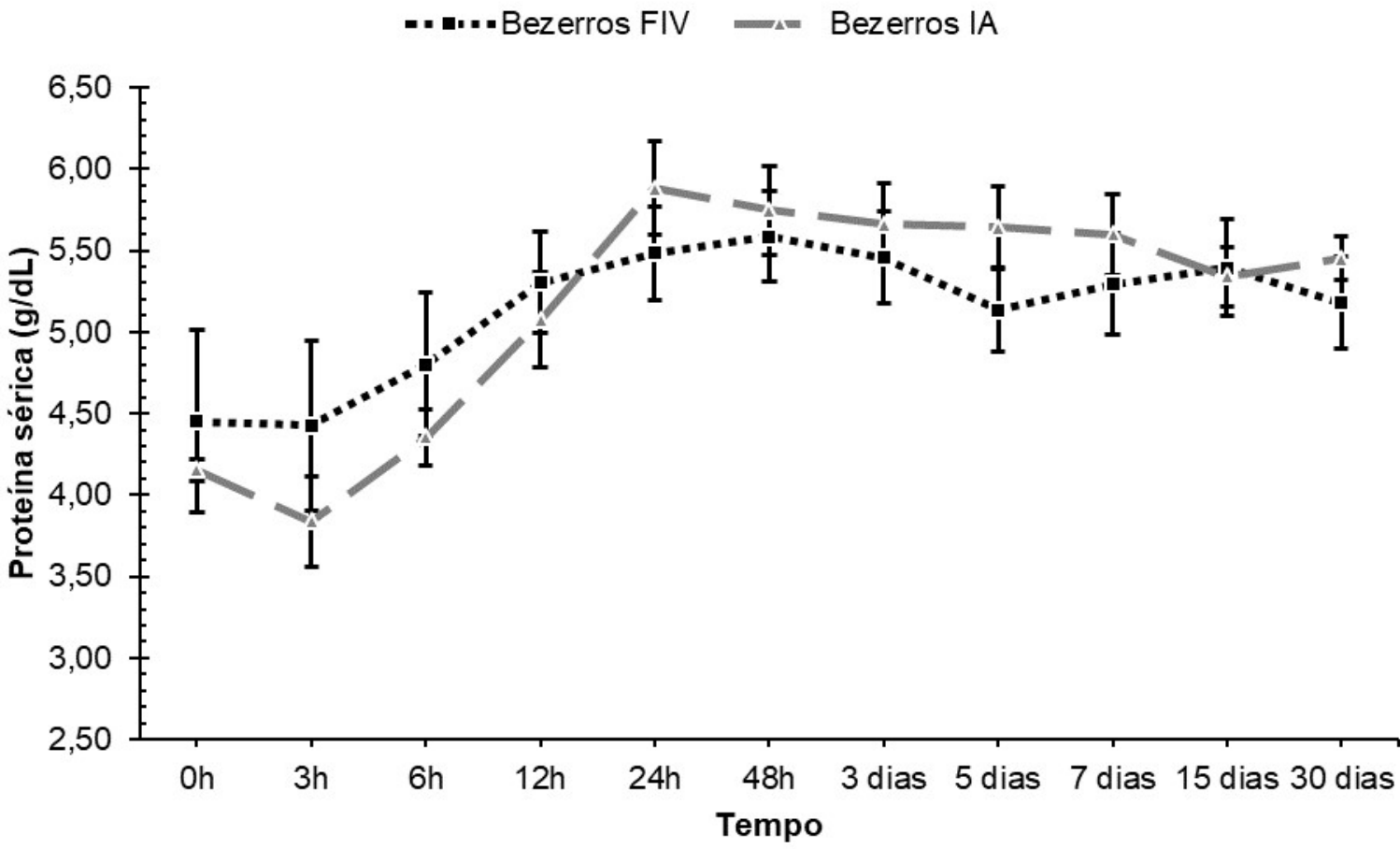

Fonte: Própria autoria.

Gráfico 17 - Médias com erros padrão para albumina sérica de bezerros oriundos de FIV e por IA nos primeiros 30 dias de vida obtidos por cesariana com indução do parto - Pirassununga - 2018

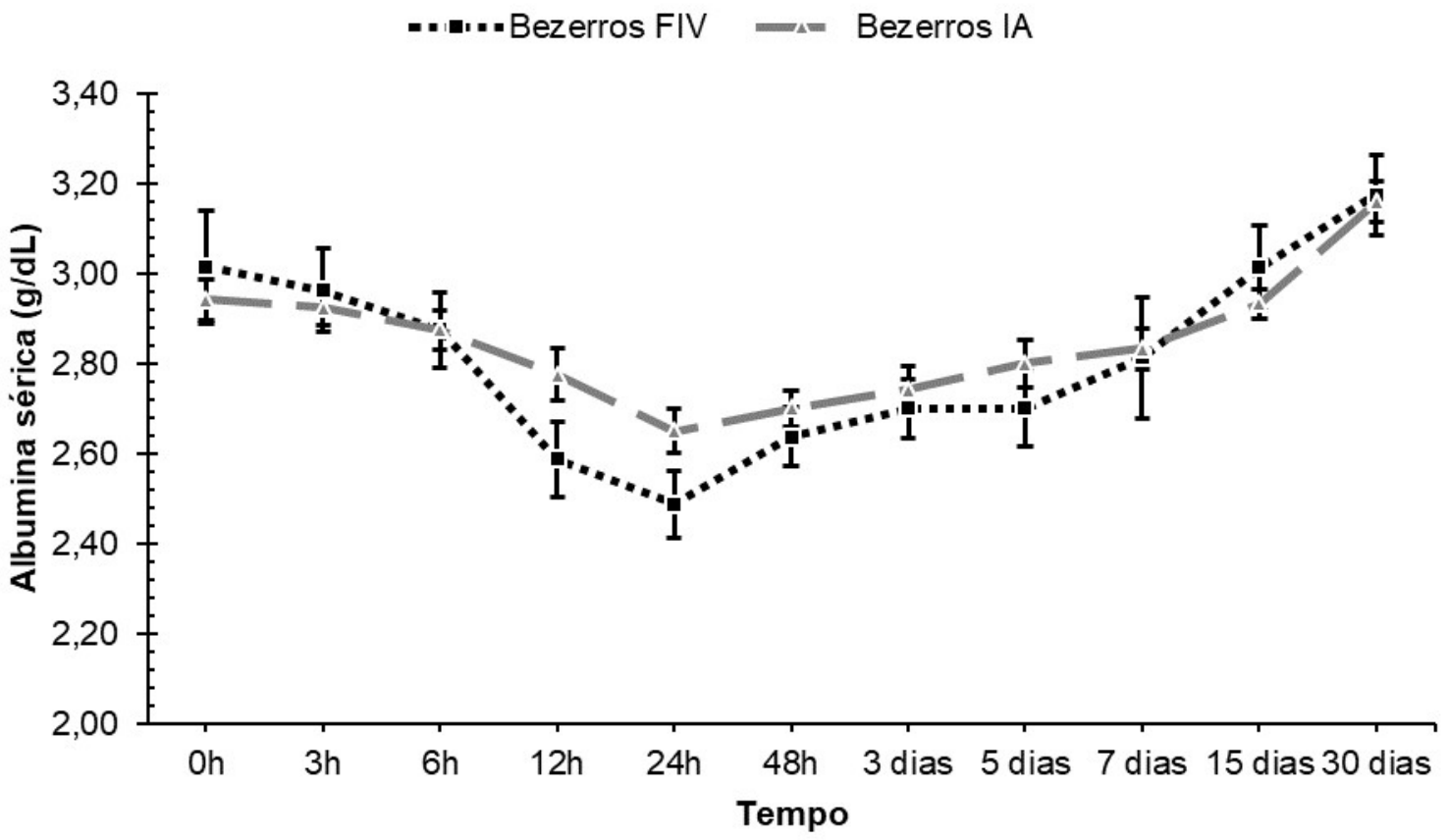

Fonte: Própria autoria 


\subsubsection{Procedimento experimental 3}

Nas tabelas 18 e 19 e nos gráficos 18 e 19 estão apresentados, respectivamente, os resultados da proteína e albumina sérica de vacas receptoras de embriões por FIV da raça Nelore com bezerros apresentando peso ao nascimento elevado (síndrome do bezerro gigante), vacas receptoras de embriões por FIV da raça Nelore com bezerros apresentando peso dentro do padrão da raça ao nascimento e vacas gestantes de bezerros da raça Nelore por IA (grupo controle). Não houve diferença estatística significativa entre os tratamentos dentro de cada tempo separadamente para proteína $(P>0,05)$, houve entre os períodos de avaliação para a vaca do grupo controle $(P<0,05)$. Não houve diferença estatística significativa entre os tratamentos dentro de cada tempo separadamente para albumina $(P>0,05)$, nem entre os períodos de avaliação dentro de cada tratamento $(P>0,05)$.

As médias de proteína de ambos os grupos estavam próximos dos valores de referência para bovinos adultos $(6,7-7,5 \mathrm{~g} / \mathrm{dL})$ relatados por Kaneko, Harvey e Bruss (2008), e inferiores aos observados para novilhas gestantes por Abud et al. (2016), e em vacas Nelore por Oliveira (2015). Observou-se, apenas no grupo controle, diferença estatística entre o momento 288 dias de gestação $(6,6 \mathrm{~g} / \mathrm{dL})$ e até 6 horas após o parto $(6,8 \mathrm{~g} / \mathrm{dL})$.

Já para albumina, constatou-se que as médias dos grupos estavam próximos dos valores de referência para bovinos adultos $(3,0-3,5 \mathrm{~g} / \mathrm{dL})$ relatados por Kaneko, Harvey e Bruss (2008), assim como aos observados por Abud et al. (2016) para novilhas gestantes da raça Nelore e por Oliveira (2015) em vacas Nelore.

Assim como no procedimento experimental 1, os animais deste experimento não apresentavam indícios de lesão hepática e também estavam sob as mesmas condições de dieta. Apesar da variação dos valores, todos encontravam-se próximos aos valores de referência, sem que houvesse diferenças entre os grupos para os teores de proteína e albumina sérica. Corroborando os valores da GGT, não houve indícios de efeito da gestação por FIV, mesmo quando o bezerro apresentou síndrome do bezerro gigante, sobre as concentrações séricas de proteína e albumina no final da gestação. 
Tabela 18 - Médias, erros padrão, medidas mínimas e máximas para proteína sérica $(\mathrm{g} / \mathrm{dL})$ de vacas gestantes por FIV e por IA no final da gestação e até $6 \mathrm{~h}$ após o parto natural

\begin{tabular}{|c|c|c|c|c|c|c|c|c|}
\hline \multirow[b]{2}{*}{ Tratamento } & \multicolumn{4}{|c|}{288 dias } & \multicolumn{4}{|c|}{ Até 6h após o parto } \\
\hline & $\mathrm{n}$ & Média & $\begin{array}{c}\text { Erro } \\
\text { Padrão }\end{array}$ & $\begin{array}{l}\operatorname{Min} \mathrm{e} \\
\operatorname{Max}\end{array}$ & $\mathrm{n}$ & Média & $\begin{array}{l}\text { Erro } \\
\text { Padrão }\end{array}$ & $\begin{array}{l}\operatorname{Min} e \\
\operatorname{Max}\end{array}$ \\
\hline Receptoras & & & & 6,1 & & & & 5,4 \\
\hline $\begin{array}{l}\text { FIV bez } \\
\text { peso } \\
\text { elevado }\end{array}$ & 17 & $6,7 \mathrm{aA}$ & 0,1 & 7,5 & 17 & 6,6 aA & 0,2 & 7,7 \\
\hline Receptoras & & & & 5,7 & & & & 4,5 \\
\hline $\begin{array}{l}\text { FIV bez } \\
\text { peso } \\
\text { padrão }\end{array}$ & 30 & $6,7 \mathrm{aA}$ & 0,1 & 8,5 & 32 & $6,8 \mathrm{aA}$ & 0,1 & 8,5 \\
\hline $\begin{array}{l}\text { Vacas IA } \\
\text { (controle) }\end{array}$ & 15 & $6,6 \mathrm{aB}$ & 0,2 & $\begin{array}{l}5,6 \\
7,8\end{array}$ & 16 & $6,8 \mathrm{aA}$ & 0,1 & $\begin{array}{l}6,0 \\
8,1\end{array}$ \\
\hline
\end{tabular}

Médias seguidas por letras minúsculas diferentes na mesma coluna diferiram estatisticamente entre si pelo Teste de Tukey $(P<0,05)$. Médias seguidas por letras maiúsculas diferentes na mesma linha diferiram estatisticamente entre si pelo Teste t pareado $(P<0,05)$

Fonte: Própria autoria.

Gráfico 18 - Médias com erros padrão para proteína sérica de vacas receptoras de FIV de bezerros com peso elevado após o nascimento, receptoras de FIV com bezerros de peso padrão após o nascimento e vacas gestantes por IA, no final da gestação e até 6h após o parto natural a termo - Pirassununga - 2018

$\square$ Receptoras FIV bez peso elevado $\square$ Receptoras FIV bez peso padrão $\square$ Vacas IA (controle)

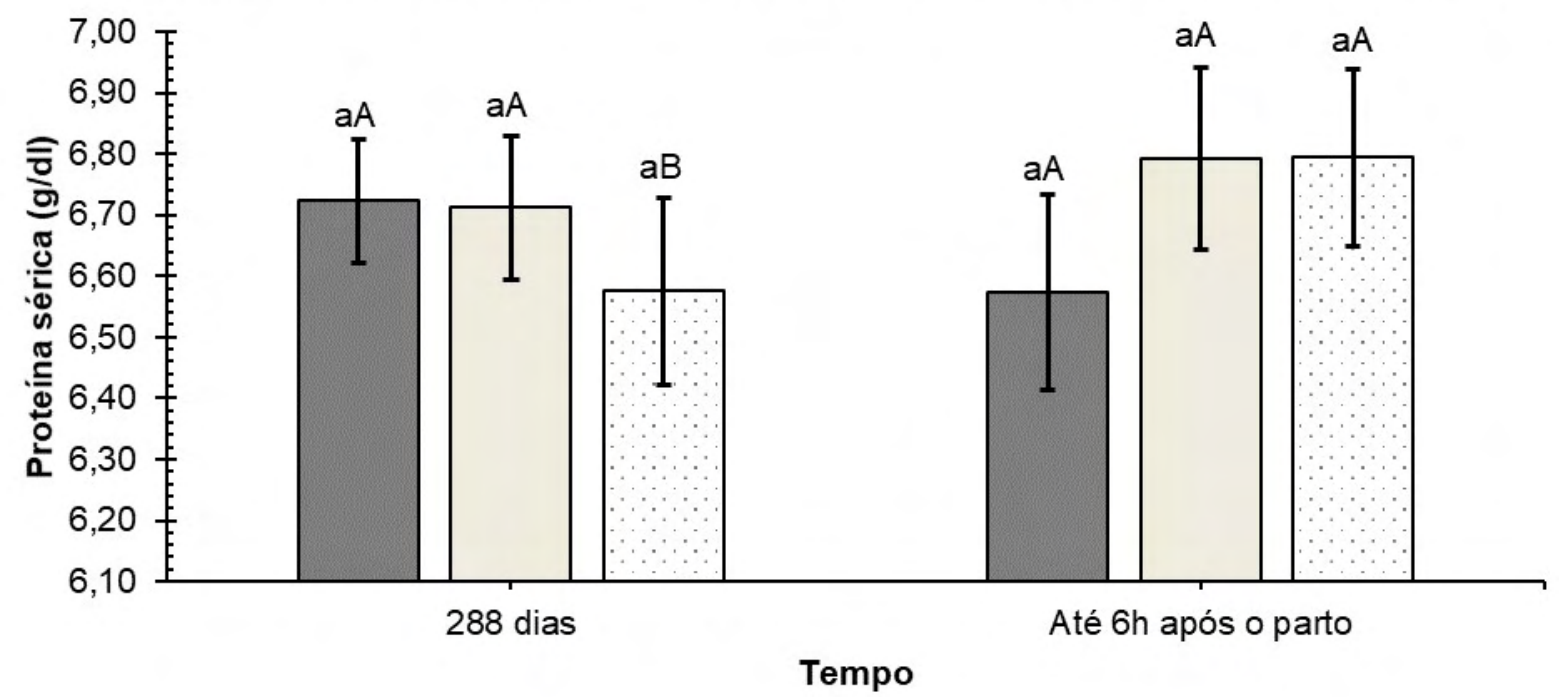

Colunas de cores diferentes seguidas com letras minúsculas diferentes, no mesmo tempo, diferiram estatisticamente entre si pelo Teste de Tukey $(P<0,05)$. Colunas de mesma cor seguidas por letras maiúsculas diferentes, diferiram estatisticamente entre si pelo Teste t pareado $(P<0,05)$

Fonte: Própria autoria. 
Tabela 19 - Médias, erros padrão, medidas mínimas e máximas para albumina sérica $(\mathrm{g} / \mathrm{dL})$ de vacas gestantes por FIV e por IA no final da gestação e até $6 \mathrm{~h}$ após o parto natural

\begin{tabular}{|c|c|c|c|c|c|c|c|c|}
\hline \multirow[b]{2}{*}{ Tratamento } & \multicolumn{4}{|c|}{288 dias } & \multicolumn{4}{|c|}{ Até $6 \mathrm{~h}$ após o parto } \\
\hline & $\mathrm{n}$ & Média & $\begin{array}{c}\text { Erro } \\
\text { Padrão }\end{array}$ & $\begin{array}{l}\text { Min e } \\
\text { Max }\end{array}$ & $\mathrm{n}$ & Média & $\begin{array}{c}\text { Erro } \\
\text { Padrão }\end{array}$ & $\begin{array}{l}\text { Min e } \\
\text { Max }\end{array}$ \\
\hline \multirow{2}{*}{$\begin{array}{l}\text { Receptoras } \\
\text { FIV bez peso } \\
\text { elevado }\end{array}$} & \multirow[b]{2}{*}{17} & \multirow[b]{2}{*}{3,4 aA } & \multirow[b]{2}{*}{0,1} & 2,9 & \multirow[b]{2}{*}{17} & \multirow[b]{2}{*}{$3,4 \mathrm{aA}$} & \multirow[b]{2}{*}{0,1} & 2,8 \\
\hline & & & & 4,3 & & & & 4,3 \\
\hline \multirow{2}{*}{$\begin{array}{l}\text { Receptoras } \\
\text { FIV bez peso } \\
\text { padrão }\end{array}$} & \multirow{2}{*}{31} & \multirow{2}{*}{$3,4 \mathrm{aA}$} & \multirow{2}{*}{0,1} & 1,6 & \multirow[b]{2}{*}{32} & \multirow{2}{*}{$3,4 \mathrm{aA}$} & \multirow[b]{2}{*}{0,1} & 2,5 \\
\hline & & & & 4,2 & & & & 4,1 \\
\hline \multirow{2}{*}{$\begin{array}{l}\text { Vacas IA } \\
\text { (controle) }\end{array}$} & \multirow{2}{*}{15} & \multirow{2}{*}{3,5 aA } & \multirow{2}{*}{0,1} & 3,0 & \multirow{2}{*}{16} & \multirow{2}{*}{$3,6 \mathrm{aA}$} & \multirow{2}{*}{0,1} & 3,0 \\
\hline & & & & 4,2 & & & & 4,2 \\
\hline
\end{tabular}

Médias seguidas por letras minúsculas diferentes na mesma coluna diferiram estatisticamente entre si pelo Teste de Tukey $(P<0,05)$. Médias seguidas por letras maiúsculas diferentes na mesma linha diferiram estatisticamente entre si pelo Teste t pareado $(P<0,05)$

Fonte: Própria autoria.

Gráfico 19 - Médias com erros padrão para albumina sérica de vacas receptoras de FIV de bezerros com peso elevado após o nascimento, receptoras de FIV com bezerros de peso padrão após o nascimento e vacas gestantes por IA, no final da gestação e até 6h após o parto natural a termo - Pirassununga - 2018

口Receptoras FIV bez peso elevado $\mathrm{QReceptoras} \mathrm{FIV} \mathrm{bez} \mathrm{peso} \mathrm{padrão}$

$\square$ Vacas IA (controle)

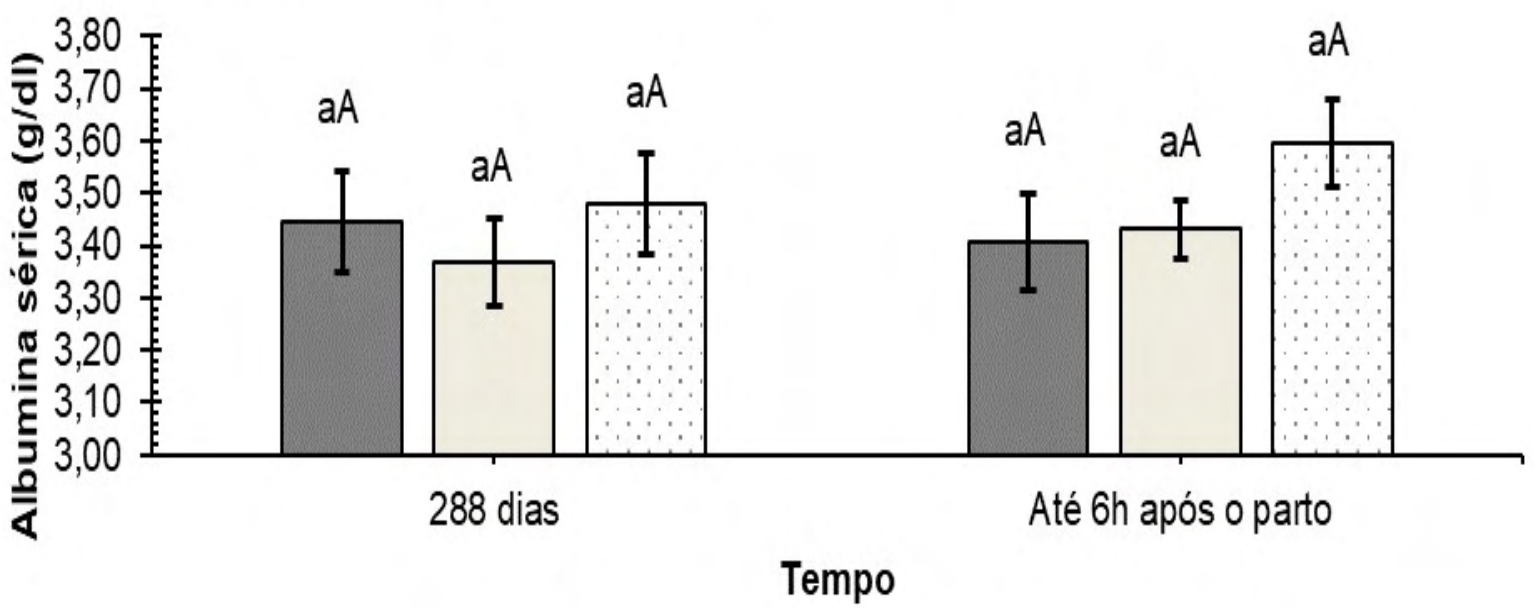

Colunas de cores diferentes seguidas com letras minúsculas diferentes, no mesmo tempo, diferiram estatisticamente entre si pelo Teste de Tukey $(P<0,05)$. Colunas de mesma cor seguidas por letras maiúsculas diferentes, diferiram estatisticamente entre si pelo Teste t pareado $(P<0,05)$

Fonte: Própria autoria. 


\subsubsection{Procedimento experimental 4}

Nas tabelas 20 e 21 e nos gráficos 20 e 21 estão apresentados, respectivamente, os resultados da proteína e albumina sérica dos bezerros oriundos de FIV com peso elevado ao nascimento (síndrome do bezerro gigante), bezerros oriundos de FIV com peso ao nascimento dentro do padrão da raça e por IA (grupo controle). Não houve diferença estatística significativa entre os tratamentos dentro de cada tempo separadamente para proteína $(P>0,05)$, houve entre os períodos de avaliação dentro de cada tratamento $(P<0,05)$. Também não houve diferença estatística significativa entre os tratamentos dentro de cada tempo separadamente para albumina $(P>0,05)$, houve entre os períodos de avaliação dentro para os bezerros com peso ao nascimento dentro do padrão da raça $(P<0,05)$.

Para proteína constatou-se variação de acordo com o fator etário relatados por Feitosa et al. (2001) e por Fagliari et al. (2006). Neste trabalho, no momento até 6 horas de vida a média foi significativamente inferior ao momento entre 24 e 36 horas, comportamento semelhante ao observado por Marchese (2014) e Gasparelli (2007). Sendo constatado a capacidade absortiva dos bezerros de FIV, mesmo quando apresentaram síndrome do bezerro gigante, corroborando os valores de GGT para transferência de imunidade passiva,

Foi possível observar que os teores de albumina do presente trabalho estavam abaixo dos valores de referência para bovinos adultos $(3,0-3,5 \mathrm{~g} / \mathrm{dL})$ relatados por Kaneko, Harvey e Bruss (2008) em ambos os tempos, e semelhante ao observado por Borges et al. (2001) e Schütz (2012). As médias da albumina, no grupo dos bezerros de FIV com peso ao nascimento dentro de padrão da raça demonstrou diferença nos tempos avaliados, com o teor sérico estatisticamente superior no momento até 6 horas de vida.

Neste experimento, devido a rotina da propriedade, foram acompanhados bezerros logo após o nascimento antes de ingerir o colostro e os nascidos entre 2 e 6 horas que já haviam mamado o colostro, seja por mamadeira ou diretamente do teto da vaca. Dessa forma, foi possível observar que os teores séricos de proteína no momento até 6 horas de vida, apenas o grupo dos bezerros FIV com peso elevado ao nascimento estavam abaixo de 6,0 g/dL e que entre 24 e 36 horas de vida todos os grupos superaram este valor, a partir do qual é considerado como 
transferência de imunidade passiva bem-sucedida, demonstrado por Feitosa et al. (2001).

Tabela 20 - Médias, erros padrão, medidas mínimas e máximas para proteína sérica $(\mathrm{g} / \mathrm{dL})$ de bezerros oriundos de FIV e por IA nas primeiras 36 horas devida obtidos por parto natural

\begin{tabular}{|c|c|c|c|c|c|c|c|c|}
\hline \multirow[b]{2}{*}{ Tratamento } & \multicolumn{4}{|c|}{ Até $6 \mathrm{~h}$ de vida } & \multicolumn{4}{|c|}{ Entre $24 \mathrm{~h}$ e $36 \mathrm{~h}$ de vida } \\
\hline & $\mathrm{n}$ & Média & $\begin{array}{c}\text { Erro } \\
\text { Padrão }\end{array}$ & $\begin{array}{l}\text { Min e } \\
\text { Max }\end{array}$ & $n$ & Média & $\begin{array}{c}\text { Erro } \\
\text { Padrão }\end{array}$ & $\begin{array}{l}\text { Min e } \\
\text { Max }\end{array}$ \\
\hline Bezerros & & & & 3,77 & & & & 4,15 \\
\hline $\begin{array}{l}\text { FIV peso } \\
\text { elevado }\end{array}$ & 16 & $5,55 \mathrm{aB}$ & 0,37 & 9,13 & 17 & 6,56 aA & 0,33 & 8,99 \\
\hline Bezerros & & & & 2,32 & & & & 4,81 \\
\hline $\begin{array}{l}\text { FIV peso } \\
\text { padrão }\end{array}$ & 31 & $6,13 \mathrm{aB}$ & 0,30 & 9,08 & 31 & 6,89 aA & 0,22 & 9,30 \\
\hline $\begin{array}{l}\text { Bezerros IA } \\
\text { (controle) }\end{array}$ & 27 & $6,24 \mathrm{aB}$ & 0,26 & $\begin{array}{l}3,90 \\
8,73\end{array}$ & 27 & $6,50 \mathrm{aA}$ & 0,21 & $\begin{array}{l}4,82 \\
8,69\end{array}$ \\
\hline
\end{tabular}

Médias seguidas por letras minúsculas diferentes na mesma coluna diferiram estatisticamente entre si pelo Teste de Tukey $(P<0,05)$. Médias seguidas por letras maiúsculas diferentes na mesma linha diferiram estatisticamente entre si pelo Teste t pareado $(P<0,05)$

Fonte: Própria autoria.

Gráfico 20 - Médias com erros padrão para proteína sérica de bezerros oriundos de FIV e por IA nas primeiras 36 horas devida obtidos por parto natural - Pirassununga $-2018$

口Bezerros FIV peso elevado aBezerros FIV peso padrão aBezerros IA (controle)

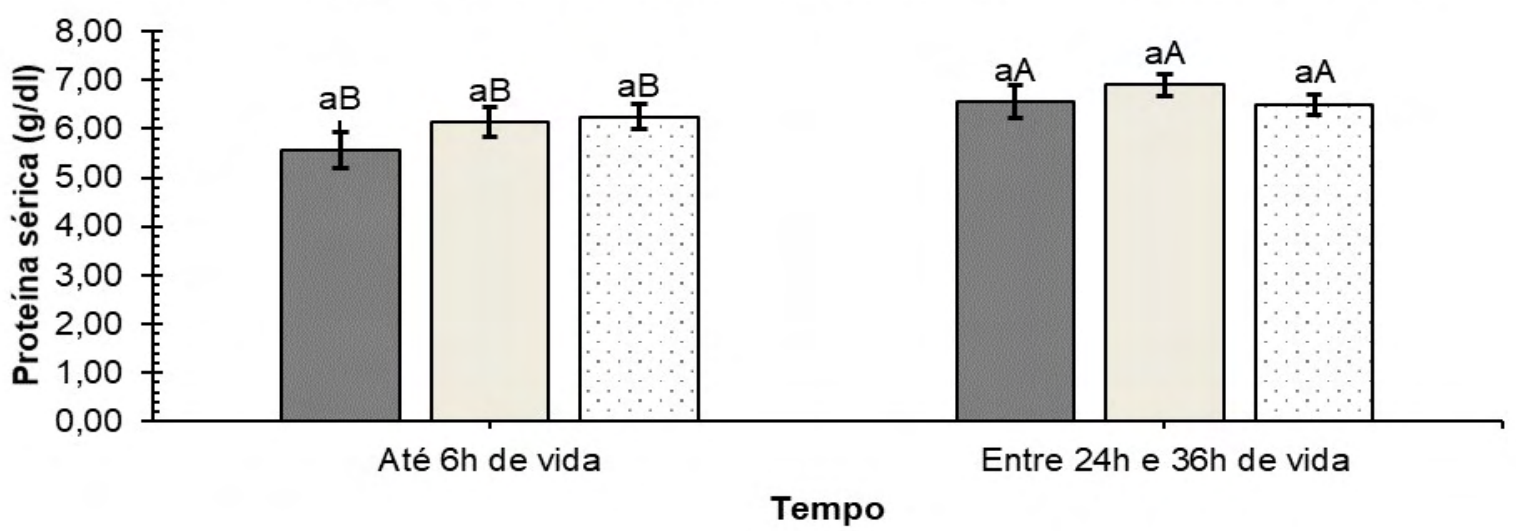

Colunas de cores diferentes seguidas com letras minúsculas diferentes, no mesmo tempo, diferiram estatisticamente entre si pelo Teste de Tukey $(P<0,05)$. Colunas de mesma cor seguidas por letras maiúsculas diferentes, diferiram estatisticamente entre si pelo Teste t pareado $(P<0,05)$

Fonte: Própria autoria.

A análise dos resultados da albumina do presente estudo revelou comportamento e valores condizentes ao relatado por Marchese (2014), 
considerando os momentos 6 e 48 horas de vida para o grupo controle de sua pesquisa. Estes resultados, em concordância com o procedimento experimental 1, destaca não haver influência da FIV, mesmo quando os bezerros apresentam síndrome do bezerro gigante, na concentração sérica de proteína e albumina em bezerros neonatos.

Tabela 21 - Médias, erros padrão, medidas mínimas e máximas para albumina sérica $(\mathrm{g} / \mathrm{dL})$ de bezerros oriundos de FIV e por IA nas primeiras 36 horas devida obtidos por parto natural

\begin{tabular}{|c|c|c|c|c|c|c|c|c|}
\hline \multirow[b]{2}{*}{ Tratamento } & \multicolumn{4}{|c|}{ Até $6 \mathrm{~h}$ de vida } & \multicolumn{4}{|c|}{ Entre $24 \mathrm{~h}$ e $36 \mathrm{~h}$ de vida } \\
\hline & $\mathrm{n}$ & Média & $\begin{array}{c}\text { Erro } \\
\text { Padrão }\end{array}$ & $\begin{array}{l}\text { Min e } \\
\text { Max }\end{array}$ & $\mathrm{n}$ & Média & $\begin{array}{c}\text { Erro } \\
\text { Padrão }\end{array}$ & $\begin{array}{l}\text { Min e } \\
\text { Max }\end{array}$ \\
\hline Bezerros & & & & 2,10 & & & & 2,10 \\
\hline $\begin{array}{l}\text { FIV peso } \\
\text { elevado }\end{array}$ & 16 & 2,79 aA & 0,08 & 3,20 & 17 & 2,70 aA & 0,08 & 3,10 \\
\hline Bezerros & & & & 2,20 & & & & 2,00 \\
\hline $\begin{array}{l}\text { FIV peso } \\
\text { padrão }\end{array}$ & 31 & $2,80 \mathrm{aA}$ & 0,07 & 3,80 & 31 & $2,64 \mathrm{aB}$ & 0,06 & 3,30 \\
\hline $\begin{array}{l}\text { Bezerros IA } \\
\text { (controle) }\end{array}$ & 27 & $2,73 \mathrm{aA}$ & 0,07 & $\begin{array}{l}2,20 \\
3,50\end{array}$ & 27 & $2,74 \mathrm{aA}$ & 0,07 & $\begin{array}{l}2,10 \\
3,40\end{array}$ \\
\hline
\end{tabular}

Médias seguidas por letras minúsculas diferentes na mesma coluna diferiram estatisticamente entre si pelo Teste de Tukey $(P<0,05)$. Médias seguidas por letras maiúsculas diferentes na mesma linha diferiram estatisticamente entre si pelo Teste t pareado $(P<0,05)$

Fonte: Própria autoria.

Gráfico 21 - Médias com erros padrão para albumina sérica de bezerros oriundos de FIV e por IA nas primeiras 36 horas devida obtidos por parto natural - Pirassununga $-2018$

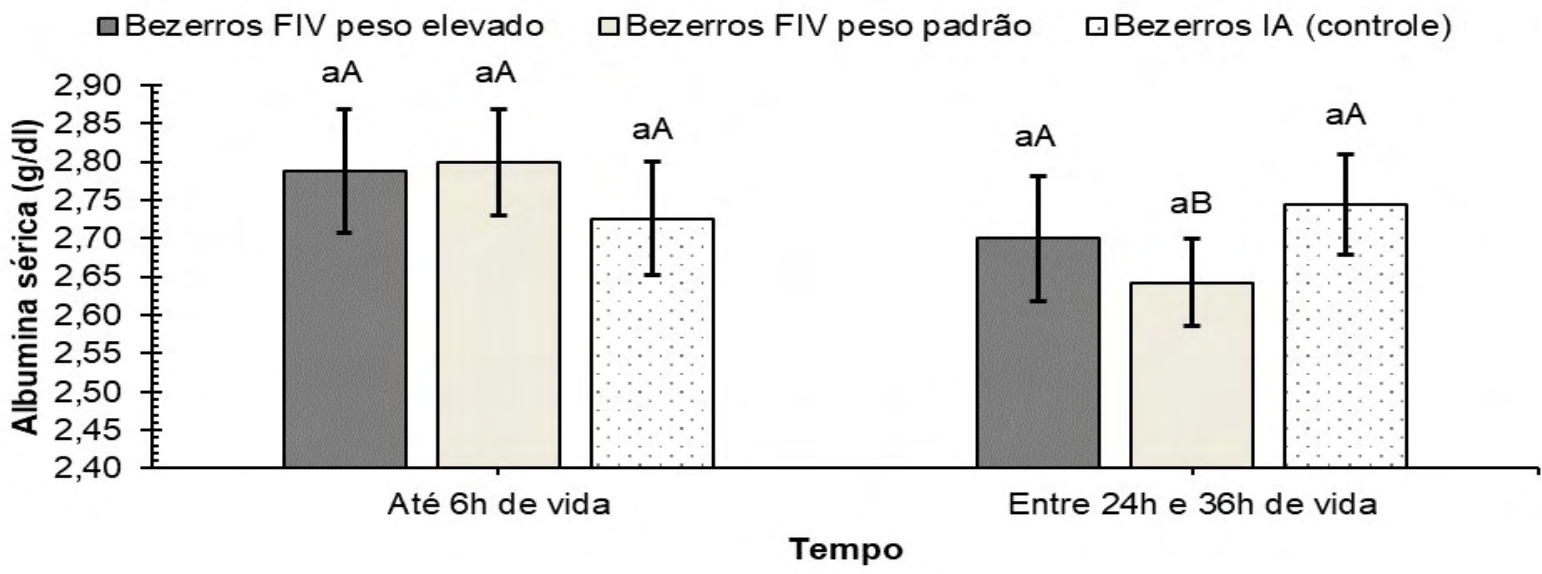

Colunas de cores diferentes seguidas com letras minúsculas diferentes, no mesmo tempo, diferiram estatisticamente entre si pelo Teste de Tukey $(P<0,05)$. Colunas de mesma cor seguidas por letras maiúsculas diferentes, diferiram estatisticamente entre si pelo Teste t pareado $(P<0,05)$

Fonte: Própria autoria. 


\subsection{FUNÇÃO DO METABOLISMO ENERGÉTICO}

Para facilitar o entendimento durante a apresentação dos resultados e discussão as determinações bioquímicas de colesterol, triglicérides, glicose, lactato, $\beta$-hidroxibutirato e NEFA para avaliação da função do metabolismo energético das vacas e colesterol, triglicérides, glicose, lactato, $\beta$-hidroxibutirato, NEFA, insulina, e frutosamina para avaliação da função do metabolismo energético dos bezerros foram divididos para cada procedimento experimental.

\subsubsection{Procedimento experimental 1}

Na tabela 22 e no gráfico 22 está representado os resultados do colesterol sérico de vacas receptoras de embriões por FIV da raça Nelore e vacas gestantes de bezerros da raça Nelore por IA (grupo controle). Houve diferença estatística significativa entre os tratamentos nos momentos 270 e 280 dias de gestação, separadamente $(P<0,05)$, houve também entre os períodos de avaliação para o grupo controle $(P<0,05)$. Nos tempos 270 e 280 dias de gestação os teores foram superiores para o grupo controle. As médias do colesterol do grupo das receptoras de FIV permaneceram próximos dos valores de referência para bovinos adultos (80 - $120 \mathrm{mg} / \mathrm{dL}$ ) relatados por Kaneko, Harvey e Bruss (2008) e inferiores aos observados para novilhas gestantes por Abud et al. (2016), e em vacas Nelore por Oliveira (2015).

O colesterol é sintetizado, principalmente no fígado e baixos teores séricos podem estar associados a hepatopatias (THRALL et al., 2015), o que não foi constatado no presente trabalho. Outro fator de alteração nos valores séricos remete-se ao balanço energético negativo (BEN), nesta condição os níveis de colesterol diminuem (GONZÁLEZ et al., 2000), como observado nas vacas do grupo controle deste trabalho, apesar de permanecerem em níveis séricos acima dos valores de referência supracitado. Estes resultados indicam que o balanço energético das vacas e receptoras não se encontravam em desequilíbrio no final da gestação, que pudesse levar a diminuição sérica do colesterol, também não foi observado efeito da gestação por FIV sobre o metabolismo do colesterol. 
Tabela 22 - Médias, erros padrão, medidas mínimas e máximas para colesterol sérico $(\mathrm{mg} / \mathrm{dL})$ de vacas gestantes por FIV e por IA no final da gestação, período de indução e antes de serem submetidas a cesariana

\begin{tabular}{|c|c|c|c|c|c|c|c|c|}
\hline \multirow[b]{2}{*}{ Tempo } & \multicolumn{4}{|c|}{ Receptoras FIV } & \multicolumn{4}{|c|}{ Vacas IA } \\
\hline & $\mathrm{n}$ & Média & $\begin{array}{c}\text { Erro } \\
\text { Padrão }\end{array}$ & $\begin{array}{l}\operatorname{Min} e \\
\operatorname{Max}\end{array}$ & $\mathrm{n}$ & Média & Erro Padrão & $\begin{array}{l}\text { Mine } \\
\text { Max }\end{array}$ \\
\hline 270 & 8 & $97,4 \mathrm{aB}$ & 6,9 & $\begin{array}{c}62,9 \\
116,7\end{array}$ & 8 & $166,6 \mathrm{aA}$ & 17,1 & $\begin{array}{l}74,7 \\
215,3\end{array}$ \\
\hline 280 & 8 & $95,0 \mathrm{aB}$ & 4,3 & $\begin{array}{c}78,7 \\
120,2\end{array}$ & 8 & $130,3 \mathrm{abA}$ & 13,7 & $\begin{array}{c}69,4 \\
180,5\end{array}$ \\
\hline $\begin{array}{c}\text { antes } \\
\text { indução }\end{array}$ & 8 & 85,3 aA & 10,8 & $\begin{array}{c}15,2 \\
111,9\end{array}$ & 8 & $88,3 \mathrm{cA}$ & 14,4 & $\begin{array}{l}23,6 \\
158,1\end{array}$ \\
\hline $\begin{array}{c}12 \mathrm{~h} \\
\text { indução }\end{array}$ & 8 & $82,0 \mathrm{aA}$ & 9,7 & $\begin{array}{c}18,3 \\
104,1\end{array}$ & 6 & $115,7 \mathrm{bcA}$ & 16,3 & $\begin{array}{c}54,8 \\
172,5\end{array}$ \\
\hline cesariana & 8 & $89,1 \mathrm{aA}$ & 5,2 & $\begin{array}{c}64,2 \\
111,3 \\
\end{array}$ & 11 & $98,2 \mathrm{bcA}$ & 10,3 & $\begin{array}{c}54,4 \\
163,7 \\
\end{array}$ \\
\hline
\end{tabular}

Médias seguidas por letras minúsculas diferentes na mesma coluna diferiram estatisticamente entre si pelo Teste de Tukey $(P<0,05)$. Médias seguidas por letras maiúsculas diferentes na mesma linha diferiram estatisticamente entre si pelo Teste $t$ (Student) $(P<0,05)$

Fonte: Própria autoria.

Gráfico 22 - Médias com erros padrão para colesterol sérico de vacas gestantes por FIV e por IA no final da gestação até a indução e a realização da cesariana Pirassununga -2018

- Receptoras FIV $\backsim$ Vacas IA

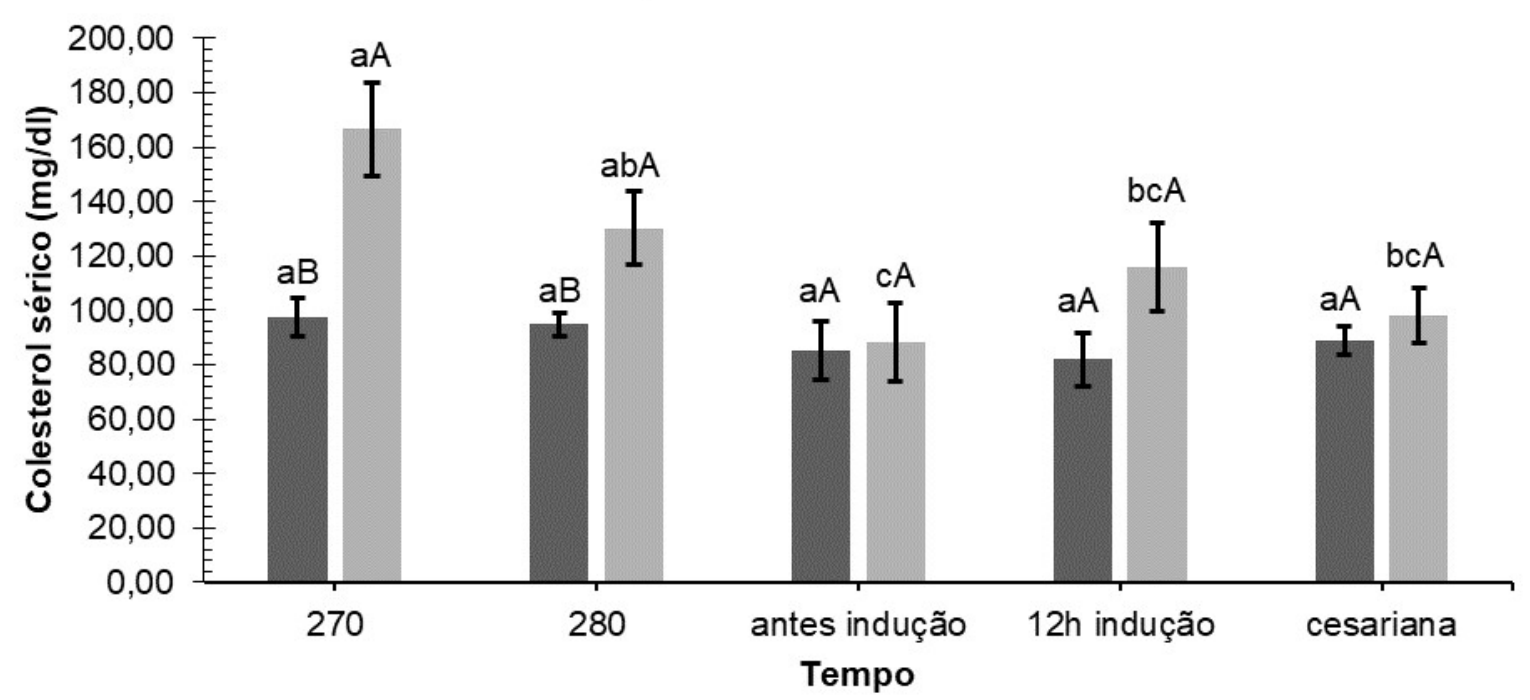

Colunas de mesma cor seguidas com letras minúsculas diferentes, diferiram estatisticamente entre si pelo Teste de Tukey $(P<0,05)$. Colunas de cor diferente dentro de cada tempo seguidas por letras maiúsculas diferentes, diferiram estatisticamente entre si pelo Teste $t$ (Student) $(P<0,05)$

Fonte: Própria autoria. 
Na tabela 23 no gráfico 23 está representado os resultados de triglicérides sérico de vacas receptoras de embriões por FIV da raça Nelore e vacas gestantes de bezerros da raça Nelore por IA (grupo controle). Houve diferença estatística significativa entre os tratamentos nos momentos 270 e 280 dias de gestação e 12 horas após a indução dentro de cada tempo separadamente $(P<0,05)$, e entre os períodos de avaliação dentro de cada tratamento $(P<0,05)$.

Nos momentos 270 e 280 dias de gestação e 12 horas após a indução, os teores de triglicérides foram superiores para o grupo controle. Observou-se efeito sobre o tempo, sendo que as maiores diferenças foram entre 280 dias de gestação (37,7 e 54,6 mg/dL) e 12 horas após a indução (16,3 e 32,7 mg/dL) respectivamente para as vacas FIV e grupo controle. No entanto, a médias de triglicérides de ambos os grupos estavam acima dos valores de referência para bovinos adultos ( 0 - 14 $\mathrm{mg} / \mathrm{dL}$ ) relatados por Kaneko, Harvey e Bruss (2008) e semelhantes aos observados em vacas Nelore por Oliveira (2015).

Tabela 23 - Médias, erros padrão, medidas mínimas e máximas para triglicérides sérico $(\mathrm{mg} / \mathrm{dL})$ de vacas gestantes por FIV e por IA no final da gestação, período de indução e antes de serem submetidas a cesariana

\begin{tabular}{|c|c|c|c|c|c|c|c|c|}
\hline \multirow[b]{2}{*}{ Tempo } & \multicolumn{4}{|c|}{ Receptoras FIV } & \multicolumn{4}{|c|}{ Vacas IA } \\
\hline & $\mathrm{n}$ & Média & $\begin{array}{c}\text { Erro } \\
\text { Padrão }\end{array}$ & $\begin{array}{l}\text { Min e } \\
\text { Max }\end{array}$ & $\mathrm{n}$ & Média & $\begin{array}{c}\text { Erro } \\
\text { Padrão }\end{array}$ & $\begin{array}{l}\text { Min e } \\
\text { Max }\end{array}$ \\
\hline \multirow{2}{*}{270} & \multirow{2}{*}{8} & \multirow{2}{*}{$30,8 \mathrm{abB}$} & \multirow{2}{*}{2,8} & 23,2 & \multirow{2}{*}{8} & \multirow{2}{*}{51,3 aA } & \multirow{2}{*}{5,7} & 34,7 \\
\hline & & & & 46,5 & & & & 77,1 \\
\hline \multirow{2}{*}{280} & \multirow{2}{*}{8} & \multirow{2}{*}{$37,7 \mathrm{aB}$} & \multirow{2}{*}{4,5} & 18,6 & \multirow{2}{*}{8} & \multirow{2}{*}{54,6 aA } & \multirow{2}{*}{5,2} & 38,5 \\
\hline & & & & 62,3 & & & & 76,0 \\
\hline \multirow{2}{*}{$\begin{array}{c}\text { antes } \\
\text { indução }\end{array}$} & \multirow{2}{*}{8} & \multirow{2}{*}{$33,4 \mathrm{abA}$} & \multirow{2}{*}{3,1} & 23,0 & \multirow{2}{*}{8} & \multirow{2}{*}{$34,8 \mathrm{bA}$} & \multirow{2}{*}{4,2} & 15,7 \\
\hline & & & & 46,1 & & & & 54,8 \\
\hline \multirow{2}{*}{$\begin{array}{c}\text { 12h } \\
\text { indução }\end{array}$} & \multirow{2}{*}{8} & \multirow{2}{*}{$16,3 \mathrm{cB}$} & \multirow{2}{*}{1,8} & 10,3 & \multirow{2}{*}{6} & \multirow{2}{*}{$32,7 \mathrm{bA}$} & \multirow{2}{*}{5,0} & 22,5 \\
\hline & & & & 26,7 & & & & 53,2 \\
\hline \multirow{2}{*}{ cesariana } & \multirow{2}{*}{8} & \multirow{2}{*}{$23,2 \mathrm{bcA}$} & \multirow{2}{*}{4,0} & 11,5 & \multirow{2}{*}{11} & \multirow{2}{*}{$34,4 \mathrm{bA}$} & \multirow{2}{*}{3,7} & 14,5 \\
\hline & & & & & & & & 52,5 \\
\hline
\end{tabular}

Médias seguidas por letras minúsculas diferentes na mesma coluna diferiram estatisticamente entre si pelo Teste de Tukey $(P<0,05)$. Médias seguidas por letras maiúsculas diferentes na mesma linha diferiram estatisticamente entre si pelo Teste $t$ (Student) $(P<0,05)$

Fonte: Própria autoria. 
Gráfico 23 - Médias com erros padrão para Triglicérides sérico de vacas gestantes por FIV e por IA no final da gestação até a indução e a realização da cesariana Pirassununga - 2018

- Receptoras FIV $\quad$ Vacas IA

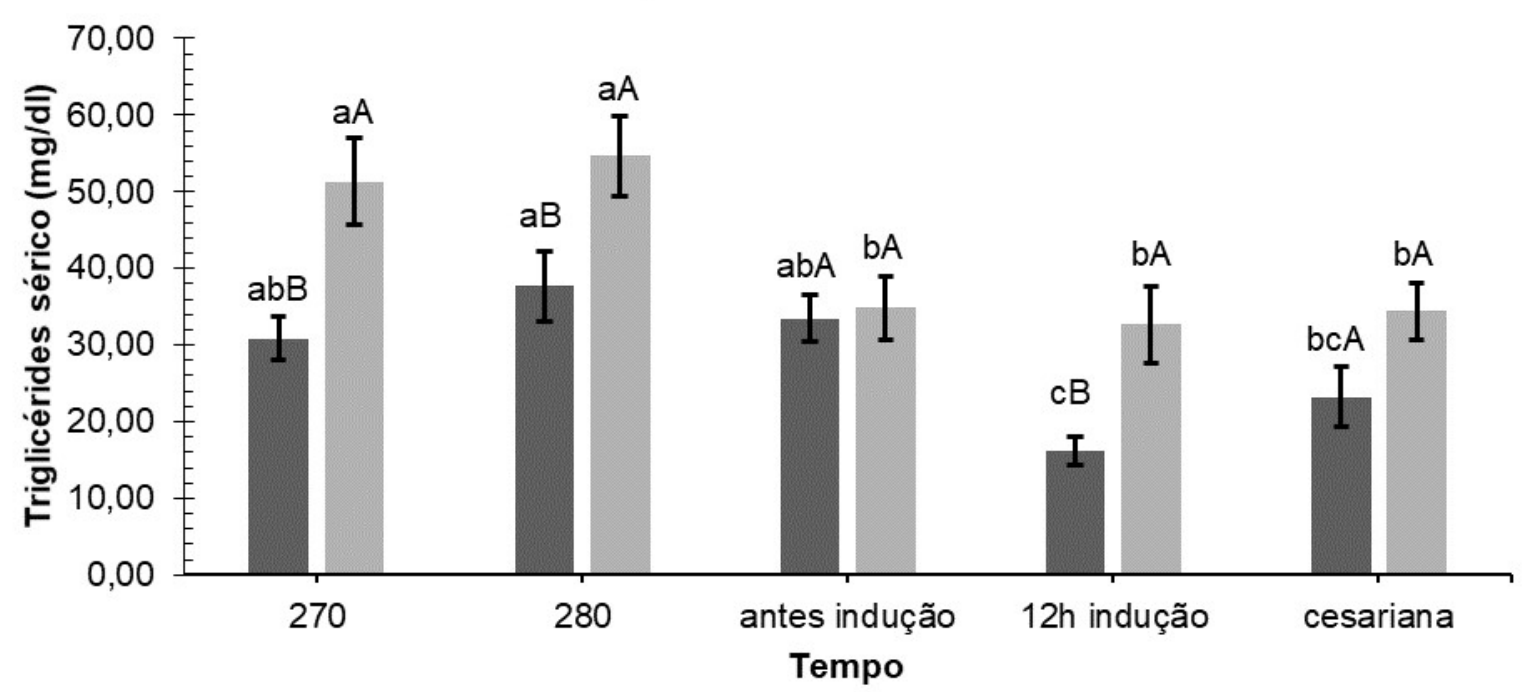

Colunas de mesma cor seguidas com letras minúsculas diferentes, diferiram estatisticamente entre si pelo Teste de Tukey $(P<0,05)$. Colunas de cor diferente dentro de cada tempo seguidas por letras maiúsculas diferentes, diferiram estatisticamente entre si pelo Teste $t$ (Student) $(P<0,05)$

Fonte: Própria autoria.

O triglicérides é originado a partir da reesterificação do NEFA, trata-se de lipídeos esterificados (KANEKO; HARVEY; BRUSS, 2008). Dentre as diversas funções, atua como reserva energética e seu nível sérico depende da relação entre ingestão e consumo, em condições de BEN sua síntese hepática fica diminuída (THRALL et al., 2015). Em ruminantes, a gestação é outra condição responsável por variação no metabolismo lipídico onde os processos de lipólise e lipogênese são altamente responsivos a glicemia (CALDEIRA, 2005). Neste experimento constatouse não haver influência da gestação por FIV sobre a síntese de triglicérides, uma vez que foi possível observar que os teores permaneceram acima dos valores de referência, mesmo ocorrendo diminuição dos níveis séricos em ambos os grupos, com maior intensidade para as vacas receptoras de FIV.

$\mathrm{Na}$ tabela 24 e no gráfico 24 está representado os resultados da glicose plasmática de vacas receptoras de embriões por FIV da raça Nelore e vacas gestantes de bezerros da raça Nelore por IA (grupo controle). Houve diferença estatística significativa entre os tratamentos nos momentos 270 e 280 dias de gestação separadamente $(P<0,05)$, e entre os períodos de avaliação dentro de cada tratamento $(\mathrm{P}<0,05)$. 
Tabela 24 - Médias, erros padrão, medidas mínimas e máximas para glicose plasmática $(\mathrm{mg} / \mathrm{dL})$ de vacas gestantes por FIV e por IA no final da gestação, período de indução e antes de serem submetidas a cesariana

\begin{tabular}{|c|c|c|c|c|c|c|c|c|}
\hline \multirow[b]{2}{*}{ Tempo } & \multicolumn{4}{|c|}{ Receptoras FIV } & \multicolumn{4}{|c|}{ Vacas IA } \\
\hline & $\mathrm{n}$ & Média & $\begin{array}{c}\text { Erro } \\
\text { Padrão }\end{array}$ & $\begin{array}{l}\text { Min e } \\
\text { Max }\end{array}$ & $\mathrm{n}$ & Média & $\begin{array}{c}\text { Erro } \\
\text { Padrão }\end{array}$ & $\begin{array}{l}\text { Min e } \\
\text { Max }\end{array}$ \\
\hline 270 & 8 & 49,3 bB & 6,3 & $\begin{array}{l}22,4 \\
76,0\end{array}$ & 8 & 102,5 aA & 12,4 & $\begin{array}{c}46,6 \\
155,7\end{array}$ \\
\hline 280 & 8 & $55,3 \mathrm{abB}$ & 4,0 & $\begin{array}{l}34,2 \\
71,7\end{array}$ & 8 & $70,2 \mathrm{bA}$ & 4,7 & $\begin{array}{c}53,8 \\
103,2\end{array}$ \\
\hline $\begin{array}{c}\text { antes } \\
\text { indução }\end{array}$ & 8 & $62,8 \mathrm{abA}$ & 7,2 & $\begin{array}{l}33,5 \\
88,0\end{array}$ & 8 & $72,5 \mathrm{abA}$ & 5,6 & $\begin{array}{l}45,6 \\
94,9\end{array}$ \\
\hline $\begin{array}{c}12 \mathrm{~h} \\
\text { indução }\end{array}$ & 8 & $71,8 \mathrm{aA}$ & 2,1 & $\begin{array}{l}61,4 \\
79,8\end{array}$ & 7 & $95,2 \mathrm{abA}$ & 16,1 & $\begin{array}{c}70,4 \\
142,3\end{array}$ \\
\hline cesariana & 8 & $67,4 \mathrm{abA}$ & 8,1 & $\begin{array}{c}34,0 \\
103,3\end{array}$ & 12 & $109,4 a b A$ & 12,6 & $\begin{array}{c}71,2 \\
202,6 \\
\end{array}$ \\
\hline
\end{tabular}

Médias seguidas por letras minúsculas diferentes na mesma coluna diferiram estatisticamente entre si pelo Teste de Tukey $(P<0,05)$. Médias seguidas por letras maiúsculas diferentes na mesma linha diferiram estatisticamente entre si pelo Teste t (Student) $(P<0,05)$

Fonte: Própria autoria.

Gráfico 24 - Médias com erros padrão para glicose plasmática de vacas gestantes por FIV e por IA no final da gestação até a indução e a realização da cesariana Pirassununga -2018

- Receptoras FIV $\quad$ Vacas IA

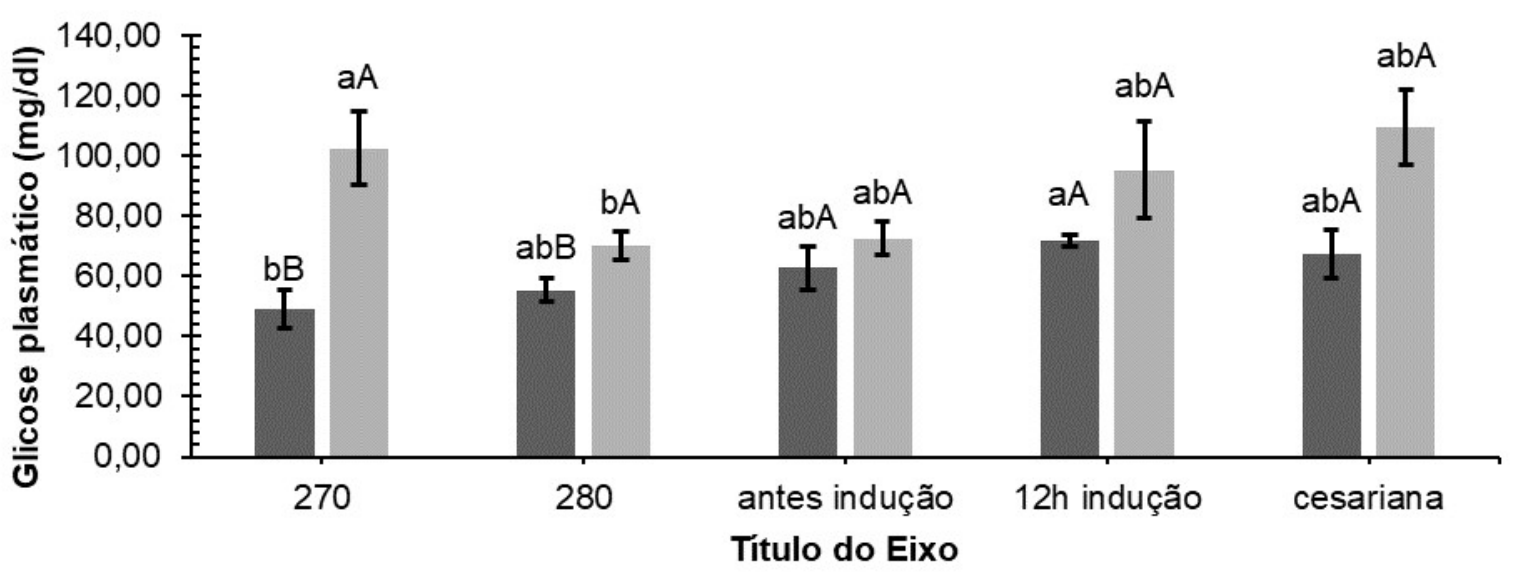

Colunas de mesma cor seguidas com letras minúsculas diferentes, diferiram estatisticamente entre si pelo Teste de Tukey $(\mathrm{P}<0,05)$. Colunas de cor diferente dentro de cada tempo seguidas por letras maiúsculas diferentes, diferiram estatisticamente entre si pelo Teste $t$ (Student) $(P<0,05)$

Fonte: Própria autoria.

Os teores de glicose foram superiores para o grupo controle nos momentos 270 e 280 dias de gestação. Observou-se também que as maiores diferenças, para o efeito tempo para as vacas FIV foram entre 270 dias de gestação $(49,3 \mathrm{mg} / \mathrm{dL}) \mathrm{e}$ 
12 horas após a indução $(71,8 \mathrm{mg} / \mathrm{dL})$, já para grupo controle foram entre 280 dias de gestação (70,2 mg/dL) e antes da cesariana (109,4 mg/dL).

As médias de glicose para as vacas receptoras de FIV permaneceram dentro da faixa de referência para bovinos adultos (40 a $80 \mathrm{mg} / \mathrm{dL}$ ) relatado por Swenson e Reece (1996), contudo, mesmo dentro da faixa de referência, observou-se pequeno incremento no momento 12 horas após a indução, suficiente para causar diferença entre o momento 270 dias de gestação. Já, o grupo controle revelou efeito pelo tempo, os animais apresentaram hiperglicemia no início, talvez por aumento do cortisol endógeno devido as alterações de manejo imposto pela pesquisa, já descrito. A partir do momento 280 dias de gestação os valores permaneceram dentro da faixa de referência supracitada, e no final do experimento, após a indução com dexametasona, observou-se hiperglicemia novamente.

Os valores plasmáticos de glicose das vacas receptoras de FIV foram semelhantes ao descrito por Abud et al. (2016) até o momento antes da indução, da mesma forma, os valores do grupo controle foram semelhantes ao descrito por Oliveira (2015). Os glicocorticoides possuem efeito antagônico a ação da insulina e impede a absorção da glicose pelos tecidos periféricos deixando-os disponíveis para os órgãos vitais, como resultado ocorre elevação dos teores plasmáticos de glicose (BURTON, 1995).

Os resultados obtidos neste trabalho não demonstraram influência da gestação por FIV sobre as concentrações séricas de glicose e reforçam as considerações de González et al. (2000) sobre a relevância da avaliação do nível glicêmico em condição de severo déficit energético, em situações de gestação ou lactação, e pela sua perda de relevância, devido a insensibilidade da glicemia a mudanças nutricionais e a sua sensibilidade ao estresse.

$\mathrm{Na}$ tabela 25 e no gráfico 25 está representado os resultados do lactato plasmático de vacas receptoras de embriões por FIV da raça Nelore e vacas gestantes de bezerros da raça Nelore por IA (grupo controle). Não houve diferença estatística significativa entre os tratamentos dentro de cada tempo separadamente $(P>0,05)$, nem entre os períodos de avaliação dentro de cada tratamento $(P>0,05)$. As médias de lactato das receptoras de FUV estavam próximos dos valores de referência para bovinos adultos $(5-20 \mathrm{mg} / \mathrm{dL}$ ) relatados por Kaneko, Harvey e Bruss (2008), embora os valores tenha sido superiores aos da referência para as 
vacas de IA, não foi suficiente para revelar diferença estatística entre os tratamentos, talvez pela grande variação entre os resultados nos momentos 280 dias de gestação para o grupo controle e para os dois grupos no momento cesariana.

Tabela 25 - Médias, erros padrão, medidas mínimas e máximas para lactato plasmático (mg/dL) de vacas gestantes por FIV e por IA no final da gestação, período de indução e antes de serem submetidas a cesariana

\begin{tabular}{|c|c|c|c|c|c|c|c|c|}
\hline \multirow[b]{2}{*}{ Tempo } & \multicolumn{4}{|c|}{ Receptoras FIV } & \multicolumn{4}{|c|}{ Vacas IA } \\
\hline & $\mathrm{n}$ & Média & $\begin{array}{c}\text { Erro } \\
\text { Padrão }\end{array}$ & $\begin{array}{l}\text { Min e } \\
\text { Max }\end{array}$ & $\mathrm{n}$ & Média & $\begin{array}{c}\text { Erro } \\
\text { Padrão }\end{array}$ & $\begin{array}{l}\text { Min e } \\
\text { Max }\end{array}$ \\
\hline \multirow{2}{*}{270} & \multirow{2}{*}{8} & \multirow{2}{*}{19,9 aA } & \multirow{2}{*}{7,0} & 4,9 & \multirow{2}{*}{8} & \multirow{2}{*}{$32,2 \mathrm{aA}$} & \multirow{2}{*}{5,6} & 11,9 \\
\hline & & & & 60,2 & & & & 53,8 \\
\hline \multirow{2}{*}{280} & \multirow{2}{*}{8} & \multirow{2}{*}{$17,6 \mathrm{aA}$} & \multirow{2}{*}{6,1} & 3,9 & \multirow{2}{*}{7} & \multirow{2}{*}{37,0 aA } & \multirow{2}{*}{15,2} & 11,8 \\
\hline & & & & 56,5 & & & & 112,8 \\
\hline \multirow{2}{*}{$\begin{array}{c}\text { antes } \\
\text { indução }\end{array}$} & \multirow{2}{*}{8} & \multirow{2}{*}{$18,8 \mathrm{aA}$} & \multirow{2}{*}{3,4} & 8,5 & \multirow{2}{*}{8} & \multirow{2}{*}{19,9 aA } & \multirow{2}{*}{2,8} & 8,7 \\
\hline & & & & 30,2 & & & & 31,4 \\
\hline \multirow{2}{*}{$\begin{array}{c}12 \mathrm{~h} \\
\text { indução }\end{array}$} & \multirow{2}{*}{8} & \multirow{2}{*}{$19,3 \mathrm{aA}$} & \multirow{2}{*}{8,6} & 4,6 & \multirow{2}{*}{7} & \multirow{2}{*}{27,5 aA } & \multirow{2}{*}{4,5} & 7,7 \\
\hline & & & & 72,0 & & & & 46,1 \\
\hline \multirow{2}{*}{ cesariana } & \multirow{2}{*}{8} & \multirow{2}{*}{31,3 aA } & \multirow{2}{*}{12,3} & 3,9 & \multirow{2}{*}{11} & \multirow{2}{*}{43,8 aA } & \multirow{2}{*}{10,1} & 7,6 \\
\hline & & & & 90,9 & & & & 134,9 \\
\hline
\end{tabular}

Médias seguidas por letras minúsculas diferentes na mesma coluna diferiram estatisticamente entre si pelo Teste de Tukey $(P<0,05)$. Médias seguidas por letras maiúsculas diferentes na mesma linha diferiram estatisticamente entre si pelo Teste $t$ (Student) $(P<0,05)$

Fonte: Própria autoria.

Gráfico 25 - Médias com erros padrão para lactato plasmático de vacas gestantes por FIV e por IA no final da gestação até a indução e a realização da cesariana Pirassununga - 2018

\section{- Receptoras FIV $\quad$ Vacas IA}

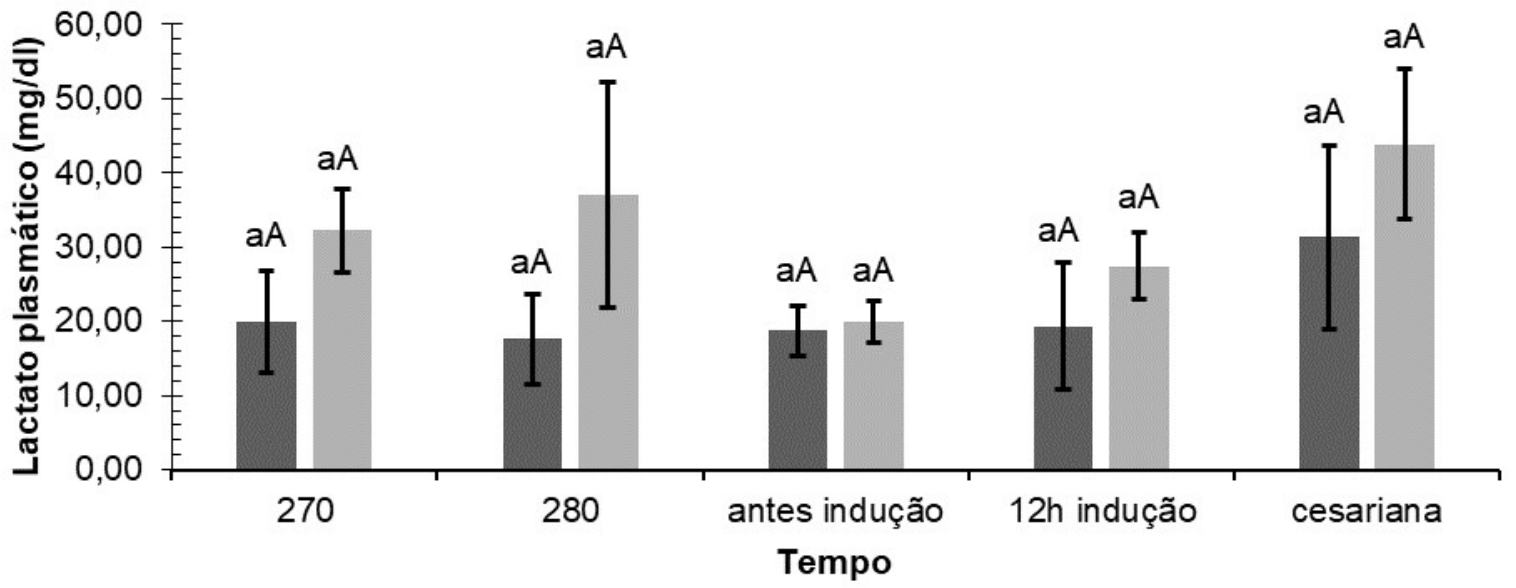

Colunas de mesma cor seguidas com letras minúsculas diferentes, diferiram estatisticamente entre si pelo Teste de Tukey $(P<0,05)$. Colunas de cor diferente dentro de cada tempo seguidas por letras maiúsculas diferentes, diferiram estatisticamente entre si pelo Teste $t$ (Student) $(P<0,05)$

Fonte: Própria autoria. 
O lactato é produzido no eritrócito e no músculo esquelético, como resultado da glicólise anaeróbica. Em situações que levam a hipoglicemia, como no final da gestação pode ser utilizado como precursor da gliconeogenese, para síntese de glicose no fígado, neste momento seus teores plasmáticos podem ficar aumentados (CORREAA; GONZÁLEZ; SILVA, 2010). Comportamento não observado neste experimento, Embora os valores das vacas IA estarem acima da faixa de referência, não representou diferença estatística, dessa forma não ficou demonstrado efeito da gestação por FIV sobre a concentração sérica de lactato.

Na tabela 26 e no gráfico 26 estão representados os resultados de ßhidroxibutirato sérico de vacas receptoras de embriões por FIV da raça Nelore e vacas gestantes de bezerros da raça Nelore por IA (grupo controle). Não houve diferença estatística significativa entre os tratamentos dentro de cada tempo separadamente $(P>0,05)$, nem entre os períodos de avaliação dentro de cada tratamento $(P>0,05)$.

Tabela 26 - Médias, erros padrão, medidas mínimas e máximas para $\beta$ hidroxibutirato sérico $(\mathrm{mg} / \mathrm{dL})$ de vacas gestantes por FIV e por IA no final da gestação, período de indução e antes de serem submetidas a cesariana

\begin{tabular}{|c|c|c|c|c|c|c|c|c|}
\hline \multirow[b]{2}{*}{ Tempo } & \multicolumn{4}{|c|}{ Receptoras FIV } & \multicolumn{4}{|c|}{ Vacas IA } \\
\hline & $\mathrm{n}$ & Média & $\begin{array}{c}\text { Erro } \\
\text { Padrão }\end{array}$ & $\begin{array}{l}\text { Min e } \\
\text { Max }\end{array}$ & $\mathrm{n}$ & Média & $\begin{array}{c}\text { Erro } \\
\text { Padrão }\end{array}$ & $\begin{array}{l}\text { Min e } \\
\text { Max }\end{array}$ \\
\hline 270 & 8 & $8,2 \mathrm{aA}$ & 1,2 & $\begin{array}{c}4,4 \\
15,0\end{array}$ & 8 & $16,0 \mathrm{aA}$ & 4,3 & $\begin{array}{c}6,77 \\
44,25\end{array}$ \\
\hline 280 & 8 & 10,9 aA & 2,6 & $\begin{array}{c}4,8 \\
26,8\end{array}$ & 8 & $13,5 \mathrm{aA}$ & 2,8 & $\begin{array}{c}4,55 \\
30,21\end{array}$ \\
\hline $\begin{array}{c}\text { antes } \\
\text { indução }\end{array}$ & 8 & $12,3 \mathrm{aA}$ & 6,2 & $\begin{array}{c}1,9 \\
55,2\end{array}$ & 8 & $17,5 \mathrm{aA}$ & 5,0 & $\begin{array}{c}4,98 \\
48,78\end{array}$ \\
\hline $\begin{array}{c}12 \mathrm{~h} \\
\text { indução }\end{array}$ & 8 & $11,1 \mathrm{aA}$ & 4,8 & $\begin{array}{c}3,2 \\
44,1\end{array}$ & 6 & 18,4 aA & 4,0 & $\begin{array}{c}8,44 \\
30,21\end{array}$ \\
\hline cesariana & 8 & 15,6 aA & 8,7 & $\begin{array}{c}3,1 \\
75,6\end{array}$ & 11 & $12,9 \mathrm{aA}$ & 1,2 & $\begin{array}{c}4,38 \\
17,98\end{array}$ \\
\hline
\end{tabular}

Médias seguidas por letras minúsculas diferentes na mesma coluna diferiram estatisticamente entre si pelo Teste de Tukey $(P<0,05)$. Médias seguidas por letras maiúsculas diferentes na mesma linha diferiram estatisticamente entre si pelo Teste $t$ (Student) $(P<0,05)$

Fonte: Própria autoria. 
Gráfico 26 - Médias com erros padrão para $\beta$-hidroxibutirato sérico de vacas gestantes por FIV e por IA no final da gestação até a indução e a realização da cesariana - Pirassununga - 2018

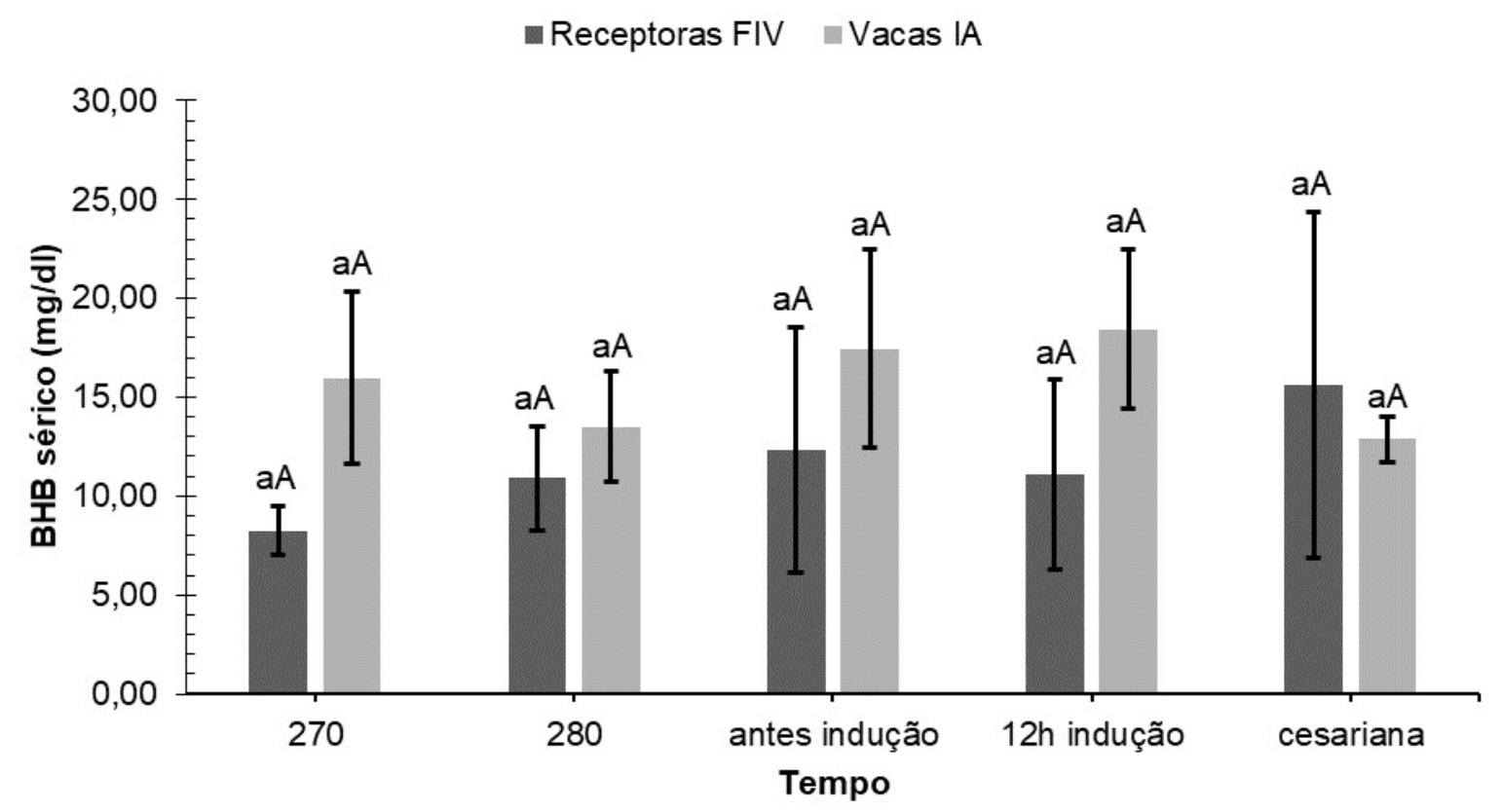

Colunas de mesma cor seguidas com letras minúsculas diferentes, diferiram estatisticamente entre si pelo Teste de Tukey $(P<0,05)$. Colunas de cor diferente dentro de cada tempo seguidas por letras maiúsculas diferentes, diferiram estatisticamente entre si pelo Teste $t$ (Student) $(P<0,05)$

Fonte: Própria autoria.

O BHB está entre os metabólitos mais utilizados para avaliação do status energético em bovinos. Em conjunto com a NEFA, estão relacionados com a taxa de mobilização de reservas lipídicas em momentos de déficit energético, como no final da gestação em bovinos de corte (GONZÁLEZ et al., 2000).

Apesar das médias de BHB nas receptoras de FIV, no momento antes da indução terem excedido o intervalo de referência para bovinos adultos $(8,0-11,8$ $\mathrm{mg} / \mathrm{dL}$ ) relatados por Kaneko, Harvey e Bruss (2008) e antes da cesariana ter ultrapassado o valor considerado positivo para cetose $(14,4 \mathrm{mg} / \mathrm{dL})$ mencionado por Oetzel (2015). No grupo controle observou-se valores superiores ao intervalo de referência e, exceto no momento 280 dias de gestação, apresentaram valores positivos para cetose supracitados. A variação entre os resultados dos dois grupos não permitiu que determinasse diferença estatística entre os tratamentos. Não sendo observado a influência da gestação por FIV nas concentrações séricas de BHB.

Na tabela 27 e no gráfico 27 estão representados os resultados do ácido graxo não esterificado sérico de vacas receptoras de embriões por FIV da raça Nelore e vacas gestantes de bezerros da raça Nelore por IA (grupo controle). Houve 
diferença estatística significativa entre os tratamentos nos momentos 270 dias de gestação, antes da indução e 12 horas após a indução separadamente $(P<0,05)$, e entre os períodos de avaliação no grupo controle $(P<0,05)$. Nos momentos 270 dias de gestação, antes da indução e 12 horas após a indução, os teores de NEFA do grupo das vacas receptoras de FIV foram inferiores ao grupo controle. Com relação aos tempos avaliados, foi possível observar apenas no grupo controle variação ascendente nos níveis de NEFA, obtendo-se diferença entre os momentos 270 e antes da cesariana.

As médias de NEFA nas receptoras de FIV permaneceram abaixo do valor de referência para bovinos de corte $(<0,91 \mathrm{mmol} / \mathrm{L})$ considerado pelo Laboratório de Diagnóstico Veterinário do Colégio de Medicina Veterinária da Universidade do Estado de Oregon, Estados Unidos (OREGON STATE UNIVERSITY, 2018) e foi inferior aos resultados relatados por Oliveira (2015). No grupo controle os teores permaneceram, em todos os momentos, acima do valor de corte supracitado e foi semelhante aos resultados relatados por Oliveira (2015).

Tabela 27 - Médias, erros padrão, medidas mínimas e máximas para NEFA sérico (mmol/L) de vacas gestantes por FIV e por IA no final da gestação, período de indução e antes de serem submetidas a cesariana

\begin{tabular}{|c|c|c|c|c|c|c|c|c|}
\hline \multirow[b]{2}{*}{ Tempo } & \multicolumn{4}{|c|}{ Receptoras FIV } & \multicolumn{4}{|c|}{ Vacas IA } \\
\hline & $\mathrm{n}$ & Média & $\begin{array}{c}\text { Erro } \\
\text { Padrão }\end{array}$ & $\begin{array}{l}\text { Min e } \\
\text { Max }\end{array}$ & $n$ & Média & $\begin{array}{c}\text { Erro } \\
\text { Padrão }\end{array}$ & $\begin{array}{l}\text { Min e } \\
\text { Max }\end{array}$ \\
\hline 270 & 8 & $0,57 \mathrm{aB}$ & 0,09 & $\begin{array}{l}0,14 \\
1,00\end{array}$ & 8 & $0,91 \mathrm{bA}$ & 0,12 & $\begin{array}{l}0,59 \\
1,40\end{array}$ \\
\hline 280 & 8 & $0,82 \mathrm{aA}$ & 0,26 & $\begin{array}{l}0,16 \\
2,42\end{array}$ & 8 & $1,06 \mathrm{abA}$ & 0,12 & $\begin{array}{l}0,47 \\
1,30\end{array}$ \\
\hline $\begin{array}{c}\text { antes } \\
\text { indução }\end{array}$ & 8 & $0,70 \mathrm{aB}$ & 0,19 & $\begin{array}{l}0,14 \\
1,54\end{array}$ & 8 & $1,19 a b A$ & 0,10 & $\begin{array}{l}0,53 \\
1,36\end{array}$ \\
\hline $\begin{array}{c}12 \mathrm{~h} \\
\text { indução }\end{array}$ & 8 & $0,64 \mathrm{aB}$ & 0,14 & $\begin{array}{l}0,15 \\
1,16\end{array}$ & 6 & $1,27 a b A$ & 0,03 & $\begin{array}{l}1,13 \\
1,32\end{array}$ \\
\hline cesariana & 8 & $0,83 \mathrm{aA}$ & 0,21 & $\begin{array}{l}0,15 \\
1,78 \\
\end{array}$ & 11 & $1,26 \mathrm{aA}$ & 0,17 & $\begin{array}{l}0,44 \\
2,53 \\
\end{array}$ \\
\hline
\end{tabular}

Médias seguidas pela mesma letra minúscula na coluna não diferiram estatisticamente entre si pelo Teste de Tukey $(P>0,05)$. Médias seguidas por letras diferentes na linha diferiram estatisticamente pelo Teste $t(P<0,05)$

Fonte: Própria autoria. 
Gráfico 27 - Médias com erros padrão para NEFA sérico de vacas gestantes por FIV e por IA no final da gestação até a indução e a realização da cesariana Pirassununga - 2018

- Receptoras FIV $\square$ Vacas IA

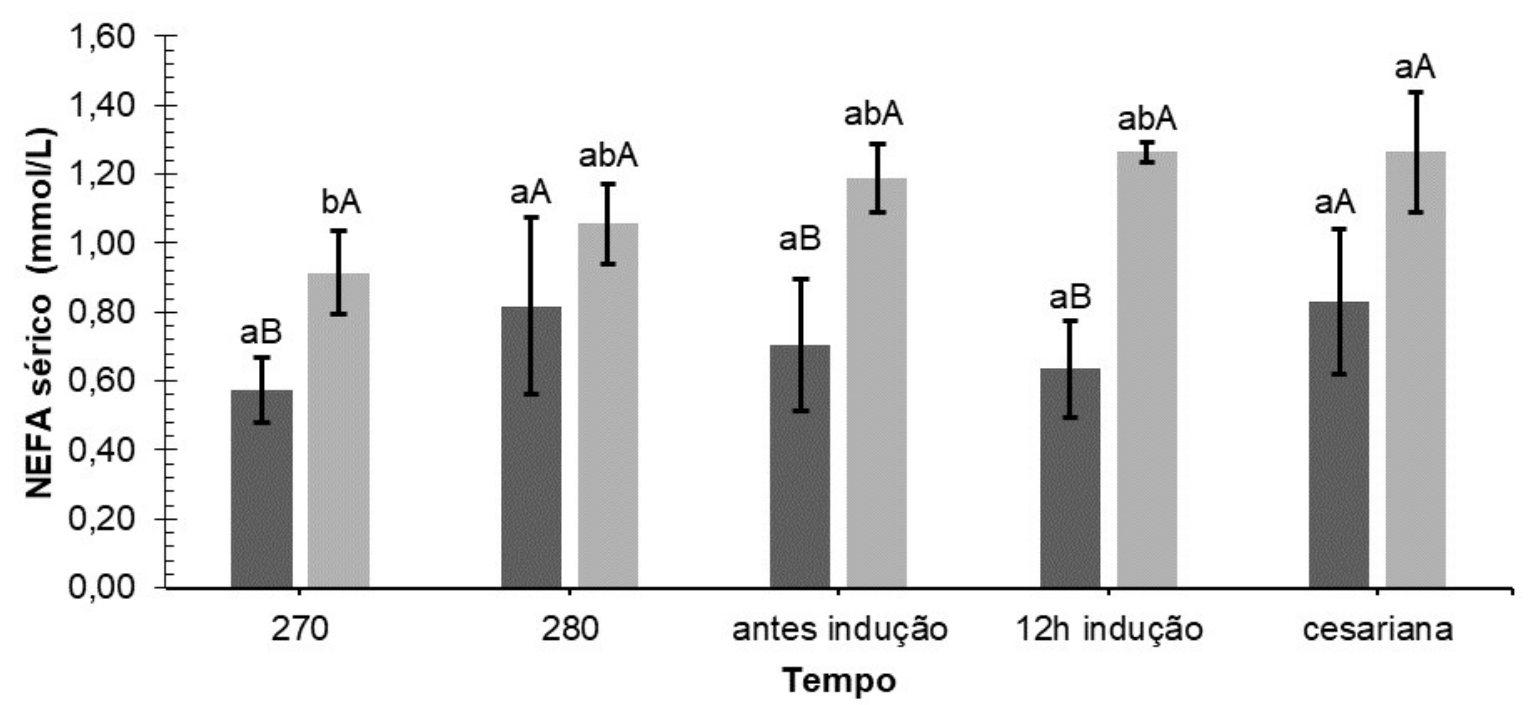

Colunas de mesma cor seguidas com letras minúsculas diferentes, diferiram estatisticamente entre si pelo Teste de Tukey $(P<0,05)$. Colunas de cor diferente dentro de cada tempo seguidas por letras maiúsculas diferentes, diferiram estatisticamente entre si pelo Teste $t$ (Student) $(P<0,05)$

Fonte: Própria autoria.

A NEFA constitui o metabólito mais significativo para estimar o status energético em gado de corte, uma vez que apresenta grande sensibilidade em déficit energético moderado e sob o consumo de alimento, por outro lado a NEFA também é sensível aos efeitos das catecolaminas liberadas em condições de estresse, como mudanças de manejo, tornando seu uso limitado (GONZÁLEZ et al., 2000). Neste trabalho não foi constatado efeito da gestação por FIV sobre o metabolismo da NEFA, sugere-se que a variação nos níveis de deste metabólito no grupo controle seja efeito do estresse causado pelo manejo do procedimento experimental.

\subsubsection{Procedimento experimental 2}

Na tabela 28 e no gráfico 28 estão representados os resultados do colesterol sérico dos bezerros oriundos de FIV e por IA (grupo controle). Houve diferença significativa entre os tratamentos no momento 30 dias de vida, $(P>0,05)$, e entre os períodos de avaliação, no momento 30 dias de vida dentro de cada tratamento $(P>0,05)$. 
Os valores da concentração sérica de ambos os grupos apresentaram comportamento semelhante até o $15^{\circ}$ dia de vida, no tempo 30 dias de vida houve diferença estatística entre os grupos, quando os valores do grupo dos bezerros de FIV foram estatisticamente inferiores aos do grupo controle. A variação dos valores de acordo com o tempo também foi semelhante entre os grupos até os 15 dias de vida, quando o grupo controle demonstrou considerável elevação.

Tabela 28 - Médias, erros padrão, medidas mínimas e máximas para colesterol sérico $(\mathrm{mg} / \mathrm{dL})$ de bezerros oriundos de FIV e por IA nos primeiros 30 dias de vida obtidos por cesariana com indução do parto

\begin{tabular}{|c|c|c|c|c|c|c|c|c|}
\hline \multirow[b]{2}{*}{ Tempo } & \multicolumn{4}{|c|}{ Bezerros FIV } & \multicolumn{4}{|c|}{ Bezerros IA } \\
\hline & $n$ & Média & $\begin{array}{c}\text { Erro } \\
\text { Padrão } \\
\end{array}$ & $\begin{array}{c}\text { Min e } \\
\text { Max }\end{array}$ & $\mathrm{n}$ & Média & $\begin{array}{c}\text { Erro } \\
\text { Padrão } \\
\end{array}$ & $\begin{array}{l}\text { Min e } \\
\text { Max }\end{array}$ \\
\hline Oh & 7 & $38,94 \mathrm{cdA}$ & 14,05 & $\begin{array}{c}19,77 \\
122,70\end{array}$ & 12 & $21,16 \mathrm{gA}$ & 1,74 & $\begin{array}{c}5,02 \\
28,89\end{array}$ \\
\hline $3 h$ & 8 & $36,08 \mathrm{dA}$ & 9,67 & $\begin{array}{c}21,17 \\
102,94\end{array}$ & 12 & $23,15 \mathrm{fg} A$ & 1,63 & $\begin{array}{c}9,23 \\
32,47\end{array}$ \\
\hline $6 h$ & 8 & $37,04 \mathrm{dA}$ & 11,93 & $\begin{array}{c}20,03 \\
120,10\end{array}$ & 12 & $23,41 \mathrm{fg} A$ & 1,25 & $\begin{array}{l}12,36 \\
30,31\end{array}$ \\
\hline $12 \mathrm{~h}$ & 8 & $30,92 \mathrm{dA}$ & 5,20 & $\begin{array}{l}20,01 \\
65,85\end{array}$ & 12 & $23,82 \mathrm{fg} A$ & 1,48 & $\begin{array}{l}11,96 \\
30,02\end{array}$ \\
\hline $24 \mathrm{~h}$ & 8 & $29,42 \mathrm{dA}$ & 2,30 & $\begin{array}{l}17,41 \\
38,40\end{array}$ & 12 & $29,62 \operatorname{efg} A$ & 1,81 & $\begin{array}{l}21,30 \\
41,49\end{array}$ \\
\hline $48 \mathrm{~h}$ & 8 & $43,58 \mathrm{~cd} A$ & 3,75 & $\begin{array}{l}32,19 \\
64,56\end{array}$ & 12 & 38,95 efA & 2,01 & $\begin{array}{l}25,69 \\
48,02\end{array}$ \\
\hline 3 dias & 8 & $53,79 \mathrm{~cd} A$ & 6,26 & $\begin{array}{l}39,85 \\
93,37\end{array}$ & 12 & $44,16 \mathrm{de} A$ & 2,35 & $\begin{array}{l}34,55 \\
61,81\end{array}$ \\
\hline 5 dias & 8 & 59,78 bcdA & 6,54 & $\begin{array}{l}32,66 \\
95,90\end{array}$ & 11 & $61,22 \mathrm{cdA}$ & 3,46 & $\begin{array}{l}51,15 \\
83,99\end{array}$ \\
\hline 7 dias & 8 & $73,30 \mathrm{abcA}$ & 11,26 & $\begin{array}{c}43,80 \\
135,71\end{array}$ & 12 & $64,89 \mathrm{cA}$ & 6,50 & $\begin{array}{c}40,91 \\
122,37\end{array}$ \\
\hline 15 dias & 8 & $94,93 \mathrm{abA}$ & 13,63 & $\begin{array}{c}58,14 \\
165,16\end{array}$ & 12 & 99,82 bA & 3,80 & $\begin{array}{c}85,12 \\
128,41\end{array}$ \\
\hline 30 dias & 8 & $99,01 \mathrm{aB}$ & 13,32 & $\begin{array}{c}49,75 \\
159,74 \\
\end{array}$ & 12 & 153,89 aA & 8,17 & $\begin{array}{r}115,55 \\
211,42 \\
\end{array}$ \\
\hline
\end{tabular}

Médias seguidas por letras minúsculas diferentes na mesma coluna diferiram estatisticamente entre si pelo Teste de Tukey $(P<0,05)$. Médias seguidas por letras maiúsculas diferentes na mesma linha diferiram estatisticamente entre si pelo Teste $t$ (Student) $(P<0,05)$

Fonte: Própria autoria. 
Gráfico 28 - Médias com erros padrão para colesterol sérico de bezerros oriundos de FIV e por IA nos primeiros 30 dias de vida obtidos por cesariana com indução do parto - Pirassununga - 2018
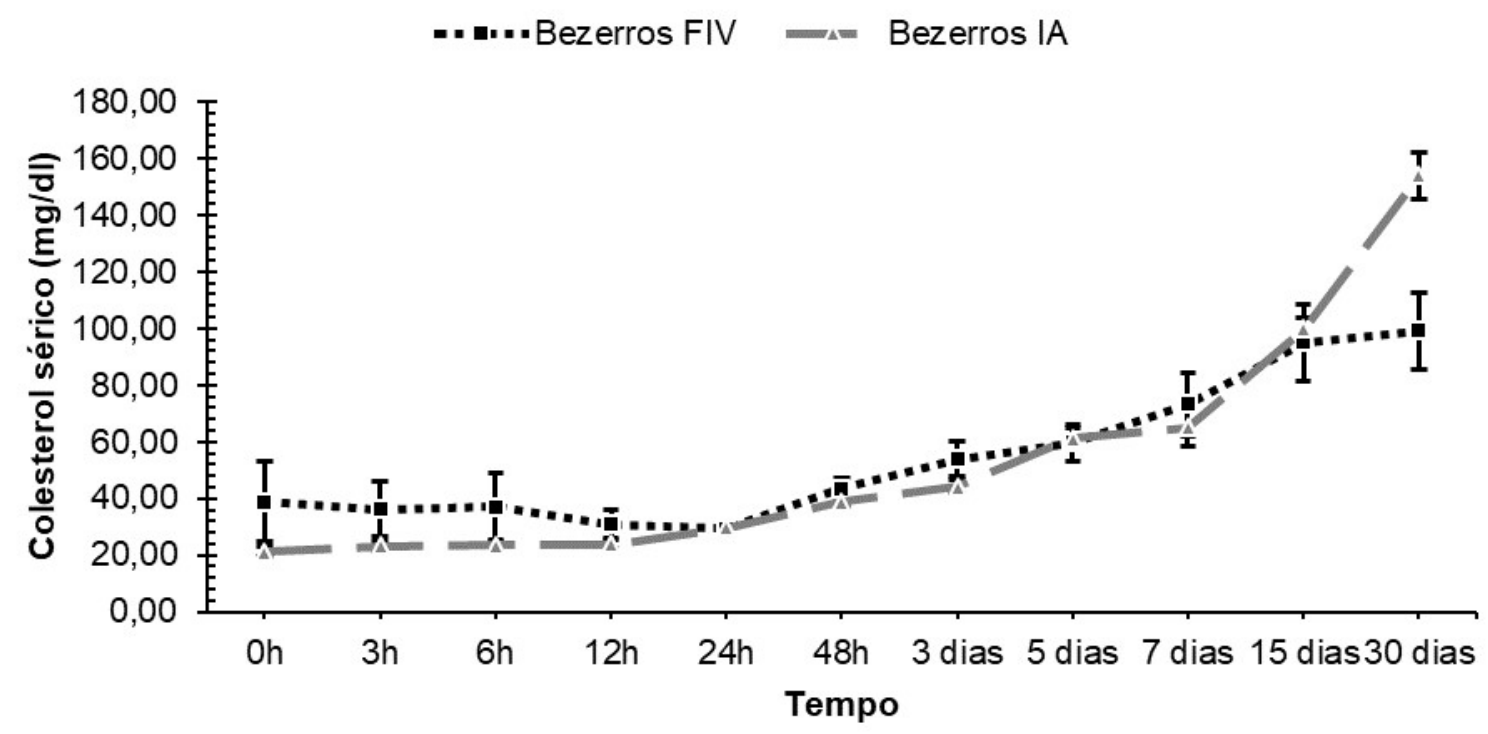

Fonte: Própria autoria.

As médias de ambos os grupos permaneceram abaixo dos valores de referência até o $7^{\circ}$ dia. Nos momentos 15 e 30 dias de vida dos bezerros de FIV os valores permaneceram dentro da faixa de referência $(86$ - $120 \mathrm{mg} / \mathrm{dL})$ relatados por Pogliani e Birgel Junior (2007) para bezerros da raça holandesa com até três meses de idade. Já o grupo controle ficou dentro da referida faixa no $15^{\circ}$ dia de vida e excedeu a faixa de referência no $30^{\circ}$ dia de vida.

Esta dinâmica com menores valores nos primeiros dias e aumento progressivo com o passar do tempo de vida determinado pela influência do fator etário, foi semelhante ao revelado por Piccioni et al. (2010) e Marchese (2014). aumento do teor de colesterol aos 30 dias de vida no grupo controle pode ser explicado pela qualidade e consumo de colostro nas primeiras semanas refletirem até os 30 dias de vida, associado ao consumo de alimento sólido Piccioni et al. (2010).

$\mathrm{Na}$ tabela 29 e no gráfico 29 estão representados os resultados do triglicérides sérico dos bezerros oriundos de FIV e por IA (grupo controle). Houve diferença estatística significativa entre os tratamentos no momento 3 dias de vida separadamente $(P<0,05)$, e entre os períodos de avaliação dentro de cada tratamento $(P<0,05)$. 
Tabela 29 - Médias, erros padrão, medidas mínimas e máximas para Triglicérides plasmático $(\mathrm{mg} / \mathrm{dL})$ de bezerros oriundos de FIV e por IA nos primeiros 30 dias de vida obtidos por cesariana com indução do parto

\begin{tabular}{|c|c|c|c|c|c|c|c|c|}
\hline \multirow[b]{2}{*}{ Tempo } & \multicolumn{4}{|c|}{ Bezerros FIV } & \multicolumn{4}{|c|}{ Bezerros IA } \\
\hline & $n$ & Média & Erro Padrão & $\begin{array}{l}\text { Min e } \\
\text { Max }\end{array}$ & $n$ & Média & Erro Padrão & $\begin{array}{l}\operatorname{Min} e \\
\operatorname{Max}\end{array}$ \\
\hline $\mathrm{Oh}$ & 7 & 19,09 bA & 10,08 & 5,81 & 12 & $12,38 \mathrm{bA}$ & 0,61 & 11,50 \\
\hline & & & & $\begin{array}{c}79,27 \\
9.39\end{array}$ & & & & $\begin{array}{l}17,91 \\
11,50\end{array}$ \\
\hline $3 \mathrm{~h}$ & 8 & $28,38 \mathrm{abA}$ & 8,21 & 75,12 & 12 & $20,05 \mathrm{abA}$ & 2,01 & 33,67 \\
\hline $6 \mathrm{~h}$ & 8 & $25,34 \mathrm{abA}$ & 14,11 & $\begin{array}{c}6,13 \\
123,69\end{array}$ & 12 & $15,19 a b A$ & 1,39 & $\begin{array}{l}11,50 \\
24,50\end{array}$ \\
\hline $12 \mathrm{~h}$ & 8 & $24,01 \mathrm{abA}$ & 9,21 & $\begin{array}{c}8,13 \\
85,50\end{array}$ & 12 & $22,46 \mathrm{abA}$ & 4,11 & $\begin{array}{l}11,50 \\
54,22\end{array}$ \\
\hline $24 \mathrm{~h}$ & 8 & $24,02 \mathrm{abA}$ & 3,96 & $\begin{array}{c}8,27 \\
45,64\end{array}$ & 12 & $26,29 a b A$ & 4,27 & $\begin{array}{l}11,50 \\
58,39\end{array}$ \\
\hline $48 \mathrm{~h}$ & 8 & $47,52 \mathrm{abA}$ & 12,80 & $\begin{array}{c}17,89 \\
114,36\end{array}$ & 12 & 35,48 aA & 5,58 & $\begin{array}{l}11,50 \\
81,60\end{array}$ \\
\hline 3 dias & 8 & 60,57 aA & 15,14 & $\begin{array}{c}12,10 \\
138,03\end{array}$ & 12 & $30,98 \mathrm{abB}$ & 3,22 & $\begin{array}{l}11,50 \\
53,56\end{array}$ \\
\hline 5 dias & 8 & $43,85 \mathrm{abA}$ & 9,79 & $\begin{array}{l}16,34 \\
93,65\end{array}$ & 11 & $30,37 \mathrm{abA}$ & 5,79 & $\begin{array}{l}11,50 \\
66,85\end{array}$ \\
\hline 7 dias & 8 & $48,81 \mathrm{abA}$ & 11,04 & $\begin{array}{c}13,21 \\
106,88\end{array}$ & 12 & $30,66 \mathrm{abA}$ & 8,28 & $\begin{array}{c}11,50 \\
116,11\end{array}$ \\
\hline 15 dias & 8 & $36,37 \mathrm{abA}$ & 10,48 & $\begin{array}{c}6,00 \\
81,33\end{array}$ & 12 & $34,38 \mathrm{abA}$ & 8,71 & $\begin{array}{c}11,50 \\
114,81\end{array}$ \\
\hline 30 dias & 8 & $43,45 \mathrm{abA}$ & 11,20 & $\begin{array}{c}7,91 \\
83,25\end{array}$ & 12 & $26,42 \mathrm{abA}$ & 5,19 & $\begin{array}{l}11,50 \\
70,36\end{array}$ \\
\hline
\end{tabular}

Médias seguidas por letras minúsculas diferentes na mesma coluna diferiram estatisticamente entre si pelo Teste de Tukey $(P<0,05)$. Médias seguidas por letras maiúsculas diferentes na mesma linha diferiram estatisticamente entre si pelo Teste $t$ (Student) $(P<0,05)$

Fonte: Própria autoria.

Os valores de triglicérides foram semelhantes entre os grupos no período avaliado, existindo diferença estatística entre os tratamentos no momento 3 dias de vida, quando a média dos bezerros de FIV apresentaram elevação. O efeito do tempo foi observado nos bezerros de FIV e no grupo controle com maior diferença entre 0 hora $(19,09 \mathrm{mg} / \mathrm{dL})$ e 3 dias $(60,57 \mathrm{mg} / \mathrm{dL})$ de vida e entre 0 hora $(912,38 \mathrm{mg} / \mathrm{dL})$ e 48 horas $(35,48 \mathrm{mg} / \mathrm{dL})$ de vida, respectivamente. Os teores estavam próximos da faixa de referência $(16-35 \mathrm{mg} / \mathrm{dL}$ ) constatado por Pogliani e Birgel Junior (2007), e semelhante ao observado por Moraes (2011) e Marchese 
(2014). Neste trabalho não foi constatado efeito da FIV sobre a concentração sérica de triglicérides em bezerros neonatos.

Gráfico 29 - Médias com erros padrão para Triglicérides plasmático de bezerros oriundos de FIV e por IA nos primeiros 30 dias de vida obtidos por cesariana com indução do parto - Pirassununga - 2018

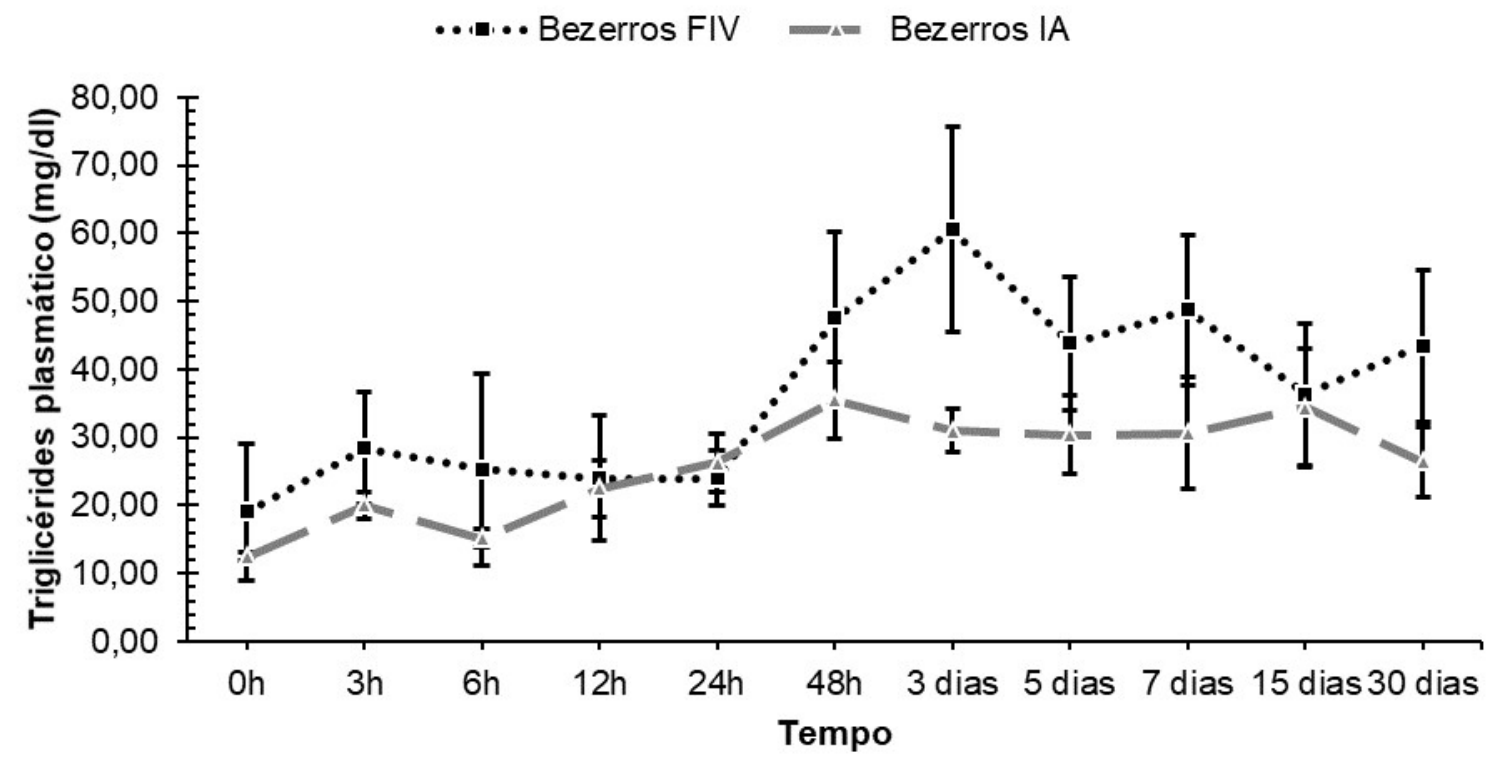

Fonte: Própria autoria.

$\mathrm{Na}$ tabela 30 e no gráfico 30 estão representados os resultados da glicose plasmática dos bezerros oriundos de FIV e por IA (grupo controle). Houve diferença estatística significativa entre os tratamentos no momento 24 horas de vida separadamente $(P>0,05)$, e entre os períodos de avaliação para os bezerros do grupo controle $(P>0,05)$. O efeito sobre os tratamentos foi evidenciado, apenas no momento 24 horas de vida, com valor superior para os bezerros do grupo controle.

A expectativa de hipoglicemia ao nascimento nos bezerros de FIV, como observado por Birgel Junior et al. (2011a, b) e por Meirelles et al. (2010) em bezerros clones foi observada nos momentos 0,3 e 6 horas de vida para os bezerros FIV e apenas no momento 0 horas de vida no controle. Na sequência, a glicemia permaneceu próximo da referência para bovinos lactentes (80 a 120 mg/dL) relatado por Swenson e Reece (1996). Neste trabalho foi possível evidenciar comportamento semelhante ao observado por Paiva et al. (2006) e Marchese (2014) em seu grupo controle, ao relatarem que os teores plasmáticos de glicose aumentam gradativamente, influenciado pelo consumo de colostro. As diferenças 
sobre o efeito tempo evidenciado no grupo controle do presente estudo remete-se a quantidade de consumo de leite durante o período experimental, como constatado por Kühne et al. (2000) em bezerros com aleitamento natural e por mamadeira.

Tabela 30 - Médias, erros padrão, medidas mínimas e máximas para glicose plasmática $(\mathrm{mg} / \mathrm{dL})$ de bezerros oriundos de FIV e por IA nos primeiros 30 dias de vida obtidos por cesariana com indução do parto

\begin{tabular}{|c|c|c|c|c|c|c|c|c|}
\hline \multirow[b]{2}{*}{ Tempo } & \multicolumn{4}{|c|}{ Bezerros FIV } & \multicolumn{4}{|c|}{ Bezerros IA } \\
\hline & $\mathrm{n}$ & Média & $\begin{array}{c}\text { Erro } \\
\text { Padrão }\end{array}$ & $\begin{array}{c}\text { Min e } \\
\text { Max }\end{array}$ & $\mathrm{n}$ & Média & $\begin{array}{c}\text { Erro } \\
\text { Padrão }\end{array}$ & $\begin{array}{l}\text { Min e } \\
\text { Max }\end{array}$ \\
\hline Oh & 7 & $60,04 \mathrm{aA}$ & 9,17 & $\begin{array}{l}25,56 \\
87,68\end{array}$ & 12 & $61,66 \mathrm{cA}$ & 9,63 & $\begin{array}{c}15,19 \\
142,58\end{array}$ \\
\hline $3 h$ & 8 & $59,15 \mathrm{aA}$ & 14,19 & $\begin{array}{c}18,81 \\
145,67\end{array}$ & 12 & $84,35 \mathrm{bcA}$ & 14,20 & $\begin{array}{c}30,63 \\
181,81\end{array}$ \\
\hline $6 \mathrm{~h}$ & 8 & $77,27 \mathrm{aA}$ & 24,42 & $\begin{array}{c}21,63 \\
217,13\end{array}$ & 12 & $96,51 \mathrm{abcA}$ & 15,23 & $\begin{array}{c}40,41 \\
225,02\end{array}$ \\
\hline $12 \mathrm{~h}$ & 8 & $91,93 \mathrm{aA}$ & 25,98 & $\begin{array}{c}40,38 \\
269,47\end{array}$ & 12 & 81,06 bcA & 12,60 & $\begin{array}{c}25,61 \\
196,14\end{array}$ \\
\hline $24 \mathrm{~h}$ & 8 & $91,21 \mathrm{aB}$ & 9,14 & $\begin{array}{c}63,93 \\
130,06\end{array}$ & 12 & $123,67 \mathrm{abA}$ & 9,14 & $\begin{array}{c}78,53 \\
197,32\end{array}$ \\
\hline $48 h$ & 8 & $94,27 \mathrm{aA}$ & 3,19 & $\begin{array}{c}75,75 \\
103,09\end{array}$ & 12 & $130,99 \mathrm{aA}$ & 14,29 & $\begin{array}{c}11,09 \\
193,46\end{array}$ \\
\hline 3 dias & 8 & $90,97 \mathrm{aA}$ & 5,24 & $\begin{array}{c}73,77 \\
118,09\end{array}$ & 12 & 99,75 abcA & 10,82 & $\begin{array}{c}8,53 \\
162,49\end{array}$ \\
\hline 5 dias & 8 & $106,99 \mathrm{aA}$ & 11,82 & $\begin{array}{c}75,00 \\
179,15\end{array}$ & 9 & 88,13 abcA & 11,23 & $\begin{array}{c}9,37 \\
119,82\end{array}$ \\
\hline 7 dias & 8 & 102,15 aA & 16,63 & $\begin{array}{c}50,86 \\
205,07\end{array}$ & 12 & $103,91 \mathrm{abcA}$ & 11,16 & $\begin{array}{c}11,53 \\
167,49\end{array}$ \\
\hline 15 dias & 8 & $99,33 \mathrm{aA}$ & 6,34 & $\begin{array}{c}81,32 \\
136,05\end{array}$ & 12 & $120,46 \mathrm{abA}$ & 11,92 & $\begin{array}{c}8,22 \\
166,31\end{array}$ \\
\hline 30 dias & 8 & 89,14 aA & 9,85 & $\begin{array}{c}39,77 \\
132,67\end{array}$ & 10 & $109,69 \mathrm{abA}$ & 13,12 & $\begin{array}{c}4,77 \\
154,65\end{array}$ \\
\hline
\end{tabular}

Médias seguidas por letras minúsculas diferentes na mesma coluna diferiram estatisticamente entre si pelo Teste de Tukey $(P<0,05)$. Médias seguidas por letras maiúsculas diferentes na mesma linha diferiram estatisticamente entre si pelo Teste $t$ (Student) $(P<0,05)$

Fonte: Própria autoria. 
Gráfico 30 - Médias com erros padrão para glicose plasmática de bezerros oriundos de FIV e por IA nos primeiros 30 dias de vida obtidos por cesariana com indução do parto - Pirassununga - 2018

.....Bezerros FIV $-\Delta=$ Bezerros IA

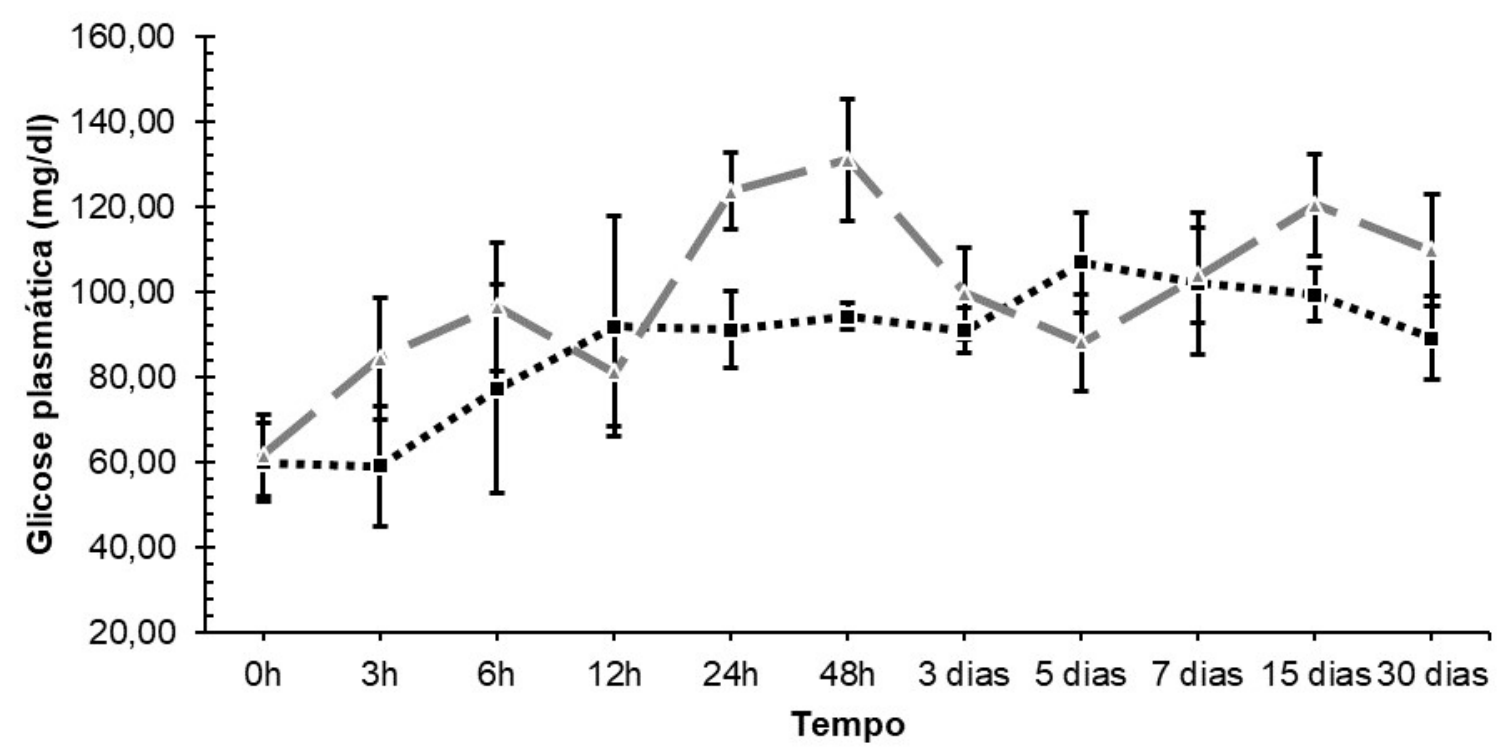

Fonte: Própria autoria.

Na tabela 31 e no gráfico 31 estão representados os resultados da lactato plasmático dos bezerros oriundos de FIV e por IA (grupo controle). Não houve diferença estatística significativa entre os tratamentos dentro de cada tempo separadamente $(P>0,05)$, houve entre os períodos de avaliação dentro de cada tratamento $(P<0,05)$.

Os bezerros oriundos de FIV e os do grupo controle revelaram teores mais elevados ao nascimento (58,82 e 58,68 $\mathrm{mg} / \mathrm{dL}$, respectivamente), superiores também aos valores de referência para bovinos adultos $(5-20 \mathrm{mg} / \mathrm{dL})$ relatados por Kaneko, Harvey e Bruss (2008).

Após o procedimento de cesariana os bezerros de ambos os grupos apresentaram teores de lactato semelhante ao observado por Marchese (2014), com bezerros clones. Neste trabalho constatou-se não haver efeito da FIV sobre a concentração deste metabólito. Sugere-se que o teor de lactato, imediatamente após o nascimento, seria indicativo de hipóxia e refletiria a intensa mobilização das reservas de energia, em parte, pelo aumento da atividade simpática diante dos fatores estressantes do parto e da adaptação a vida extrauterina (STEINHARDT et al., 1995). 
Tabela 31 - Médias, erros padrão, medidas mínimas e máximas para lactato plasmático $(\mathrm{mg} / \mathrm{dL})$ de bezerros oriundos de FIV e por IA nos primeiros 30 dias de vida obtidos por cesariana com indução do parto

\begin{tabular}{|c|c|c|c|c|c|c|c|c|}
\hline \multirow[b]{2}{*}{ Tempo } & \multicolumn{4}{|c|}{ Bezerros FIV } & \multicolumn{4}{|c|}{ Bezerros IA } \\
\hline & $\mathrm{n}$ & Média & $\begin{array}{l}\text { Erro } \\
\text { Padrão }\end{array}$ & $\begin{array}{l}\text { Min e } \\
\text { Max }\end{array}$ & $\mathrm{n}$ & Média & $\begin{array}{l}\text { Erro } \\
\text { Padrão }\end{array}$ & $\begin{array}{l}\text { Min e } \\
\text { Max }\end{array}$ \\
\hline $\mathrm{Oh}$ & 8 & $59,82 \mathrm{aA}$ & 10,15 & $\begin{array}{c}9,73 \\
105,78\end{array}$ & 12 & 58,68 aA & 8,71 & $\begin{array}{r}25,52 \\
115,03\end{array}$ \\
\hline $3 \mathrm{~h}$ & 8 & 40,28 abcA & 7,67 & $\begin{array}{l}18,20 \\
69,68\end{array}$ & 12 & $28,67 \mathrm{bA}$ & 2,56 & $\begin{array}{r}16,49 \\
40,75\end{array}$ \\
\hline $6 h$ & 8 & $41,14 \mathrm{abA}$ & 10,37 & $\begin{array}{c}22,93 \\
110,54\end{array}$ & 12 & $38,72 \mathrm{abA}$ & 3,51 & $\begin{array}{l}23,31 \\
57,58\end{array}$ \\
\hline $12 \mathrm{~h}$ & 8 & $27,60 \mathrm{bcA}$ & 3,17 & $\begin{array}{l}13,07 \\
40,05\end{array}$ & 12 & $38,43 a b A$ & 4,52 & $\begin{array}{r}15,76 \\
74,99\end{array}$ \\
\hline $24 \mathrm{~h}$ & 8 & $27,38 \mathrm{bcA}$ & 4,13 & $\begin{array}{l}15,93 \\
52,48\end{array}$ & 12 & 25,85 bA & 3,42 & $\begin{array}{r}10,23 \\
50,17\end{array}$ \\
\hline $48 \mathrm{~h}$ & 8 & 27,82 bcA & 4,58 & $\begin{array}{l}16,18 \\
54,67\end{array}$ & 12 & 20,38 bA & 7,20 & $\begin{array}{c}8,55 \\
99,14\end{array}$ \\
\hline 3 dias & 8 & $26,31 \mathrm{bcA}$ & 5,08 & $\begin{array}{l}15,27 \\
54,17\end{array}$ & 12 & $20,85 \mathrm{bA}$ & 7,69 & $\begin{array}{c}9,13 \\
104,86\end{array}$ \\
\hline 5 dias & 8 & $26,49 \mathrm{bcA}$ & 7,23 & $\begin{array}{l}10,83 \\
61,48\end{array}$ & 9 & $22,03 \mathrm{bA}$ & 13,21 & $\begin{array}{c}5,76 \\
127,56\end{array}$ \\
\hline 7 dias & 8 & 19,62 bcA & 6,88 & $\begin{array}{c}7,40 \\
67,05\end{array}$ & 12 & 17,32 bA & 7,60 & $\begin{array}{c}6,80 \\
100,58\end{array}$ \\
\hline 15 dias & 8 & $13,14 \mathrm{cA}$ & 2,84 & $\begin{array}{c}6,28 \\
31,08\end{array}$ & 12 & $16,61 \mathrm{bA}$ & 8,11 & $\begin{array}{c}5,44 \\
105,61\end{array}$ \\
\hline 30 dias & 8 & $16,46 \mathrm{bcA}$ & 4,69 & $\begin{array}{c}5,23 \\
40,88\end{array}$ & 12 & 18,49 bA & 8,31 & $\begin{array}{c}4,90 \\
105,49\end{array}$ \\
\hline
\end{tabular}

Médias seguidas por letras minúsculas diferentes na mesma coluna diferiram estatisticamente entre si pelo Teste de Tukey $(P<0,05)$. Médias seguidas por letras maiúsculas diferentes na mesma linha diferiram estatisticamente entre si pelo Teste $t$ (Student) $(P<0,05)$

Fonte: Própria autoria. 
Gráfico 31 - Médias com erros padrão para lactato plasmático de bezerros oriundos de FIV e por IA nos primeiros 30 dias de vida obtidos por cesariana com indução do parto - Pirassununga - 2018
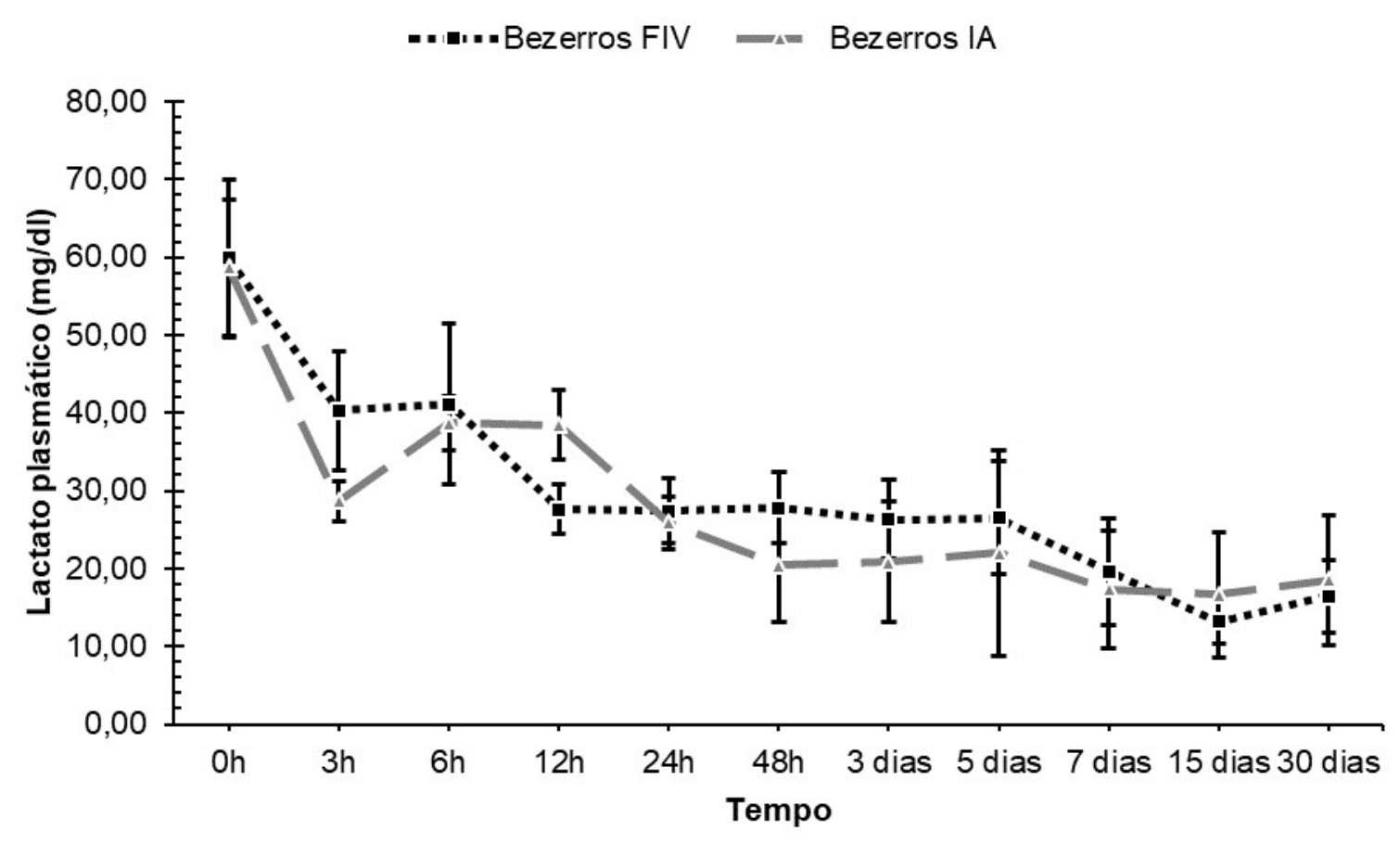

Fonte: Própria autoria.

Nas tabelas 32 e 33 e no gráfico 32 e 33 estão representados os resultados de ß-hidroxibutirato e NEFA séricos dos bezerros oriundos de FIV e por IA (grupo controle). Não houve diferença estatística significativa entre os tratamentos dentro de cada tempo separadamente para BHB $(P>0,05)$, houve entre os períodos de avaliação dentro de cada tratamento, nos bezerros IA $(P<0,05)$. Houve diferença estatística significativa entre os tratamentos no momento 30 dias de vida separadamente para NEFA $(P<0,05)$, houve também entre os períodos de avaliação nos bezerros IA $(P<0,05)$.

Neste trabalho observou-se que a média dos teores de BHB do grupo de bezerros FIV foi semelhante ao dos bezerros do grupo controle. Entretanto, apenas este último revelou diferença entre os tempos avaliados, sendo notada a maior diferença entre 12 horas de vida $(0,59 \mathrm{mg} / \mathrm{dL})$ e 7 dias de vida $(1,67 \mathrm{mg} / \mathrm{dL})$. Os valores estavam próximos da faixa de referência $(1,14-2,14 \mathrm{mg} / \mathrm{dL})$ relatados por Pogliani e Birgel Junior (2007) e semelhante ao observado por Piccioni et al. (2010). Sugere-se que as variações nos resultados de BHB tenham caráter fisiológico, sem efeito da FIV nas concentrações séricas deste metabólito. 
Tabela 32 - Médias, erros padrão, medidas mínimas e máximas para $\beta$ hidroxibutirato sérico $(\mathrm{mg} / \mathrm{dL})$ de bezerros oriundos de FIV e por IA nos primeiros 30 dias de vida obtidos por cesariana com indução do parto

\begin{tabular}{|c|c|c|c|c|c|c|c|c|}
\hline \multirow[b]{2}{*}{ Tempo } & \multicolumn{4}{|c|}{ Bezerros FIV } & \multicolumn{4}{|c|}{ Bezerros IA } \\
\hline & $\mathrm{n}$ & Média & Erro Padrão & $\begin{array}{l}\text { Min e } \\
\text { Max }\end{array}$ & $\mathrm{n}$ & Média & Erro Padrão & $\begin{array}{l}\text { Min e } \\
\text { Max }\end{array}$ \\
\hline \multirow{2}{*}{$\mathrm{Oh}$} & \multirow{2}{*}{6} & \multirow{2}{*}{$2,02 \mathrm{aA}$} & \multirow{2}{*}{0,35} & 0,54 & \multirow{2}{*}{12} & \multirow{2}{*}{0,78 bA } & \multirow{2}{*}{0,21} & 0,31 \\
\hline & & & & 2,89 & & & & 2,59 \\
\hline \multirow{2}{*}{$3 \mathrm{~h}$} & \multirow{2}{*}{8} & \multirow{2}{*}{$1,48 \mathrm{aA}$} & \multirow{2}{*}{0,46} & 0,63 & \multirow{2}{*}{12} & \multirow{2}{*}{$0,81 \mathrm{abA}$} & \multirow{2}{*}{0,22} & 0,31 \\
\hline & & & & 4,55 & & & & 2,75 \\
\hline \multirow{2}{*}{$6 \mathrm{~h}$} & \multirow{2}{*}{8} & \multirow{2}{*}{$1,29 \mathrm{aA}$} & \multirow{2}{*}{0,60} & 0,30 & \multirow{2}{*}{12} & \multirow{2}{*}{ 0,61 bA } & \multirow{2}{*}{0,14} & 0,31 \\
\hline & & & & 5,41 & & & & 1,84 \\
\hline \multirow{2}{*}{$12 \mathrm{~h}$} & \multirow{2}{*}{8} & \multirow{2}{*}{$0,93 \mathrm{aA}$} & \multirow{2}{*}{0,19} & 0,16 & \multirow{2}{*}{12} & \multirow{2}{*}{$0,59 \mathrm{bA}$} & \multirow{2}{*}{0,12} & 0,31 \\
\hline & & & & 1,88 & & & & 1,53 \\
\hline \multirow[b]{2}{*}{$24 \mathrm{~h}$} & \multirow[b]{2}{*}{8} & & & 0,51 & & & & 0,31 \\
\hline & & 1,23 aA & 0,15 & 1,95 & 12 & 0,72 bA & 0,18 & 2,28 \\
\hline & & & & 1,03 & & & & 0,31 \\
\hline $48 \mathrm{~h}$ & 8 & 1,63 aA & 0,32 & 3,82 & 12 & $0,97 \mathrm{abA}$ & 0,16 & 1,93 \\
\hline & & & & 0,89 & & & & 0,31 \\
\hline 3 dias & 8 & 1,49 aA & 0,15 & 2,34 & 12 & $1,41 \mathrm{abA}$ & 0,25 & 3,37 \\
\hline 5 dina & 0 & $100 \Omega$ & 010 & 0,16 & 11 & 121 & $0 ? 0$ & 0,31 \\
\hline 5 ulas & 0 & $1,00 \mathrm{~d} A$ & 0,10 & 1,39 & 111 & $1, \angle 1 \mathrm{aDA}$ & $0, \angle 0$ & 2,23 \\
\hline 7 & & 1 & & 0,16 & & 1 & 011 & 0,31 \\
\hline 1 alds & $r$ & $1,01 \mathrm{~d} A$ & 0,19 & 1,61 & 12 & $1,6 /$ aA & 0,44 & 5,57 \\
\hline & & & & 0,16 & & & & 0,31 \\
\hline 15 dias & $r$ & $2,1 \angle \mathrm{aA}$ & $0, \angle 8$ & 2,42 & 12 & 1,18 abA & 0,25 & 3,20 \\
\hline & & & & 0,26 & & & & 0,44 \\
\hline 30 dias & $r$ & 1,33 aA & 0,18 & 1,56 & 12 & $1,0 / \mathrm{abA}$ & 0,14 & 1,96 \\
\hline
\end{tabular}

Médias seguidas por letras minúsculas diferentes na mesma coluna diferiram estatisticamente entre si pelo Teste de Tukey $(P<0,05)$. Médias seguidas por letras maiúsculas diferentes na mesma linha diferiram estatisticamente entre si pelo Teste $t$ (Student) $(P<0,05)$

Fonte: Própria autoria. 
Gráfico 32 - Médias com erros padrão para $\beta$-hidroxibutirato sérico de bezerros oriundos de FIV e por IA nos primeiros 30 dias de vida obtidos por cesariana com indução do parto - Pirassununga - 2018

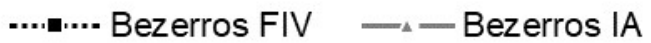

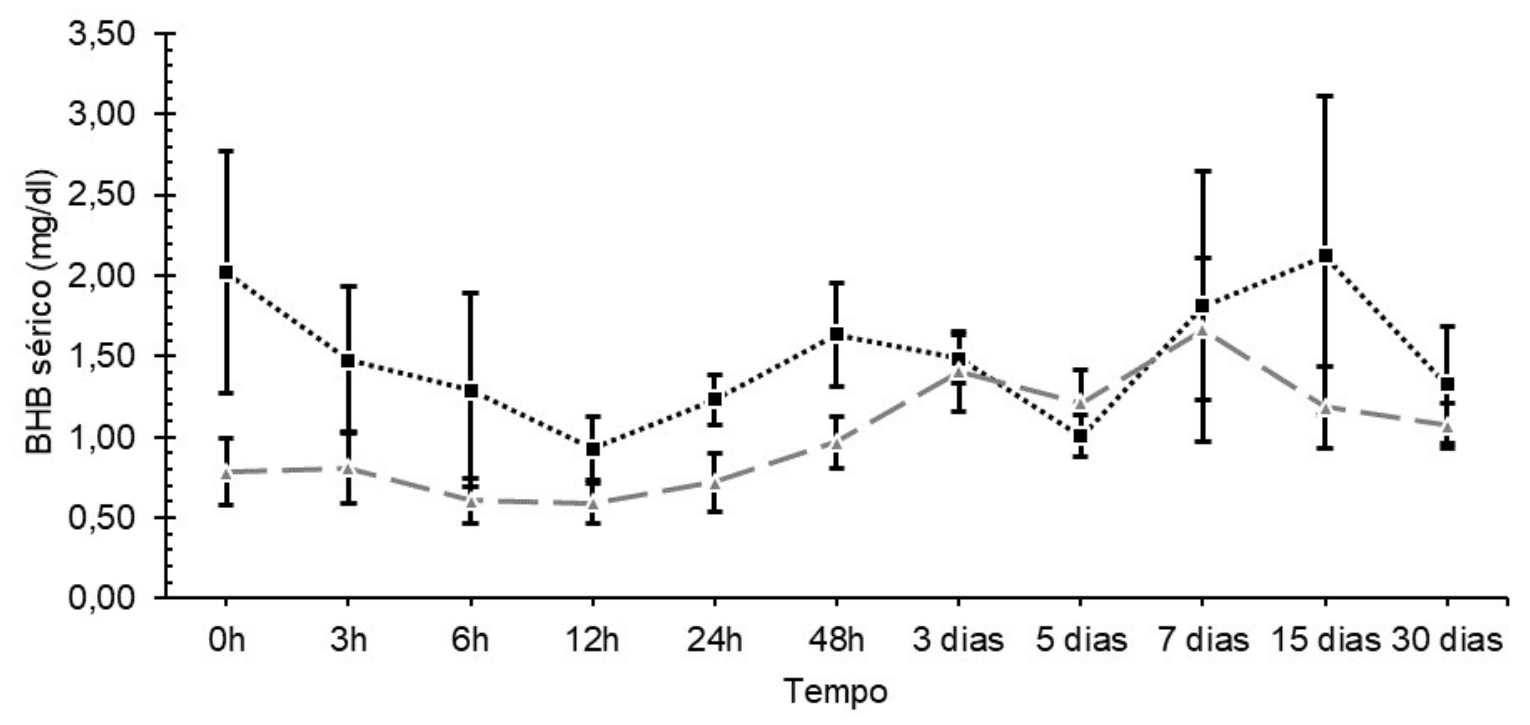

Fonte: Própria autoria.

Após o nascimento, com a ruptura do cordão umbilical, o neonato deixa de receber nutrientes maternos. A partir deste instante os bezerros desenvolvem hipoglicemia (Girard et al., 1992), passando a obter glicose através do glicogênio hepático armazenado no final da gestação e da gordura marrom. Com o esgotamento das reservas de glicogênio hepático, a obtenção de energia ocorre, principalmente, pela gliconeogênese com mobilização de NEFA e formação de corpos cetônicos. Neste instante o nível sérico de NEFA e BHB aumenta rapidamente, até o momento em que bezerro possa ingerir o colostro em quantidade adequada, para a partir de então seus teores séricos diminuírem (Girard, 1990; Girard et al., 1992)

Ao ingerir o colostro, o neonato passa a ter ácidos graxos de cadeia longa disponível para iniciar os processos de oxidação para obtenção de energia, com isso há produção de corpos cetônicos em baixos níveis (Girard et al., 1992), com concentração de BHB abaixo dos limites de detecção de 1,04 mg/dL observados por Hammon et al. (2012). 
Tabela 33 - Médias, erros padrão, medidas mínimas e máximas para NEFA sérico $(\mathrm{mmol} / \mathrm{L})$ de bezerros oriundos de FIV e por IA nos primeiros 30 dias de vida obtidos por cesariana com indução do parto

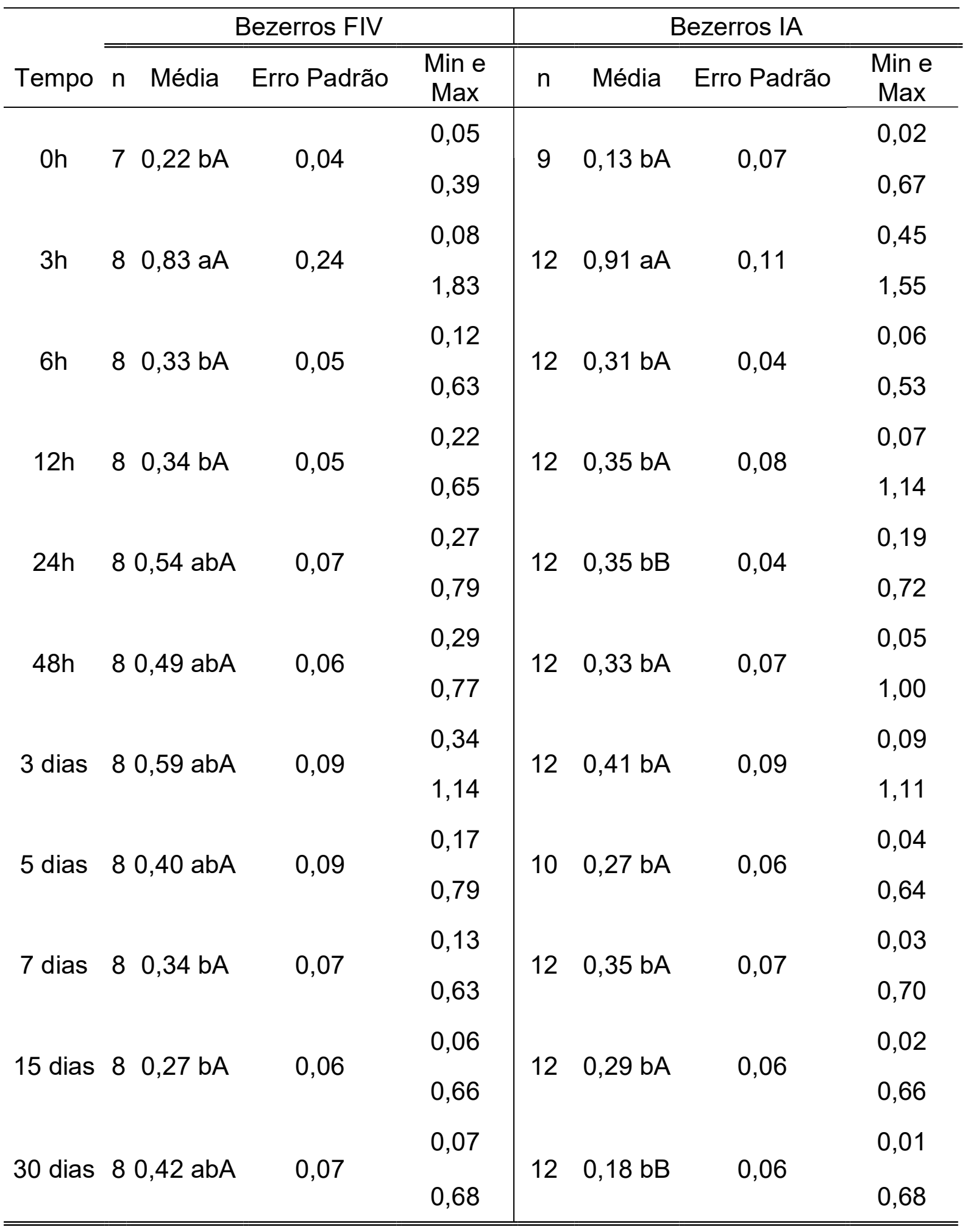

Médias seguidas por letras minúsculas diferentes na mesma coluna diferiram estatisticamente entre si pelo Teste de Tukey $(P<0,05)$. Médias seguidas por letras maiúsculas diferentes na mesma linha diferiram estatisticamente entre si pelo Teste $t$ (Student) $(P<0,05)$

Fonte: Própria autoria. 
Gráfico 33 - Médias com erros padrão para NEFA sérico de bezerros oriundos de FIV e por IA nos primeiros 30 dias de vida obtidos por cesariana com indução do parto - Pirassununga - 2018

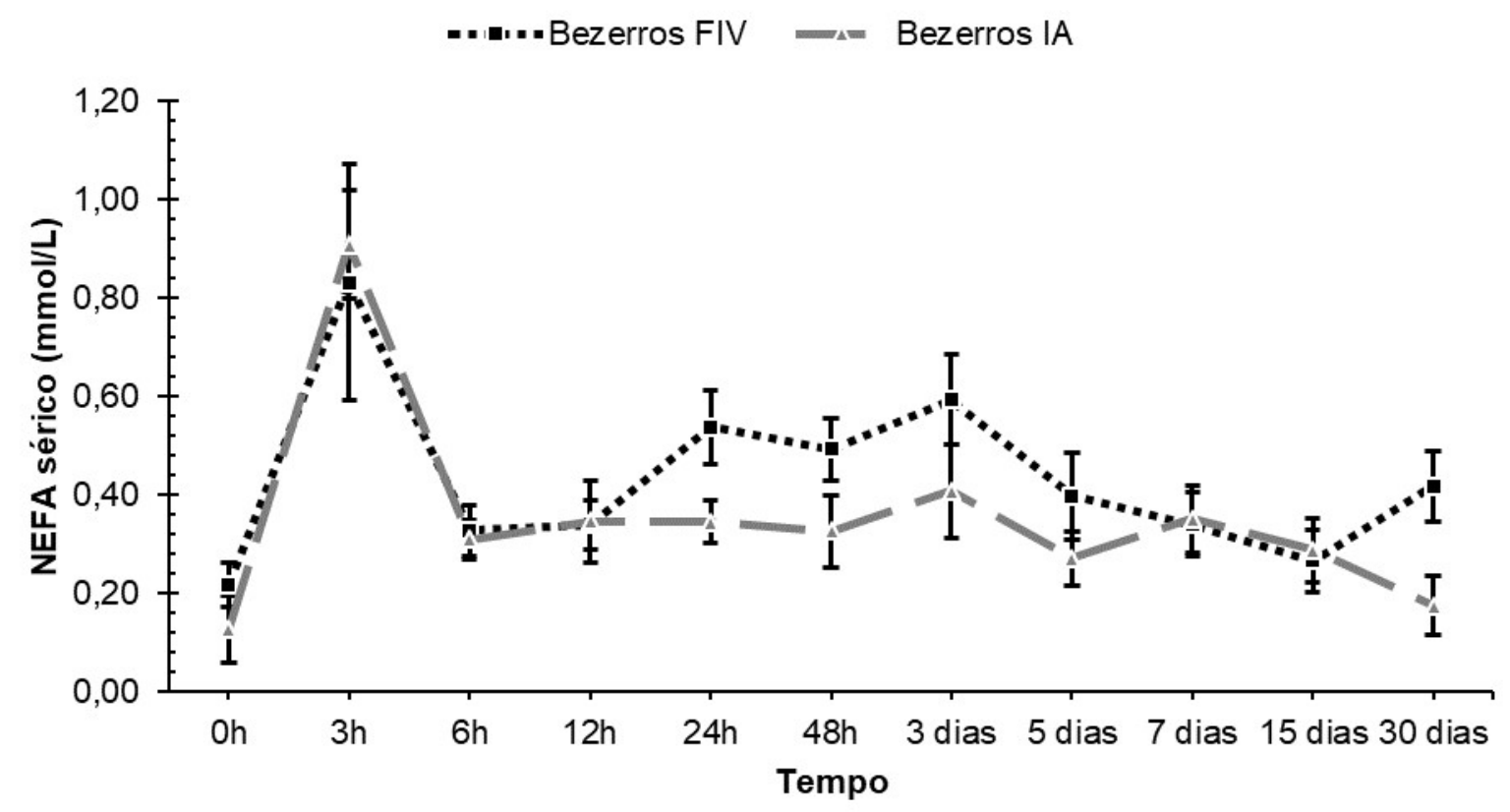

Fonte: Própria autoria.

Os resultados de NEFA diferiram entre os tratamentos apenas no momento 30 dias de vida, quando seus teores já estão sob grande influência da dieta (GIRARD et al., 1992). Também se constatou a elevação dos teores nos primeiros momentos após o nascimento, a partir de 3 horas de vida, semelhante ao relatado por Girard et al. (1992) e próximos aos valores observados por Piccioni et al. (2010) e Steinhoff-Wagner (2011). Em todos os momentos permaneceram abaixo dos teores de referência para bovinos de corte $(<0,91 \mathrm{mmol} / \mathrm{L})$ considerado pelo Laboratório de Diagnóstico Veterinário do Colégio de Medicina Veterinária da Universidade do Estado de Oregon, Estados Unidos (OREGON STATE UNIVERSITY, 2018). Neste trabalho não foi observado efeito da FIV sobre a concentração sérica de NEFA.

Na tabela 34 e no gráfico 34 estão representados os resultados da insulina sérica dos bezerros oriundos de FIV e por IA (grupo controle). Houve diferença estatística significativa entre os tratamentos no momento 7 dias de vida separadamente $(P<0,05)$, e não houve entre os períodos de avaliação dentro de cada tratamento $(P>0,05)$. 
Em partos laboriosos os neonatos podem apresentar diminuição dos níveis circulantes de insulina, independente de hipoglicemia, imediatamente após o nascimento por efeito do aumento da atividade simpática (GIRARD et al., 1992), sendo que após a ingestão de colostro os níveis de insulina se elevam (RAUPRICH; HAMMON; BLUM, 2000). Este efeito não foi observado neste trabalho, uma vez que os valores estavam acima do referenciado por Kaneko, Harvey e Bruss (2008) e aos observados por Lents et al. (1998) desde o nascimento e persistiram até os 7 dias de vida. Os valores da insulina sérica revelaram semelhança entre os grupos, ao nascimento, ambos estavam hiperinsulinêmicos comparados a referência supracitada. Houve diferença entre os grupos no momento 7 dias de vida, onde os bezerros do grupo FIV mantiveram os valores e o grupo controle revelou diminuição na média, apesar de não ter sido suficiente para gerar diferença estatística no tempo para este grupo. Sugere-se resistência à insulina nos bezerros de FIV devidos seus teores elevados quanto aos valores de referência e por demonstrarem hipoglicemia até 12 horas de vida, mesmo tendo sido feito a colostragem com $5 \%$ do peso vivo na primeira hora e completado os 10\% com até 6 horas de vida, comparados aos bezerros controle que alcançaram a normoglicemia com 3 horas de vida.

Tabela 34 - Médias, erros padrão, medidas mínimas e máximas para insulina sérica $(\mathrm{ng} / \mathrm{mL})$ de bezerros oriundos de FIV e por IA nos primeiros 30 dias de vida obtidos por cesariana com indução do parto

\begin{tabular}{|c|c|c|c|c|c|c|c|c|}
\hline \multirow[b]{2}{*}{ Tempo } & \multicolumn{4}{|c|}{ Bezerros FIV } & \multicolumn{4}{|c|}{ Bezerros IA } \\
\hline & $\mathrm{n}$ & Média & Erro Padrão & $\begin{array}{c}\operatorname{Min} e \\
\operatorname{Max}\end{array}$ & $n$ & Média & Erro Padrão & $\begin{array}{c}\operatorname{Min} e \\
\text { Max }\end{array}$ \\
\hline $\mathrm{Oh}$ & 4 & 2,25 aA & 0,58 & $\begin{array}{l}0,70 \\
3,53\end{array}$ & 8 & 3,82 aA & 1,56 & $\begin{array}{l}0,23 \\
9,79\end{array}$ \\
\hline $12 \mathrm{~h}$ & 4 & $4,10 \mathrm{aA}$ & 1,61 & $\begin{array}{l}1,90 \\
8,76\end{array}$ & 8 & 2,86 aA & 0,66 & $\begin{array}{l}0,44 \\
5,78\end{array}$ \\
\hline $24 h$ & 4 & $4,30 \mathrm{aA}$ & 1,68 & $\begin{array}{l}2,54 \\
9,32\end{array}$ & 8 & $1,54 \mathrm{aA}$ & 0,45 & $\begin{array}{l}0,19 \\
4,34\end{array}$ \\
\hline 7 dias & 4 & $4,12 \mathrm{aA}$ & 1,78 & $\begin{array}{l}1,27 \\
9,32\end{array}$ & 8 & $1,08 \mathrm{aB}$ & 0,21 & $\begin{array}{l}0,42 \\
2,16\end{array}$ \\
\hline
\end{tabular}

Medianas seguidas por letras minúsculas diferentes na mesma coluna diferiram estatisticamente entre si pelo Teste de Tukey $(\mathrm{P}<0,05)$. Médias seguidas por letras maiúsculas diferentes na mesma linha diferiram estatisticamente entre si pelo Teste $t$ (Student) $(P<0,05)$

Fonte: Própria autoria. 
Gráfico 34 - Médias com erros padrão para insulina sérica de bezerros oriundos de FIV e por IA nos primeiros 30 dias de vida obtidos por cesariana com indução do parto - Pirassununga - 2018

-....Bezerros FIV - - Bezerros IA

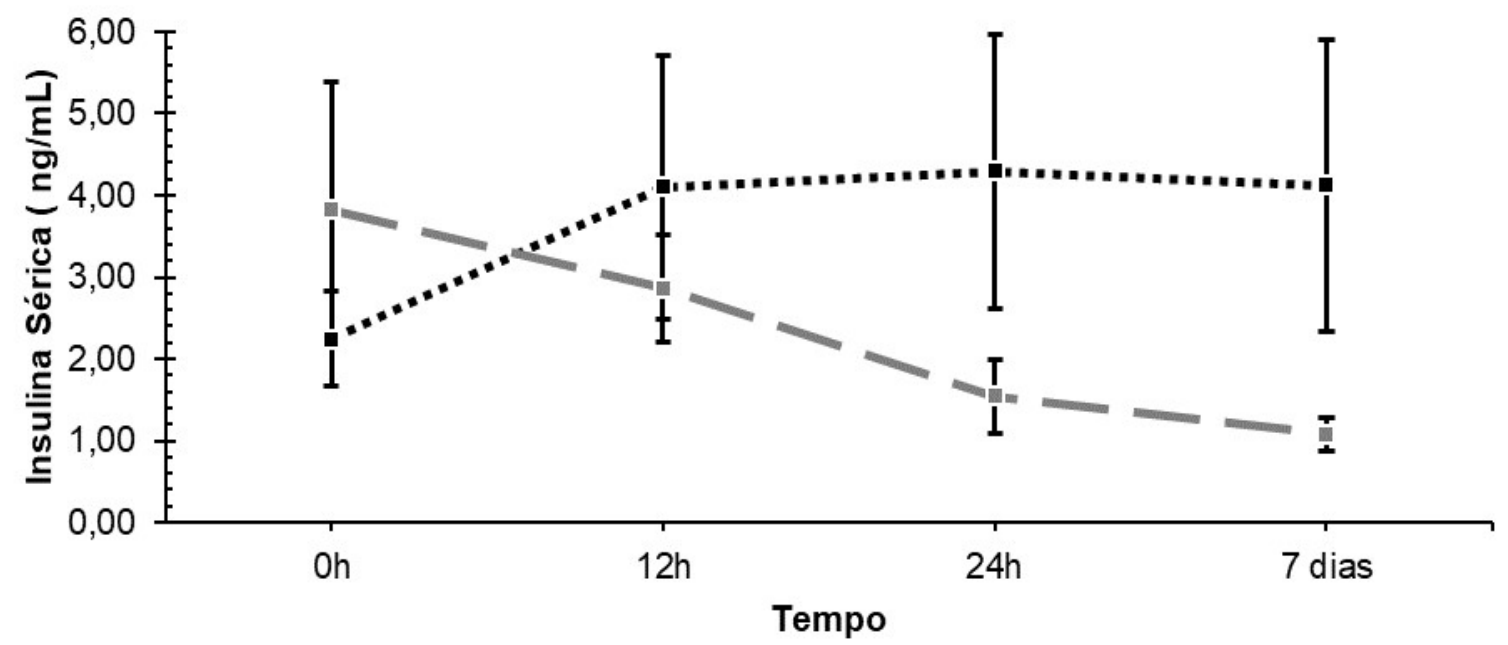

Fonte: Própria autoria.

$\mathrm{Na}$ tabela 35 e no gráfico 35 estão representados os resultados da frutosamina sérica dos bezerros oriundos de FIV e por IA (grupo controle). Não houve diferença estatística significativa entre os tratamentos no momento avaliado $(P>0,05)$.

Tabela 35 - Médias, erros padrão, medidas mínimas e máximas para frutosamina plasmática $(\mu \mathrm{mol} / \mathrm{L})$ de bezerros oriundos de FIV e por IA nos primeiros 30 dias de vida obtidos por cesariana com indução do parto

\begin{tabular}{|c|c|c|c|c|c|c|c|c|}
\hline \multirow[b]{2}{*}{ Tempo } & \multicolumn{4}{|c|}{ Bezerros FIV } & \multicolumn{4}{|c|}{ Bezerros IA } \\
\hline & $\mathrm{n}$ & Média & Erro Padrão & $\begin{array}{l}\text { Min e } \\
\text { Max }\end{array}$ & $n$ & Média & Erro Padrão & $\begin{array}{c}\text { Min e } \\
\text { Max }\end{array}$ \\
\hline Oh & 8 & $237,42 \mathrm{~A}$ & 26,42 & $\begin{array}{r}164,76 \\
412,77\end{array}$ & 12 & $218,32 \mathrm{~A}$ & 11,80 & $\begin{array}{l}146,01 \\
281,14\end{array}$ \\
\hline
\end{tabular}

Médias seguidas por letras minúsculas diferentes na linha diferiram estatisticamente entre si pelo Teste de Tukey $(P<0,05)$.

Fonte: Própria autoria. 
Gráfico 35 - Médias com erros padrão para frutosamina plasmática de bezerros oriundos de FIV e por IA nos primeiros 30 dias de vida obtidos por cesariana com indução do parto - Pirassununga - 2018

\section{- Bezerros FIV por cesariana induzidos $\quad$ QBezerros IA por cesariana induzidos}

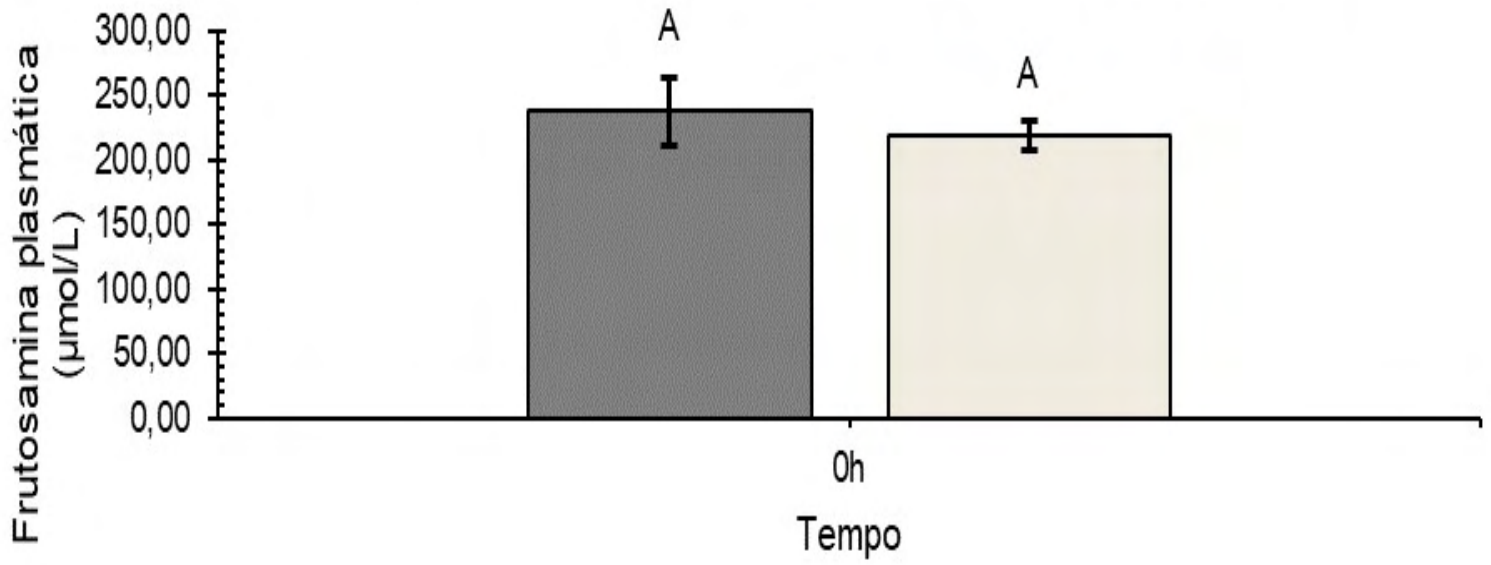

Colunas seguidas por letras maiúsculas diferentes, diferiram estatisticamente entre si pelo Teste de Tukey $(P)<0,05)$

Fonte: Própria autoria.

Frutosamina são todas as proteínas glicosiladas, por ligação irreversível da glicose com grupos amina da albumina e outras proteínas do sangue. Sua concentração sérica está diretamente relacionada com a concentração sérica da glicose nas últimas 2 a 3 semanas. Dessa forma torna-se um indicador fidedigno da concentração de glicose e de seu metabolismo, eliminando o efeito de alterações transitórias da ingestão de alimentos e pelo jejum sobre a glicemia. Alterações na concentração de frutosamina são indicativos de persistência na elevação ou diminuição sérica da glicose sanguínea, na falta de controle glicêmico nas últimas 2 a 3 semanas a depender da proteína que se ligou (THRALL et al., 2015).

Neste trabalho, os valores de frutosamina não revelaram influência da FIV . Os valores de frutosamina dos grupos ficaram dentro dos valores de referência $(213,4$ a $265 \mu \mathrm{mol} / \mathrm{L})$ revelados por Jensen, Petersen e Houe (1993) e acima do observado por Silva (2015) em bezerras da Girolandas (166,64 $\mu \mathrm{mol} / \mathrm{L})$, sem indicação no presente trabalho de alteração nos teores de glicose para o feto no final da gestação. 


\subsubsection{Procedimento experimental 3}

Na tabela 36 e no gráfico 36 estão apresentados os resultados do colesterol sérico de vacas receptoras de embriões por FIV da raça Nelore com bezerros apresentando peso elevado ao nascimento (síndrome do bezerro gigante), vacas receptoras de embriões por FIV da raça Nelore com bezerros apresentando peso dentro do padrão da raça ao nascimento e vacas gestantes de bezerros da raça Nelore por IA (grupo controle). Houve diferença estatística significativa entre os tratamentos dentro de cada tempo separadamente $(P<0,05)$, e entre os períodos de avaliação dentro de cada tratamento $(P<0,05)$.

As médias foram superiores para o grupo das vacas controle comparados aos dois grupos de vacas receptoras de FIV. Contudo todos os teores estavam próximos dos valores de referência para bovinos adultos $(80-120 \mathrm{mg} / \mathrm{dL}$ ) relatados por Kaneko, Harvey e Bruss (2008) e inferiores aos observados por Oliveira (2015) e Abud et al. (2016), mesmo a média das receptoras de bezerros com peso elevado ao nascimento no momento até 6 horas após o parto estando abaixo da referência, não foi suficiente para acusar diferença estatística.

Tabela 36 - Médias, erros padrão, medidas mínimas e máximas para colesterol sérico $(\mathrm{mg} / \mathrm{dL})$ de vacas gestantes por FIV e por IA no final da gestação e até $6 \mathrm{~h}$ após o parto natural

\begin{tabular}{|c|c|c|c|c|c|c|c|c|}
\hline \multirow[b]{2}{*}{ Tratamento } & \multicolumn{4}{|c|}{288 dias } & \multicolumn{4}{|c|}{ Até 6h após o parto } \\
\hline & $\mathrm{n}$ & Média & $\begin{array}{c}\text { Erro } \\
\text { Padrão }\end{array}$ & $\begin{array}{l}\operatorname{Min} e \\
\text { Max }\end{array}$ & $\mathrm{n}$ & Média & $\begin{array}{c}\text { Erro } \\
\text { Padrão }\end{array}$ & $\begin{array}{l}\text { Min e } \\
\text { Max }\end{array}$ \\
\hline Receptoras & & & & 22,5 & & & & 19,6 \\
\hline $\begin{array}{l}\text { FIV bez peso } \\
\text { elevado }\end{array}$ & 17 & $91,1 \mathrm{bA}$ & 6,4 & 157,3 & 17 & $74,3 \mathrm{bB}$ & 6,9 & 146,2 \\
\hline Receptoras & & & & & & & & 31,8 \\
\hline $\begin{array}{l}\text { FIV bez peso } \\
\text { padrão }\end{array}$ & 30 & $91,9 \mathrm{bA}$ & 4,8 & 148,6 & 32 & $82,7 \mathrm{bB}$ & 4,3 & 141,1 \\
\hline $\begin{array}{l}\text { Vacas IA } \\
\text { (controle) }\end{array}$ & 15 & $113,8 \mathrm{aA}$ & 7,1 & $\begin{array}{c}71,4 \\
172,3\end{array}$ & 16 & $102,5 \mathrm{aB}$ & 6,3 & $\begin{array}{c}50,9 \\
151,6\end{array}$ \\
\hline
\end{tabular}

Médias seguidas por letras minúsculas diferentes na mesma coluna diferiram estatisticamente entre si pelo Teste de Tukey $(P<0,05)$. Médias seguidas por letras maiúsculas diferentes na mesma linha diferiram estatisticamente entre si pelo Teste t pareado $(P<0,05)$

Fonte: Própria autoria. 
Gráfico 36 - Médias com erros padrão para colesterol sérico de vacas receptoras de FIV de bezerros com peso elevado após o nascimento, receptoras de FIV com bezerros de peso padrão após o nascimento e vacas gestantes por IA, no final da gestação e até $6 \mathrm{~h}$ após o parto natural a termo - Pirassununga - 2018

$\square$ Receptoras FIV bez peso elevado $\square$ Receptoras FIV bez peso padrão

aVacas IA (controle)

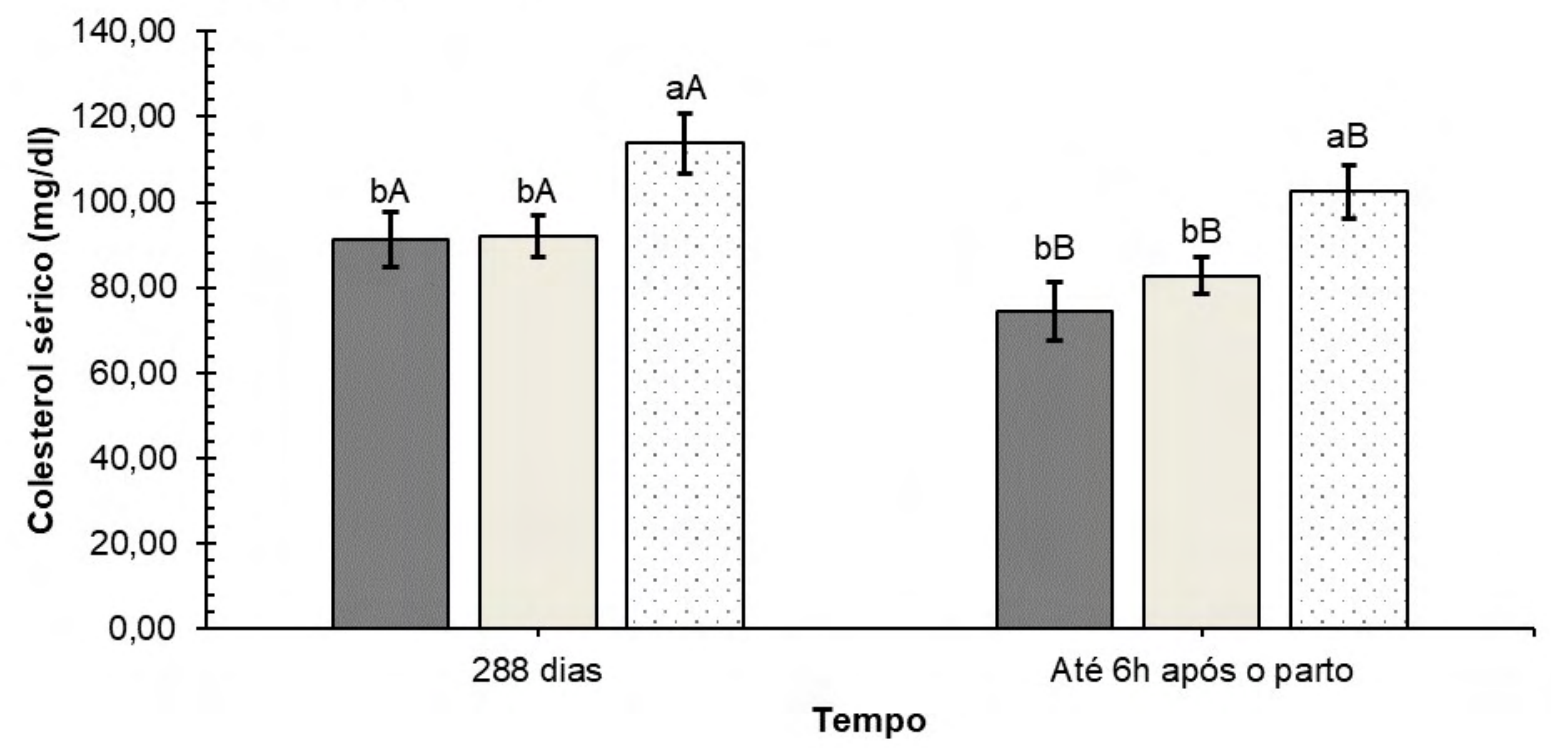

Colunas de cores diferentes seguidas com letras minúsculas diferentes, no mesmo tempo, diferiram estatisticamente entre si pelo Teste de Tukey $(P<0,05)$. Colunas de mesma cor seguidas por letras maiúsculas diferentes, diferiram estatisticamente entre si pelo Teste t pareado $(P<0,05)$

Fonte: Própria autoria.

Ambos os grupos das vacas receptoras de FIV e o das vacas controle também não demonstravam indícios de lesão hepática que justificasse valores inferiores aos de referência. Houve efeito do tempo sobre os resultados, todos os grupos diminuíram os teores de colesterol, embora permanecessem dentro do intervalo de referência. Neste trabalho, a avaliação dos resultados constata não haver influência da gestação por FIV, mesmo quando os bezerros apresentam síndrome do bezerro gigante, sobre a concentração sérica de colesterol.

Na tabela 37 e no gráfico 37 estão apresentados os resultados do triglicérides sérico de vacas receptoras de embriões por FIV da raça Nelore com bezerros apresentando peso elevado ao nascimento (síndrome do bezerro gigante), vacas receptoras de embriões por FIV da raça Nelore com bezerros apresentando peso dentro do padrão da raça ao nascimento e vacas gestantes de bezerros da raça Nelore por IA (grupo controle). Houve diferença estatística significativa entre os 
tratamentos no momento 288 dias de gestação separadamente $(P<0,05)$, e entre os períodos de avaliação dentro de cada tratamento $(P<0,05)$.

A média das vacas receptoras com bezerros apresentando peso elevado ao nascimento foram inferiores comparado as vacas controle no momento 288 dias de gestação, constatou-se também que todos os grupos apresentaram diminuição dos teores séricos no momento até 6 horas após o parto. Contudo os valores permaneceram acima da faixa de referência para bovinos adultos (0 - $14 \mathrm{mg} / \mathrm{dL})$ relatados por Kaneko, Harvey e Bruss (2008) e semelhantes aos observados por Oliveira (2015) durante o período experimental. Os resultados observados no presente experimento não revelaram influência da gestação por FIV, mesmo na existência de bezerros com síndrome do bezerro gigante nas concentrações séricas de triglicérides, as variações observadas possuem caráter fisiológico como explicado no procedimento experimental 1.

Tabela 37 - Médias, erros padrão, medidas mínimas e máximas para triglicérides sérico ( $\mathrm{mg} / \mathrm{dL}$ ) de vacas gestantes por FIV e por IA no final da gestação e até $6 \mathrm{~h}$ após o parto natural

\begin{tabular}{|c|c|c|c|c|c|c|c|c|}
\hline \multirow[b]{2}{*}{ Tratamento } & \multicolumn{4}{|c|}{288 dias } & \multicolumn{4}{|c|}{ Até 6h após o parto } \\
\hline & $\mathrm{n}$ & Média & $\begin{array}{c}\text { Erro } \\
\text { Padrão }\end{array}$ & $\begin{array}{l}\text { Min e } \\
\text { Max }\end{array}$ & $n$ & Média & $\begin{array}{c}\text { Erro } \\
\text { Padrão }\end{array}$ & $\begin{array}{l}\text { Min e } \\
\text { Max }\end{array}$ \\
\hline $\begin{array}{l}\text { Receptoras } \\
\text { FIV bez peso } \\
\text { elevado }\end{array}$ & 17 & 24,8 bA & 2,3 & $\begin{array}{c}9,4 \\
44,7\end{array}$ & 17 & $16,8 \mathrm{aB}$ & 1,3 & $\begin{array}{c}6,7 \\
27,6\end{array}$ \\
\hline $\begin{array}{l}\text { Receptoras } \\
\text { FIV bez peso } \\
\text { padrão }\end{array}$ & 30 & $28,1 \mathrm{abA}$ & 1,6 & $\begin{array}{r}11,5 \\
49,4\end{array}$ & 32 & $19,5 \mathrm{aB}$ & 1,3 & $\begin{array}{c}5,8 \\
48,3\end{array}$ \\
\hline $\begin{array}{l}\text { Vacas IA } \\
\text { (controle) }\end{array}$ & 15 & 33,5 aA & 2,3 & $\begin{array}{l}22,0 \\
48,0\end{array}$ & 16 & $21,8 \mathrm{aB}$ & 2,0 & $\begin{array}{c}9,4 \\
42,3\end{array}$ \\
\hline
\end{tabular}

Médias seguidas por letras minúsculas diferentes na mesma coluna diferiram estatisticamente entre si pelo Teste de Tukey $(P<0,05)$. Médias seguidas por letras maiúsculas diferentes na mesma linha diferiram estatisticamente entre si pelo Teste t pareado $(P<0,05)$

Fonte: Própria autoria. 
Gráfico 37 - Médias com erros padrão para triglicérides sérico de vacas receptoras de FIV de bezerros com peso elevado após o nascimento, receptoras de FIV com bezerros de peso padrão após o nascimento e vacas gestantes por IA, no final da gestação e até 6h após o parto natural a termo - Pirassununga - 2018

$\square$ Receptoras FIV bez peso elevado $\square$ Receptoras FIV bez peso padrão $\mathrm{V}$ Vacas IA (controle)

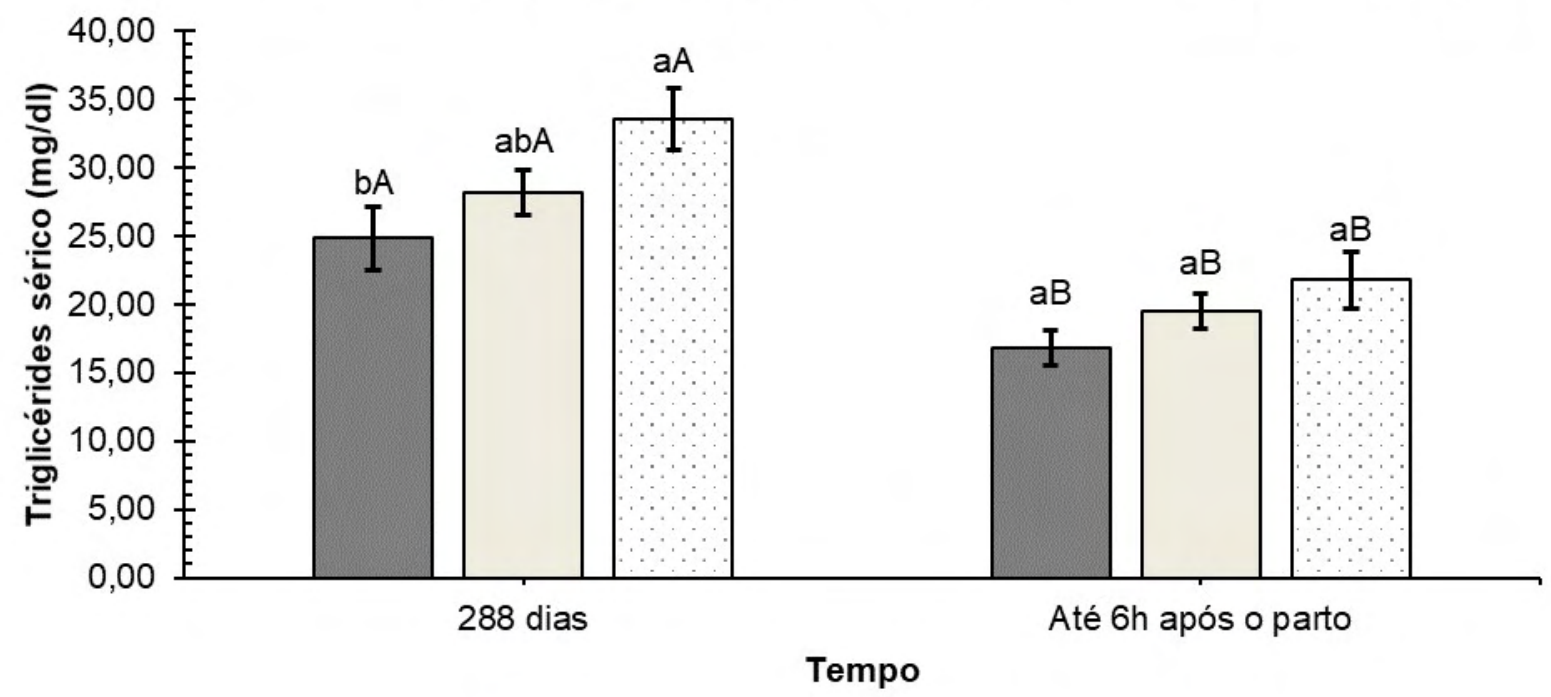

Colunas de cores diferentes seguidas com letras minúsculas diferentes, no mesmo tempo, diferiram estatisticamente entre si pelo Teste de Tukey $(P<0,05)$. Colunas de mesma cor seguidas por letras maiúsculas diferentes, diferiram estatisticamente entre si pelo Teste t pareado $(P<0,05)$

Fonte: Própria autoria

Na tabela 38 e no gráfico 38 estão apresentados os resultados da glicose plasmática de vacas receptoras de embriões por FIV da raça Nelore com bezerros apresentando peso elevado ao nascimento (síndrome do bezerro gigante), vacas receptoras de embriões por FIV da raça Nelore com bezerros apresentando peso dentro do padrão da raça ao nascimento e vacas gestantes de bezerros da raça Nelore por IA (grupo controle). Não houve diferença estatística significativa entre os tratamentos dentro de cada tempo separadamente $(P>0,05)$, e houve entre os períodos de avaliação para as vacas receptoras com bezerros apresentando peso dentro do padrão da raça ao nascimento e as de gestação por IA $(P<0,05)$.

No momento 288 dias de gestação os valores plasmáticos da glicose foram semelhantes entre os grupos avaliados, com exceção das vacas receptoras de FIV de bezerros com peso elevado ao nascimento, os níveis de glicemia aumentaram no segundo momento. No entanto, no momento até 6 horas após o parto todos os grupos estavam com teores acima da faixa de referência para bovinos adultos (40 a 
$80 \mathrm{mg} / \mathrm{dL}$ ) relatado por Swenson e Reece (1996) e observados por Pogliani e Birgel Junior (2007).

Tabela 38 - Médias, erros padrão, medidas mínimas e máximas para glicose plasmática $(\mathrm{mg} / \mathrm{dL})$ de vacas gestantes por FIV e por IA no final da gestação e até $6 \mathrm{~h}$ após o parto natural

\begin{tabular}{|c|c|c|c|c|c|c|c|c|}
\hline \multirow[b]{2}{*}{ Tratamento } & \multicolumn{4}{|c|}{288 dias } & \multicolumn{4}{|c|}{ Até $6 \mathrm{~h}$ após o parto } \\
\hline & $\mathrm{n}$ & Média & $\begin{array}{c}\text { Erro } \\
\text { Padrão }\end{array}$ & $\begin{array}{l}\operatorname{Min} \mathrm{e} \\
\operatorname{Max}\end{array}$ & $\mathrm{n}$ & Média & $\begin{array}{c}\text { Erro } \\
\text { Padrão }\end{array}$ & $\begin{array}{l}\operatorname{Min} e \\
\text { Max }\end{array}$ \\
\hline Receptoras & & & & 45,9 & & & & 46,7 \\
\hline $\begin{array}{l}\text { FIV bez } \\
\text { peso } \\
\text { elevado }\end{array}$ & 16 & 72,9 aA & 5,9 & 133,6 & 16 & 93,7 aA & 7,7 & 177,3 \\
\hline Receptoras & & & & 47,9 & & & & 39,9 \\
\hline $\begin{array}{l}\text { FIV bez } \\
\text { peso } \\
\text { padrão }\end{array}$ & 29 & $71,6 \mathrm{aB}$ & 3,3 & 119,9 & 32 & 97,5 aA & 6,8 & 212,7 \\
\hline $\begin{array}{l}\text { Vacas IA } \\
\text { (controle) }\end{array}$ & 15 & $66,8 \mathrm{aB}$ & 3,6 & $\begin{array}{l}51,8 \\
96,4\end{array}$ & 16 & $97,5 \mathrm{aA}$ & 6,9 & $\begin{array}{c}59,4 \\
145,1\end{array}$ \\
\hline
\end{tabular}

Médias seguidas por letras minúsculas diferentes na mesma coluna diferiram estatisticamente entre si pelo Teste de Tukey $(P<0,05)$. Médias seguidas por letras maiúsculas diferentes na mesma linha diferiram estatisticamente entre si pelo Teste t pareado $(P<0,05)$

Fonte: Própria autoria.

Gráfico 38 - Médias com erros padrão para glicose plasmática de vacas receptoras de FIV de bezerros com peso elevado após o nascimento, receptoras de FIV com bezerros de peso padrão após o nascimento e vacas gestantes por IA, no final da gestação e até $6 \mathrm{~h}$ após o parto natural a termo - Pirassununga - 2018

口Receptoras FIV bez peso elevado $\mathrm{R}$ Receptoras FIV bez peso padrão $\mathrm{V}$ Vacas IA (controle)

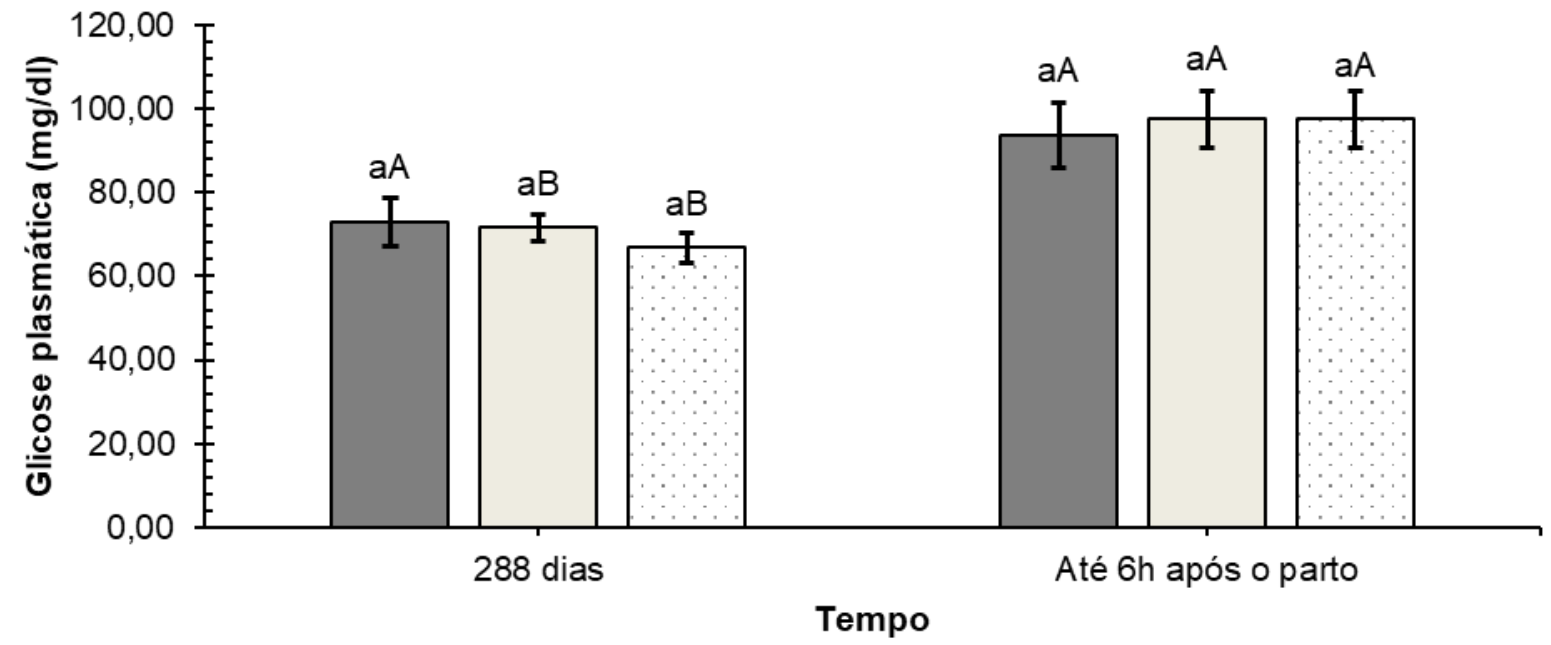

Colunas de cores diferentes seguidas com letras minúsculas diferentes, no mesmo tempo, diferiram estatisticamente entre si pelo Teste de Tukey $(P<0,05)$. Colunas de mesma cor seguidas por letras maiúsculas diferentes, diferiram estatisticamente entre si pelo Teste t pareado $(P<0,05)$

Fonte: Própria autoria. 
$\mathrm{Na}$ fisiologia do parto natural, o nível de cortisol materno aumenta pelo estresse do periparto, pelo estímulo da passagem do feto pelo canal do parto e para o estabelecimento da lactogenese (PRESTES; LANDIM-ALVARENGA, 2006). Nessas condições de estresse, há aumento dos níveis plasmáticos de glicose, simultâneo ao do cortisol endógeno (REZENDE et al., 2010). No presente estudo foi possível observar elevação dos níveis glicêmicos no momento até 6 horas após o parto nos grupos das vacas receptoras de FIV de bezerros com peso dentro do padrão e nas do grupo controle. Embora sem diferença estatística para o grupo das receptoras com bezerros de peso elevado ao nascimento, a média da glicose após o parto também estava acima dos valores de referência supracitados

Os resultados obtidos neste trabalho não demonstraram influência da gestação por FIV, mesmo na existência de bezerros com síndrome do bezerro gigante, sobre as concentrações séricas de glicose, também reforçam as considerações de González et al. (2000) sobre a perda de relevância de sua avaliação, devido a insensibilidade da glicemia a mudanças nutricionais e a sua sensibilidade ao estresse, como o parto natural.

Na tabela 39 e no gráfico 39 estão apresentados os resultados do lactato plasmático de vacas receptoras de embriões por FIV da raça Nelore com bezerros apresentando peso elevado ao nascimento (síndrome do bezerro gigante), vacas receptoras de embriões por FIV da raça Nelore com bezerros apresentando peso dentro do padrão da raça ao nascimento e vacas gestantes de bezerros da raça Nelore por IA (grupo controle). Não houve diferença estatística significativa entre os tratamentos dentro de cada tempo separadamente $(P>0,05)$, nem entre os períodos de avaliação dentro de cada tratamento $(P>0,05)$.

Neste procedimento experimental os teores plasmáticos de lactato estavam acima dos valores de referência para bovinos adultos $(5-20 \mathrm{mg} / \mathrm{dL})$ relatados por Kaneko, Harvey e Bruss (2008) para os dois grupos de vacas receptoras de FIV em ambos os momento e para as vacas do grupo controle, apenas no segundo momento. Também pode-se sugerir que as vacas de ambos os grupos não tiveram necessidade de utilizar o lactato como precursor para a gliconeogênese, suficiente para que houvesse diferença estatística entre os tratamentos e entre os tempos avaliados. A avaliação dos resultados do presente trabalho constata não haver influência da gestação por FIV, mesmo na existência de bezerros com síndrome do 
bezerro gigante, suficiente para promover sua utilização como precursor da gliconeogenese, para síntese de glicose no fígado, no final da gestação como relatado por Corrêa, González e Silva (2010).

Tabela 39 - Médias, erros padrão, medidas mínimas e máximas para lactato plasmático $(\mathrm{mg} / \mathrm{dL})$ de vacas gestantes por FIV e por IA no final da gestação e até $6 \mathrm{~h}$ após o parto natural

\begin{tabular}{|c|c|c|c|c|c|c|c|c|}
\hline \multirow[b]{2}{*}{ Tratamento } & \multicolumn{4}{|c|}{288 dias } & \multicolumn{4}{|c|}{ Até 6h após o parto } \\
\hline & $\mathrm{n}$ & Média & $\begin{array}{c}\text { Erro } \\
\text { Padrão }\end{array}$ & $\begin{array}{l}\operatorname{Mine} \\
\operatorname{Max}\end{array}$ & $\mathrm{n}$ & Média & $\begin{array}{c}\text { Erro } \\
\text { Padrão }\end{array}$ & $\begin{array}{l}\operatorname{Min} e \\
\operatorname{Max}\end{array}$ \\
\hline Receptoras & & & & 7,4 & & & & 14,4 \\
\hline $\begin{array}{l}\text { FIV bez peso } \\
\text { elevado }\end{array}$ & 13 & $30,3 \mathrm{aA}$ & 6,8 & 103,2 & 12 & $41,2 \mathrm{aA}$ & 11,6 & 133,0 \\
\hline $\begin{array}{l}\text { Receptoras } \\
\text { FIV bez peso } \\
\text { padrão }\end{array}$ & 25 & 28,9 aA & 3,8 & $\begin{array}{c}7,8 \\
83,0\end{array}$ & 29 & $37,1 \mathrm{aA}$ & 6,2 & $\begin{array}{c}7,7 \\
133,0\end{array}$ \\
\hline $\begin{array}{l}\text { Vacas IA } \\
\text { (controle) } \\
\end{array}$ & 16 & $19,9 a A$ & 2,5 & $\begin{array}{c}6,7 \\
36,4 \\
\end{array}$ & 12 & $25,3 \mathrm{aA}$ & 5,8 & $\begin{array}{c}6,3 \\
77,0\end{array}$ \\
\hline
\end{tabular}

Médias seguidas por letras minúsculas diferentes na mesma coluna diferiram estatisticamente entre si pelo Teste de Tukey $(P<0,05)$. Médias seguidas por letras maiúsculas diferentes na mesma linha diferiram estatisticamente entre si pelo Teste t pareado $(P<0,05)$

Fonte: Própria autoria

Gráfico 39 - Médias com erros padrão para Lactato plasmático de vacas receptoras de FIV de bezerros com peso elevado após o nascimento, receptoras de FIV com bezerros de peso padrão após o nascimento e vacas gestantes por IA, no final da gestação e até $6 \mathrm{~h}$ após o parto natural a termo - Pirassununga - 2018

口Receptoras FIV bez peso elevado $\mathrm{R}$ Receptoras FIV bez peso padrão $\square$ Vacas IA (controle)

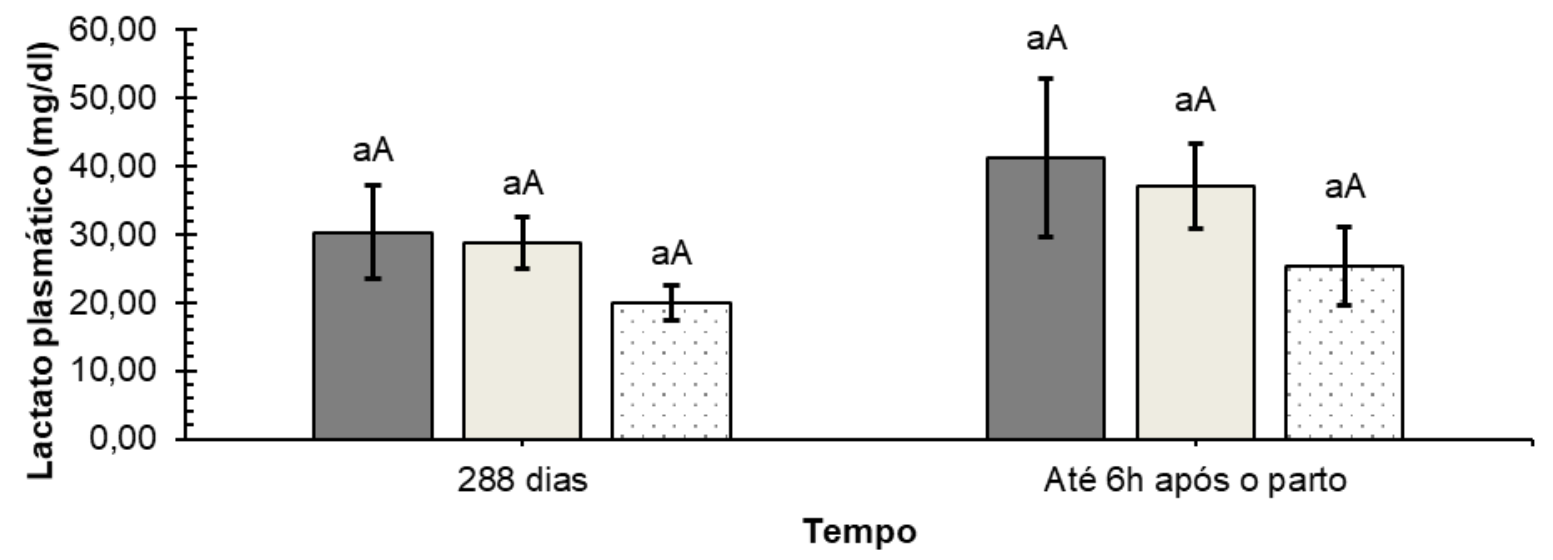

Colunas de cores diferentes seguidas com letras minúsculas diferentes, no mesmo tempo, diferiram estatisticamente entre si pelo Teste de Tukey $(P<0,05)$. Colunas de mesma cor seguidas por letras maiúsculas diferentes, diferiram estatisticamente entre si pelo Teste t pareado $(P<0,05)$

Fonte: Própria autoria. 
Nas tabelas 40 e 41 e nos gráficos 40 e 41 estão apresentados, respectivamente os resultados de ß-hidroxibutirato e NEFA séricos de vacas receptoras de embriões por FIV da raça Nelore com bezerros apresentando peso elevado ao nascimento (síndrome do bezerro gigante), vacas receptoras de embriões por FIV da raça Nelore com bezerros apresentando peso dentro do padrão da raça ao nascimento e vacas gestantes de bezerros da raça Nelore por IA (grupo controle). Não houve diferença estatística significativa entre os tratamentos dentro de cada tempo separadamente para BHB e NEFA $(P>0,05)$, houve entre os períodos de avaliação no grupo das receptoras de FIV de bezerros com peso elevado ao nascimento para $\mathrm{BHB}(\mathrm{P}<0,05)$ e não houve entre os períodos de avaliação dentro de cada tratamento para NEFA $(P>0,05)$.

O teor sérico de BHB dos animais acompanhados permaneceram abaixo do intervalo de referência para bovinos adultos $(8,0-11,8 \mathrm{mg} / \mathrm{dL})$ relatados por Kaneko, Harvey e Bruss (2008) e para ser considerado positivo para cetose $(14,4 \mathrm{mg} / \mathrm{dL})$ como mencionado por Oetzel (2003). Observou-se também que no grupo das receptoras de FIV com bezerros com peso elevado ao nascimento a média de BHB havia diminuído.

Tabela 40 - Médias, erros padrão, medidas mínimas e máximas para $\beta$ hidroxibutirato sérico $(\mathrm{mg} / \mathrm{dL})$ de vacas gestantes por FIV e por IA no final da gestação e até 6 h após o parto natural

\begin{tabular}{|c|c|c|c|c|c|c|c|c|}
\hline \multirow[b]{2}{*}{ Tratamento } & \multicolumn{4}{|c|}{288 dias } & \multicolumn{4}{|c|}{ Até 6h após o parto } \\
\hline & $\mathrm{n}$ & Média & $\begin{array}{c}\text { Erro } \\
\text { Padrão }\end{array}$ & $\begin{array}{l}\text { Min e } \\
\text { Max }\end{array}$ & $\mathrm{n}$ & Média & $\begin{array}{c}\text { Erro } \\
\text { Padrão }\end{array}$ & $\begin{array}{l}\text { Min e } \\
\text { Max }\end{array}$ \\
\hline $\begin{array}{l}\text { Receptoras } \\
\text { FIV bez peso } \\
\text { elevado }\end{array}$ & 17 & 6,3 aA & 0,7 & $\begin{array}{c}4,0 \\
16,0\end{array}$ & 17 & $4,3 \mathrm{aB}$ & 0,4 & $\begin{array}{l}2,0 \\
7,6\end{array}$ \\
\hline $\begin{array}{l}\text { Receptoras } \\
\text { FIV bez peso } \\
\text { padrão }\end{array}$ & 30 & 5,2 aA & 0,4 & $\begin{array}{c}2,4 \\
11,6\end{array}$ & 32 & 5,0 aA & 0,4 & $\begin{array}{l}2,0 \\
9,6\end{array}$ \\
\hline $\begin{array}{l}\text { Vacas IA } \\
\text { (controle) }\end{array}$ & 15 & 5,3 aA & 0,7 & $\begin{array}{c}2,7 \\
12,9\end{array}$ & 16 & 4,7 aA & 0,6 & $\begin{array}{c}2,6 \\
12,7\end{array}$ \\
\hline
\end{tabular}

Médias seguidas pela mesma letra maiúscula na linha não diferiram estatisticamente entre si pelo Teste t pareado $(P>0,05)$

Fonte: Própria autoria. 
Gráfico 40 - Médias com erros padrão para $\beta$-hidroxibutirato sérico de vacas receptoras de FIV de bezerros com peso elevado após o nascimento, receptoras de FIV com bezerros de peso padrão após o nascimento e vacas gestantes por IA, no final da gestação e até $6 \mathrm{~h}$ após o parto natural a termo - Pirassununga - 2018

$\square$ Receptoras FIV bez peso elevado $\square$ Receptoras FIV bez peso padrão

口Vacas IA (controle)

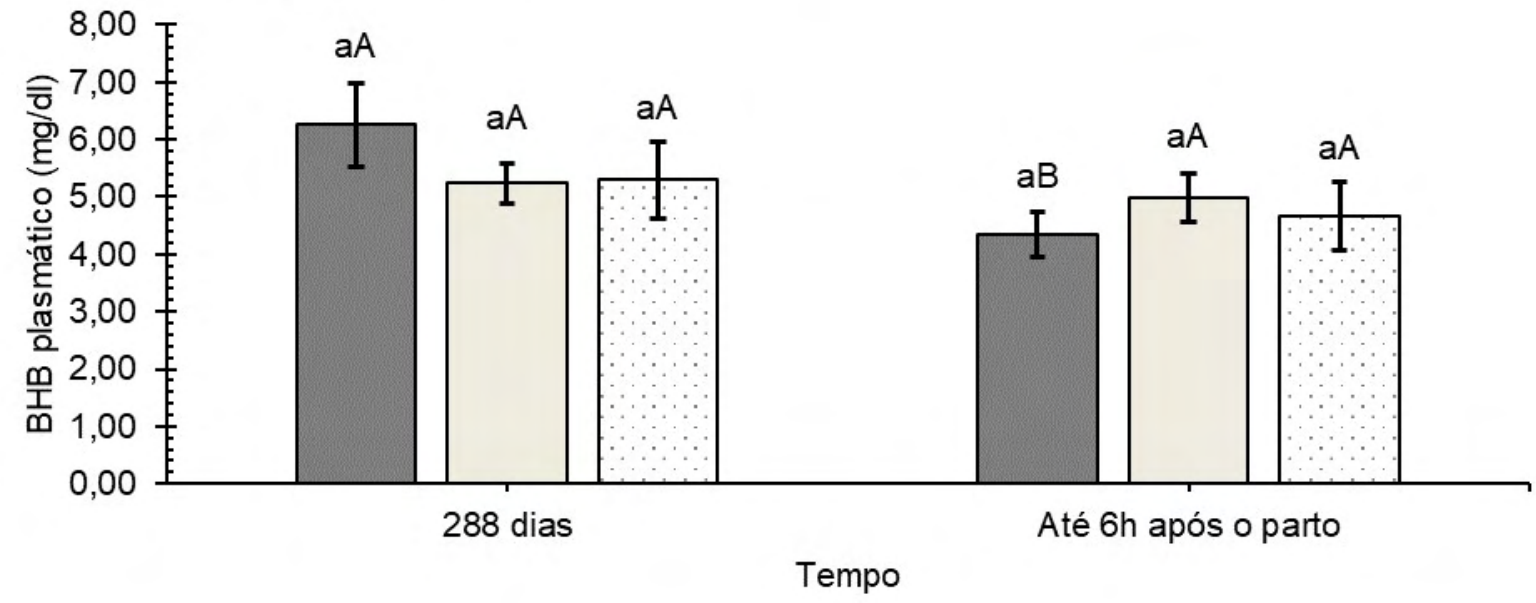

Colunas de cores diferentes seguidas com letras minúsculas diferentes, no mesmo tempo, diferiram estatisticamente entre si pelo Teste de Tukey $(P<0,05)$. Colunas de mesma cor seguidas por letras maiúsculas diferentes, diferiram estatisticamente entre si pelo Teste t pareado $(P<0,05)$

Fonte: Própria autoria.

Como já discutido no procedimento experimental 1, o BHB é considerado o metabólito de escolha para o monitoramento do déficit energético em bovinos. $\mathrm{O}$ final da gestação corresponde ao momento de maior desequilíbrio na relação entre a ingestão e consumo energético nos bovinos de corte (GONZÁLEZ et al., 2000). Kruip e Den Daas (1997) demonstraram correlação positiva entre gestações de embriões por FIV com prolongamento de gestação, aumento do peso do bezerro ao nascimento e de distocias. Neste sentido, esperava-se que no grupo de vacas receptoras de FIV de bezerros com peso elevado ao nascimento (síndrome do bezerro gigante) ocorresse o desenvolvimento de déficit energético, na condição de cetose, nos momentos finais da gestação e após o parto. Condição que não foi confirmada pelos resultados do presente trabalho, além dos valores terem permanecido abaixo dos valores de referência supracitado, este grupo foi o único a revelar diminuição entre os tempos de avaliação. 
Tabela 41 - Médias, erros padrão, medidas mínimas e máximas para NEFA plasmático (mmol/L) de vacas gestantes por FIV e por IA no final da gestação e até $6 \mathrm{~h}$ após o parto natural

\begin{tabular}{|c|c|c|c|c|c|c|c|c|}
\hline \multirow[b]{2}{*}{ Tratamento } & \multicolumn{4}{|c|}{288 dias } & \multicolumn{4}{|c|}{ Até 6h após o parto } \\
\hline & $n$ & Média & $\begin{array}{c}\text { Erro } \\
\text { Padrão }\end{array}$ & $\begin{array}{l}\operatorname{Min} e \\
\text { Max }\end{array}$ & $\mathrm{n}$ & Média & $\begin{array}{c}\text { Erro } \\
\text { Padrão }\end{array}$ & $\begin{array}{l}\text { Mine } \\
\text { Max }\end{array}$ \\
\hline Receptoras & & & & 0,30 & & & & 0,11 \\
\hline $\begin{array}{l}\text { FIV bez peso } \\
\text { elevado }\end{array}$ & 17 & $0,72 \mathrm{aA}$ & 0,06 & 1,09 & 17 & 0,69 aA & 0,08 & 1,33 \\
\hline Receptoras & & & & 0,13 & & & & 0,15 \\
\hline $\begin{array}{l}\text { FIV bez peso } \\
\text { padrão }\end{array}$ & 30 & $0,59 \mathrm{aA}$ & 0,05 & 1,25 & 32 & 0,65 aA & 0,05 & 1,23 \\
\hline $\begin{array}{l}\text { Vacas IA } \\
\text { (controle) }\end{array}$ & 15 & 0,79 aA & 0,11 & $\begin{array}{l}0,11 \\
1,72\end{array}$ & 16 & $0,69 \mathrm{aA}$ & 0,12 & $\begin{array}{l}0,03 \\
1,89\end{array}$ \\
\hline
\end{tabular}

Médias seguidas por letras minúsculas diferentes na mesma coluna diferiram estatisticamente entre si pelo Teste de Tukey $(P<0,05)$. Médias seguidas por letras maiúsculas diferentes na mesma linha diferiram estatisticamente entre si pelo Teste t pareado $(P<0,05)$

Fonte: Própria autoria.

Gráfico 41 - Médias com erros padrão para NEFA plasmático de vacas receptoras de FIV de bezerros com peso elevado após o nascimento, receptoras de FIV com bezerros de peso padrão após o nascimento e vacas gestantes por IA, no final da gestação e até 6 h após o parto natural a termo - Pirassununga - 2018

$\square$ Receptoras FIV bez peso elevado $\square$ Receptoras FIV bez peso padrão

aVacas IA (controle)

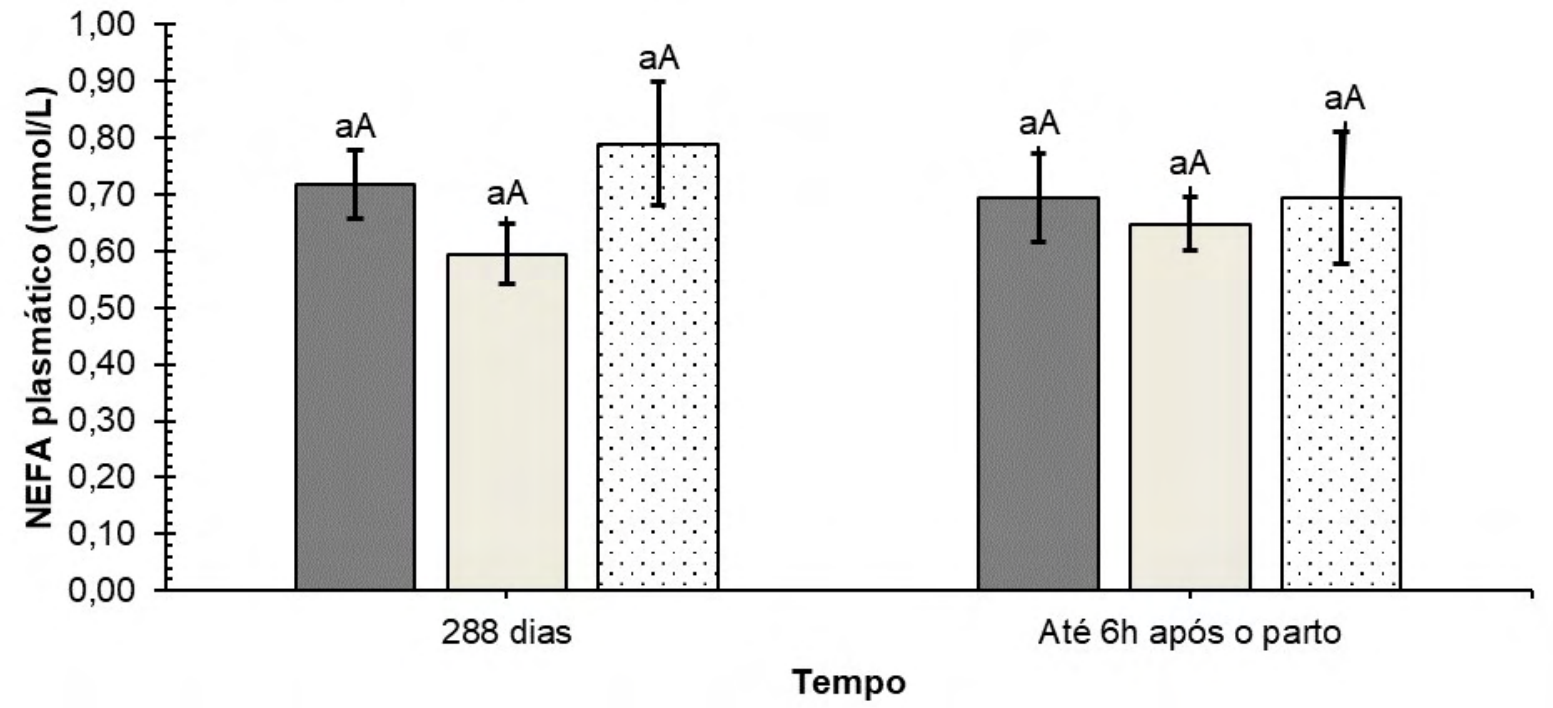

Colunas de cores diferentes seguidas com letras minúsculas diferentes, no mesmo tempo, diferiram estatisticamente entre si pelo Teste de Tukey $(P<0,05)$. Colunas de mesma cor seguidas por letras maiúsculas diferentes, diferiram estatisticamente entre si pelo Teste t pareado $(P<0,05)$

Fonte: Própria autoria. 
Os teores séricos de NEFA nos animais avaliados permaneceram abaixo do valor de referência para bovinos de corte $(<0,91 \mathrm{mmol} / \mathrm{L})$ considerado pelo Laboratório de Diagnóstico Veterinário do Colégio de Medicina Veterinária da Universidade do Estado de Oregon, Estados Unidos (OREGON STATE UNIVERSITY, 2018), também foi inferior aos resultados relatados por Oliveira (2015). Neste trabalho foi possível observar que o tipo de gestação e a ocorrência síndrome do bezerro gigante não influenciaram no status energético das vacas no final da gestação e após o parto.

\subsubsection{Procedimento experimental 4}

Para a análise os resultados de colesterol, triglicéride, glicose, Lactato, BHB e NEFA deve-se considerar que as amostras foram colhidas, em sua maioria, depois da primeira mamada. Devido os procedimentos de manejo da propriedade de origem, onde os partos eram assistidos, os bezerros que apresentavam dificuldade para mamar de forma espontânea, recebiam colostro em mamadeiras ou mesmo por sonda oro esofágica. Como pode ser observado ao analisar a GGT com valores elevados no primeiro momento avaliado.

Na tabela 42 e no gráfico 42 estão representados os resultados do colesterol sérico dos bezerros oriundos de FIV com peso elevado ao nascimento (síndrome do bezerro gigante), bezerros oriundos de FIV com peso ao nascimento dentro do padrão da raça e por IA (grupo controle). Houve diferença estatística significativa entre os tratamentos no momento 24 e 36 horas de vida separadamente $(P<0,05)$, e houve entre os períodos de avaliação dentro de cada tratamento $(P<0,05)$.

Os teores estavam abaixo dos valores de referência para bovinos lactentes (86 - $120 \mathrm{mg} / \mathrm{dL}$ ) relatados por Pogliani e Birgel Junior (2007). Neste trabalho foi possível constatar a mesma dinâmica evidenciada no procedimento experimental 2 com aumento progressivo, confirmando também a influência do fator etário, semelhante ao revelado por Piccioni et al. (2010) e Marchese (2014). Após a análise dos resultados, observou-se que bezerros oriundos de FIV, mesmo os que apresentam a síndrome do bezerro gigante, não apresentam diferenças no metabolismo do colesterol. Sugere-se que as diferenças entre os grupos ocorram pela variação na qualidade e na quantidade do consumo de colostro. 
Tabela 42 - Médias, erros padrão, medidas mínimas e máximas para Colesterol plasmático $(\mathrm{mg} / \mathrm{dL})$ de bezerros oriundos de FIV e por IA nas primeiras 36 horas devida obtidos por parto natural

\begin{tabular}{|c|c|c|c|c|c|c|c|c|}
\hline \multirow[b]{2}{*}{ Tratamento } & \multicolumn{4}{|c|}{ Até $6 \mathrm{~h}$ de vida } & \multicolumn{4}{|c|}{ Entre $24 \mathrm{~h}$ e $36 \mathrm{~h}$ de vida } \\
\hline & $\mathrm{n}$ & Média & $\begin{array}{l}\text { Erro } \\
\text { Padrão }\end{array}$ & $\begin{array}{l}\operatorname{Min} e \\
\operatorname{Max}\end{array}$ & $\mathrm{n}$ & Média & $\begin{array}{c}\text { Erro } \\
\text { Padrão }\end{array}$ & $\begin{array}{l}\text { Min e } \\
\text { Max }\end{array}$ \\
\hline \multirow{2}{*}{$\begin{array}{l}\text { Bezerros } \\
\text { FIV peso } \\
\text { elevado }\end{array}$} & \multirow[b]{2}{*}{16} & \multirow[b]{2}{*}{$28,24 \mathrm{aB}$} & \multirow[b]{2}{*}{1,85} & 13,68 & \multirow[b]{2}{*}{17} & \multirow[b]{2}{*}{$37,02 \mathrm{abA}$} & \multirow[b]{2}{*}{2,47} & 23,94 \\
\hline & & & & 42,26 & & & & 64,25 \\
\hline \multirow{2}{*}{$\begin{array}{l}\text { Bezerros } \\
\text { FIV peso } \\
\text { padrão }\end{array}$} & \multirow[b]{2}{*}{30} & \multirow[b]{2}{*}{$26,57 \mathrm{aB}$} & \multirow[b]{2}{*}{2,06} & 10,03 & \multirow[b]{2}{*}{30} & \multirow[b]{2}{*}{$34,48 \mathrm{bA}$} & \multirow[b]{2}{*}{1,67} & 20,51 \\
\hline & & & & 69,02 & & & & 51,84 \\
\hline \multirow{2}{*}{$\begin{array}{l}\text { Bezerros IA } \\
\text { (controle) }\end{array}$} & \multirow{2}{*}{27} & \multirow{2}{*}{$30,71 \mathrm{aB}$} & \multirow{2}{*}{2,32} & 10,94 & \multirow{2}{*}{27} & \multirow{2}{*}{44,49 aA } & \multirow{2}{*}{2,76} & 20,49 \\
\hline & & & & 57,80 & & & & 92,38 \\
\hline
\end{tabular}

Médias seguidas por letras minúsculas diferentes na mesma coluna diferiram estatisticamente entre si pelo Teste de Tukey $(P<0,05)$. Médias seguidas por letras maiúsculas diferentes na mesma linha diferiram estatisticamente entre si pelo Teste t pareado $(P<0,05)$

Fonte: Própria autoria.

Gráfico 42 - Médias com erros padrão para Colesterol plasmático de bezerros oriundos de FIV e por IA nas primeiras 36 horas devida obtidos por parto natural Pirassununga - 2018

\section{口Bezerros FIV peso elevado aBezerros FIV peso padrão $\quad$ aBezerros IA (controle)}

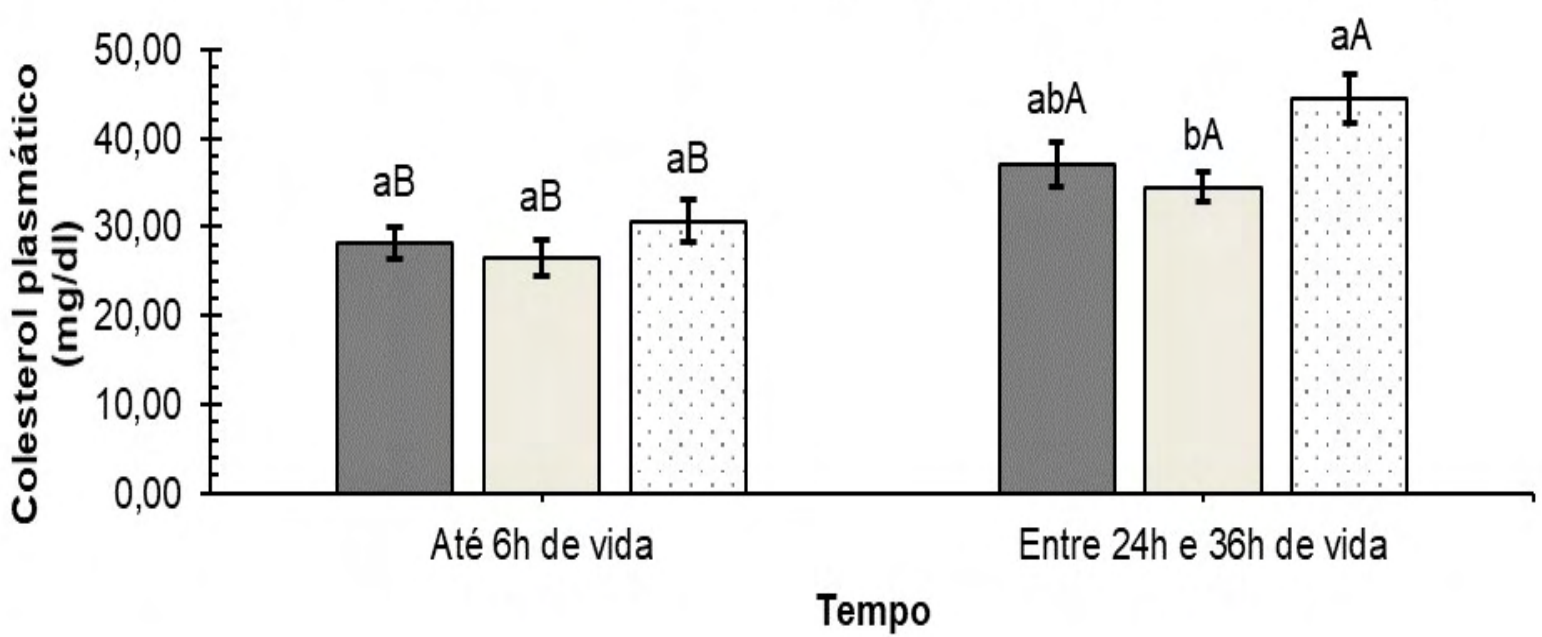

Colunas de cores diferentes seguidas com letras minúsculas diferentes, no mesmo tempo, diferiram estatisticamente entre si pelo Teste de Tukey $(P<0,05)$. Colunas de mesma cor seguidas por letras maiúsculas diferentes, diferiram estatisticamente entre si pelo Teste t pareado $(P<0,05)$

Fonte: Própria autoria. 
Nas tabelas 43 e 44 e nos gráficos 43 e 44 estão representados os resultados do triglicérides sérico e da glicose plasmática dos bezerros oriundos de FIV com peso elevado ao nascimento (síndrome do bezerro gigante), bezerros oriundos de FIV com peso ao nascimento dentro do padrão da raça e por IA (grupo controle). Houve diferença estatística significativa entre os tratamentos no momento 24 e 36 horas de vida separadamente para triglicérides $(P<0,05)$, e houve entre os períodos de avaliação para as receptoras de FIV de bezerros com peso dentro do padrão e para o grupo controle $(P<0,05)$. Não houve diferença estatística significativa entre os tratamentos dentro de cada tempo separadamente para glicose $(P>0,05)$, e houve entre os períodos de avaliação para as receptoras de FIV de bezerros com peso dentro do padrão e para o grupo controle $(P<0,05)$.

Os valores de triglicérides foram inferiores no momento até 6 horas de vida para os grupos de bezerro FIV com peso ao nascimento padrão e para os bezerros controle, e semelhante entre os tempos para os bezerros FIV com peso elevado ao nascimento. Todos os grupos, no dois momentos avaliados, revelaram teores superiores aos de referência para bovinos adultos $(0-14 \mathrm{mg} / \mathrm{dL})$ relatados por Kaneko, Harvey e Bruss (2008) e dentro do intervalo de referência para bezerros com até três meses de idade ( $16-35 \mathrm{mg} / \mathrm{dL})$ constatado por Pogliani e Birgel Junior (2007), com exceção dos bezerros controle que no momento 24 a 36 horas de vida estava mais elevado. Os resultados também foram semelhantes aos observados por Moraes (2011) e Marchese (2014). Neste trabalho não foi constatado efeito da FIV, mesmo na existência de síndrome do bezerro gigante, sobre a concentração sérica de triglicérides em bezerros neonatos.

Os teores de glicose de todos os grupos, estavam dentro da faixa de referência para bovinos lactentes (80 a $120 \mathrm{mg} / \mathrm{dL}$ ) relatado por Swenson e Reece (1996) no momento até 6 horas de vida e apresentaram hiperglicemia no segundo momento, comportamento semelhante ao observado por Piccioni et al. (2010), Ferreira (2012) e Marchese (2014), contudo variação nos resultados não permitiu que a média dos bezerros com peso elevado ao nascimento no momento entre 24 a 36 horas de vida representasse diferença estatística comparado ao primeiro momento avaliado. Os resultados deste trabalho constatam não haver influência da FIV, mesmo com a ocorrência de síndrome do bezerro gigante, no metabolismo da glicose em bezerros neonatos. 
Tabela 43 - Médias, erros padrão, medidas mínimas e máximas para triglicérides sérico $(\mathrm{mg} / \mathrm{dL})$ de bezerros oriundos de FIV e por IA nas primeiras 36 horas devida obtidos por parto natural

\begin{tabular}{|c|c|c|c|c|c|c|c|c|}
\hline \multirow[b]{3}{*}{ Bezerros } & \multicolumn{4}{|c|}{ Até $6 \mathrm{~h}$ de vida } & \multicolumn{4}{|c|}{ Entre $24 \mathrm{~h}$ e $36 \mathrm{~h}$ de vida } \\
\hline & $\mathrm{n}$ & Média & $\begin{array}{c}\text { Erro } \\
\text { Padrão }\end{array}$ & $\begin{array}{l}\text { Min e } \\
\text { Max }\end{array}$ & $\mathrm{n}$ & Média & $\begin{array}{c}\text { Erro } \\
\text { Padrão }\end{array}$ & $\begin{array}{l}\text { Min e } \\
\text { Max }\end{array}$ \\
\hline & & & & 8,06 & & & & 9,30 \\
\hline $\begin{array}{l}\text { FIV peso } \\
\text { elevado }\end{array}$ & 16 & 21,37 aA & 4,15 & 76,02 & 17 & $25,22 \mathrm{bA}$ & 3,50 & 59,48 \\
\hline Bezerros & & & & 5,81 & & & & 5,81 \\
\hline $\begin{array}{l}\text { FIV peso } \\
\text { padrão }\end{array}$ & 31 & $19,12 \mathrm{aB}$ & 1,70 & 47,29 & 31 & $27,38 \mathrm{bA}$ & 2,46 & 62,72 \\
\hline $\begin{array}{l}\text { Bezerros IA } \\
\text { (controle) }\end{array}$ & 27 & $23,12 \mathrm{aB}$ & 2,41 & $\begin{array}{c}5,81 \\
58,23\end{array}$ & 27 & 39,26 aA & 4,65 & $\begin{array}{c}11,50 \\
118,87\end{array}$ \\
\hline
\end{tabular}

Médias seguidas por letras minúsculas diferentes na mesma coluna diferiram estatisticamente entre si pelo Teste de Tukey $(P<0,05)$. Médias seguidas por letras maiúsculas diferentes na mesma linha diferiram estatisticamente entre si pelo Teste t pareado $(P<0,05)$

Fonte: Própria autoria.

Gráfico 43 - Médias com erros padrão para triglicérides sérico de bezerros oriundos de FIV e por IA nas primeiras Entre $24 \mathrm{~h}$ e $36 \mathrm{~h}$ de vida obtidos por parto natural Pirassununga - 2018

$\square$ Bezerros FIV peso elevado aBezerros FIV peso padrão $\quad$ aBezerros IA (controle)

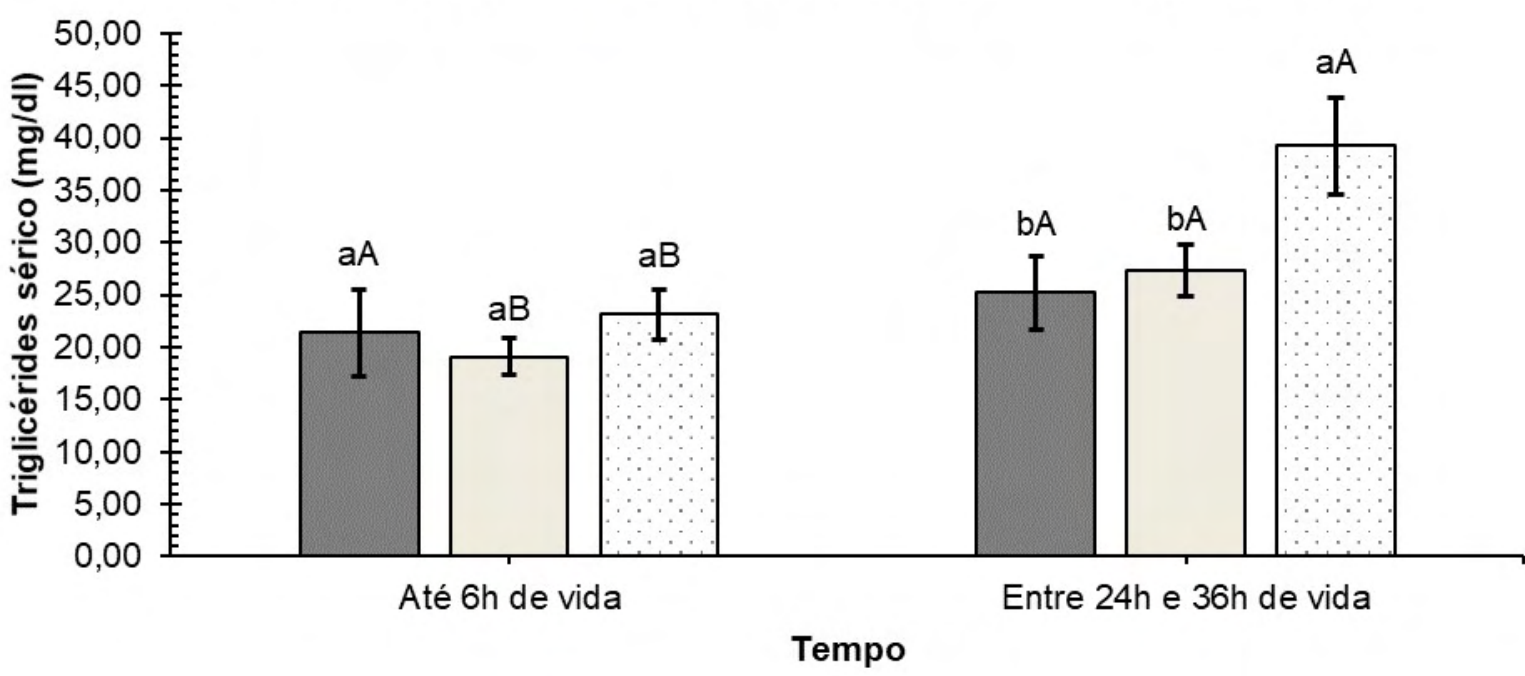

Colunas de cores diferentes seguidas com letras minúsculas diferentes, no mesmo tempo, diferiram estatisticamente entre si pelo Teste de Tukey $(P<0,05)$. Colunas de mesma cor seguidas por letras maiúsculas diferentes, diferiram estatisticamente entre si pelo Teste t pareado $(P<0,05)$

Fonte: Própria autoria. 
Tabela 44 - Médias, erros padrão, medidas mínimas e máximas para glicose plasmática $(\mathrm{mg} / \mathrm{dL})$ de bezerros oriundos de FIV e por IA nas primeiras 36 horas devida obtidos por parto natural

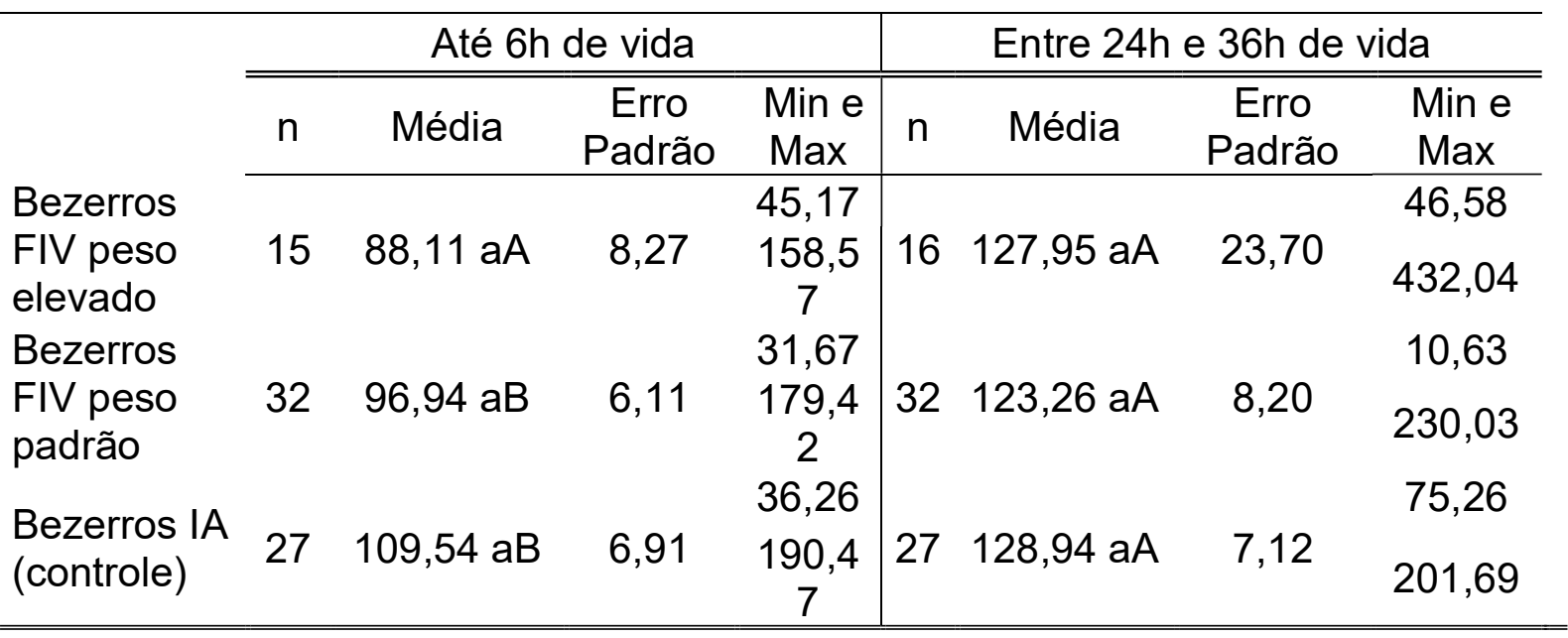

Médias seguidas por letras minúsculas diferentes na mesma coluna diferiram estatisticamente entre si pelo Teste de Tukey $(P<0,05)$. Médias seguidas por letras maiúsculas diferentes na mesma linha diferiram estatisticamente entre si pelo Teste t pareado $(P<0,05)$

Fonte: Própria autoria.

Gráfico 44 - Médias com erros padrão para glicose plasmática de bezerros oriundos de FIV e por IA nas primeiras 36 horas devida obtidos por parto natural Pirassununga - 2018

\section{$\square$ Bezerros FIV peso elevado $\quad$ Bezerros FIV peso padrão $\quad$ Bezerros IA (controle)}

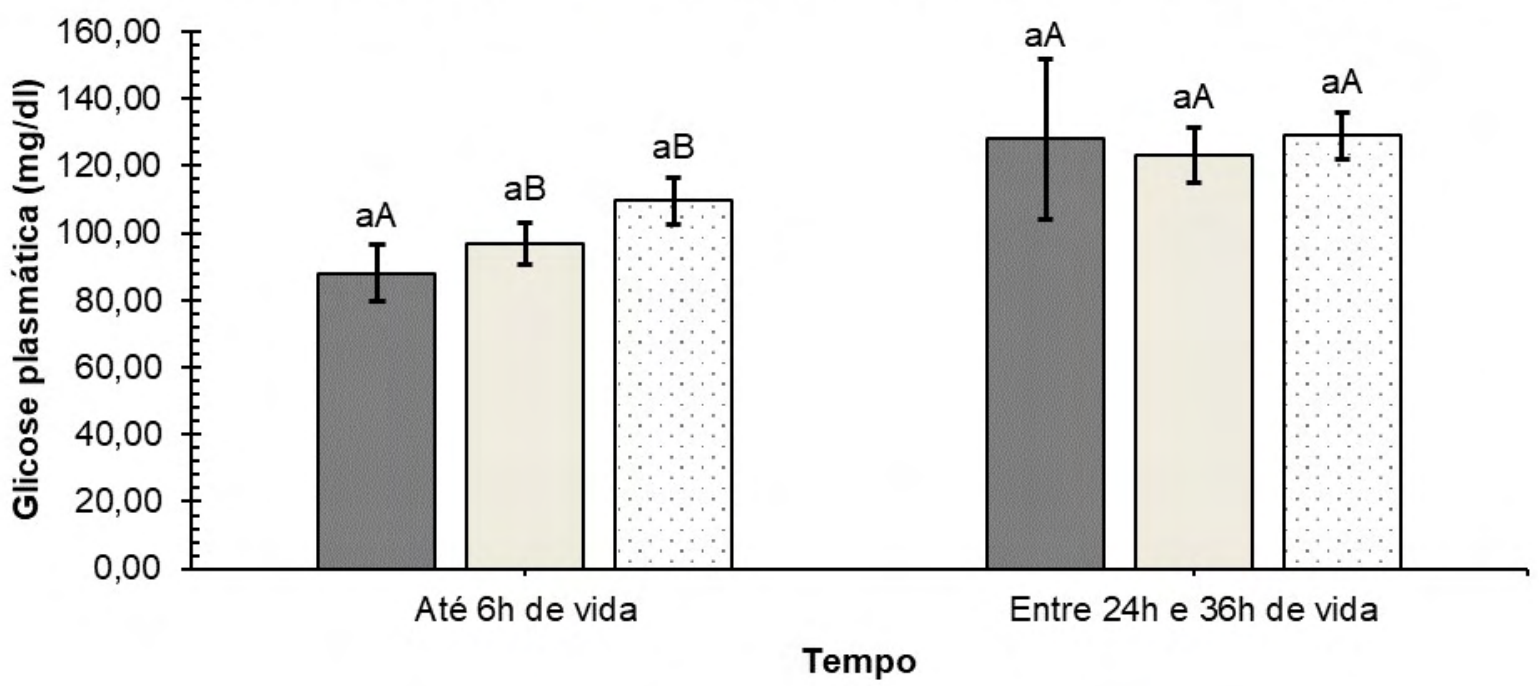

Colunas de cores diferentes seguidas com letras minúsculas diferentes, no mesmo tempo, diferiram estatisticamente entre si pelo Teste de Tukey $(P<0,05)$. Colunas de mesma cor seguidas por letras maiúsculas diferentes, diferiram estatisticamente entre si pelo Teste t pareado $(P<0,05)$

Fonte: Própria autoria. 
Na tabela 45 e no gráfico 45 estão representados os resultados do lactato plasmático dos bezerros oriundos de FIV com peso elevado ao nascimento (síndrome do bezerro gigante), bezerros oriundos de FIV com peso ao nascimento dentro do padrão da raça e por IA (grupo controle). Houve diferença estatística significativa entre os tratamentos dentro de cada tempo separadamente $(P>0,05)$, e entre os períodos de avaliação dentro de cada tratamento $(P>0,05)$.

As médias dos bezerros de FIV com peso elevado ao nascimento e dos bezerros com peso dentro do padrão foram superiores as médias dos bezerros do grupo controle, semelhante ao observado por Schütz (2012) em bezerros de FIV e por Marchese (2014) em bezerros clones e normais. No segundo momento a média de lactato dos três grupos diminuiu, no entanto, a diferença estatística entre os bezerros de FIV com peso dentro do padrão e o grupo controle persistiu (30 e 20 $\mathrm{mg} / \mathrm{dL}$, respectivamente), comportamento também relatado pelos autores supracitados. Os resultados do presente trabalho foram superiores aos valores de referência para bovinos adultos $(5-20 \mathrm{mg} / \mathrm{dL})$ relatados por Kaneko, Harvey e Bruss (2008) em todos os grupos no primeiro momento e nos dois grupos de bezerros de FIV no segundo momento.

Tabela 45 - Médias, erros padrão, medidas mínimas e máximas para Lactato plasmático $(\mathrm{mg} / \mathrm{dL})$ de bezerros oriundos de FIV e por IA nas primeiras 36 horas devida obtidos por parto natural

\begin{tabular}{|c|c|c|c|c|c|c|c|c|}
\hline \multirow[b]{2}{*}{ Tratamento } & \multicolumn{4}{|c|}{ Até $6 \mathrm{~h}$ de vida } & \multicolumn{4}{|c|}{ Entre $24 \mathrm{~h}$ e $36 \mathrm{~h}$ de vida } \\
\hline & $\mathrm{n}$ & Média & $\begin{array}{c}\text { Erro } \\
\text { Padrão }\end{array}$ & $\begin{array}{l}\text { Min e } \\
\text { Max }\end{array}$ & $\mathrm{n}$ & Média & $\begin{array}{c}\text { Erro } \\
\text { Padrão }\end{array}$ & $\begin{array}{l}\text { Min e } \\
\text { Max }\end{array}$ \\
\hline Bezerros & & & & 13,87 & & & & 9,61 \\
\hline $\begin{array}{l}\text { FIV peso } \\
\text { elevado }\end{array}$ & 14 & 45,97 aA & 8,56 & 133,00 & 12 & $25,70 \mathrm{abB}$ & 4,46 & 63,82 \\
\hline Bezerros & & & & 17,11 & & & & 9,19 \\
\hline $\begin{array}{l}\text { FIV peso } \\
\text { padrão }\end{array}$ & 27 & $42,42 \mathrm{aA}$ & 4,55 & 112,73 & 29 & $30,02 \mathrm{aB}$ & 2,90 & 71,68 \\
\hline $\begin{array}{l}\text { Bezerros IA } \\
\text { (controle) }\end{array}$ & 27 & $26,51 \mathrm{bA}$ & 1,40 & $\begin{array}{l}11,69 \\
39,03\end{array}$ & 23 & $20,16 \mathrm{bB}$ & 1,85 & $\begin{array}{l}11,03 \\
52,13\end{array}$ \\
\hline
\end{tabular}

Médias seguidas por letras minúsculas diferentes na mesma coluna diferiram estatisticamente entre si pelo Teste de Tukey $(P<0,05)$. Médias seguidas por letras maiúsculas diferentes na mesma linha diferiram estatisticamente entre si pelo Teste t pareado $(P<0,05)$

Fonte: Própria autoria. 
Gráfico 45 - Médias com erros padrão para Lactato plasmático de bezerros oriundos de FIV e por IA nas primeiras 36 horas devida obtidos por parto natural Pirassununga -2018

口Bezerros FIV peso elevado aBezerros FIV peso padrão $\quad$ BBezerros IA (controle)

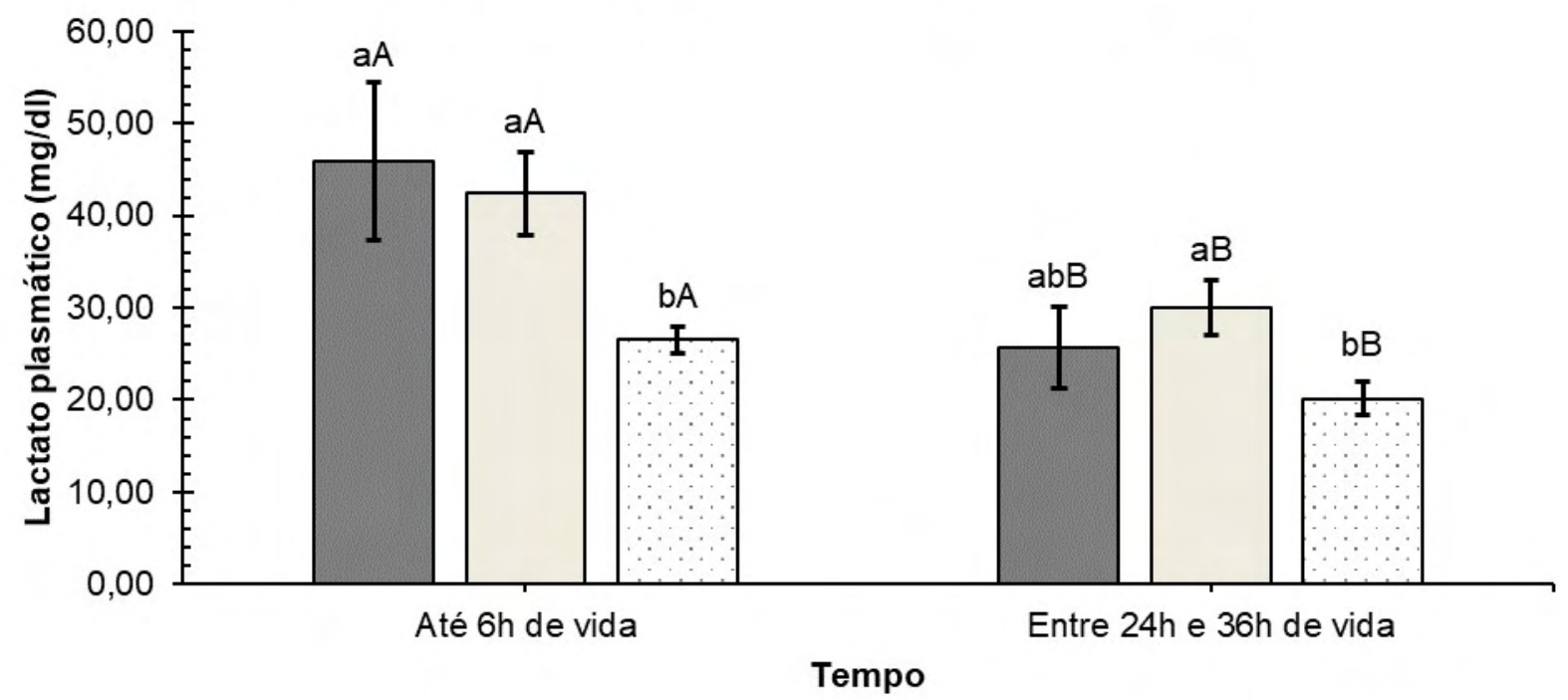

Colunas de cores diferentes seguidas com letras minúsculas diferentes, no mesmo tempo, diferiram estatisticamente entre si pelo Teste de Tukey $(P<0,05)$. Colunas de mesma cor seguidas por letras maiúsculas diferentes, diferiram estatisticamente entre si pelo Teste t pareado $(P<0,05)$

Fonte: Própria autoria.

Kruip e Den Daas (1997) demonstraram correlação positiva entre gestações de embriões por FIV com prolongamento de gestação, aumento do peso ao nascimento e de distocias. Em outra pesquisa, Steinhardt et al. (1995) indicaram que o aumento do lactato logo após o nascimento seria consequência de hipóxia e refletiria a intensa mobilização das reservas de energia, em parte, pelo aumento da atividade simpática diante diante dos fatores estressantes do parto e da adaptação a vida extrauterina. Os valores observados neste trabalho confirmam o efeito da FIV sobre a concentração sérica de lactato nas primeiras horas de vida e corroboram os resultados obtidos por Bertolini et al. (2004) em bezerros produzidos por FIV com elevação do lactato 10 minutos após o nascimento.

Nas tabelas 46 e 47 e nos gráficos 46 e 47 estão representados os resultados de ß-hidroxibutirato e NEFA séricos dos bezerros oriundos de FIV com peso elevado ao nascimento (síndrome do bezerro gigante), bezerros oriundos de FIV com peso ao nascimento dentro do padrão da raça e por IA (grupo controle). Não houve diferença estatística significativa entre os tratamentos dentro de cada tempo separadamente para BHB $(P>0,05)$, nem entre os períodos de avaliação dentro de 
cada tratamento $(P>0,05)$. Houve diferença estatística significativa entre os bezerros FIV com peso ao nascimento padrão para a raça e os bezerros IA dentro separadamente para NEFA $(P<0,05)$, não houve entre os períodos de avaliação dentro de cada tratamento $(P>0,05)$.

Esperava-se que os bezerros de FIV com peso elevado ao nascimento (macrossômicos) apresentassem déficit energético com elevação dos teores de BHB e maior sustentação da NEFA. Contudo, diante das coletas das amostras do presente trabalho terem sido realizadas, em sua maioria, após a primeira mamada natural ou assistida, os teores de BHB avaliados mantiveram seus níveis dentro do intervalo observado por Hammon et al. (2012) e abaixo dos valores de referência relatados por Pogliani e Birgel Junior (2007), também foram inferiores aos apresentados por Piccioni et al. (2010). Neste trabalho não foi confirmado o efeito da FIV, mesmo na existência da síndrome do bezerro gigante, sobre a concentração sérica de $B H B$.

Tabela 46 - Médias, erros padrão, medidas mínimas e máximas para $\beta$ hidroxibutirato sérico $(\mathrm{mg} / \mathrm{dL})$ de bezerros oriundos de FIV e por IA nas primeiras 36 horas devida obtidos por parto natural

\begin{tabular}{|c|c|c|c|c|c|c|c|c|}
\hline \multirow[b]{2}{*}{ Tratamento } & \multicolumn{4}{|c|}{ Até $6 \mathrm{~h}$ de vida } & \multicolumn{4}{|c|}{ Entre $24 \mathrm{~h}$ e $36 \mathrm{~h}$ de vida } \\
\hline & $\mathrm{n}$ & Média & $\begin{array}{c}\text { Erro } \\
\text { Padrão }\end{array}$ & $\begin{array}{l}\text { Min e } \\
\text { Max }\end{array}$ & $\mathrm{n}$ & Média & $\begin{array}{l}\text { Erro } \\
\text { Padrão }\end{array}$ & $\begin{array}{l}\operatorname{Min} e \\
\operatorname{Max}\end{array}$ \\
\hline $\begin{array}{l}\text { Bezerros } \\
\text { FIV peso } \\
\text { elevado }\end{array}$ & 16 & 0,64 aA & 0,10 & $\begin{array}{l}0,16 \\
1,42\end{array}$ & 17 & $0,87 \mathrm{aA}$ & 0,13 & $\begin{array}{l}0,33 \\
1,98\end{array}$ \\
\hline $\begin{array}{l}\text { Bezerros } \\
\text { FIV peso } \\
\text { padrão }\end{array}$ & 31 & 0,97 aA & 0,20 & $\begin{array}{l}0,16 \\
5,10\end{array}$ & 31 & $0,69 \mathrm{aA}$ & 0,08 & $\begin{array}{l}0,25 \\
2,48\end{array}$ \\
\hline $\begin{array}{l}\text { Bezerros IA } \\
\text { (controle) }\end{array}$ & 27 & 0,85 aA & 0,12 & $\begin{array}{l}0,16 \\
2,70\end{array}$ & 27 & $1,03 \mathrm{aA}$ & 0,15 & $\begin{array}{l}0,16 \\
3,45\end{array}$ \\
\hline
\end{tabular}

Médias seguidas por letras minúsculas diferentes na mesma coluna diferiram estatisticamente entre si pelo Teste de Tukey $(P<0,05)$. Médias seguidas por letras maiúsculas diferentes na mesma linha diferiram estatisticamente entre si pelo Teste t pareado $(P<0,05)$

Fonte: Própria autoria. 
Gráfico 46 - Médias com erros padrão para $\beta$-hidroxibutirato sérico de bezerros oriundos de FIV e por IA nas primeiras 36 horas devida obtidos por parto natural Pirassununga - 2018

$\square$ Bezerros FIV peso elevado aBezerros FIV peso padrão $\square$ Bezerros IA (controle)

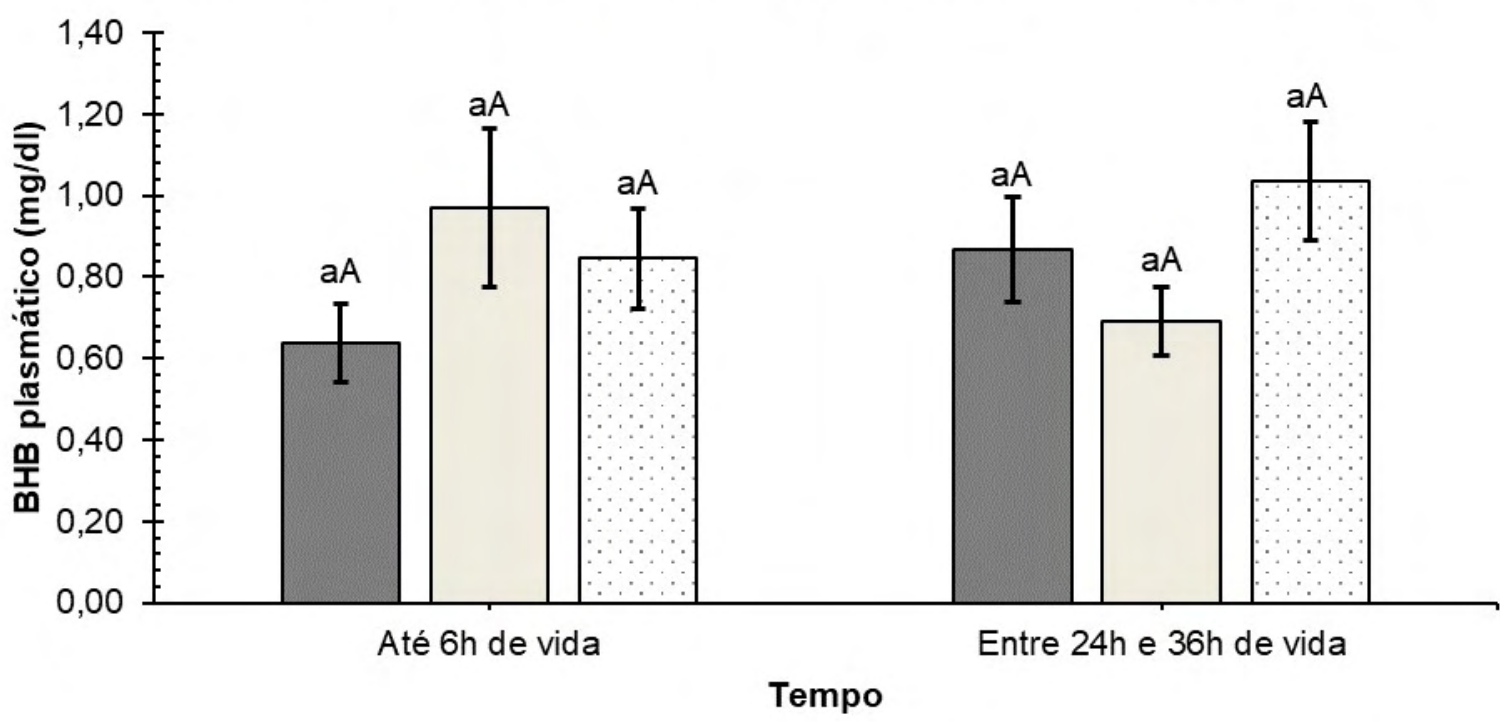

Colunas de cores diferentes seguidas com letras minúsculas diferentes, no mesmo tempo, diferiram estatisticamente entre si pelo Teste de Tukey $(P<0,05)$. Colunas de mesma cor seguidas por letras maiúsculas diferentes, diferiram estatisticamente entre si pelo Teste t pareado $(P<0,05)$

Fonte: Própria autoria.

Tabela 47 - Médias, erros padrão, medidas mínimas e máximas para NEFA plasmático $(\mathrm{mmol} / \mathrm{L})$ de bezerros oriundos de FIV e por IA nas primeiras 36 horas devida obtidos por parto natural

\begin{tabular}{|c|c|c|c|c|c|c|c|c|}
\hline \multirow[b]{2}{*}{ Tratamento } & \multicolumn{4}{|c|}{ Até $6 \mathrm{~h}$ de vida } & \multicolumn{4}{|c|}{ Entre $24 \mathrm{~h}$ e $36 \mathrm{~h}$ de vida } \\
\hline & $\mathrm{n}$ & Média & $\begin{array}{c}\text { Erro } \\
\text { Padrão }\end{array}$ & $\begin{array}{l}\text { Min e } \\
\text { Max }\end{array}$ & $\mathrm{n}$ & Média & $\begin{array}{c}\text { Erro } \\
\text { Padrão }\end{array}$ & $\begin{array}{l}\operatorname{Mine} \\
\operatorname{Max}\end{array}$ \\
\hline \multirow{2}{*}{$\begin{array}{l}\text { Bezerros } \\
\text { FIV peso } \\
\text { elevado }\end{array}$} & \multirow[b]{2}{*}{16} & \multirow[b]{2}{*}{$0,32 \mathrm{aA}$} & \multirow[b]{2}{*}{0,04} & 0,04 & \multirow[b]{2}{*}{17} & \multirow[b]{2}{*}{$0,40 \mathrm{abA}$} & \multirow[b]{2}{*}{0,05} & 0,05 \\
\hline & & & & 0,60 & & & & 0,82 \\
\hline \multirow{2}{*}{$\begin{array}{l}\text { Bezerros } \\
\text { FIV peso } \\
\text { padrão }\end{array}$} & \multirow[b]{2}{*}{31} & \multirow{2}{*}{0,43 aA } & \multirow{2}{*}{0,05} & 0,09 & \multirow[b]{2}{*}{31} & \multirow[b]{2}{*}{$0,38 \mathrm{bA}$} & \multirow{2}{*}{0,04} & 0,11 \\
\hline & & & & 1,14 & & & & 1,15 \\
\hline \multirow{2}{*}{$\begin{array}{l}\text { Bezerros IA } \\
\text { (controle) }\end{array}$} & \multirow{2}{*}{27} & \multirow{2}{*}{$0,44 \mathrm{aA}$} & \multirow{2}{*}{0,05} & 0,10 & \multirow{2}{*}{27} & \multirow{2}{*}{$0,54 \mathrm{aA}$} & \multirow{2}{*}{0,06} & 0,12 \\
\hline & & & & 1,10 & & & & 1,42 \\
\hline
\end{tabular}

Médias seguidas por letras minúsculas diferentes na mesma coluna diferiram estatisticamente entre si pelo Teste de Tukey $(P<0,05)$. Médias seguidas por letras maiúsculas diferentes na mesma linha diferiram estatisticamente entre si pelo Teste t pareado $(P<0,05)$

Fonte: Própria autoria. 
Gráfico 47 - Médias com erros padrão para NEFA plasmático de bezerros oriundos de FIV e por IA nas primeiras 36 horas devida obtidos por parto natural Pirassununga - 2018

$\square$ Bezerros FIV peso elevado $\square$ Bezerros FIV peso padrão $\square$ Bezerros IA (controle)

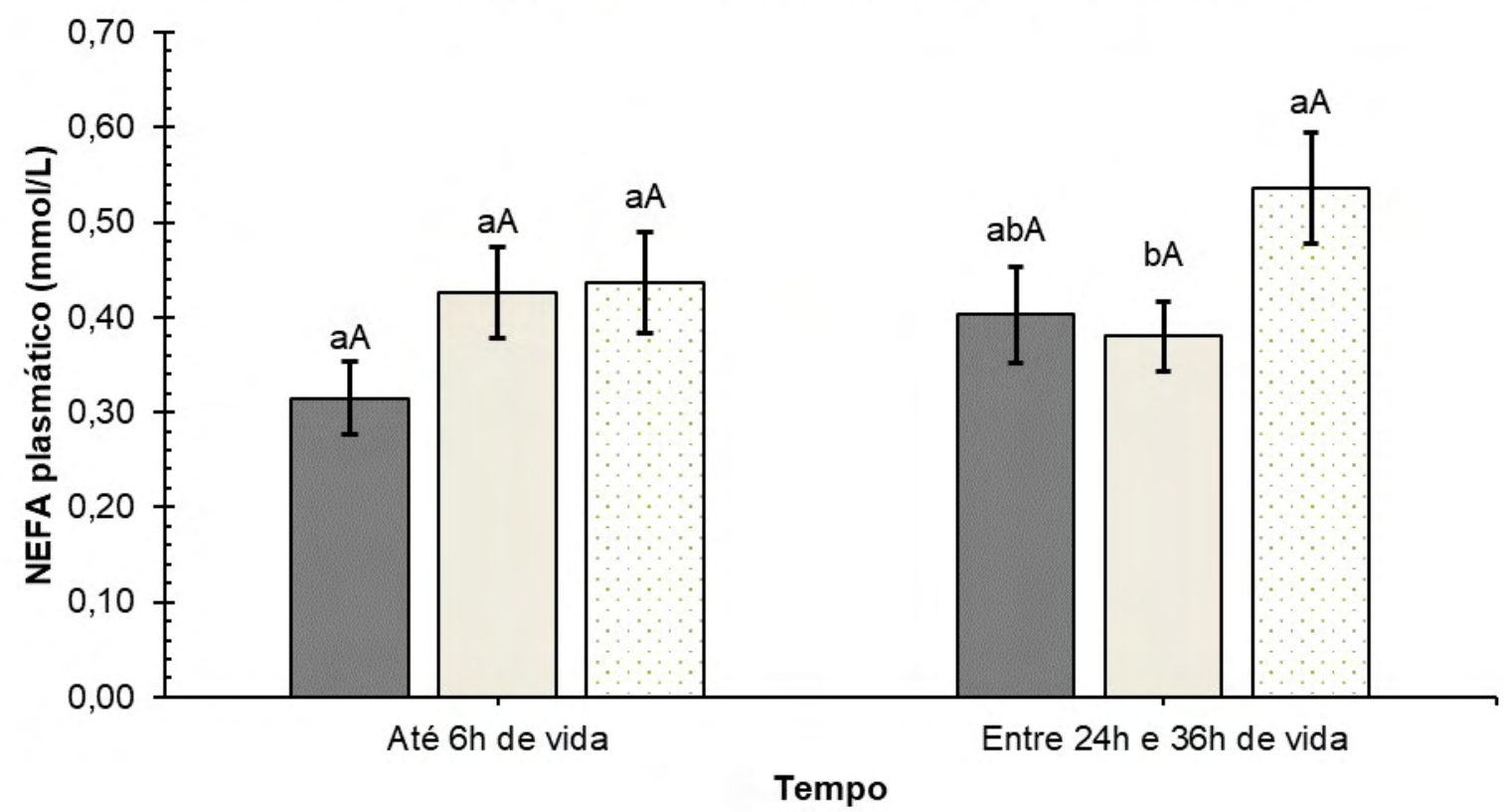

Colunas de cores diferentes seguidas com letras minúsculas diferentes, no mesmo tempo, diferiram estatisticamente entre si pelo Teste de Tukey $(P<0,05)$. Colunas de mesma cor seguidas por letras maiúsculas diferentes, diferiram estatisticamente entre si pelo Teste t pareado $(P<0,05)$

Fonte: Própria autoria.

Os resultados de NEFA do presente estudo não demonstraram as elevações relatadas por Girard et al. (1992), os valores também foram inferiores aos observados por Piccioni et al. (2010) e Steinhoff-Wagner (2011). Apenas o grupo dos bezerros com peso dentro do padrão apresentaram teor menor que o grupo controle no segundo momento avaliado, mesmo assim os valores de ambos os momentos eram inferiores aos observados pelos pesquisadores supracitados e do valor de referência $(<0,91 \mathrm{mmol} / \mathrm{L})$ considerado pelo Laboratório de Diagnóstico Veterinário do Colégio de Medicina Veterinária da Universidade do Estado de Oregon, Estados Unidos (OREGON STATE UNIVERSITY, 2018) em todos os grupos e momentos. Neste trabalho não foi observado o efeito da FIV, mesmo na existência da síndrome do bezerro gigante, sobre a concentração sérica de NEFA.

$\mathrm{Na}$ tabela 48 e no gráfico 48 estão representados os resultados da frutosamina sérica dos bezerros oriundos de FIV com peso elevado ao nascimento (síndrome do bezerro gigante), bezerros oriundos de FIV com peso ao nascimento 
dentro do padrão da raça e por IA (grupo controle). Não houve diferença estatística significativa entre os tratamentos dentro tempo separadamente $(P>0,05)$.

Tabela 48 - Médias, erros padrão, medidas mínimas e máximas para frutosamina $(\mu \mathrm{mol} / \mathrm{L})$ ao nascimento $(\mathrm{Kg})$ de bezerros oriundos de FIV e por IA nas primeiras 36 horas devida obtidos por parto natura

\begin{tabular}{|c|c|c|c|c|}
\hline \multirow[b]{3}{*}{ Bezerros } & \multicolumn{4}{|c|}{ Até $6 \mathrm{~h}$ de vida } \\
\hline & $\mathrm{n}$ & Média & Erro Padrão & Min e Max \\
\hline & & & & 119,14 \\
\hline $\begin{array}{l}\text { FIV peso } \\
\text { elevado }\end{array}$ & 16 & 173,6 a & 9,3 & 238,51 \\
\hline Bezerros & & & & 124,62 \\
\hline $\begin{array}{l}\text { FIV peso } \\
\text { padrão }\end{array}$ & 31 & 186,0 a & 4,5 & 247,48 \\
\hline $\begin{array}{l}\text { Bezerros IA } \\
\text { (controle) }\end{array}$ & 16 & 172,3 a & 6,8 & $\begin{array}{l}118,23 \\
204,46\end{array}$ \\
\hline
\end{tabular}

Médias seguidas por letras minúsculas diferentes na linha diferiram estatisticamente entre si pelo Teste de Tukey $(P<0,05)$.

Fonte: Própria autoria.

Gráfico 48 - Médias com erros padrão para frutosamina sérica ao nascimento de bezerros oriundos de FIV e por IA obtidos por parto natural - Pirassununga - 2018

$\square$ Bezerros FIV peso elevado aBezerros FIV peso padrão aBezerros IA (controle)

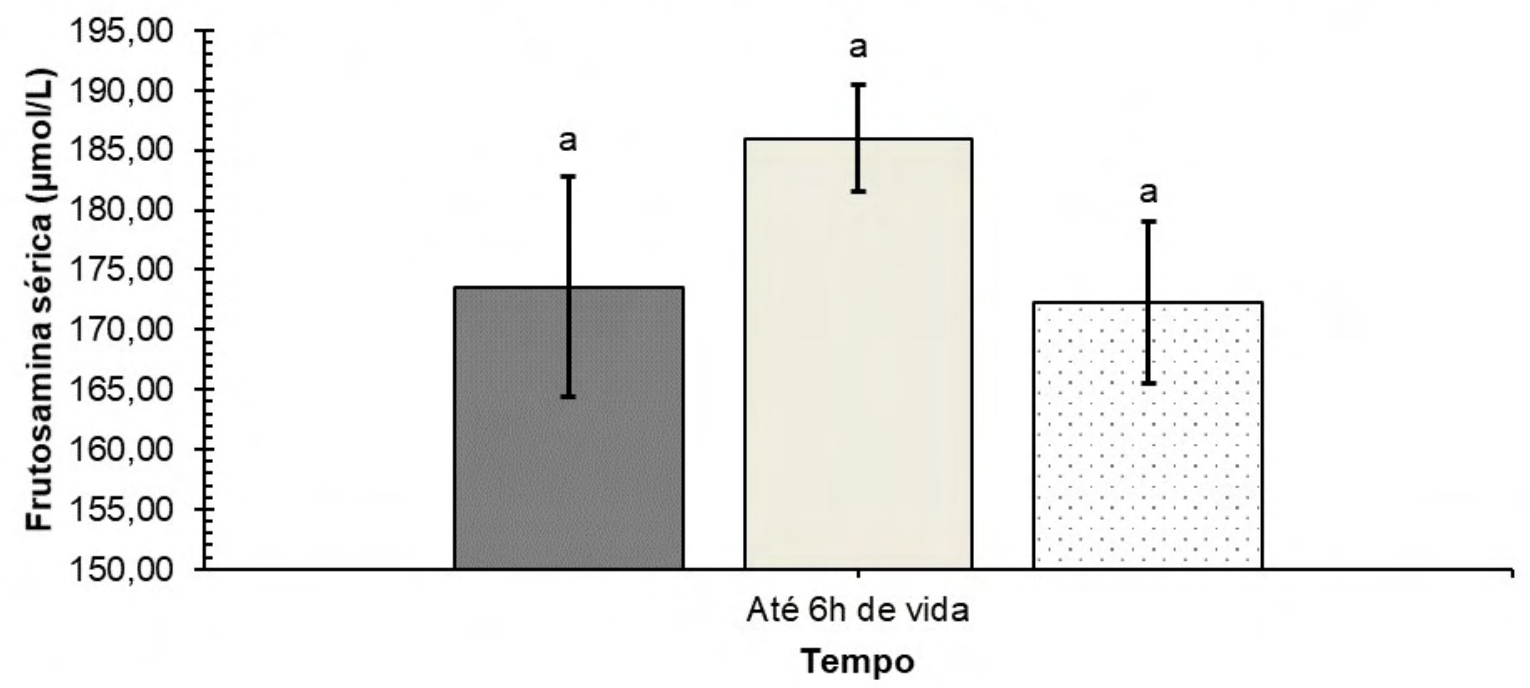

Colunas seguidas por letras minúsculas diferentes, diferiram estatisticamente entre si pelo Teste de Tukey $(P<0,05)$

Fonte: Própria autoria.

A frutosamina está diretamente relacionada com a concentração sérica da glicose nas últimas 2 a 3 semanas. Considerado um indicador fidedigno da 
concentração de glicose (THRALL et al., 2015). Assim como discutido no procedimento experimental 2 , os valores de frutosamina também não revelaram influência do tipo de gestação. Os valores do presente trabalho estavam em níveis mais baixos dos teores de referência $(213,4$ a $265 \mu \mathrm{mol} / \mathrm{L})$ revelados por Jensen, Petersen e Houe (1993), o que poderia indicar déficit glicêmico no final da gestação, contudo os resultados foram semelhantes ao observado por Silva (2015) em bezerras Girolandas (166,64 $\mu \mathrm{mol} / \mathrm{L})$. Não foi observado a influência da FIV, mesmo na existência da síndrome do bezerro gigante, sobre a concentração plasmática de frutosamina no final da gestação em bezerros neonatos. 


\section{CONCLUSÃO}

Ao comparar o perfil metabólico de bezerros produzidos por FIV e por IA com tempo de gestação controlado e nascimento por cesariana, constatou-se que o perfil bioquímico para a função renal foi semelhante, observou-se variações fisiológicas em função do tempo devido a maturação da capacidade de filtração glomerular. A mesma condição foi observada em gestações a termo com parto natural, mesmo quando os bezerros produzidos por FIV apresentavam peso elevado ao nascimento, na condição de macrossomia.

Verificou-se que independente do tipo de parto os bezerros produzidos por FIV, mesmo aqueles com macrossomia, apresentaram capacidade de absorção de imunoglobulinas compatíveis com transferência de imunidade passiva bem-sucedida, evidenciada pelo aumento da GGT.

Os valores séricos de proteína e albumina dos bezerros de FIV, mesmo os com macrossomia, foram semelhantes aos bezerros por IA e apresentaram variação fisiológica pelo fator etário e ingestão de colostro. Os bezerros nascidos por parto induzido com dexametasona e cesariana não superaram o valor referendado para boa transferência de imunidade passiva para proteína, já os bezerros nascidos por parto natural superaram.

A avaliação da glicose e insulina permitiu observar que os bezerros de FIV apresentaram hipoglicemia ao nascimento com hiperinsulinemia persistente visto no momento $12 \mathrm{~h}$ de vida.

A comparação entre triglicérides, colesterol, NEFA, BHB e lactato indicaram que os bezerros de FIV, mesmo os macrossomicos, são semelhantes aos bezerros de IA com variações fisiológicas do estresse adaptativo do nascimento, pelo fator etário e pela alimentação.

A mensuração da frutosamina ao nascimento revelou nível plasmático dentro dos padrões referenciais e semelhante entre os bezerros de FIV, mesmo os macrossômicos, e os bezerros de IA.

Ao comparar o metabolismo de vacas receptoras de FIV e vacas gestantes de IA no final da gestação, observou-se semelhança nos valores dos bioquímicos. As variações ocorreram por caráter fisiológico sem influência do tipo de gestação, mesmo para as receptoras com bezerros de FIV com peso elevado ao nascimento. 


\section{REFERÊNCIAS}

ABUD, L. J. et al. Perfil bioquímico e hematológico associados à ocorrência da gestação em novilhas Nelore. Acta Veterinaria Brasilica, Mossoró, v. 10, n. 1, p. 16-24, 2016.

ALLAIN, C. C. et al.Enzymatic determination of total serum cholesterol. Clinical Chemistry, Washington, DC, v. 20, n. 4, p. 470-475, 1974.

ASSOCIAÇÃO BRASILEIRA DOS CRIADORES DE ZEBU. Movimentação TE/FIV 2015: movimentação de embriões 2006 a 2015. Uberaba, MG, 2016. Disponível em: <http://www.abcz.org.br/abczUploads/Arquivos/1473.pdf>. Acesso em: 27 dez. 2016.

BAILEY, G. Pregnancy toxaemia in beef cattle. Primefact, Orange, NSW, n. 335, p. 1-3, 2015. Disponível em:

$<$ http://www.dpi.nsw.gov.au/_data/assets/pdf_file/0003/103845/Pregnancytoxaemia-in-beef-cattle.pdf>. Acesso em: 23 jan. 2017.

BARHAM, D.; TRINDER, P. An improved colour reagent for the determination of blood glucose by the oxidase system. Analyst, London, v. 97, p. 142-145, 1972.

BATCHELDER, B. C. A. et al. Perinatal physiology in cloned and normal calves: hematologic and biochemical profiles. Cloning Stem Cells, Larchmont, v. 9, p. 83-96, 2007.

BEHBOODI, E. et al. Birth of large calves that developed from in vitro-derived bovine embryos. Theriogenology, Stoneham, v. 44, p. 227-232, 1995.

BELLOWS, R. A.; LAMMOGLIA, M. A. Effects of severity of dystocia na cold tolerance and serum concentrations of glucose and cortisol in neonatal beef calves. Theriogenology, Stoneham, v. 53, n. 3, p. 803-813, 2000.

BENESI, F. J. et al. Parâmetros bioquímicos para avaliação da função renal e do equilíbrio hidroeletrolítico em bezerras sadias, da raça Holandesa, no primeiro mês de vida. Brazilian Journal of Veterinary Research and Animal Science, São Paulo, v. 42, n. 4, p. 291-298, 2005.

BERTOLINI, M.; ANDERSON, G. B. The placenta as a contributor to production of large calves.Theriogenology, Stoneham, v. 57, n. 1, p.181-187, 2002.

BERTOLINI, M. et al. Evidence of increased substrate availability to in vitro-derived bovine fetuses and association with accelerated conceptus growth. Reproduction, Cambridge, v. 128, p. 341-354, 2004.

BERTOLINI, M. et al. Morphology and morphometry of in vivo- and in vitro-produced bovine concepti from early pregnancy to term and association with high birth weights. Theriogenology, Stoneham, v. 58, n. 5, p.973-994, 2002a. 
BERTOLINI, M. et al. Growth, development, and gene expression by in vivo- and in vitro-produced day 7 and 16 bovine embryos. Molecular Reproduction and Development, New York, v. 63, n. 3, p.318-328, 2002b.

BIRGEL JUNIOR, E. H. et al. Distúrbios clínicos observados nos primeiros 30 dias de vida de bezerros clonados da raça Nelore. Acta Scientiae Veterinariae, Porto Alegre, v. 39, suppl. 1, p. 243-252, 2011a.

BIRGEL JUNIOR, E. H. et al. Medicina interna de bezerros clonados: distúrbios clínicos observados nos primeiros 30 dias de vida. Revista de Educação Continuada em Medicina Veterinária e Zootecnia, São Paulo, v. 9, p. 24-31, 2011b.

BLOCK, J. et al. Improving post-transfer survival of bovine embryos produced in vitro: actions of insulin-like growth factor-1, colony stimulating factor-2 and hyaluronan. Theriogenology, Stoneham, v. 76, n. 9, p. 1602-1609, 2011.

BORGES, A. S. et al. Influência da forma de administração e da quantidade fornecida de colostro sobre a concentração de proteína total e de suas frações eletroforéticas no soro sangüíneo de bezerros da raça Holandesa. Arquivo Brasileiro de Medicina Veterinaria e Zootecnia, Belo Horizonte, v. 53, n. 5, p. 629-634, 2001.

BURTON, J. L. Supplemental chromium: its benefits to the bovine immune system. Animal Feed Science and Technology, Amsterdam, v. 53, n. 2, p. 117-133, 1995.

CALDEIRA, R. M. Monitorização da adequação do plano alimentar e do estado nutricional em ovelhas. Revista Portuguesa de Ciências Veterinárias, Lisboa, v. 100, p. 125-139, 2005.

CAMARGO, L. S. A. et al. Gestation length, birth weight and offspring gender ratio of in vitro-produced Gyr (Bos indicus) cattle embryos. Animal Reproduction Science, Amsterdam, v. 120, n. 1-4, p.10-15, 2010.

CHAVATTE-PALMER P. et al. Review: health status of cloned cattle at different ages. Cloning and Stem Cells, Larchmont, v. 6, p. 94-100, 2004.

CORREA, F. R.; SCHILD, A. L.; MENDEZ, M. C. Cetose em vacas de corte em gestação. Pesquisa Veterinária Brasileira, Rio de Janeiro, v. 10, n. 1/2, p. 43-45, 1990.

CORREAA, M. N.; GONZÁLEZ, F. H. D.; SILVA, S. C. Transtornos metabólicos nos animais domésticos. Pelotas: Universitária PREC/UFPEL, 2010.

CROSIER, A. E. et al. Development of skeletal muscle and expression of candidate genes in bovine fetuses from embryos produced in vivo or in vitro. Biology of Reproduction, Champaign, v. 67, n. 2, p. 401-408, 2002.

DICKINSON, J. E.; PALMER, S. M. Gestacional diabetes: pathophysiology and diagnosis. Seminars in Perinatology, Orlando, v. 14, n. 1, p. 2-11, 1990. 
DOORNENBAL, H.; TONG, A. K.; MURRAY, N. L. Reference values of blood parameters in beef cattle of different ages and stages of lactation. Canadian Journal of Veterinary Research = Revue Canadienne De Recherche Veterinaire, v. 52, n. 1, p. 99-105, 1988.

DOUMAS, B. T.; BIGGS, H. G.; WATSON, W. Albumin standards and the measurement of serum albumin with bromocresol green. Clinica Chimica Acta, Amsterdam, v. 31, p. 87-96, 1971.

EGLI, C. P.; BLUM, J. W. Clinical, haematological, metabolic and endocrine traits during the first three months of life of suckling simmentaler calves held in a cow-calf operation. Zentralblatt für Veterinärmedizin. Reihe A, Berlin, v. 45, p. 99-118, 1998.

EHRHARDT R, A.; BELL, A. W Developmental increase in glucose transporter concentration in the sheep placenta. American Journal of Physiology, Rockville, v. 273, p. 1132-1141, 1997.

ELPHICK, M. C. Modified colorimetric ultramicro method for estimating NEFA in serum. Journal of Clinical Pathology, London, v. 21, n. 5, p. 567-570, 1968.

FAGLIARI, J. J. et al. Constituintes sangüíneos de bovinos lactantes, desmamados e adultos das raças Nelore (Bos indicus) e Holandesa (Bos taurus) e de bubalinos (Bubalus bubalis) da raça Murrah. Arquivo Brasileiro de Medicina Veterinária e Zootecnia, Belo Horizonte, v. 50, n. 3, p. 263-271, 1998.

FAGLIARI, J. J. et al. Proteinograma sérico de bezerros recém-nascidos da raça Holandesa obtido por eletroforese em gel de poliacrilamida. Arquivo Brasileiro de Medicina Veterinária e Zootecnia, Belo Horizonte, v. 58, n. 3, p. 450-453, 2006.

FAGLIARI, J. J. et al. Relação entre o nível sérico de gamaglobulinas e as atividades de gamaglutamiltransferase, fosfatase alcalina e aspartato aminotransferase de bezerros recém-nascidos. Arquivo Brasileiro de Medicina Veterinaria e Zootecnia, Belo Horizonte, v. 48, n. 2, p. 105-112, 1996.

FARIN, C. E.; ALEXANDER, J. E.; FARIN, P. W. Expression of messenger RNAs for insulin-like growth factors and their receptors in bovine fetuses at early gestation from embryos produced in vivo or in vitro. Theriogenology, Stoneham, v. 74, n. 7, p. 1288-1295, 2010.

FARIN, C. E.; FARIN, P. W.; PIEDRAHITA, J. A. Development of fetuses from in vitro-produced and cloned bovine embryos. Journal of Animal Science, Champaign, v. 82, supl. Issue 13, p. E53-E62, 2004.

FARIN, P. W.; CROSIER, A. E.; FARIN, C. E. Influence of in vitro systems on embryo survival and fetal development in cattle. Theriogenology, Stoneham, v. 55, n. 1, p. 151-170, 2001. 
FARIN, P. W.; FARIN, C. E. Transfer of bovine embryos produced in vivo or in vitro: survival and fetal development. Biology of Reproduction, Champaign, v. 52, n. 3, p. 676-682, 1995.

FARIN, P. W.; FARIN, C. E.; MUNGAL, S. A. Measurements of bovine fetuses and placentas at 63 days after transfer of embryos produced in vivo or in vitro.Theriogenology, Stoneham, v. 47, n. 1, p.319-319, 1997.

FARIN, P. W.; PIEDRAHITA, J. A.; FARIN, C. E. Errors in development of fetuses and placentas from in vitro-produced bovine embryos. Theriogenology, Stoneham, $\mathrm{V}$. 65, n. 1, p.178-191, 2006.

FARIN, P. W. et al. Placental morphology following transfer of bovine embryos produced in vivo or in vitro. Theriogenology, Stoneham, v. 53, n. 1, p.474, 2000.

FEITOSA, A. C. R.; ANDRADE, F. S. Avaliação da frutosamina como parâmetro de controle glicêmico na gestante diabética. Arquivos Brasileiros de Endocrinologia \& Metabologia, Salvador, v. 58, n. 7, p.724-730, out. 2014.

FEITOSA, F. L. F. et al. Diagnóstico de falha de transferência de imunidade passiva em bezerros através da determinação de proteína total e de suas frações eletroforéticas, imunoglobulinas $\mathrm{g}$ e $\mathrm{m}$ e da ativade da gama glutamil transferase no soro sangüíneo. Ciência Rural, Santa Maria, v. 31, n. 2, p. 251-255, 2001.

FEITOSA, F. L. F. et al. Determinação do perfil bioquímico hepático sérico de bezerros holandeses e mestiços, na região de Araçatuba/SP. Ciência Animal Brasileira, Goiânia, supl. 1, p. 255-259, 2009.

FERNANDES, S. R. et al. Lipidograma como ferramenta na avaliação do metabolismo o energético em ruminantes. Brasil Agrociência, Pelotas, v. 18, n. 1-4, p. 21-32, 2012.

FERREIRA, L. D. O. Perfil bioquímico e eletrolítico, equilíbrio ácido-base e transferência de imunidade passiva de bezerras oriundas de partos eutócicos e distócicos. 2012. 80 p. Dissertação (Mestrado) - Escola de Veterinária, Universidade Federal de Minas Gerais, 2012. Disponível em: <http://www.bibliotecadigital.ufmg.br/dspace/bitstream/handle/1843/BUOS95ZH3R/final_disserta_o.pdf?sequence=1>. Acesso em: 15 mar. 2018

FIGUEIREDO, R. A. et al. Ovarian follicular dynamics in Nelore breed (Bos indicus) cattle. Theriogenology, Stoneham, v. 47, n. 8, p.1489-1505,1997.

FLEMING, S. A. Endocrine and metabolic diseases: ketosis of ruminants (acetonemia). In: SMITH, B. P. Large animal internal medicine. 4th ed. Saint Louis: Elservier, 2009. Cap. 41. p. 1364-1369.

FOSSATI, P.; PRENCIPE, L. Serum triglycerides determined colorimetrically with an enzyme that produces hydrogen peroxide. Clinical Chemistry, Washington, DC, v. 28, n. 10, p. 2077-2080, 1982. 
FRANDSON, R. D.; WILKE, W. L.; FAILS, A. D. Nutrição e metabolismo: metabolismo. In: FRANDSON, R. D.; WILKE, W. L.; FAILS, A. D. Anatomia e fisiologia dos animais de fazenda. 7. ed. Rio de Janeiro: Guanabara Koogan, 2011. Cap. 22. p. 301-306.

GARDINER, R. M. Cerebral blood flow and oxidative metabolism during hypoxia and asphyxia in the new-born calf and lamb.The Journal of Physiology, London, v. 305, n. 1, p.357-376, 1980.

GARRY, F. B. et al. Postnatal characteristics of calves produced by nuclear transfer cloning. Theriogenology, Stoneham, v. 45, n. 1, p. 141-152, 1996.

GASPARELLI, E. R. F. Determinação da atividade sérica de enzimas hepáticas e da concentração de uréia, creatinina, cortisol, imunoglobulina $\mathbf{G}$ dos valores hemogasométricos de bezerros da raça Nelore oriundos de fertilização in vivo (FV) e fertilização in vitro (FIV). 2007. 73f. Dissertação (Mestrado) - Universidade Estadual Paulista, Curso de Medicina Veterinária, 2007. Disponível em:

$<$ https://alsafi.ead.unesp.br/bitstream/handle/11449/92203/gasparelli_erf_me_araca. pdf?sequence=1\&isAllowed=y>. Acesso em: 20 maio 2018.

GIRARD, J. Metabolic adaptations to change of nutrition at birth. Biology of Neonate, Paris, v. 58, supl. 1, p. 3-15, 1990.

GIRARD, J. et al. Adaptations of glucose and fatty acid metabolism during perinatal period and suckling-weaning transition. Physiological Reviews, Rockville, v. 72, n. 2, p. 507-562, 1992.

GONZÁLEZ, F. H. D. et al. (Ed.) Perfil metabólico em ruminantes: seu uso em nutrição e doenças nutricionais. Porto Alegre, 2000.

GRANT, R. J.; ALBRIGHT, J. L. Effect of animal grouping on feeding behavior and intake of dairy cattle. Journal of Dairy Science, Champaign, v. 84, p. E156-E163, 2001.

HALES, C. N.; BARKER, D. J. P. Type 2 (non-insulin-dependent) diabetes mellitus: the thrifty phenotype hypothesis. International Journal of Epidemiology, Oxford, $v$. 42, n. 5, p. 1215-1222, 2013.

HAMMON, H. M. et al. Energy metabolism in the newborn farm animal with emphasis on the calf: endocrine changes and responses to milk-born and systemic hormones. Domestic Animal Endocrinology, Amsterdam, v. 43, n. 2, p. 171-185, 2012.

HASLER, J. F. Commercial production of in vitro derived bovine embryos. Arquivos da Faculdade de Veterinária da UFRGS, v. 24, supl., p.117-134, 1996. . Disponível em: <http://www.ufrgs.br/actavet/1-29/1996-suplemento.pdf>. Acesso em: 09 out. 2015

HASLER, J. F. et al. Production, freezing and transfer of bovine IVF embryos and subsequent calving results. Theriogenology, Stoneham, v. 43, n. 1, p. 141-152, 1995. 
HERAS, S. et al. Suboptimal culture conditions induce more deviations in gene expression in male than female bovine blastocysts. BMC Genomics, London, v. 17, n. 1, p. 72, 2016.

HILL, J. R. et al. Evidence for placental abnormality as the major cause of mortality in first-trimester somatic cell cloned bovine fetuses. Biology of Reproduction, Champaign, v. 63, n. 6, p. 1787-1794, 2000.

HORTA, A. E. M. Large calf syndrome associated to the transfer of in vitro produced embryos. Revista Portuguesa de Zootecnia, Vila Real, v. 6, n. 1, p. 27-41, 1999.

HOUSE, J. K. Perinatal adaptation, asphyxia and resuscitation: perinatal adaptation. In: SMITH, B. P. Large animal internal medicine. 4th ed. Saint Louis: Elsevier, 2009. Cap. 16. p. 252-253.

JACOBSEN, $\mathrm{H}$ et al. In vitro embryo production versus artificial insemination: delivery type, birth weight and blood chemistry of the newborn calf. Theriogenology, Stoneham, v. 51, n. 1, p. 226-226, 1999. doi: http://dx.doi.org/10.1016/s0093$691 \times(99) 91785-5$.

JACOBSEN, $\mathrm{H}$. et al. Body dimensions and birth and organ weights of calves derived from in vitro produced embryos cultured with or without serum and oviduct epithelium cells. Theriogenology, Stoneham, v. 53, n. 9, p. 1761-1769, 2000a.

JACOBSEN, $\mathrm{H}$. et al. Ease of calving, blood chemistry, insulin and bovine growth hormone of newborn calves derived from embryos produced in vitro in culture systems with serum and co-culture or with PVA. Theriogenology, Stoneham, v. 54, n. 1, p.147-158, 2000b.

JAMES, D. The mammalian facilitative glucose transporter family. NIPS, Belfast, v.10, p. 67-71, 1995.

JENSEN, A. L.; PETERSEN, M. B.; HOUE, H. Determination of the fructosamine concentration in bovine serum samples. Journal of Veterinary Medicine. Series A, Berlin, v. 40, n. 1-10, p. 111-117, 1993.

JUCHEM, S. O. et al. Efeito da administração de propileno-glicol e monensina sódica pré-parto em vacas de alta produção: 1. Produção e composição do leite. In: REUNIÃO ANUAL DA SOCIEDADE BRASILEIRA DE ZOOTECNIA, 37., 2000, Viçosa. Anais... Viçosa: Gmosis, 2000, 17 par. CD-Rom. Nutrição de Ruminantes. NUR-104.

KANEKO, J. J.; HARVEY, J. W.; BRUSS, M. L. Clinical biochemistry of domestic animals. 5th ed. San Diego: Academic Press, 2008.

KHURANA, N. K.; NIEMANN, H. Energy metabolism in preimplantation bovine embryos derived in vitro or in vivo. Biology of Reproduction, Champaign, v. 62, p. 847-856, 2000. 
KRUIP, T. A. M.; BEVERS, M. M.; KEMP, B. Environment of oocyte and embryo determines health of IVP offspring. Theriogenology, Stoneham, v. 53, n. 2, p.611618, 2000.

KRUIP, T. A. M.; DEN DAAS, J. H. G. In vitro produced and cloned embryos: effects on pregnancy, parturition and offspring. Theriogenology, Stoneham, v. 47, n. 1, p. 43-52, 1997.

KÜHNE, S. et al. Growth performance, metabolic and endocrine traits, and absorptive capacity in neonatal calves fed either colostrum or milk replacer at two levels. Journal of Animal Science, Champaign, v. 78, n. 3, p. 609-620, 2000.

LEITE, R. F. et al. Transferência de imunidade passiva em bezerras alimentadas com colostro de vacas com mastite subclínica. Arquivos do Instituto Biológico, São Paulo, v. 84, p. 1-7, 2017.

LENTS, C. A. et al. Concentrations of GH, IGF-I, insulin, and glucose in postnatal beef calves. Animal Science Research Report, Blacksburg, n. January, p. 215-222, 1998.

MACHADO, U. F. Transportadores de glicose. Arquivos Brasileiros de Endocrinologia \& Metabologia, São Paulo, v. 42, n. 6, p. 413-421, 1998.

MARCHESE, F. J. M. Perfil bioquímico de bezerros da raça Nelore, originados por meio da técnica de transferência nuclear de célula somática (TNCS ) clonagem. 2014. 93f. Dissertação (Mestrado) - Faculdade de Medicina Veterinária e Zootecnia, Universidade de São Paulo, São Paulo, 2014. Disponível em:

<http://www.teses.usp.br/teses/disponiveis/10/10132/tde-13012015-105154/en.php>. Acesso em: 2 maio 2018.

MARTINS, C. F. O impacto da transferência de embriões (TE) e da fecundação in vitro (FIV) na produção de bovinos no Brasil. Planaltina: Embrapa Cerrados, 2010.

MEIRELLES F. V. et al. Delivery of cloned offspring: experience in Zebu cattle (Bos indicus). Reproduction, Fertility and Development, Melbourne, v. 22, n. 1, p. 88-97, 2010.

MCEVOY, T. G. et al. Embryo technologies and animal health - consequences for the animal following ovum pick-up, in vitro embryo production and somatic cell nuclear transfer. Theriogenology, Stoneham, v. 65, n. 5, spe. issue, p. 926-942, 2006.

MIGLINO, M. A. et al. Placentation in cloned cattle: structure and microvascular architecture. Theriogenology, Stoneham, v. 68, p. 604-617, 2007

MILES, J. R. et al. Angiogenesis and morphometry of bovine placentas in late gestation from embryos produced in vivo or in vitro. Biology of Reproduction, Champaign, v. 71, n. 6, p.1919-1926, 2004. 
MORAES, D. V. Perfil bioquímico sérico de bezerros mestiços durante o primeiro ano de vida. 2011. 32f. Dissertação (Mestrado) - Universidade Federal de Uberlândia, Uberlândia, 2011. Disponível em:

<https://repositorio.ufu.br/bitstream/123456789/13018/1/d.pdf>. Acesso em: 2 maio 2018.

MUECKLER, M. Facilitative glucose transporters. European Journal of Biochemistry, Berlin, v. 219, p. 713-725, 1994.

NAGY, D. W. Resuscitation and critical care of neonatal calves. Veterinary Clinics of North America: Food Animal Practice, Columbia, v. 25, n. 1, p.1-11, 2009.

NUMABE, T. et al. Birth weight and birth rate of heavy calves conceived by transfer of in vitro or in vivo produced bovine embryos. Animal Reproduction Science, Amsterdam, v. 64, n. 1-2, p. 13-20, 2000.

OETZEL, G. R. Herd-based biological testing for metabolic disorders. In: AMERICAN ASSOCIATION OF BOVINE PRACTITIONERS ANNUAL CONFERENCE, 36., 2003, Columbus, $\mathrm{OH}$. Preconvention Seminar 7: Dairy Herd Problem Investigation Strategies. Madison: University of Wiscosin, 2003. p. 1-16. Disponivel em: $<$ https://www.vetmed.wisc.edu/dms/fapm/fapmtools/2nutr/herdtest.pdf>. Acesso em: 23 jan. 2017.

OLIVEIRA, A. P. Avaliação clínica, morbi-mortalidade e desenvolvimento de bezerros da raça Brahman produzidos por fertilização in vitro e inseminação artificial. 2011. 66 f. Dissertação (Mestrado) - Curso de Medicina Veterinária, Universidade Estadual Paulista, Botucatu, 2011. Disponível em:

<https://repositorio.unesp.br/bitstream/handle/11449/99362/oliveira_ap_me_botfmvz. pdf?sequence=1\&isAllowed=y>. Acesso em: 15 jan. 2017.

OLIVEIRA, B. M. M. Avaliação do perfil sanguíneo de vacas prenhes e vazias submetidas à IATF com sêmen avaliado por sondas fluorescentes e sua relação com hemodiânimca uterina. 2015. 166f. Tese (Doutorado) - Faculdade de Medicina Veterinária e Zootecnia, Universidade de São Paulo, Pirassununga, 2015. Disponível em: <http://www.teses.usp.br/teses/disponiveis/10/10131/tde-26012016140413/pt-br.php>. Acesso em: 22 jun. 2018.

OREGON STATE UNIVERSITY. College of Veterinary Medicine. Veterinary Diagnostic Laboratory. Biochemistry reference intervals. Disponível em: $<$ https://vetmed.oregonstate.edu/sites/vetmed.oregonstate.edu/files/biochemistry_ref erence_intervals_1.pdf>. Acesso em: 18 jul. 2018.

PAIVA, F. A. et al. Efeito do manejo de fornecimento de colostro na imunidade passiva, cortisol e metabólitos plasmáticos de bezerros Holandeses. Arquivo Brasileiro de Medicina Veterinária e Zootecnia, Belo Horizonte, v. 58, n. 5, p. 739-743, 2006. 
PEEK, S. F. et al. Hypokalemia, muscle weakness, and recumbency in dairy cattle (17 Cases 1991-1998). In: AMERICAN ASSOCIATION OF BOVINE PRACTITIONERS ANNUAL CONFERENCE, 36., 2003, Columbus, OH.

Preconvention Seminar 7: Dairy Herd Problem Investigation Strategies. Madison: University of Wiscosin, 2003. Disponível em: <https://www.vetmed.wisc.edu/dms/fapm/fapmtools/2nutr/hypokal.pdf>. Acesso em: 30 jun. 2018.

PERRY, G. 2015 statistics of embryo collection and transfer in domestic farm animals. Data Retrieval Committee Annual Report / International Embryo Transfer Society, 2015. p. 1-16. Disponível em:

<http://www.iets.org/pdf/comm_data/IETS_Data_Retrieval_2015_V2.pdf>. Acesso em: 21 mar. 2017.

PICCIONE, G. et al. Monitoring of physiological and blood parameters during perinatal and neonatal period in calves. Arquivo Brasileiro de Medicina Veterinária e Zootecnia, Belo Horizonte, v. 62, n. 1, p. 1-12, 2010.

POGLIANI, F. C.; BIRGEL JÚNIOR, E. H. Valores de referência do lipidograma de bovinos da raça holandesa, criados no Estado de São Paulo. Brazilian Journal of Veterinary Research and Animal Science, São Paulo, v. 44, n. 5, p. 373-383, 2007.

PRESTES, N. C.; LANDIM-ALVARENGA, F. C. Obstetrícia veterinária. Rio de Janeiro: Guanabara Koogan, 2006.

PRESTES, N. C. et al. Histopathologic characterization of "Ivp" calves that during the perinatal period - cases report. ARS Veterinaria, Jaboticabal, v. 25, n. 1, p. 38-41, 2009. Disponível em:

<http://www.arsveterinaria.org.br/index.php/ars/article/viewFile/251/182>. Acesso em: 07 out. 2015.

PRESTES, N. P. Produção in vitro de embriões bovinos- problemas e desafios visão obstétrica. Acta Scientiae Veterinariae, Porto Alegre, v. 33, supl. 1, p. 119124, 2005.

RADOSTITS, O. M. et al. Clínica veterinária: um tratado de doenças dos bovinos, ovinos, suínos, caprinos e eqüinos. 9. ed. Rio de Janeiro: Guanabara Koogan, 2002.

RAUPRICH, A. B. E.; HAMMON, H. M.; BLUM, J. W. Effects of Feeding Colostrum and a Formula with Nutrient Contents as Colostrum on Metabolic and Endocrine Traits in Neonatal Calves.Biol Neonate, Basel, v. 78, p.53-64, nov. 2000.

REINDERS, J. M. C. et al. Is the large IVP calf syndrome related to pregnancy diabetes? Theriogenology, Stoneham, v. 49, n. 1, p.297-297, 1998.

RÉRAT, M. et al. In vitro embryo production: growth performance, feed efficiency, and hematological, metabolic, and endocrine status in calves. Journal of Dairy Science, Champaign, v. 88, n. 7, p. 2579-2593, 2005. 
REZENDE, P. L. P. et al. Suplementação com cromo (Cr3) para bovinos em condições de estresse. PUBVET, Londrina, v. 4, n. 21, Ed. 126, Artigo 857, 2010. Disponível em: <https://repositorio.bc.ufg.br/xmlui/bitstream/handle/ri/13115/Artigo Pedro Leonardo de Paula Rezende -2010 .pdf? sequence $=5$ \&isAllowed $=y>$. Acesso em: 10 maio 2018.

ROOK, J. S. Pregnancy toxemia of ewes, does, and beef cows. Veterinary Clinics of North America: Food Animal Practice, Philadelphia, v. 16, n. 2, p. 293-317, 2000.

ROSA, A. N. F.; MENEZES, G. R. O. Papel do Zebu na pecuária de corte brasileira. Brasília: Embrapa Gado de Corte, 2016. Disponível em: $<$ https://www.embrapa.br/web/portal/busca-de-noticias/-/noticia/9523901/artigopapel-do-zebu-na-pecuaria-de-corte-brasileira>. Acesso em: 27 dez. 2016.

SANGILD, P. T. et al. Blood chemistry, nutrient metabolism, and organ weights in fetal and newborn calves derived from in vitro-produced bovine embryos. Biology of Reproduction, Champaign, v. 62, n. 6, p. 1495-504, 2000.

SARTORI, R. et al. Update and overview on assisted reproductive technologies (ARTs ) in Brazil. Animal Reproduction, Belo Horizonte, v. 13, n. 3, p. 300-312, 2016.

SCHMIDT, M. et al. Pregnancies, calves and calf viability after transfer of in vitro produced bovine embryos. Theriogenology, Stoneham, v. 46, n. 3, p. 527-539, 1996.

SCHÜTZ, L. F. Evidências de atividade da via metabólica da frutose em neonatos bovinos derivados de embriões produzidos in vitro e in vivo e seu efeito no período neonatal imediato. 2012. 93f. Dissertação (Mestrado) - Centro de Ciências Agroveterinárias, Universidade do Estado de Santa Catarina, Lajes, 2012. Disponível em:

<http://tede.udesc.br/bitstream/tede/2123/1/PGCA12MA106.pdf>. Acesso em: 15 jul. 2018.

SILVA, R. J. Perfil bioquímico sanguíneo de bezerras girolandas do nascimento aos 120 dias de idade girolandas do nascimento aos 120 dias de idade. 2015. 66f. Dissertação (Mestrado) - Universidade Federal Rural de Pernambuco, Guaranhuns, 2015. Disponível em:

<https://sucupira.capes.gov.br/sucupira/public/consultas/coleta/trabalhoConclusao/vi ewTrabalhoConclusao.jsf?popup=true\&id_trabalho=3550812>. Acesso em: 15 jul. 2018.

SINCLAIR, K. D.; BROADBENT, P. J.; DOLMAN, D. F. In vitro produced embryos as a means of achieving pregnancy and improving productivity in beef cows. Animal Science, Aberdden, v. 60, n. 1, p. 55-64, 1995.

SOUZA, D. F. et al. Dinâmica pré e pós-colostral de parâmetros bioquímicos em cordeiros. Ciência Animal Brasileira, Goiânia, v. 15, n. 3, p. 313-321, 2014. 
STACCHEZZINI, S.; FABARO, P.; CREMONESI, F. Field experiences with the transfer of in vitro or in vivo derived piedmontese embryos in holstein recipients.Theriogenology, Stoneham, v. 47, n. 1, p. 381-381, 1997.

STEINHARDT, M. et al. Klinisch-chemische und hämatologische Blutwerte und Anpassungsreaktionen bei Saugkälbern in den ersten Lebenswochen. Deutsche tierärztliche Wochenschrift, Hannover, v. 102, n. 10, p. 399-405, 1995.

STEINHOFF-WAGNER, J. et al. Maturation of endogenous glucose production in preterm and term calves1. Journal of Dairy Science, Champaign, v. 94, n. 10, p. 5111-5123, 2011.

STRUFALDI, B. Prática de bioquímica clínica. São Paulo: Faculdade de Ciências Farmacêuticas da Universidade de São Paulo, 1987.

SUMITA, N. M.; ANDRIOLO, A. Importância da determinação da hemoglobina glicada no monitoramento do paciente portador de diabetes mellitus. Jornal Brasileiro de Patologia e Medicina Laboratorial, Rio de Janeiro, v. 42, n. 3, p. 169-174, 2006.

SWENSON, M. J.; REECE, W. O. Dukes fisiologia dos animais domésticos. 11. ed. Rio de Janeiro: Guanabara Koogan, 1996.

TAVERNE, M. A. M. et al. The monitoring of bovine pregnancies derived from transfer of in vitro produced embryos. Reproduction Nutrition Development, [s.I.], v. 42, n. 6, p.613-624, nov. 2002.

THIBIER, M. Transfers of both in vivo derived and in vitro produced embryos in cattle still on the rise and contrasted trends in other species. In: AMERICAN SOCIETY FOR REPRODUCTIVE IMMUNOLOGY, ANNUAL MEETING, 27., 2006, Toronto. Data Retrieval Committee Annual Report. Ontario: American Society For Reproductive Immunology, 2006. p. 14-16. Disponível em:

<http://www.iets.org/pdf/comm_data/December2006.pdf>. Acesso em: 21 dez. 2016.

THRALL, M. A. et al. Hematologia e bioquímica clínica veterinária. 2. ed. Rio de Janeiro: Guanabara Koogan, 2015.

VAALA, W. E.; LESTER, G. D. Perinatal adaptation, asphyxia and resuscitation: acute asphyxia in the neonate. In: SMITH, B. P. Large animal internal medicine. 4th ed. Saint Louis: Elsevier, 2009. Cap. 16. p. 253-258.

VAN WAGTENDONK-DE LEEUW, A. M.; AERTS, B. J.; DEN DAAS, J. H. Abnormal offspring following in vitro production of bovine preimplantation embryos: a field study. Theriogenology, Stoneham, v. 49, n. 5, p. 883-94, 1998.

VAN WAGTENDONK-DE LEEUW, A. M. et al. Effects of different reproduction techniques: AI, MOET or IVP, on health and welfare of bovine offspring.

Theriogenology, Stoneham, v. 53, n. 2, p. 575-597, 2000. 
VIANA, J. H. M. et al. Follicular dynamics in zebu cattle. Pesquisa Agropecuária Brasileira, Brasília, v. 35, n. 12, p. 2501-2509, 2000.

VIANA, J. H. M. et al. Features and perspectives of the Brazilian in vitro embryo industry. Animal Reproduction, Belo Horizonte, v. 9, n. 1, p. 12-18, 2012.

WATANABE, D. et al. Oral glucose tolerance test and determination of serum fructosamine level in beagle dogs. Journal Toxicological Sciences, Sapporo, v. 29, n. 1, p. 33-36, 2004.

WATANABE, M. R. et al. Variation in ultrasound guided oocyte recovery in Nellore cows per session and in vitro embryo production.Theriogenology, Stoneham, v. 51, n. 1, p.438-438, 1999.

WILLIAMSON, D. H.; MELLANBY, J.; KREBS, H. A. Enzymatic determination of D(-) ß-hydroxybutyric acid and acetoacetic acid in blood. Biochemical Journal, London, v. 82, n. 1, p. 90-96, 1962.

WILSON, J. M. et al. Comparison of birth weight and growth characteristics of bovine calves produced by nuclear transfer (cloning), embryo transfer and natural mating.

Animal Reproduction Science, Amsterdam, v. 38, n. 1-2, p.73-83, 1995.

YALOW, R. S.; BERSON, S. A. Immunoassay of plasma insulin in a man. Journal of Clinical Investigation, New Haven, v. 39, n. 7, p. 1157-1175, 1960

YOUNG, L. E.; SINCLAIR, K. D.; WILMUT, I. Large offspring syndrome in cattle and sheep. Reviews of Reproduction, v. 3, n. 3, p. 155-163, 1998. 